\title{
Regulation of polymeric immunoglobulin receptor by reovirus in intestinal epithelial cells
}

\author{
Kasturi Pal \\ West Virginia University
}

Follow this and additional works at: https://researchrepository.wvu.edu/etd

\section{Recommended Citation}

Pal, Kasturi, "Regulation of polymeric immunoglobulin receptor by reovirus in intestinal epithelial cells" (2006). Graduate Theses, Dissertations, and Problem Reports. 2400.

https://researchrepository.wvu.edu/etd/2400

This Dissertation is protected by copyright and/or related rights. It has been brought to you by the The Research Repository @ WVU with permission from the rights-holder(s). You are free to use this Dissertation in any way that is permitted by the copyright and related rights legislation that applies to your use. For other uses you must obtain permission from the rights-holder(s) directly, unless additional rights are indicated by a Creative Commons license in the record and/ or on the work itself. This Dissertation has been accepted for inclusion in WVU Graduate Theses, Dissertations, and Problem Reports collection by an authorized administrator of The Research Repository @ WVU.

For more information, please contact researchrepository@mail.wvu.edu. 


\title{
REGULATION OF POLYMERIC IMMUNOGLOBULIN \\ RECEPTOR BY REOVIRUS IN INTESTINAL EPITHELIAL CELLS
}

Kasturi Pal

\section{DISSERTATION}

Submitted to the School of Medicine at West Virginia University in partial fulfillment of the requirements for the degree of

Doctor of Philosophy

In

Immunology and Microbial Pathogenesis

\author{
Christopher F. Cuff, Ph.D, Chair \\ Daniel C. Flynn, Ph.D \\ David N. Weissman, M.D \\ Jia Luo, Ph.D \\ Michael R. Miller, Ph.D \\ Department of Microbiology, Immunology, and Cell Biology \\ Morgantown, WV \\ 2006
}

Keywords: Mucosal Immunology, Polymeric Immunoglobulin receptor, Secretory IgA, Reovirus, Host defense, Nuclear Factor kappa B. 


\title{
ABSTRACT \\ Regulation of Polymeric Immunoglobulin Receptor by Reovirus in \\ Intestinal Epithelial Cells
}

\begin{abstract}
Kasturi Pal
Most pathogens invade the human body through mucosal surfaces. Enteric viruses are one such group of pathogens that are of great public health significance because they cause a number of serious diseases including gastroenteritis, hepatitis and poliomyelitis. Gastrointestinal disease is the second most common cause of morbidity worldwide, with diarrhea ranking first among infectious diseases in the categories of frequency and mortality in children. The mucosal epithelium provides the first line of defense against invading pathogens by serving as the first sensors of microbial infection and launching an innate immune response that leads to the development of adaptive immunity. An immunologic function of the mucosal epithelium is to mediate transcytosis of secretory immunoglobulin A (sIgA) from the lamina propria into the intestinal lumen. Transcytosis of $\operatorname{IgA}$ is dependent on the polymeric immunoglobulin receptor (pIgR) expressed by mucosal and glandular epithelial cells because one molecule of pIgR must be synthesized for each molecule of transported IgA. Thus, pIgR plays a role in mucosal host defense, and factors that influence expression of pIgR could affect mucosal immunity. This dissertation describes efforts to understand the role of intestinal epithelial cells (IECs) as an active participant of mucosal immunity during enteric virus infection. We used reovirus to demonstrate that a newly appreciated role of the IECs in responding to infection is upregulation of $\mathrm{pIgR}$ expression, which appears to serve as an innate host defense mechanism. Our studies demonstrate that reovirus upregulates pIgR expression in the intestinal epithelial cell line HT-29 in a replication independent fashion, and that binding of virus to cellular receptors and partial disassembly of virus inside acidified endosomes are required steps for this innate immune response by IECs. In addition, we demonstrate that activation of calpain and NFאB signaling and reovirus induced PIGR gene transcription in IECs upregulate pIgR expression during infection. Signaling induced by virus-host interaction might serve to augment pIgR-mediated transcytosis of IgA in vivo, thereby linking the innate and acquired immune responses to enteric viruses. Our studies will contribute to improving human health by advancing understanding of IEC biology and function, viral pathogenesis, and induction of innate and adaptive immunity to viruses, particularly in the intestine.
\end{abstract}




\section{DEDICATION}

Dedicated to maa and bapi, my parents who have nurtured, supported and inspired me and helped me realize my dreams. 


\section{ACKNOWLEDGMENTS}

I thank my guide, my thesis adviser Dr. Christopher F. Cuff for generously imparting his knowledge to me that opened new horizons. I pay tribute to him for being so enthusiastic about my research that has made my sojourn so enjoyable. Above all, I thank the kind person in him who was there for me during one of the most difficult times of my life. I thank my committee members-Dr. Flynn, Dr. Weissman, Dr. Luo, and Dr. Miller for their valuable time, thoughtful suggestions, guidance and helping me take informed decisions on my future career choices. I am thankful to our collaborator Dr. Charlotte S. Kaetzel, for offering expert opinions, resources and guidance. I thank my past and present collegues in lab for being such a great team. And last, but not least, I thank my husband Nayan, for being there for me always, for being a patient listener to my everyday chores in lab, for rejoicing in my achievements, supporting in my pitfalls and for taking such pride in my career choice. With you I had a ' happy family' miles away from my family. 


\section{TABLE OF CONTENTS}

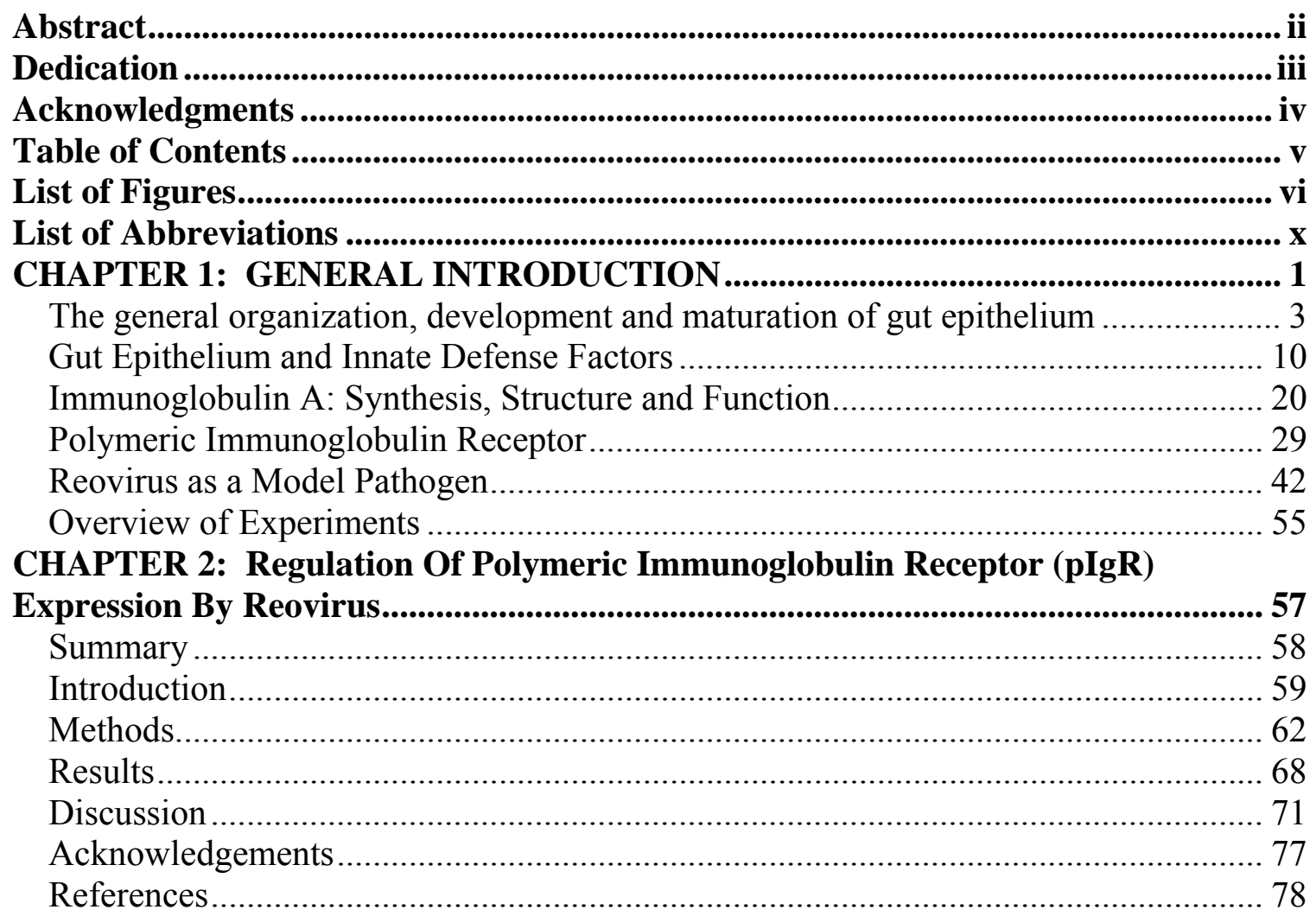

CHAPTER 3: Role Of Nuclear Factor Kappa B (NFkB) In Reovirus-Mediated Upregulation Of Polymeric Immunoglobulin Receptor Expression ........................... 105

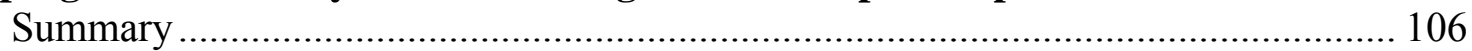

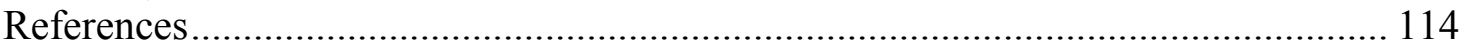

CHAPTER 4: Assessing The Role Of Viral Double Stranded RNA In Reovirus Mediated Upregulation Of Polymeric Immunoglobulin Receptor............................. 125

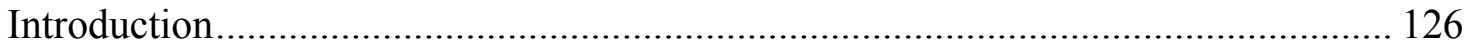

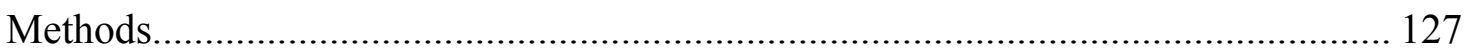

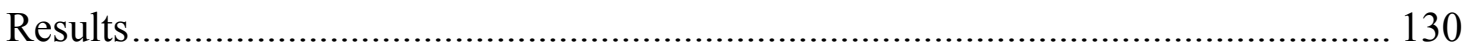

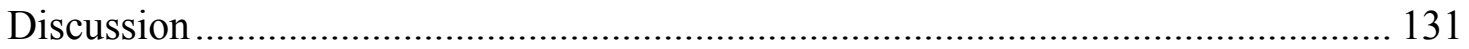

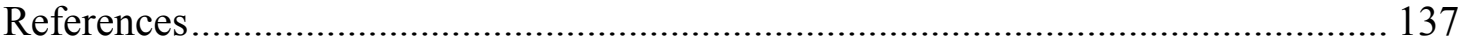

CHAPTER 5: Assess Polymeric Immunoglobulin Receptor Expression In Intestinal

Epithelial Cells During In Vivo Virus Infection............................................................... 139

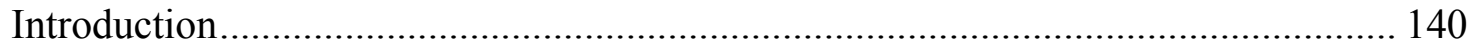

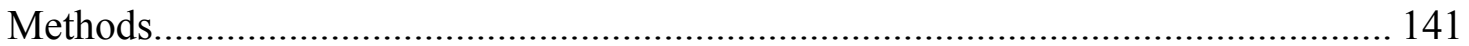

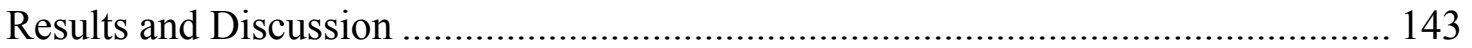

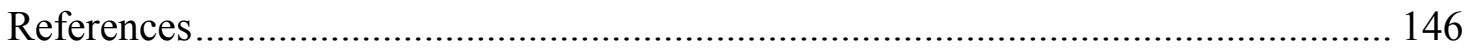

CHAPTER 6: General Discussion.............................................................................. 147

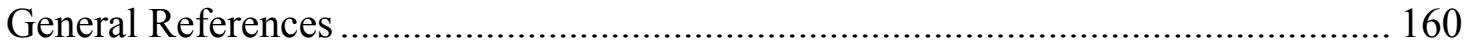




\section{LIST OF FIGURES}

\section{Chapter 1: General Introduction}

Figure 1. Schematic representation of intestinal basement membrane.

Figure 2. Anatomy of a crypt - villus unit of small intestine.

Figure 3. Three tiers of protection of mucosal epithelia by IgA.

Figure 4. Pathway of passage of pIgR through polarized epithelial cells.

Figure 5. Schematic structure of human polymeric immunoglobulin receptor.

Figure 6. Organization of the polymeric immunoglobulin receptor (PIGR) gene locus and regulatory elements.

Figure 7. Transcytosis of empty receptor and dimeric IgA leading to generation of free secretory component (FSC) and secretory $\operatorname{IgA}(\mathrm{sIgA})$ respectively.

Figure 8. Structure of reovirus virion and ISVP after proteolytic digestion of outer capsid proteins.

Figure 9. Illustration of life cycle of Reovirus.

Figure 10. Usurpation of the Ras signaling pathway by Reovirus. 


\section{Chapter 2: Regulation of polymeric immunoglobulin receptor (pIgR) expression by Reovirus}

Figure 1. Reovirus upregulates pIgR mRNA expression in HT-29 cells.

Figure 2. UV-irradiated L-cell lysates $\left(4 \times 10^{4}\right.$ cells $\left./ \mathrm{ml}\right)$ or wheat germ agglutinin

(WGA) $(50 \mu \mathrm{g} / \mathrm{ml})$ does not upregulate pIgR mRNA expression in HT-29 cells.

Figure 3. UV-inactivated reovirus increases pIgR protein levels in HT-29 cells. 104

Figure 4. Reovirus specific antibody abolishes up-regulation of pIgR mRNA in 105 HT-29 cells.

Figure 5. Ammonium chloride blocks reovirus-mediated pIgR up-regulation in 106 HT-29 cells.

Figure 6. Bafilomycin-A1 blocks reovirus-mediated pIgR up-regulation in HT-29 cells.

Figure 7. Calpain inhibition abrogates reovirus-mediated pIgR up-regulation in 108 HT-29 cells.

Figure 8 . Neither $\mathrm{NH}_{4} \mathrm{Cl}$ nor aLLN affect endocytosis of reovirus by HT-29 cells.

Figure S1. Linearity of RT-PCR reaction for pIgR using total mRNA and efficiency calculation of PCR reactions. 
Figure S2. Immunoblot analysis of pIgR protein in stimulated cells.

Figure S3. Calpain inhibition ameliorates reovirus-mediated $\mathrm{pIgR}$ protein upregulation in HT-29 cells.

Figure S4. Reovirus upregulates pIgR mRNA expression in Calu-3 cells.

Chapter 3: Role of nuclear factor kappa B (NFאB) in reovirus mediated upregulation of polymeric immunoglobulin receptor expression.

Figure 1. Helenalin inhibits reovirus-mediated pIgR up-regulation HT-29 cells.

Figure 2. Dominant negative mutant of $\mathrm{I} \kappa \mathrm{B} \alpha$ blocks reovirus-mediated $\mathrm{pIgR}$ mRNA upregulation in HT-29 cells.

Figure 3. Reovirus enhances transcription of wild-type PIGR gene reporter plasmids.

Chapter 4: Assessing the role of viral double stranded RNA in reovirus mediated upregulation of polymeric immunoglobulin receptor.

Figure 1. Poly I:C upregulates pIgR mRNA expression in HT-29 cells.

Figure 2. The intact, segmented dsRNA genome from reovirus.

Figure 3. Extracellular reovirus dsRNA does not upregulate pIgR mRNA expression in HT-29 cells. 
Chapter 5: Assess polymeric immunoglobulin receptor (pIgR) expression in intestinal epithelial cells during in vivo virus infection

Figure 1. Expression of pIgR mRNA in germfree mice. 


\section{LIST OF ABBREVIATIONS}

pIgR

SIgA

FSC

DC

IEC

TLR

ds

SS

Reovirus

PAMP

PRR

PP

GI

NFKB

JNK

SE

ECM

TFF

CTL

BAL

LPS

APC

TAP

LAP

IFN- $\gamma$

IL

TNF

GALT

M-cell

FAE

LP

IEL

IBD

Nod

CAR

LBP

ISVP

JAM

LRR

MyD88

TRIF

RIG-1

IPS-1

IRF

STAT

RT-PCR

PKR

Polymeric Immunoglobulin Receptor

Secretory Immunoglobulin A

Free Secretory Component

Dendritic cells

Intestinal Epithelial Cell

Toll like Receptor

Double stranded

Single stranded

Respiratory Enteric Orphan Virus

Pathogen Associated Molecular Pattern

Pattern Recognition Receptor

Peyer's patches

Gastrointestinal

Nuclear Factor Kappa B

Janus Kinase

Surface Epithelium

Extracellular Matrix

Trefoil Factor Family

Cytotoxic T lymphocyte

Bronchoalveolar lavage

Lipopolysaccharide

Antigen presenting

Tracheal Antimicrobial Peptide

Lingula Antimicrobial Peptide

Interferon gamma

Interleukin

Tumor Necrosis Factor

Gut-associated lymphoid tissue

Microfold cell

Follicle-associated epithelium

Lamina propria

Intraepithelial lymphocyte

Inflammator Bowel Disease

Nucleotide-binding Oligomerization Domain

Capase Activating and Recruitment Domain

LPS binding protein

Intermediate subviral

Junction adhesion

Leucine rich repeat

Myeloid Differentiation Factor 88

TIR domain-containing adaptor

Retinoic acid inducible gene - 1

Interferon Stimulator Promoter-1

Melanoma differentiation associated gene- 5

Interferon Regulator Factor

Signal transducers and activators of transcription

Reverse Transcriptase Polymerase Chain Reaction Protein Kinase R 


\section{CHAPTER 1: GENERAL INTRODUCTION}

Most of the pathogens, particularly viruses, invade the human body by the mucosal epithelia. The mucosal surface is one of the first important interfaces between pathogens and the host, and as such is critical in prevention of infectious disease. The gastrointestinal mucosa comprised of a single layer of intestinal epithelial cells (IECs) form a barrier between the body and a luminal environment, which not only contains essential nutrients but also potentially harmful pathogens. Thus the major challenge faced by IECs is to allow entry of nutrients from lumen for processing and absorption while rigorously excluding passage of toxins and pathogens. In general, toxins and microorganism that breach the epithelial barrier have unimpeded access to the systemic circulation. Maintainance of an intact epithelium throughout the length of the digestive system is essential for host defense and disruption of mucosal barrier leads to a number of gastrointestinal diseases.

The gastrointestinal barrier has two specific components, (1) the intrinsic barrier and (2) the extrinsic barrier. The intrinsic barrier comprises the epithelial cells lining the digestive tract while the extrinsic barrier consists of secretions including mucus, trefoil peptides and defensins, which modulate and maintain integrity of mucosal epithelial cells. 
The IECs are an important component in mucosal host defense and act at the interface between the innate and acquired immune responses to pathogens in the gastrointestinal tract. The innate immune arm of IECs and associated extrinsic barrier block the invading pathogens non-specifically, while the adaptive immune responses triggered by initial signaling through IECs provides pathogen specific immunity. IECs function as first sensors of infection as direct contact with microbes or their metabolic products such as lipopolysaccharide (LPS) and double stranded RNA (dsRNA) initiate innate responses including production of antimicrobial substances that fight infection directly and secretion of chemokines and cytokines that promote acquired adaptive immune responses. A hallmark feature of adaptive mucosal immune responses is the production and secretion of secretory immunoglobulin A (sIgA). Dimeric IgA produced by plasma cells in lamina propria of the intestine is transported through adjacent secretory epithelia by polymeric immunoglobulin receptor (pIgR) expressed by glandular and IECs into intestinal secretions. Secretory antibodies including sIgA and secretory $\operatorname{IgM}(\operatorname{sIgM})$ mediate immune exclusion at mucosal surfaces along with non-specific innate defenses to restrict colonization of mucosal surfaces by microorganisms and inhibit potentially dangerous soluble factors and antigens to breach the epithelial barrier. Thus, pIgR synthesized by IECs and secretory antibodies are very important for maintaining the integrity of the gut and factors that influence regulation of pIgR expression could affect mucosal immunity. So it is of great interest to investigate modulation of $\mathrm{pIgR}$ and hence secretory antibodies during pathogenic interactions. 
This dissertation is comprised of a series of studies examining the regulation of $\mathrm{pIgR}$ expression in response to an enteric pathogen, reovirus in IECs. These studies showed that reovirus induced expression of $\mathrm{pIgR}$ in IECs and characterized the various signaling pathways including calpains and nuclear factor kappa $\mathrm{B}(\mathrm{NF \kappa B})$ involved in virusmediated upregulation of pIgR. Signaling induced by microbes and their products that augment pIgR-mediated transcytosis of IgA, links the innate and acquired immune responses to viruses.

\section{THE GENERAL ORGANIZATION, DEVELOPMENT AND MATURATION OF GUT EPITHELIUM}

Embryology of Gastrointestinal Tract. The human gastrointestinal tract (GI) can be recognized early during ontogeny in the fourth week of gestation. During development the GI tract can be divided into foregut, midgut and hindgut. The foregut develops into esophagus, stomach, duodenum up to ampulla of Vater and associated organs including liver and pancreas. The midgut gives rise to the distal $2 / 3$ portions of duodenum, jejunum, ileum and proximal transverse colon. The hindgut accounts for distal transverse colon, remaining portion of large intestine up to the proximal anal canal (121).

Development and Maturation of Small and Large Intestines. In humans, the small intestine and the colon develops around fifth week of gestation, which is relatively early compared to other mammals including mice and rats. Simple cuboidal epithelial cells initially line the small intestine and colon. At 8 weeks of gestation, the epithelium is 
undifferentiated and stratified and and heparin sulphate, type IV collagen, and laminin, produced by epithelial cells form a basement membrane before differentiation (25). At 9 week, the first important morphogenetic change is marked by development of the villi first in the proximal intestine and successively in the distal portions of the intestine. At this stage the villi is lined with a functional epithelium so that a typical adult -like architechture is established in the small intestine. The four different cell types that comprise the functional epithelium are absorptive columnar, goblet, enteroendocrine and Paneth cells. In the following weeks of gestation the villi continues to develop in size and number. At $14-16$ weeks of gestation a second important morphogenetic event occurs that results in invagination of the intervillous epithelium in the adjacent mesenchyme to form crypts that harbors the majority of proliferative cells of the epithelium. Thus, sequential morphogenesis leads to establishment of the crypt - villus axis that serves as a typical intestinal renewing unit in the small intestine. The morphogenesis of colon is similar to that of small intestine but the onset of development is delayed by 2-3 weeks. Interestingly, the villi structures in the developing colon eventually disappear after 30 weeks to form definitive adult -like glandular surface epithelium (SE) axis, where proliferative cells are restricted to the lower third of the glands $(119,120,259)$.

Although not in humans, but in mice, some functional maturational changes of the small intestine occur at the time of weaning, a process that begins in the third week after birth. For example, in rodents development of many absorptive and enzymatic activities coincide with weaning. During weaning the infant GI tract is exposed to a special diet of 'maternal milk' that is high in fat and low in carbohydrates. Increases in small intestine 
weight, size and DNA or protein content have been reported in pigs, rabbits, rodents and dogs when fed colostrums compared to conventional diet, suggests a role for maternal milk in impacting intestinal maturation $\{787,788\}$.

\section{Basement Membrane of Intestine.}

The intestinal epithelium lies on thin and continuous sheet of specialized extracellular matrix (ECM) called the basement membrane, which separates the underying interstitial connective tissue or stroma containing various cells types including the mesenchymal cells from the epithelial cells (317). The basement membrane is composed of glycoproteins and peptidoglycans including laminins, type IV collagens, nidogens and heparan sulphate proteoglycans $(294,295,317)$. The intestinal basement membrane comprises of three layers and is considered a simple basement membrane (Fig. 1). It has three distinct layers including the lamina densa (LD) adjacent to the intestinal epithelium, the lamina lara (LR) that separates the LD from underlying stroma and the lamina fibroreticularis (LFR), which connects the overlying basement membranes (LD and LR) to the underlying extracellular matrix of the connective tissue (317). One of the primary functions of basement membrane is to provide structural support for the intestinal cells and offer compartmentalization. However, it has become evident over the past decade that basement membrane composition dictates the necessary microenvironment and influences a number of functions of the surrounding epithelial cells including growth, migration, differentiation, tissue specific gene expression and apoptosis

$(317,375,376,377,378)$. These cellular functions during development and maturation of GI tract are regulated by various components of the basement membranes including 
fibronectins, tenascins and laminins and their interaction with cellular receptors such as members of the integrin superfamily $(115,116,372)$.

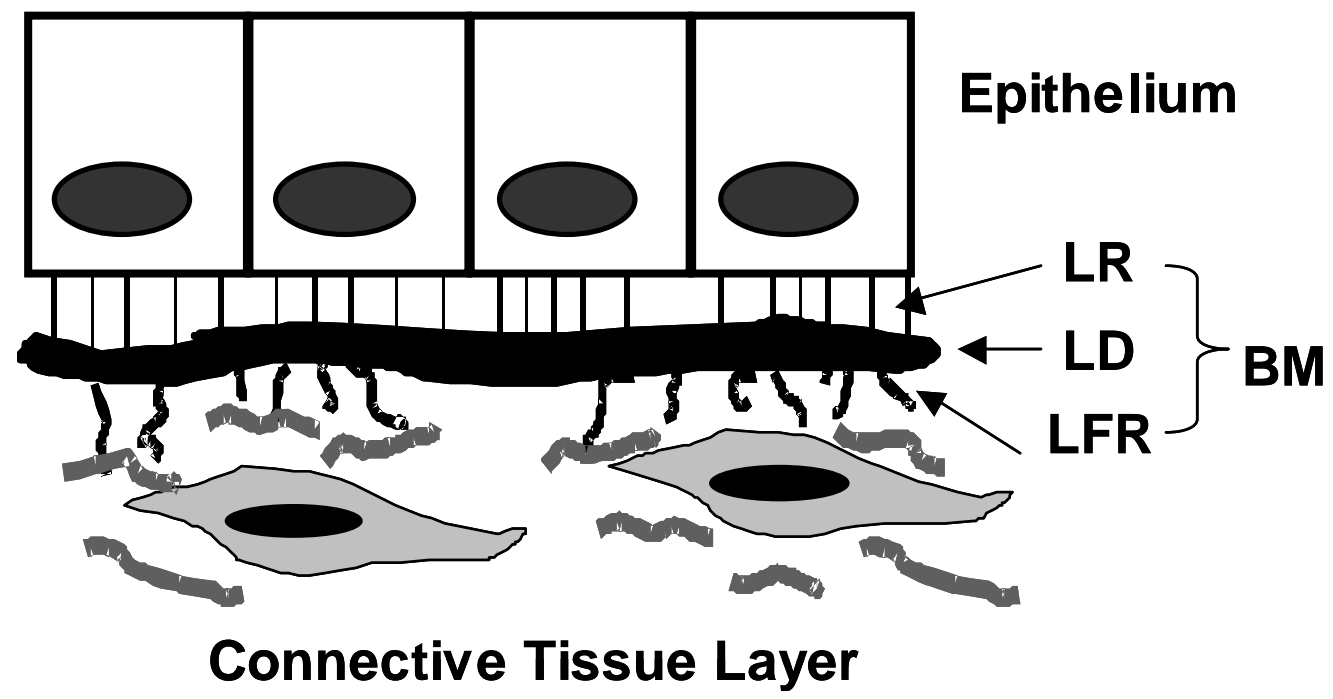

Figure 1. Schematic Representation of Intestinal Basement Membrane.

Basement membrane is composed of three layers including a lamina rara (LR) adjacent to epithelium, a lamina densa (LD) and a lamina fibroreticularis (LFR) that connects the basement membrane (BM) the the underlying connective tissue. Diagram is adapted from Quondamatteo et al. (2002) (317). 


\section{Stem Cells of the Gastrointestinal Tract.}

The regenerative property of the gut epithelium depends on the multipotent intestinal stem cells that are stationary and anchored at specific locations along the entire length of gut epithelium. Despite the lack of specific biomarkers for the intestinal stem cells, they can be recognized morphologically by their undifferentiated, embryonic cell like features such as a high nucleus-to-cytoplasm ratio, diffused chromatin, large reticulated nucleoli and cytoplasm with few cellular organelles but abundant in free ribosomes. In addition, intestinal stem cells are also distinct functionally as evident from their remarkable capacity to proliferate to maintain their own renewal and produce all lineage precursors of the gut epithelium $(14,310,312)$. In the small intestine, these stem cells are arranged in a ring like formation just above the Paneth cells in the crypt base, which marks the origin of migration of epithelial cells to repopulate the differentiated, functional mature cells of villi that are constantly shed in the intestinal lumen (14). The number of stem cells per crypt is tightly regulated and each crypt comprised of approximately 250 epithelial cells harbors 4-6 functional stem cells. Regulation of stem cell number is vital because one additional stem cell might lead to an excess of 60-120 cells per crypt. Such regulation is enforced by apoptosis in small intestine that removes excess but otherwise healthy stem cells and / or stem cells with DNA damage and thereby checks replication errors despite the rapid proliferation rate (238). Control of cell division in intestinal stem cell is an active area of research and it has been proposed that a specific type of mitosis occurs in the functional stem cell that is responsible for its self-renewal and maintainance.

Typically, normal stem cells undergo mitosis asymmetrically resulting in one daughter 
stem cell and one daughter cell that continue to divide, mature and differentiate.

Alternatively, there is a 5\% chance of symmetric mitosis in the stem cells producing either two stem cells or two maturing cells (223). The small intestinal stem cells gives rise to three main precursors including pre-absorptive, pre-goblet and pre-Paneth cells that ultimately evolve into absorptive, goblet and Paneth cell lineages respectively (176). The entire gut epithelial cell types except the Paneth cells of small intestine migrate upward from the base of the crypts as they mature and differentiate. It has been speculated that since the small intestinal stem cells lies adjacent to Paneth cells always localized at crypt base, the latter might contribute to control of stem cells (311)

\section{Cell Differentiation in Crypt - Villus unit of Small Intestine.}

The small intestine mucosa is composed of large finger-like projections called villi that project into the intestinal lumen and the surrounding crypts of Lieberkuhn that extends from base of villi and project away from the lumen (Fig. 2). A single layer of columnar epithelial cell lines both the cypts and villi. The intestinal epithelium is a very dynamic tissue and regenerates itself over a 3-5 day period in humans. Within the crypts multipotent crypt stem cells divide through life, giving rise to the epithelial lineages. The stem cells are localized at fixed positions in the middle to lower crypt cell region. Columnar epithelial cells differentiate as they migrate from the crypt base to the villus tip in $5-6$ days in the proximal human small intestine and 3 days in the human ileum $(145,402,403)$. Migration continues until cells are lost from the tip of a villus and shed into the intestinal lumen. The exceptions are the intestinal Paneth cells, which reside at 
the base of the crypts and turn over every 23.3 days being cleared from the crypt base by phagocytosis $(32,33)$.

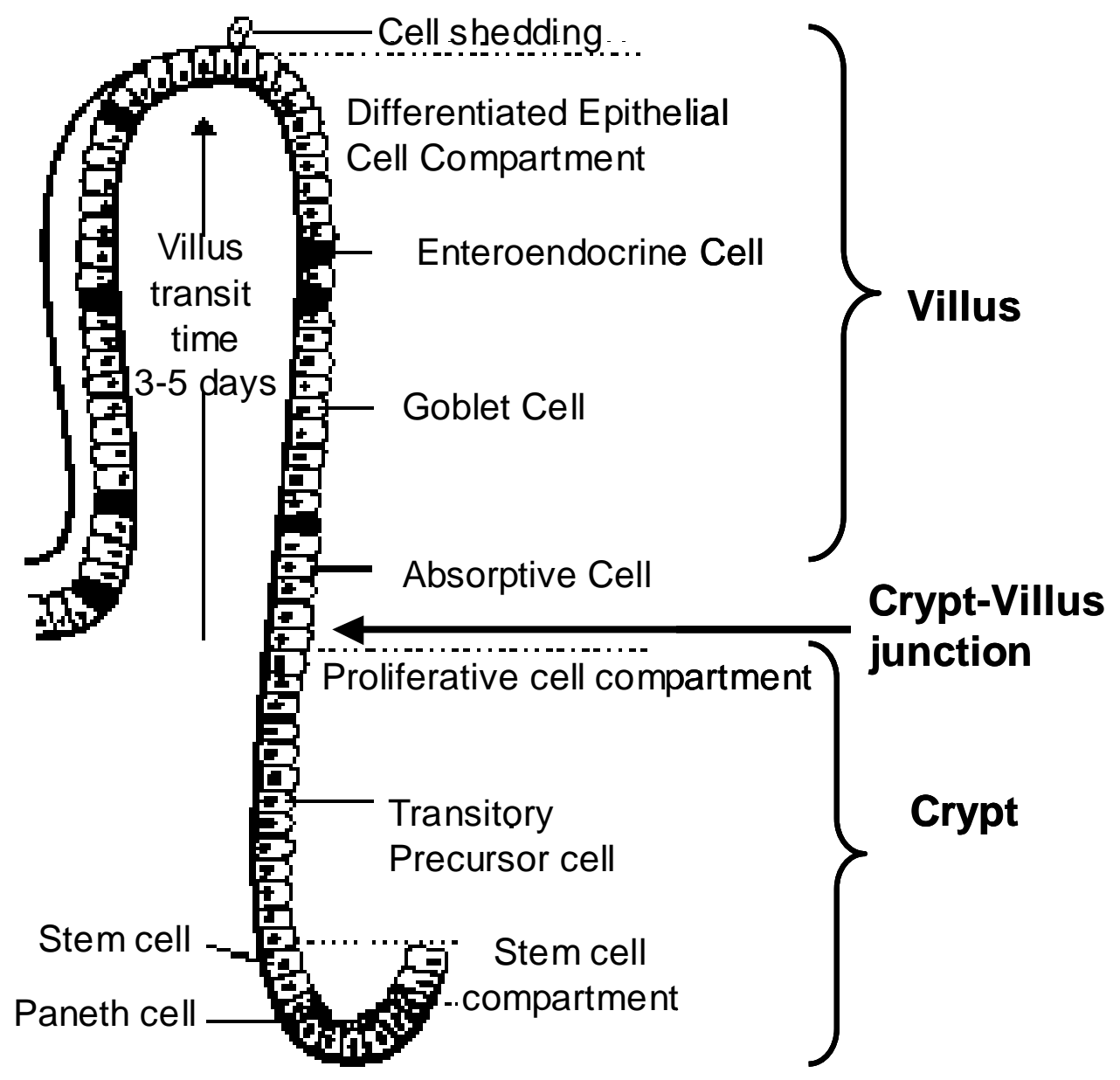

Figure 2. Anatomy of a crypt - villus unit of small intestine.

Stem cells lie in the base of the crypt above paneth cell cluster. Transitory progenitor cells derived from stem cells migrate along the crypt-villus axis, rapidly dividing with an average cell -cycle time of 12h. Progenitor cells ultimately differentiate into goblet, enteroendocrine, and absorptive cells. Migration of cells in completed in 3-5 days and finally they are shed into the lumen. Progenitors destined to give rise to Paneth cells migrate downward towards crypt base. Diagram is adapted from Fujita et al. (2004) (107). 


\section{GUT EPITHELIUM AND INNATE DEFENSE FACTORS}

Physical Barrier. The collective mechanisms by which the IECs controls the commensal microflora and and actively responds to invading pathogens is referred to as innate intestinal epithelial defense. The intestinal epithelium lining serves as a formidable physical barrier to foreign antigens and microbes in the gut lumen and thus contributes in host defense. The intestinal epithelium maintains its integrity by tight junctions between IECs and thereby restricts uptake of noxious antigens while allowing passage of nutrients by pinocytosis $(331,392)$. The major function of the GI tract is digestion and absoption of nutrients. To perform its primary function, the majority of the mucosal epithelium is composed of absorptive epithelial cells (enterocytes). The apical surface of enterocytes in tightly packed with microvilli that are covered with glycocalyx. The carbohydrate rich glycocalyx coat contains various enzymes and nonenzymatic proteins including disaccharidases, peptidases, receptors and transport proteins that help in digestion and absorption of nutrients $(106,112,151)$. In addition, the gut epithelium is bathed in copious secretions of mucus that forms the outermost coat of the mucosal immune system and acts as a selective permeable barrier like the cell membrane of epithelial cells. Humans secrete a total of approximately 10 liters of mucus per day. Mucus is a sticky slippery gel with viscoelastic properties and is composed of $1 \%$ mucin, $1 \%$ free protein, $1 \%$ dialyzable salts and more than $95 \%$ water. The viscoelastic property of mucus is provided by the secreted mucins, which are, long fibrous peptides coated with a complex and diverse array of oligosaccharides (237). Mucus protects the IEC surfaces as a lubricant that protects against mechanical damage and serves as a shield by entrapping 
harmful antigens and microorganisms before they can bind and interact with the cells $(104,232)$. Mucus prevents adherence of microorganisms including enteropathogenic Escherichia coli, Entamoeba histolytica and Yerssinia enterolytica by trapping the pathogens and covering their cellular binding sites with mucin and secretory IgA $(61,236,328)$. Recent studies have demonstrated that preformed mucus can be secreted from goblet cells in response to stimulation by luminal pathogens to provide an additional protective coat on the mucosal epithelial surface that restricts excessive uptake of antigens and pathogens $(105,296,331)$. However, mucus selects and support colonization of gut by friendly and protective commensals and thus plays a role in establishing local mucosal ecosystems that reduce or prevent colonization by pathogens $(72,345)$.

Innate Defense Factors. The IECs are armed with an impressive set of constitutive innate immune defense mechanisms including defensins, trefoil peptides, lactoferrin and complement that protect the underlying biological compartments.

(a) Defensins: IECs express a class of antimicrobial peptides called defensins. Defensins are the most abundant antimicrobial peptides released at the mucosal surfaces. They are 3 to $4 \mathrm{kDa}$ cationic, arginine -rich $\beta$-sheet peptides with six cysteines that form three disulphide bridges $(172,211,288)$. Defensins are categorized as $\alpha-$ defensins and $\beta$ defensins depending on their pattern of disulphide bonding (111). In the intestine, the defensins were first identified in the mice Paneth cells located at the base of the crypts of Lieburkuhn and hence this family of mouse $\alpha$-defensins is called cyrptidins (289). Secretion of defensins from Paneth cells might provide antimicrobial defense to the intestinal stem cells lodged in crypts and thus provide a protective barrier for the highly 
proliferative compartment of intestine. In newborn mice cryptidin mRNA expression is not discernable but its expression gradually increase and reach adult levels by the fourth postnatal week. The mechanisms controling cryptidin gene expression is not fully understood $(80,287,289,290)$. Interestingly, levels of cryptidin mRNA expression were normal in nude and germ free mice suggesting that its expression is independent of both T-cell mediated signals or colonization of gut by intestinal microflora $(80,288)$.

Cryptidins exhibit antimicrobial activity by permeabilizing microbial cell membranes in a number of virulent bacteria including Staphylococcus aureus, Listeria monocytogenes, Salmonella typhimurium, Escherichia coli and fungi such as Candida albicans and Aspergillus fumigatus $(92,210,211,212)$. In humans, two intestinal $\alpha$-defensins namely human defensin 5 (HD-5) and HD-6 have been identified in the Paneth cell granules (307). HD-5 and HD-6 mRNA expression can be detected by reverse transcriptase polymerase chain reaction (RT-PCR) by 13.5 weeks of gestation that parallels with the time when Paneth cells become morphologically distinguishable by electron microscopy (EM). It has been demonstrated that recombinant HD-5 retained its antimicrobial activity even after exposure to concentrations of trypsin that are physiologically present in the intestinal lumen. HD-5 was effective against L. monocytogenes, E. coli and S. typhimurium $(307,308)$.

The first $\beta$-defensin isolated from cow is called tracheal antimicrobial peptide (TAP) and its expression is restricted to the airway tissue $(88,90)$. Later, another homologous peptide was isolated from bovine tongue and named lingual antimicrobial peptide (LAP) (340). Studies have shown that TAP and LAP mRNA expression is upregulated by LPS 
and TNF- $\alpha$ suggesting that these bovine $\beta$-defensins provide an inducible mechanism of host innate defense $(89,90,357)$. In humans, members of $\beta$-defensins namely hBD-1 and hBD-2 are more widely distributed within the GI tract. However, they are not under the inducible control of cytokines such as TNF- $\alpha$, IL-6 or IFN- $\gamma(411)$. Human BD-2 has been recently identified and not much is known about its regulation and induction by cytokines or microbial components. Singh et al. reported that inflammatory cytokine IL$1 \mathrm{~b}$ induced hBD-2 in primary cultures of airway epithelial cells $(350,351)$. In addition, since hBD-2 was isolated exclusively from bronchoalveolar lavage (BAL) of cystic fibrosis patients, it suggest that this $\beta$-defensin is only induced under inflammatory conditions unlike hBD-1 which is present in BAL of all patients (17). However, future studies will determine if the similar mechanisms of human $\beta$-defensin induction and regulation applies to the intestinal tissues.

(b) Trefoil Peptides: Trefoil peptides or trefoil factors are a family of extracellular small peptides that are synthesized and secreted by mucin secreting epithelial cells or goblet cells in the gastrointestinal tract. The trefoil factor family (TFF) peptides are so named because they assume a trifoliate pattern of chain folding tightly held together by three pairs of disulphide bonds between cysteine residues $(303,306)$. The distinct cysteine-rich 'trefoil' domains maintain stability of the molecule and render them resistant to proteolytic degradation by gut proteinases $(306,332)$. In humans, three trefoil factors namely TFF1, TFF2 and TFF3 have been identified $(65,379)$. All the three trefoil factors are highly expressed in gastrointestinal tract: TFF1 is mainly expressed in stomach and the antral mucosa; TFF2, in pancreas and stomach and TFF3 is expressed throughout the 
small and large intestines $(306,332)$. The trefoil factors play an important role in maintaining integrity of the mucosal epithelium by coating the apical surface of the IECs and thereby protecting them from direct assault by pathogens and toxins $(192,305)$. Recent studies have demonstrated that the trefoil factors act as motogens, which induces cell migration without promoting cell division. The expressions of trefoil peptides are upregulated in chronic inflammatory bowel disease (IBD) and peptic ulcers, suggesting a role for these peptides in healing injured mucosal epithelium. Trefoil peptides are a central player in the process of restitution, the initial phase of mucosal repair, which is accomplished by rapid migration of the surviving epithelial cells from wound edge to denuded areas ultimately re-establishing surface epithelial continuity and integrity. Studies in mice with targeted deletions in trefoil genes exhibit susceptibility to epithelial injury, impaired mucosal healing and death from extensive colitis, reinforcing the contribution of trefoil peptides in epithelial restitution and maintainance of the intestinal mucosa $(100,240,371)$.

(c) Pattern Recognition Receptors: IECs are the first sensors of 'non-self' particles including pathogens and their microbial products initiating an innate immune response. IECs are decorated with an impressive arsenal of efficient sensing and defence molecules called pattern recognition receptors (PRRs) that recognize pathogen-associatedmolecular-patterns (PAMPS), such as LPS, a glycolipid derived from the outermost membrane of pathogenic gram -negative bacteria, peptidoglycan (PGN), bacterial DNA, dsRNA and single stranded RNA (ssRNA) (139,304). 
PRRs can be categorized into secreted, intracellular and cell surface forms (253). IECs secrete soluble CD14 and also express a membrane bound form of CD14 (mCD14) $(56,110)$. CD14 facilitates binding of LPS to IEC, which is enhanced in presence of LPS binding protein (LBP). It has been reported that low dose of LBP first recognizes bacterial LPS and then transfers it to second receptor CD14, that directly transduces signal in IECs and uncontrolled stimulation of host cells might result in septic shock (207,208,341). However, high dose of LBP serves to inhibit LPS-mediated host cell stimulation and subsequent cytokine release suggesting a protective effect against LPSmediated septic shock without imparing physiologic defense mechanism against infection $(205,414)$.

IECs express intracellular PRRs such as NOD (nucleotide-binding oligomerization domain) proteins and Toll like receptor 3 (TLR3) $(156,252,298)$. Members of the Nod family include Apaf-1, Ced-4, Nod1, Nod2, and the cytosolic products of plant disease resistance genes. Nod proteins function as cytosolic sensors for the innate recognition of microorganisms, induction of apoptosis, and regulators of inflammatory responses $(157,158)$. The C-terminal domain of Nod proteins serve as the intracellular ligand sensing domain while the $\mathrm{N}$-terminal domains interact with downstream effector molecules and subsequently activate various signaling pathways leading to various immune responses and apoptosis (156). In IECs, Nod1 and Nod2 recognize intracellular bacterial LPS; interact with downstream effector molecule Rip-2 via caspase activating and recruitment domains (CARDs) and ultimately mediate activation of NFKB and JNK $(117,298,299)$. Nod proteins including mammalian Nod1 and Nod2 represent an 
evolutionarily conserved system of intracellular surveillance PRRs for recognizing cytosolic LPS and pathogen components derived from invading bacteria.

In addition to soluble PRRs and intracellular Nod proteins, IECs are equipped with an array of surface expressed and intracellular pathogen detection receptors called TLRs. In insects and mammals, TLRs are type I transmembrane proteins that play a crucial role in the recognition of invading pathogens and the activation of subsequent immune responses against them. TLRs recognize pathogens through the PAMPs, which are conserved structural moieties of pathogens essential for their viability and therefore serve as ideal targets for detection $(23,252,337,365)$. To date, 13 TLRs have been identified including TLRs 1-9 are common to mouse and humans, while TLR 10 and TLRs 11-13 is unique to human and mouse respectively $(252,362,365)$. All TLRs are structurally similar in that they are comprised of three major domains including an amino-terminal domain containing a series of leucine rich repeat (LRRs) motifs, followed by a single putative transmembrane domain and a carboxy-terminal toll/ IL-1 receptor (TIR) domain. The LLR domain is important for pathogen recognition while the TIR domain interacts with the downstream adaptor proteins including TRIF and MyD88 to transduce signaling events leading to inflammatory and antimicrobial innate immune responses in host cells $(28,159,257,277,407)$.

TLRs are functionally expressed in a wide variety of cell types including macrophages, neutrophils, dendritic cells and epithelial cells $(252,286)$. Although, TLRs $1-9$ is expressed in the IEC, the GI tract exhibits a restricted and differential expression of 
TLRs. Selective expression of TLRs allow the enterocytes to maintain a state of balanced responsiveness to microbes in normal healthy condition by mediating tolerance to commensals while sensitively recognizing danger signals of potentially harmful pathogens $(55,286)$. The level of TLR2 and TLR4 expression decreases from the base of intestinal crypt cells to the more mature IECs of the intestinal villus. Higher expression of TLR2 and TLR4 in the crypt cells allows them to effectively sense and destroy bacteria, maintain a sterile environment at the base of crypt-villus unit and thereby protect the resident stem cells that are required for regeneration of epithelium $(152,285)$. The apical surfaces of IECs express minimal levels of TLR2 and TLR4, which traffic to intracellular compartments upon activation by PGN and LPS respectively. Redistribution of TLRs from apical surfaces to intracellular compartments allows IECs to detect pathogens while limiting the extent of TLR -mediated signaling and subsequent inflammation $(53,152,153)$. In addition, TLR5 is expressed exclusively on the basolateral surface of IECs, suggesting that signaling through TLR5 is triggered only in response to flagellete invasive bacteria such as that breach the mucosal epithelial barrier $(114,135)$. Some recent studies have suggested the existence of an apical population of TLR5 receptors but atleast in GI tract TLR5 is expressed basolaterally in IECs (184).

In addition to TLRs that sense bacteria, IECs express TLR3, TLR7 and TLR8 that specialize in recognizing viral PAMPs $(4,91,140)$. Various viral proteins and nucleic acids either activate TLRs or inhibit their function and a complex interplay occurs in host cells that ultimately leads to clearance of virus by activation of innate immune system or leads to evasion of TLR surveillance by virus enabling it to replicate. TLR-3 is 
constitutively expressed in human intestinal epithelial cells (55), although the precise intracellular location of TLR-3 has not yet been identified. In human dendritic cells TLR-3 is expressed intracellularly in vesicles and possibly at a low level in late endosomes $(109,243,244)$. An intracellular localization on TLR3 is consistent with its role of responding to viral nucleic acids likely available for interaction during partial viral disassembly and / or during replication inside host cells (27). It has been implicated that TLR 7 and 8 recognize viral PAMPs specifically ssRNA in endosomal or lysosomal compartments. This is consistent with the possible route of naked virus nucleic acid exposure to TLRs upon receptor-mediated uptake of virus particles inside endosomes $(91,140)$.

Stimulation of TLRs triggers activation of a common MyD88-dependent signaling pathway as well as a MyD88-independent pathway mediated by several TIR domaincontaining adaptors proteins such as MyD88, TIRAP, and TRIF. Recruitment of common adaptor MyD88 to TLR activates IL-1 receptor associated kinases (IRAKs), which interact with TNF receptor associated factor 6 (TRAF6), ultimately leading to the activation of MAP kinases and the transcription factor $\mathrm{NF} \kappa \mathrm{B}$ resulting in proinflammatory cytokine production $(404,407)$. The MyD88 -independent signaling requires adaptor molecule TRIF for TLR3- and TLR4-mediated signaling pathways, leading to activation of transcription factors $\mathrm{NF \kappa B}$ and interferon regulatory factor 3 (IRF3) facilitating IFN- $\beta$ production for mammalian antiviral host defense $(404,405,406)$. 
The TLR- microbial interaction and signaling results in the secretion of anti-bacterial peptides, defensins, and proinflammatory cytokines such as TNF- $\alpha$ and IL-6 which initiate an inflammatory response to clear the invading pathogen and is essential for initiation of the adaptive immune responses. Proinflammatory cytokines subsequently recruit cells of adaptive immunity including neutrophils, macrophages and dendritic cells (DCs). Neutrophils and macrophages play an active role in clearance of the pathogens and contribute to host survival, while DCs primarily function as antigen presenting cells (APCs) to both naïve and memory $\mathrm{T}$ cells and drive their differentiona into $\mathrm{T}$ helper (Th)effector cells $(193,242,252,337)$. TLR-mediated recognition and microbial -epitheial cross talk at mucosal surfaces bridges the immediate innate and subsequent adaptive immune responses to invading mucosal pathogens. 


\section{IMMUNOGLOBULIN A: SYNTHESIS, STRUCTURE AND FUNCTION}

IgA synthesis. Immunoglobulin A $(\operatorname{Ig} A)$ is the primary immunoglobulin induced at the mucosal sites and it provides the first line of specific defense at mucosal surfaces $(46,201,202,204,246,248)$. One of the key effector functions of gut associated lymphoid tissue (GALT) is the elaboration of B cells into an IgA producing plasma cell. Multiple steps are involved in the priming and maturation of a naïve B cell to an IgA producing cell $(182,183)$. The major source of precursors of the IgA plasma cells in the intestine is the organized lymphoid follicles of the PPs, where naïve B cells with surface IgM are switched to IgA bearing cells with the help of T cells and cytokines $(75,183)$. Protein antigens including ovalbumin, bacterial proteins, and viruses are phagocytosed by APCs, digested into peptides and reexpressed coupled with Major Histocompatibility Complex (MHC) II molecules on surface of APCs. CD4+ T cells are activated upon interaction between its T-cell receptor (TCR) and peptide/ MHC II on APCs. Activated T cells then directly contact B cells via binding of specific cell surface molecules CD40 ligand on T cell and CD40 on B cell, and such cognate interactions results in T- dependent B cell activation $(8,9,272)$. However, $\mathrm{B}$ cells can also be activated via a $\mathrm{T}$ independent mechanism by T independent (TI) antigens including bacterial LPS, dextran sulphates and capsular polysaccharides of bacteria such as Streptococcus pneumoniae, Neisseria meningitidis (94). Macpherson et al. (233) reported a T independent pathway of B cell differentiation to IgA producing plasma cells. Although, the conventional pathway of B cell development requires membrane $\operatorname{IgM}$ or IgD heavy chain expression at an early stage in B cell ontogeny, recent studies have shown that it is not an absolute requirement for the generation of $\operatorname{Ig} \mathrm{A}^{+} \mathrm{B}$ cells. Some murine $\operatorname{IgA}$ can be produced $\mathrm{T}$ cell independently 
by B1 cells originated from peritoneal cavity and likely represents an evolutionarily primitive system for recognition of commensal bacteria by polyreactive antibodies. In contrast, the B2 cells in the germinal centers of MALT produces the bulk of IgA by a T cell dependent (TD) manner (233). At the inductive sites, TGF- $\beta$ primarily drives class switching of B cells to generate $\operatorname{IgA}{ }^{+} \mathrm{B}$ cells $(39,60)$. These committed cells then migrate from Peyer's patches to the draining mesenteric lymph nodes, where they continue to divide and differentiate. Finally they exit the lymph nodes and pass via the thoracic duct into the blood and home to the lamina propria where they mature as IgA-secreting plasma cells $(203,297)$, and some B cells differentiate into memory cells (368).

Structure of IgA. IgA exists in both monomeric and polymeric forms. IgA present in human serum or external secretions displays characteristic structural differences, particularly in the relative proportions of monomeric and dimeric forms. In adults over $90 \%$ of the $\operatorname{Ig} \mathrm{A}$ in serum is monomeric, while in secretions $\operatorname{Ig} \mathrm{A}$ is primarily polymeric, most often dimeric, in the form of $\operatorname{sgA}(43,48,130)$. Monomeric $\operatorname{IgA}(\mathrm{mIgA})$ is composed of two $\alpha(53-\mathrm{kDa})$ and two $\kappa$ or $\lambda(22.5-\mathrm{kDa})$ chains. Human $\alpha$ chains are glycoproteins (6-10\% carbohydrate) consisting of one variable and three constant domains. Dimeric IgA consists of two monomers connected by disulphide bonds and linked to an additional polypeptide called J chain (15-kDa; $8 \%$ carbohydrate) (discussed in $\mathrm{J}$ chain). A distinguishing feature of polymeric $\operatorname{IgA}(\mathrm{pIgA}$ ), as well as $\operatorname{IgM}$ (which is generally pentameric), is the presence of $\mathrm{J}$ chain, which is incorporated into $\operatorname{PgA}$ and IgM just prior to their secretion from plasma cells and plays a regulatory though not indispensable role in the polymerization of these isotypes $(45,130,254)$. 
IgA is the most heterogeneous immunoglobulin isotype. In addition to existing in a variety of molecular forms, it exists in two distinct subclasses, IgA1 and IgA2. A major difference between the two subclasses is found in the hinge region. $\operatorname{IgA} 2$ molecules lack a 13 amino acid segment, which is present in the hinge region of IgA1 and consists exclusively of prolyl, seryl, and threonyl residues. Four to five of the seryl and threonyl residues carry O-linked glycans. Though the extended hinge region confer greater segmental flexibility on IgA1 molecules, the O-glycosylation sites renders this isotype susceptible to the activity of certain post-proline endopeptidases, called IgA1 proteases, produced by bacterial pathogens and commensals colonizing the mucosa including Neisseria meningitides, Streptococcus pneumoniae and Haemophilus influenzae type b $(187,190,191)$. The absence of hinge region in IgA2 molecules renders them resistant to cleavage by IgA1-specific proteases, which is advantageous by IgA2 antibody function at mucosal surfaces $(186,189)$. The human IgA2 subclass exists in two allotypic forms designated $\mathrm{A} 2 \mathrm{~m}(1)$ and $\mathrm{A} 2 \mathrm{~m}(2)$. The $\mathrm{A} 2 \mathrm{~m}(1)$ allotype is unconventional in that the heavy $(\mathrm{H})$ and light $(\mathrm{L})$ chains are not covalently linked, and therefore can be separated by non-reducing dissociating agents (122,393). Population studies of the IgA2 allotypes have revealed a characteristic racial and ethnic distribution, where A2m(1) allotype is highly predominant in caucasians and $\mathrm{A} 2 \mathrm{~m}(2)$ dominates in people of African origin $(388,393)$. The distribution of two IgA subclasses varies significantly in the different parts of the immune system (251). In serum, $90 \%$ of the $\operatorname{IgA}$ is IgA1 which, is consistent with a similar predominance of IgA1-producing cells in the bone marrow, where most serum IgA is produced (86). However, in secretions IgA is produced by plasma cells at effector sites. IgA1 also predominates in the salivary, upper respiratory and upper 
gastrointestinal tract secretions, while $\operatorname{IgA} 2$ is present in higher proportions in lower gastrointestinal tract. The distribution of IgA subclasses depends on the nature of the antigen such that proteins primarily induce IgA1 response, while immunization with carbohydrates favor generation of IgA2 producing cells (369).

Role of J-chain. The joining $(\mathrm{J})$ chain is a small polypeptide, expressed by mucosal and glandular plasma cells, which regulates polymerization of $\operatorname{IgA}$ and $\operatorname{IgM}$ $(63,155,195,261)$. Incorporation of J- chain provides $\mathrm{pIgA}$ and $\operatorname{IgM}$ with a number of unique advantageous features. First, it increases the valency of antigen-binding sites, which make the antibodies suitable for agglutinating bacteria and viruses with little or no complement-activating potential allowing them to operate in a non-inflammatory fashion. Second and most importantly, only J-chain-containing polymers show high affinity for the pIgR, also known as transmembrane secretory component (SC) $(165,166,194)$. This epithelial glycoprotein mediates active external transfer of $\operatorname{pIgA}$ and pentameric IgM to exocrine secretions. Thus, secretory IgA (sIgA) and sIgM, as well as free SC (FSC), are generated by endoproteolytic cleavage of the pIgR extracellular domain. IgA remains covalently linked to the secretory piece forming sIgA by a single disulfide bond between Cys 311 of one alpha-chain and Cys 467 of the secretory component $(165,166)$. The secretory antibodies form the first line of defense against inhaled, ingested and sexually transmitted pathogens at mucosal sites. The $\mathrm{J}$ chain is critical for creating the binding site for $\mathrm{pIgR}$ / SC in the Ig polymers, not only by driving their polymerization but also by interacting directly with the receptor protein. Therefore, both the J chain and the pIgR / 
SC are key proteins in secretory immunity and factors that affect them could modulate mucosal immunity.

\section{IgA in mucosal immunity.}

Polymeric Immunoglobulin Receptor (pIgR) and secretory IgA.

After secretion from plasma cells, $\operatorname{IgA}$ is transported from the lamina propria to the intestinal across the adjacent mucosal epithelium by $\mathrm{pIgR}$, which is a transmembrane glycoprotein expressed on the basolateral surface of mucosal epithelial cells $(43,44,45,46,264)$ (discussed in details in pIgR section). Dimeric IgA binds to $\mathrm{pIgR}$ and the whole complex is then endocytosed and transcytosed through vesicular compartments to the apical surface $(7,264,280,281)$. At the apical surface $\mathrm{pIgR}$ is cleaved between the cytoplasmic and transmembrane domains by a leupeptin sensitive endopeptidase releasing sIgA into the intestinal secretions (268). Polymeric $\operatorname{IgA}(\mathrm{pIgA})$ is covalently linked by disulfide bonds to the extracellular portion of the receptor called secretory component and this complex of pIgA and SC forms the molecular complex referred to as $\operatorname{sIgA}(273)$.

Function of secretory IgA, pIgR and free secretory component.

SIgA is the first line of specific immunological defense at mucosal surfaces $(46,179,200)$. SIgA is an effective isotype at mucosa as it is very stable and resistant to degrading enzymes. SIgA provides three tiers of immune protection at mucosal surfaces (Fig. 3). First, sIgA blocks the interaction of bacterial or viral adhesins and their receptors on the apical surface of mucosal epithelial cells, inhibits motility, or facilitates 
entrapment in mucus $(169,248,267,273,367)$. Second, during transcytosis, IgA can also neutralize intracellular microbial pathogens within epithelial cells $(36,169,246,247,248,248)$. Third, IgA can bind to soluble antigens in the mucosal lamina propria and promote transcytosis of immune complexes by pIgR into the intestinal lumen; thereby ridding the body of locally formed immune complexes $(171,248)$. The SC portion protects the binding site for $\mathrm{Fc}-\alpha$ receptor in sIgA. Several studies have shown that, receptor bound $\operatorname{IgA}$ and $\operatorname{sIg} \mathrm{A}$ can trigger cellular functions including degranulation and respiratory burst by binding to Fc-receptor for IgA on phagocytic cells $(262,263)$. Free secretory component protects $\operatorname{sg}$ A from proteolytic degradation in vitro $(221,318)$ and in vivo in the GI tract and oral cavity $(66,76)$. It also prevents binding of pathogens including Escherichia coli, Streptococcus pneumoniae, and bacterial toxins to the epithelium $(79,81,118,133,134,169)$. Free SC can limit infection by binding of its unusual N-glycans to bacterial components such as Clostridium difficile toxin A and fimbriae of enterotoxigenic Escherichia coli $(79,82)$. Using pIgR knockout mice, Uren et al. reinforced the importance of $\mathrm{p} \operatorname{IgR} / \mathrm{s} \operatorname{IgA}$ for the protection of gastrointestinal surfaces against secreted bacterial toxins including cholera toxin. However, $\operatorname{pgR} / \operatorname{sIg} \mathrm{A}$ was found to be dispensable for protection against infection with Salmonella typhimurium or Citrobacter rodentium $(231,386)$. Thus, $\mathrm{pIgR} / \mathrm{sIgA}$ provides protection against bacterial exotoxin but do not play a major role in controlling numbers of pathogenic and commensal bacteria in the gut. Interestingly, pIgR knockout mice lack secretory Igs and have 100-fold more serum IgA that normal mice. Also, pIgR knockout mice have approximately thrice as many IgA-secreting plasma cells in lamina propria compared to wild type mice, suggesting that pIgR might contribute to mucosal B-cell 
homeostasis in addition to transcytosis of pIgA (386). PIgR knockout mice also exhibit reduced protection against infection with influenza $\mathrm{A}$ and $\mathrm{B}$ viruses following intranasal immunization. Lack of intracellular neutralization of viruses during pIgR-mediated IgA transcytosis and impaired immune exclusion in absence of pIgR likely contributes to defective protection against influenza virus in $\mathrm{pIgR}$ knockout mice $(11,12)$. Sun et al. demonstrated the critical role of $\mathrm{pIgR} / \operatorname{sIgA}$ in protection against nasal colonization by $S$. pneumoniae in pIgR knockout mice (360). In addition, to antigen-specific functions, sIgA and free SC contributes to regulation of innate, non-specific responses to pathogens. Overall, $\operatorname{sIg} \mathrm{A} / \mathrm{pIgR}$ contribute to maintaining the integrity of the mucosal barrier, and regulation of receptor expression contributes to host defense.

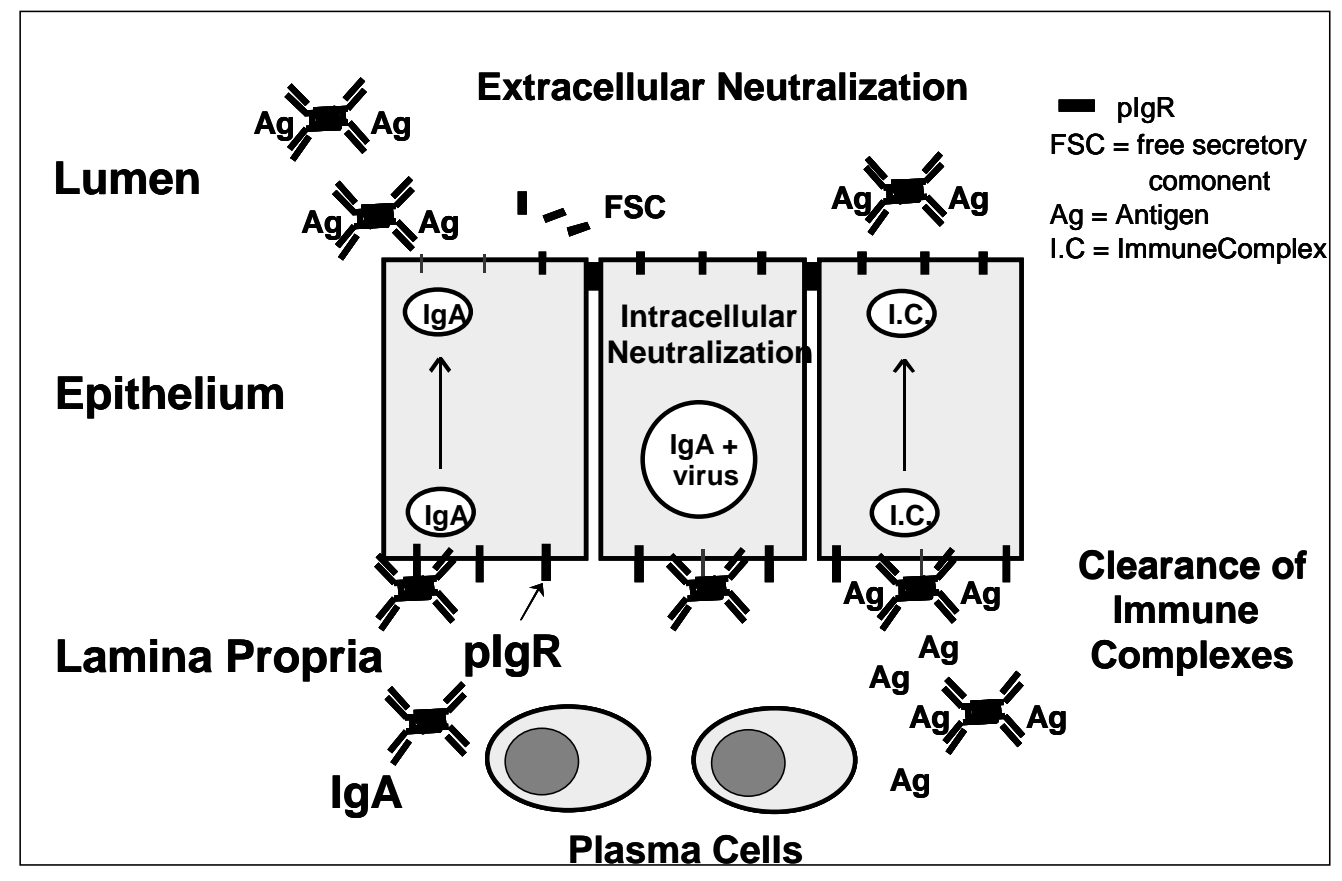

Figure 3. Three tiers of protection of mucosal epithelia by IgA.

First, sIgA blocks the interaction of bacterial or viral adhesins and their receptors on mucosal epithelial cells. Second, sIgA neutralizes pathogens intracellularly. Third, immune complexes are removed during pIgR-mediated IgA transcytosis. Diagram is adapted from Mazanec et al. (1993) (248). 


\section{Function of serum IgA.}

Serum IgA is mainly monomeric. It is produced by B-lymphocytes in the bone marrow and in some lymphoid organs. Humans produce as much serum IgA as they do IgG. Serum IgA provides anti-inflammatory effects by inhibiting complement mediated IgG and IgM responses $(123,188,327)$. However, serum IgA may initiate complement activation by the alternative $(147,162)$ or by the mannan-binding lectin pathway $(321)$. In addition, IgA in the human amniotic fluid protects the fetus by binding to natural maternal IgG autoantibodies (316).

\section{IgG and other Ig at mucosa.}

All the five classes of immunoglobulins including $\operatorname{IgA}, \operatorname{IgG}, \operatorname{IgM}, \operatorname{IgE}$ and $\operatorname{IgD}$ are found at mucosa. $\operatorname{IgG}$ in mucosal secretions is generally considered to originate from serum either by diffusion or by hepatobiliary route specifically in humans $(42,315)$. However, IgG can be locally produced irrespective of the systemic immune system $(30,41)$.

Interestingly, like IgA and IgM, a bi-directional transcytosis route exists for transportation of IgG through mucosal epithelium. In human and mouse lung epithelium, IgG can bind to a MHC class I-related Fc receptor, FcRn, which mediates transcytosis of this immunoglobulin across the mucosal barrier to the apical side (355). In lungs, protection provided by $\operatorname{IgG}$ has been found to be more effective against viral infections than IgA $(249,293)$. Thus, IgG response to mucosal antigens can complement that of secretory $\operatorname{Ig} \mathrm{A}$ in the defense against some pathogens and suggests that both $\operatorname{IgG}$ and $\operatorname{IgA}$ are important for mucosal immunity. 
Pentameric IgM is actively transported by $\mathrm{pIgR}$ through the mucosal epithelia into secretions in a similar fashion as $\operatorname{IgA}(47)$. However, $\operatorname{sgM}$ is not as resistant to proteolytic enzymes as SIgA because of its non-covalent binding to the secretory component portion of pIgR (41). Nevertheless, it contributes to mucosal defense and in IgA deficient patients; higher concentrations of $\operatorname{sgM}$ are produced to compensate for the IgA deficiency (42).

Traces of $\operatorname{IgE}$ and $\operatorname{IgD}$ are found in mucosal secretions. IgE is believed to contribute to protection against parasites and allergy, while IgD may play a role in maturation of mucosal immune system but specific functions of $\operatorname{IgD}$ in secretions is still debatable $(269,270,342)$. 


\section{POLYMERIC IMMUNOGLOBULIN RECEPTOR}

\section{Synthesis of $\mathrm{pIgR}$}

In polarized epithelial cells pIgR is synthesized as a $90-100 \mathrm{kDa}$ precursor protein in the rough endoplasmic reticulum and sent to the Golgi apparatus and then to the trans -Golgi network. In the Golgi apparatus the precursor protein is glycosylated and it matures into a $100-120-\mathrm{kDa}$ protein (43). The pathway of passage of $\mathrm{pIgR}$ through the polarized epithelial cells has been extensively characterized (Fig. 4). In the trans -Golgi network, newly synthesized pIgR is sorted into vesicles that deliver it to the basolateral surface of epithelial cells where it may bind to its ligand, pIgA produced by plasma cells, most commonly found in the lamina propria underlying the epithelium. With or without bound pIgA, pIgR is endocytosed and targeted to basolateral early endosomes. The complex then passage through a common endosomal compartment and are sorted into apical recycling endosomes (ARE) and transcytosed to the apical membrane, where proteolytic cleavage of the extracellular ligand-binding portion of $\mathrm{pIgR}$ results in the generation of either free SC or secretory $\operatorname{IgA}(266,268)$. A fraction of $\mathrm{pIgR}$ at the apical surface may be re-internalized into apical early endosomes (AEE), then redelivered to the apical surface through the ARE $(7,264,265,267)$. Studies have shown that phosphorylation of Ser -664 in the cytoplasmic domain of the pIgR is a signal for transcytosis of the receptor $(58,149)$. Binding of dimeric $\operatorname{IgA}(\mathrm{dIgA})$ also stimulates pIgR transcytosis, which is independent of the Ser -664 phosphorylation. It is speculated that dIgA binding may cause $\mathrm{pIgR}$ dimerization or some conformational change that may serve as a signal for transcytosis (354). 


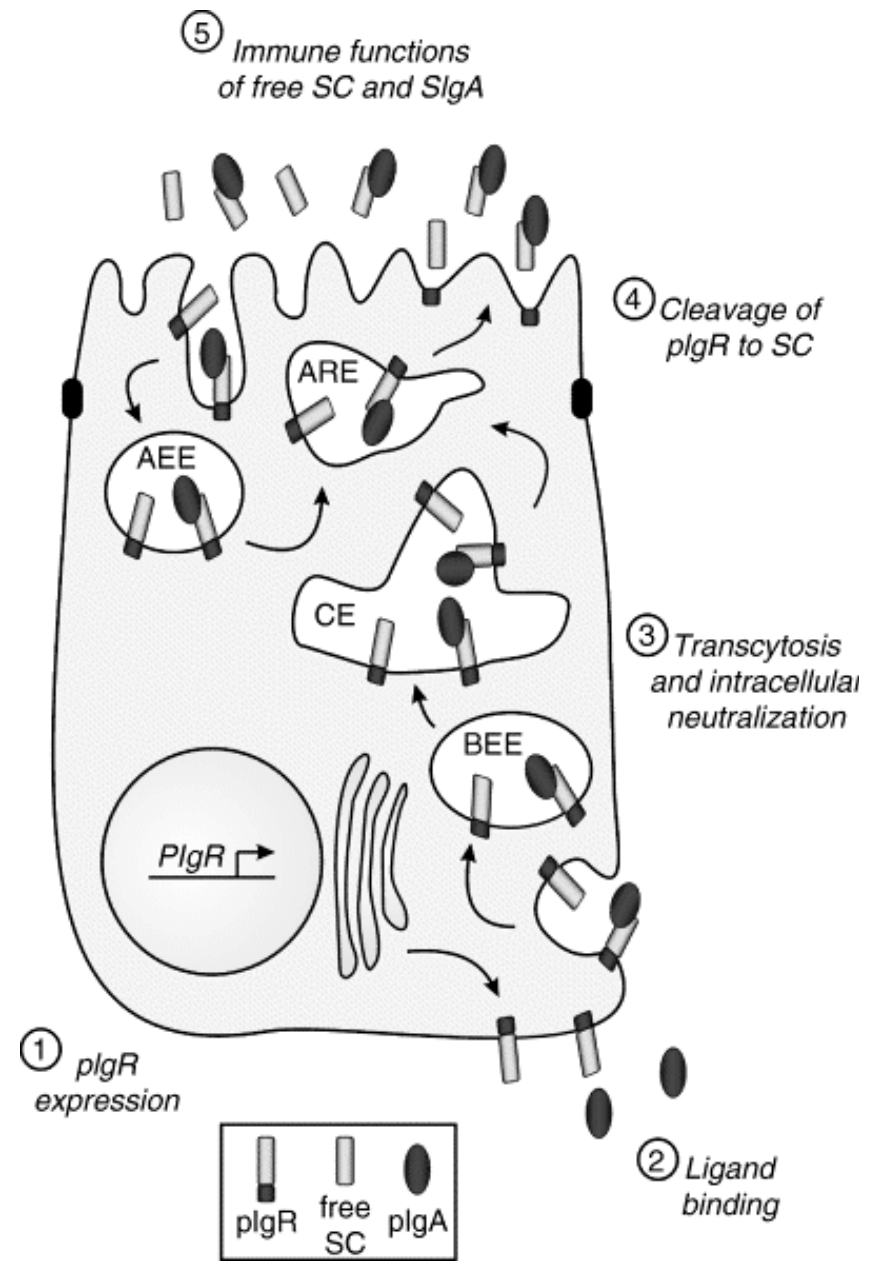

Figure 4. Pathway of passage of pIgR through polarized epithelial cells.

BEE, basolateral early endosome; CE, common endosome; ARE, apical recycling endosome; AEE, apical early endosome. 1. Expression of pIgR on basolateral surface of polarized epithelial cells. 2 . Ligand binding to pIgR. 3. Transcytosis of IgA and intracellular neutralization of pathogens. 4.

Proteolytic cleavage of pIgR to SC. 5. Immune function of free SC and sIgA (Kaetzel et al. 2005, with permission). 


\section{Structure of pIgR}

$\mathrm{pIgR}$ is a transmembrane glycoprotein that is expressed on secretory epithelial cells. The basic structure of pIgR comprises an extracellular domain, a transmembrane domain and a cytoplasmic domain (Fig. 5). The N-terminal extracellular region consists of 560 amino acids. The extracellular region of $\mathrm{pIgR}$ is the ligand-binding portion of the molecule and is cleaved at the apical surface. It is comprised of five immunoglobulin-like domains and a sixth non-immunoglobulin-like domain connecting it to the membrane-spanning piece. Each of the five immunoglobulin-like extracellular domains contains an internal disulphide bond, characteristic of immunoglobulin homology units, that is conserved in all known species of pIgR. A second internal disulphide bond exists in all species in domains 1 and 5, and in some species in domains 2, 3 and 4. A third highly conserved disulphide bond in present in domain 5. In human $\operatorname{sgA}$, this extra disulphide bond in domain 5 is rearranged to form a disulphide bond with the cysteine residues in one of the alpha heavy chains of $\operatorname{sgA}(96)$. Domain 1 of $\mathrm{pIgR}$ is critical and sufficient for binding polymeric IgA and IgM. The crystal structure of domain 1 from human $\mathrm{pIgR}$ immensely contributed to the understanding of ligand binding properties of $\operatorname{pIgR}(132)$. The overall structure of domain 1 was very similar to the immunoglobulin variable domains, including conservation of the five key residues that stabilize the $\beta$-pleated sheet structure of the 'immunoglobulin fold'. Though the domain 1 contained loop structures analogous to the complementarity-determining regions (CDRs) of antibodies, some marked differences existed. The relatively long CDR1 loop in the pIgR domain 1 containing a single helical turn was crucial for pIgA binding, as mutations within the helix in CDR1 of 
rabbit pIgR abolished the ligand binding surface (74). The CDR2 loop comprised of only two amino acids, with a highly divergent amino acid at position 53 (Glu in human pIgR) followed by an invariant Gly at position 54 . CDR2 plays an important role in binding of human pIgR to pIgM. The CDR3 loop in human pIgR tilts away from the CDR1 and CDR2 loops and this unique conformation increases the pIg-binding surface area (132). In addition, the $\mathrm{C}$-terminal domains of human $\operatorname{IgA}(\mathrm{C} \alpha 3)$ and $\operatorname{IgM}(\mathrm{C} \mu 4)$ are required for J-chain binding, polymerization and association with $\operatorname{PIgR}(146)$. The presence of Jchain connecting the immunoglobulin subunits of pIgA and pIgM is essential for binding pIgR. J -chain deficient mice have reduced IgA levels in external secretions $(143,144,165,230)$. The transmembrane region consists of 23 amino acids and is highly conserved among different species $(15,16)$. The transmembrane domain contains a kinkinducing proline $(\mathrm{P})$ residue that is suggested to play a role in transmembrane signal transduction (43). Proteolytic cleavage of pIgR in this domain releases IgA bound or unbound secretory component into mucosal secretions (268). The C-terminal cytoplasmic region consists of 103 amino acids and contains highly conserved signals for basolateral targeting, intracellular sorting, endocytosis and transcytosis of pIgR $(10,57,58)$. 


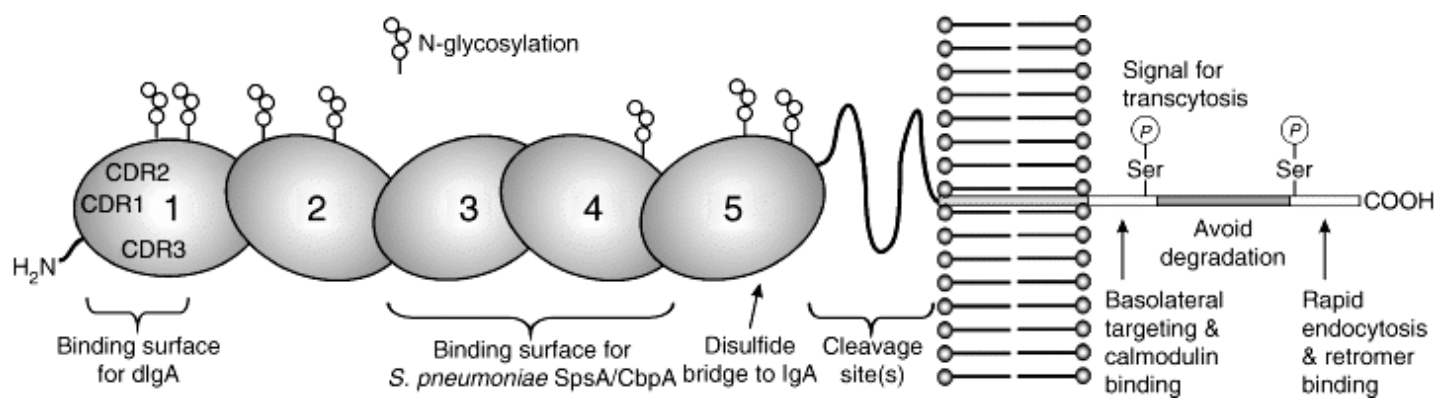

Figure 5. Schematic structure of human polymeric immunoglobulin receptor. The $\mathrm{pIgR}$ is

a type I transmembrane protein, with an extracellular ligand binding comprising five domains with homology to immunoglobulin variable regions. The three complementarity-determining regions (CDRs) in domain 1 form a non-covalent binding surface for dimeric $\operatorname{IgA}(\operatorname{dIg} \mathrm{A})$. During transcytosis, a disulfide bridge is formed between domain 5 of pIgR and the Fc $\alpha$ region of dimeric IgA. Peptide motifs in domains 3 and 4 cooperate to form a binding surface for the SpsA protein of Streptococcus pneumoniae. A peptide of unknown structure links domain 5 to the membrane-spanning region and contains site(s) for proteolytic cleavage of pIgR to secretory component (SC). Seven N-glycan residues on domains 1, 2, 4, and 5 contribute to innate immune functions of SC and may facilitate transcytosis of pIgR. The cytoplasmic domain of pIgR contains highly conserved signals for intracellular sorting, endocytosis, and transcytosis. (Kaetzel et al. 2005, with permission). 
Gene organization of pIgR

A

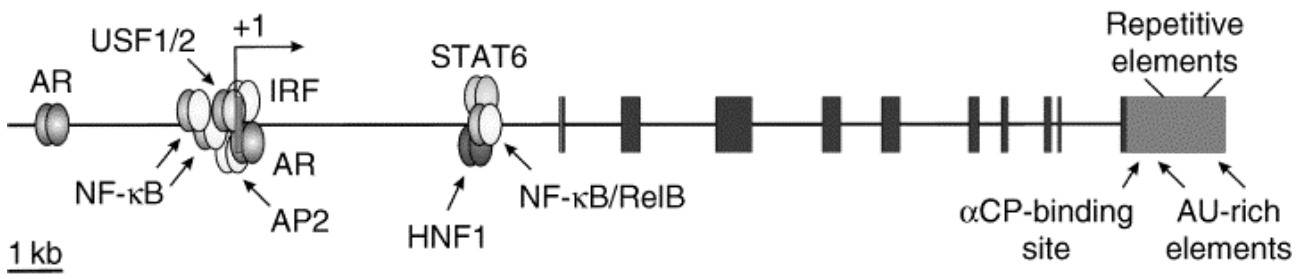

B

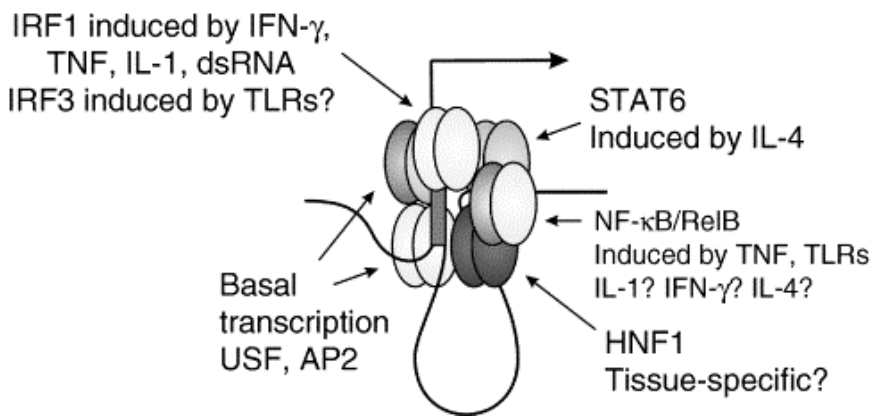

Figure 6. Organization of the polymeric immunoglobulin receptor (PIGR) gene locus and regulatory elements. (A) Eleven exons comprise the PIGR gene, encoding the 5'untranslated region (UTR) (blue box), the coding region (red boxes), and the 3'-UTR (blue box) of pIgR mRNA. The locations of potential binding sites for regulatory proteins are designated. (B) Working model for regulation of PIGR gene transcription by cytokines and microbial factors. AR, androgen receptor; $\mathrm{AP}$, activator protein; $\alpha \mathrm{CP}$, cytoplasmic poly $(\mathrm{C})-$ binding protein $\alpha$; IRF, interferon regulatory factor; $\mathrm{HNF}$, hepatocyte nuclear factor; NF- $\mathrm{kB}$, nuclear factor-кB; STAT, signal transducer and activator of transcription; USF, upstream stimulatory factor. (Kaetzel et al. 2005, with permission). 
Krajci et. al. determined the genomic organization of the human pIgR gene (24).

Human PIGR gene consists of 11 exons and 10 introns spanning 17944 base pairs on chromosome 1 (Fig. 5) $(169,196)$. The first exon is not translated while the open reading frame is encoded by exons $2-11$. The extracellular region of $\mathrm{pIgR}$ includes five immunoglobulin like domains. Domains 1,4 and 5 encoded by single separate exons are always present in the pIgR mRNA but domains 2 and 3 encoded by the same exon are sometimes deleted by alternative mRNA splicing in rabbit pIgR (85). The $5^{\prime}$-flanking region, exon 1 and intron 1 of the PIGR gene contain the binding sites for constitutively expressed and induced transcription factors. The DNA element inverted repeat sequence (IRS). An 'E-box' motif at position -71 of the human PIGR gene and -74 of the mouse PIGR gene is essential for basal promoter activity $(142,164,239,353)$. The E-box is the binding site for transcription factors involved in pIgR synthesis. E-box motifs with the sequence 'CACG/ ATG' bind transcriptions factors of the basic helix-loop-helix/ leucine zipper family, including the Myc, upstream stimulatory factor (USF) family members $(164,185,229,352)$. Recently, Bruno et al. have demonstrated that USF-1 and USF-2 but not c-Myc bind to the PIGR E-box in vitro and in vivo and enhance promoter activity (52). Hempen et al. have shown that activator protein 2 (AP2) binds to a site adjacent to USF site and cooperatively enhances PIGR promoter activity (142). The human pIgR gene contains several regulatory DNA elements that serve as targets to cytokine induction. The pIgR gene contains 3 interferon -stimulated response elements (ISREs), two upstream of transcription start (centered around position -133 and -100) and one in exon 1 (centered around position +13 ) that can be induced by proinflammatory cytokines 
including IFN- $\gamma$ and TNF- $\alpha$, which are produced in response to bacterial and viral infections (302). Analyses of regulatory regions in the human PIGR gene have identified an element in exon 1, that is perfectly conserved in the human, mouse, and rat, binds members of interferon regulatory factor (IRF) family of cytokine-inducible transcription factors $(128,302)$.

Regulators of pIgR expression. A number of factors modulate expression of $\mathrm{pIgR}$ (169). (a) Cytokines: A number of cytokines including IFN- $\gamma$, TNF- $\alpha$, IL-1 and IL-4 has been shown to upregulate pIgR expression in epithelial cells. Binding of IFN- $\gamma$ to its cell surface receptor activates the receptor associated Janus kinases (JAKs). JAKs in turn phosphorylate the cytosolic proteins called signal transducers and activators of transcription (STATs). Phosphorylated STATs form dimers, which then translocate to the nucleus and increase transcription of IRF1 gene $(34,170,301,302)$. In contrast, binding of TNF and IL-1 to cell surface receptors induces activation of IRF1 gene by activating nuclear factor kappa B (NFkB), which translocates to nucleus and binds to an element adjacent to STAT1 site in the IRF-promoter (300). On the other hand, weak activation of NFkB by IFN- $\gamma$ could eventually increase PIGR gene transcription indirectly, by synergizing with STAT1 to activate IRF1 gene transcription (34). Newly synthesized IRF-1 protein is again translocated back from the cytosol to the nucleus where it can bind to exon 1 of the pIgR promoter and enhance transcription $(1,34)$. Two NFKB-binding sites have been identified in the 5' flanking region of human PIGR gene, mutation of which resulted in a modest decrease in TNF-induced PIGR promoter activity (366). Schjerven et al. have demonstrated that a novel NFkB site in intron 1 cooperates with the 
IRF-1 site in exon 1 to mediate TNF-induced transcription of human PIGR gene (335). However, no cooperativity was found between the NFkB sites in intron 1 and 5' flanking region of the PIGR gene. TNF-induced PIGR gene transcription also requires de novo synthesis of the RelB subunit of NFkB, which is consistent with the delayed kinetics of transcriptional activation (336). Proinflammatory cytokines such as TNF and IL-1 typically activate the 'classical' NFKB pathway, characterized by rapid activation of RelA/ p50 dimers and early transcription of genes involved in innate immunity and inflammatory responses (38). The TNF-induced activation of classical NFkB pathway in intestinal epithelial cells enhances transcription from RELB gene and indirectly increases PIGR transcription by increasing steady state levels of RelB protein. Recently, Bruno et al. demonstrated that long-term exposure of transformed human intestinal epithelial cells HT-29 to TNF causes sustained upregulation of RelB and pIgR expression (51). In addition, certain members of the TNF cytokine family but not TNF- $\alpha$ itself could activate NFкB by the fairly recently discovered 'alternative pathway' (38). It is possible that TNF might induce synthesis of an as yet unidentified cytokine or signaling molecule that eventually activates newly synthesized RelB via the 'alternative' NFKB pathway. Induction of PIGR gene transcription through the alternative NFKB pathway that serve to augment pIgR-mediated IgA transcytosis might provide a bridge between innate and adaptive immune responses.

Interestingly, the Th-1 type cytokine IFN- $\gamma$ and the Th-2 type cytokine IL-4, which are usually antagonistic, regulate expression of pIgR in a cooperative fashion. IL-4 alone or coupled with IFN- $\gamma$ has been shown to upregulate pIgR mRNA and protein expression in 
human intestinal and respiratory epithelial cell lines (1). Studies by Schjerven et al. shed some light on the paradigm of coordinate regulation of pIgR by IL-4 and IFN- $\gamma$. Schjerven et al. discovered a novel IL-4 inducible STAT6 site in intron 1 of the human PIGR gene. IL-4 activates PIGR transcription with delayed kinetics suggesting a requirement for de novo protein synthesis. But, STAT6 translocates to nucleus within minutes of IL-4 activation. However, these contradictory observations was explained when Schjerven et al. postulated the existence of an unidentified IL-4 induced protein that cooperates with STAT6 to form an IL-4 responsive enhancer element (334). Alternatively, since the NFkB/ RelB and STAT6 site in intron 1 are very close, it is possible that de novo synthesized RelB might synergize with STAT6 to activate the IL-4 dependent enhancer element (169). But this alternate hypothesis has not yet been tested and future studies with provide more insight into the mechanism of cooperative regulation of PIGR gene by IFN- $\gamma$ and IL-4. Overall, proinflammatory cytokines including IFN- $\gamma$, TNF- $\alpha$, IL-1 and IL-4 increase pIgR expression in epithelial cells.

(b) Hormones. A number of polypeptide and steroid hormones including estrogen, progesterone, androgens, glucocorticoids and prolactin regulate expression of $\mathrm{pIgR}$ in a cell type specific manner. The antagonistic effects of estrogen and progesterone modulate expression of pIgR during the estrous cycle $(31,181)$. However, the binding sites for estrogen and progesterone receptors on PIGR have not yet been identified and the mechanisms by which the regulate pIgR expression is still unknown. Androgens upregulate pIgR expression in the reproductive tissues of males and females. Two important androgen receptor binding sites have been identified on PIGR gene (67). In 
addition, pIgR mRNA and protein expression is upregulated in mammary epithelial cells in sheep in response to glucocorticoid treatment and this effect could be mediated through an IFN- $\gamma$-linked mechanism $(319,320)$. Also, prolactin likely plays a role in regulation of pIgR expression in lactating mammary glands through upregulation of IRF1 expression following activation of a JAK/ STAT pathway $(62,409)$.

(c) Microbial Factors. Signaling induced by a variety of microbes and their products have been shown to regulate expression of pIgR. Butyrate, a bacterial fermentation product and important energy source in colon upregulates pIgR expression $(198,199)$. Bacteroides thetaiotaomicron, increased pIgR expression by 2-4 fold when the gut of germ free mice was colonized with this commensal bacterium (150). Bruno et al. (unpublished communication) have found that pIgR mRNA levels were 8-10 fold higher in the colon than in the small intestine of mice. In addition, antibiotic metronidazole treatment in mice that selectively ablates anaerobic bacteria including Bacteroides thetaiotaomicron, resulted in a 50\% decrease in pIgR mRNA levels, suggesting a role for commensal bacteria in the maintenance of pIgR expression in gut.

Signaling induced by microbes and their products may serve to augment pIgR-mediated transcytosis of polymeric immunoglobulins including $\operatorname{IgA}$ and IgM, linking the innate and acquired immune responses. Host cells mediate innate immune responses to pathogen through TLR signaling $(23,365)$. Interestingly, intestinal epithelial cells express a variety of TLRs and inflammatory responses upregulate expression of these pattern recognition receptors (PRRs) $(55,56)$. Recently, Schneeman et al. have 
discovered that a bacterial lipopolysaccharide LPS, a ligand for TLR4 and a chemical analog of viral dsRNA, poly I: C, a ligand for TLR3 upregulates pIgR expression in HT29 cells (338). Both these ligands, induce de novo synthesis of RelB and activation of PIGR gene transcription depends on the NFאB element in intron 1. In addition, poly I: C also activates IRF-1 and thereby mediates pIgR upregulation. IRF-3, a related transcription factor that binds to the same consensus element as IRF-1 on PIGR gene is also activated through TLR3 and TLR4 signaling pathways (407). It is likely that IRF-3 might cooperatively interact with $\mathrm{NF \kappa B}$ and upregulate pIgR expression, but such mechanism is yet to be established by future studies. Recently, it has been demonstrated that during $\mathrm{pIgR}$-mediated transport dIgA intracellularly neutralizes LPS within epithelial cells, suggesting that LPS induced upregulation of pIgR, which serve to augment IgA transcytosis might be an important mechanism in controlling intestinal inflammation induced by proinflammatory PRRs such as LPS (102).

\section{Function of pIgR}

A hallmark feature of adaptive mucosal immune responses is the production and generation of sIgA and free SC, which is entirely dependent upon the sacrificial receptor pIgR expressed by mucosal and glandular epithelial cells (Fig. 7). PIgR is responsible for transport of polymeric immunoglobulins, primarily pIgA from lamina propria to the intestinal lumen, where the receptor is cleaved releasing $\operatorname{sIgA}$ or the free secretory component in the luminal secretions $(43,380)$. In average adults, approximately 3 grams of $\operatorname{sIgA}$ is transported daily into intestinal lumen. The magnitude of $\mathrm{pIgR}$-mediated epithelial transcytosis of pIgA is impressive, since the daily production of IgA exceeds 
the production of all other immunoglobulin classes combined $(255,258)$. Because one molecule of pIgR is required for every molecule of transported polymeric immunoglobulin, synthesis of pIgR by epithelial cells is a rate-limiting step for generation of secretory pIg $(267,273,367)$. Thus, pIgR plays a role in mucosal host defense, and factors that influence expression of pIgR could affect mucosal immunity. The respective roles of SIgA and free SC have been discussed previously under 'function of secretory IgA and free secretory component'.

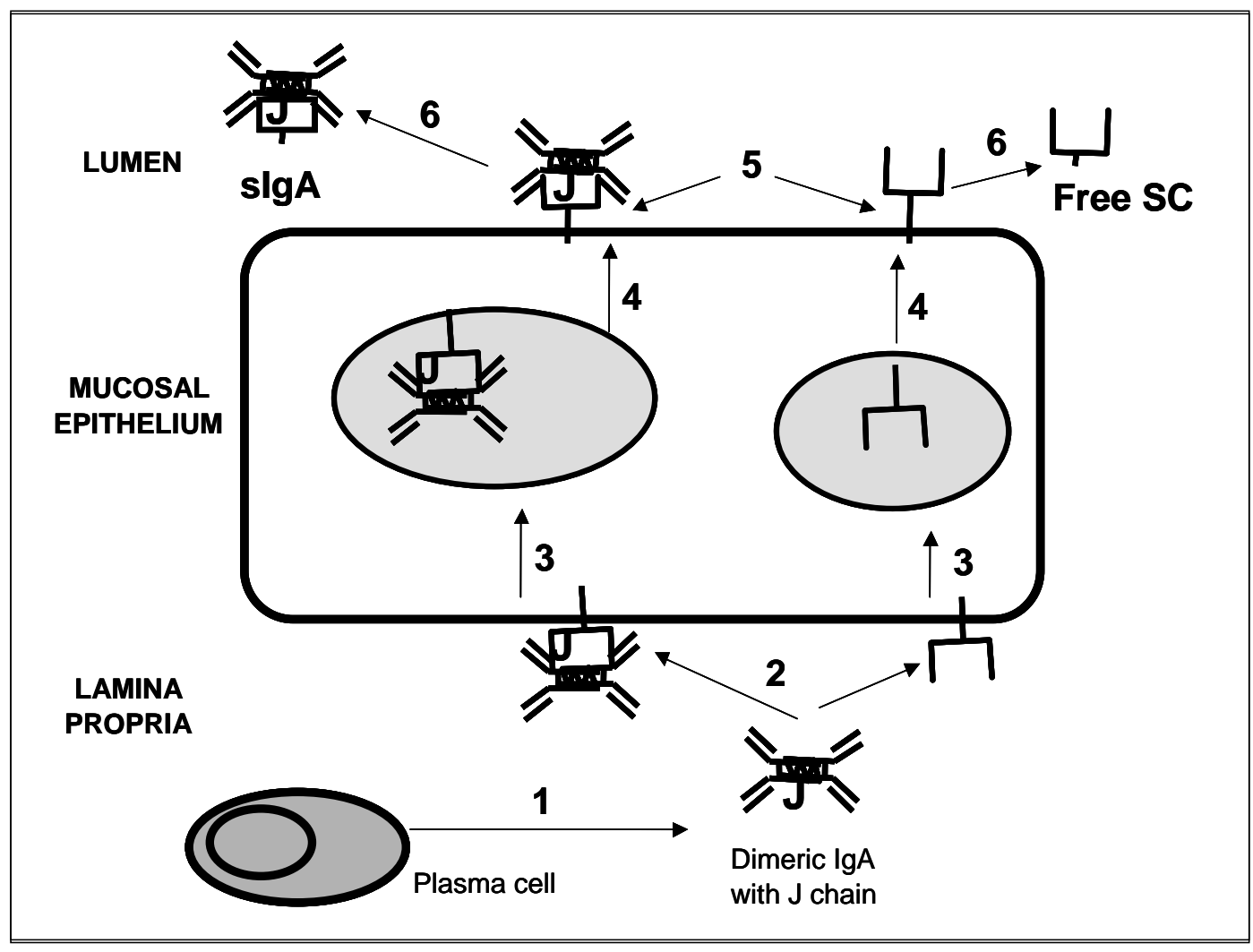

Figure 7. Transcytosis of empty receptor and dimeric IgA leading to generation of free secretory component (FSC) and secretory IgA (sIgA) respectively. 1) The dIgA is produced by the plasma cells in lamina propria. 2) dIgA binds to pIgR via its J-chain. 3) The dIgA-pIgR complex traverses the epithelial cell through endocytic vesicles by transcytosis. 4) The complex reaches the apical epithelial surface. 5) PIgR is proteolytically cleaved between its extracellular and transmembrane domains. 6) SIgA and FSC is released in secretions.

Diagram is adapted from Kantele (1992) (175). 


\section{REOVIRUS AS A MODEL PATHOGEN}

Mammalian Orthoreoviruses (reovirus) is a model pathogen for studying immune responses and pathogenesis to enteric virus infection. Respiratory enteric orphan virus (reovirus) serves as an excellent probe to study different aspects of immunity against enteric virus infection because it is well characterized at molecular level, naturally infects a wide variety of mammalian species including mice and humans and is of low pathogenecity in immunocompetent hosts $(214,323)$. In experimental models of mice, reovirus has been shown to induce gastroenteritis, hepatitis, myocarditis, meningoencephalitis, biliary atresia and autoimmune syndromes $(22,78,113,138,278,283,284,326,346,347,356,384)$. Though, reovirus is ubiquitous in nature and infects a wide range of mammalian hosts, it is typically non-pathogenic in immunocompetent hosts. Approximately $85 \%$ of human adults are seropositive for antireovirus antibodies suggesting previous exposure to reovirus (343). Although attempts to correlate reovirus infections in humans with disease have been inconclusive, prenatal and perinatal reovirus infections have been associated with a rare pediatric liver disease, extrahepatic biliary atresia $(173,382)$. In addition, reovirus can be pathogenic or lethal and might induce diseases including hydrocephalus, encephalitis, and lethal hepatitis in neonatal and severe combined immunodeficient (SCID) mice $(113,129,391)$. In adult mice an oral (OR) or intravenous (IV) dose of $10^{10}$ plaque forming units is lethal, killing the mice by $48 \mathrm{hrs}$ post infection and autopsy revealed pneumonitis, inflammation and hemorrhagic areas of the intestines (325). Reovirus (Fig. 8) is a lytic, non-enveloped, icosohedral, 10-segmented dsRNA genome containing virus. The viral genome 
comprises 10 unique segments, three large (L), three medium (M), and four small (S) fragments, each of which encodes a single protein, except the bicistronic S1 gene from which two proteins are synthesized $(284,344)$. Reoviruses were originally classified into 3 serotypes designated T1, T2, and T3 based on expression of the viral haemagglutinin, which serves as the viral ligand for cellular receptors (383). Of the 3 serotypes, T1 and T3 have been extensively used to investigate different aspects of viral pathogenesis and mucosal immunity, while T2 has been utilized to study immunological mechanisms of diabetes in neonatal mice $(136,137,235,390)$. Although both T1 and T3 infect hosts via the intestine, significant differences exist in the capacity of the serotypes to bind to intestinal epithelial cells and replicate in the intestine (396). Differences among serotypes have been atttributed to the $\mathrm{S} 1$ gene, $\sigma 1$ protein that is responsible for cellular tropism and diseases characteristic of the different serotypes $(180,322,325,381,397)$. Neurovirulence studies utilizing viral reassortants demonstrated that the $\sigma 1$ of type 1 reovirus was responsible for the development of hydrocephalus and the destruction of the ependymal cells, whereas, the $\sigma 1$ of type 3 caused necrotizing encephalitis in newborn mice (397). Interestingly, the $\sigma 1$ protein, which is a long trimeric fiber that extends 40 $\mathrm{nm}$ from the viral capsid serves as the reovirus cell attachment protein in all three serotypes $(37,209)$. 


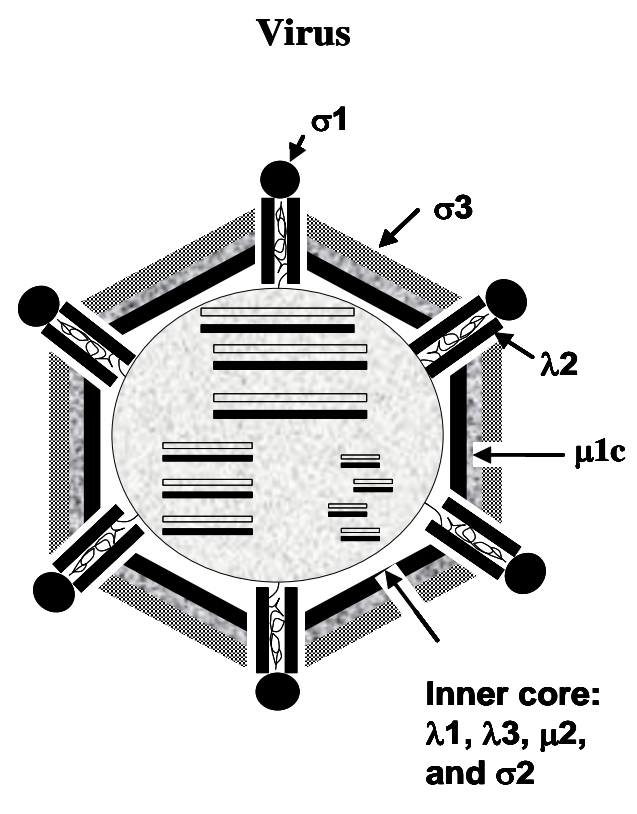

Intermediate subviral particle

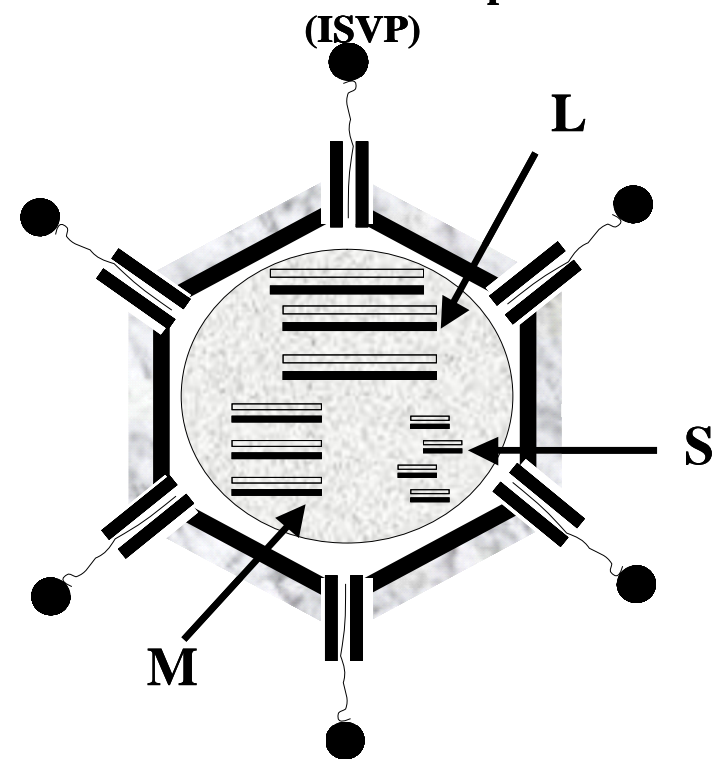

Figure 8. Structure of reovirus virion and ISVP after proteolytic digestion of outer

capsid proteins. The virus has an intact outer capsid and $\sigma 1$ protein in an un-extended conformation. After proteolytic cleavage of the outer capsid the $\sigma 1$ protein is fully extended and capable of binding cell surface receptors. Core contains ten dsRNA segments: 3 Large (L), 3 Medium (M) and 3 Small (S) . 


\section{Reovirus Infection.}

When reovirus enters a host through the oral route, proteases including pancreatic chymotrypsin in luminal secretions activate the virus by cleaving the outer capsid proteins of virions to form the intermediate subviral particles (ISVPs) (Fig. 8) resulting in a conformational change of the cell binding protein $\sigma 1(45,46,47)$. The exposed $\sigma 1$ of ISVPs bind Microfold (M) cells, which are a specific cell type in the intestinal epithelium overlying lymphoid follicles called Peyer's patches (PPs) that endocytose a variety of protein and peptide antigens $(5,24,35)$. Wolf et al. demonstrated that both $\mathrm{T} 1$ and $\mathrm{T} 3$ bind to $M$ cells and this specific binding and uptake by PP exposes the virus to innate and adaptive immune cells in the intestine $(271,399,400,401)$. Although, both T1 and T3 infect hosts through gastrointestinal tract and induce robust mucosal and systemic immune responses, significant differences exist in the capacity of the serotypes to bind IECs and replicate in intestine. Reoviruses use the cell surface molecule, junctional adhesion molecule (JAM) expressed basolaterally on the epithelial cell to gain entry and for infecting and spreading to the adjacent epithelial cells $(21,141)$. In addition to JAM, T3 but not T1 binds to sialic acid residues on as yet unidentified cellular proteins (20). However, the long held notion the T1 does not bind sialic acid is debatable because Helander et al. demonstrated that $\mathrm{T} 1$ is capable of binding on sialic acid residues expressed on M cells (141). Reovirus T3, but not T1, also binds to the apical surfaces of absorptive IECs and are endocytosed (180). It is unclear whether this is a 'dead-end' path for T3 virus. Endocytosed viruses appear to become trapped in lysosomes in IEC and basolateral transport has not been uniformly observed (180). On the other hand, at least in young animals, T3 infection induces villus shortening and mild mononuclear 
infiltration in the lamina propria. Alterations in IEC from T3-infected neonates include reduction in lactase and enterokinase activities, and increased maltase and leucine aminopeptidase activities (50). Together these results indicate that reovirus $\mathrm{T} 3 \mathrm{can}$ bind to and be taken up by IECs and affect IEC function, even though replication and viral shedding is limited. Although T3 enters absorptive epithelial cells from the lumenal surface, replication of infectious $\mathrm{T} 1$ virus in the intestine appears to be more efficient than $\mathrm{T} 3$ because infectious virus is shed longer and at higher levels following T1 infection than T3. Reovirus T1 causes enteric disease primarily in the ileal crypts of Lieberkuhn. During T1 infection, viral entry into IECs occurs through the basolateral surfaces (326); most likely as a result of T1 binding to cellular JAM. Productive infection is limited to immature crypt enterocytes, likely due to a requirement for factors available only in replicating host cells to support replication of virus. One such critical host factor is an activated Ras signaling pathway that exhibits an active epidermal growth factor receptor-Ras/RalGEG/p38 pathway. Either Ras or another downstream component of activated Ras pathway inhibits the activation of protein kinase R (PKR), a dsRNAactivated eIF2 $\alpha$ kinase (Fig. 10). Reovirus replication proceeds unimpeded in the Raspositive crypt enterocytes in absence of anti-viral host protein synthesis through the PKR pathway $(71,358)$. In cells lacking an activated Ras signaling pathway, active (phosphorylated) PKR phosphorylates eIF2 $\alpha$, halting translation initiation, which inhibits blocks viral protein synthesis. However, activated PKR does not prevent entry of reovirus and induction of early mRNA transcription (358). 


\section{Reovirus Replication.}

Reovirus enters host cell by receptor -mediated endocytosis. Inside the endosomes the outer shell of the virus particle is modified by removal of two proteins and cleavage of another by lysosomal enzymes. This uncoating process activates the viral RNAdependent RNA Polymerase and hence initiates the virus replication. Reoviruses contain within their virions all the enzymes required for replication and RNA synthesis including RNA-dependent RNA Polymerase, nucleotide phosphohydrolase and enzymes that participate in the capping of messenger RNA, RNA methyltransferase and guanyl transferase. Replication of reovirus RNA occurs exclusively in the cytoplasm of the host (Fig. 9). However, replication seems to proceed within an intracellular equivalent of the viral core, called the subviral particle, which remains intact in the cytoplasm. Replication of reovirus genome occurs by a conservative and asychronous method. First, one strand of parental RNA is used as a template, and then the single stranded product serves as a template to form the progeny double helix $(213,339)$. The dsRNA is inactive as mRNA, and the first step in reovirus replication is transcription, using the minus strand as a template to make mRNA. Replication of reovirus starts within the viral core with the RNA-dependent RNA polymerase (the product of the L1 gene), forming a capped plusstrand mRNA, which is the exact size and a perfect complement of the parental minus strand dsRNA genome $(2,213,329,339,394,395)$. The completed capped plus-strand mRNAs are ejected from the viral core through the $\lambda 2$ spike into the host cytoplasm where they are utilized as templates for translation of structural and nonstructural proteins using the host's ribosomes $(168,213)$. After protein synthesis, the capped single-stranded plus RNA act as templates for the synthesis of the progeny minus-strand genomic RNAs, 
yielding progeny double stranded viral RNAs $(213,330)$. Interestingly, the fact that only the plus-strand mRNA is found free in the infected host cell during the course of reovirus infection has become an important factor for designing and development of reovirus RTPCR reactions.

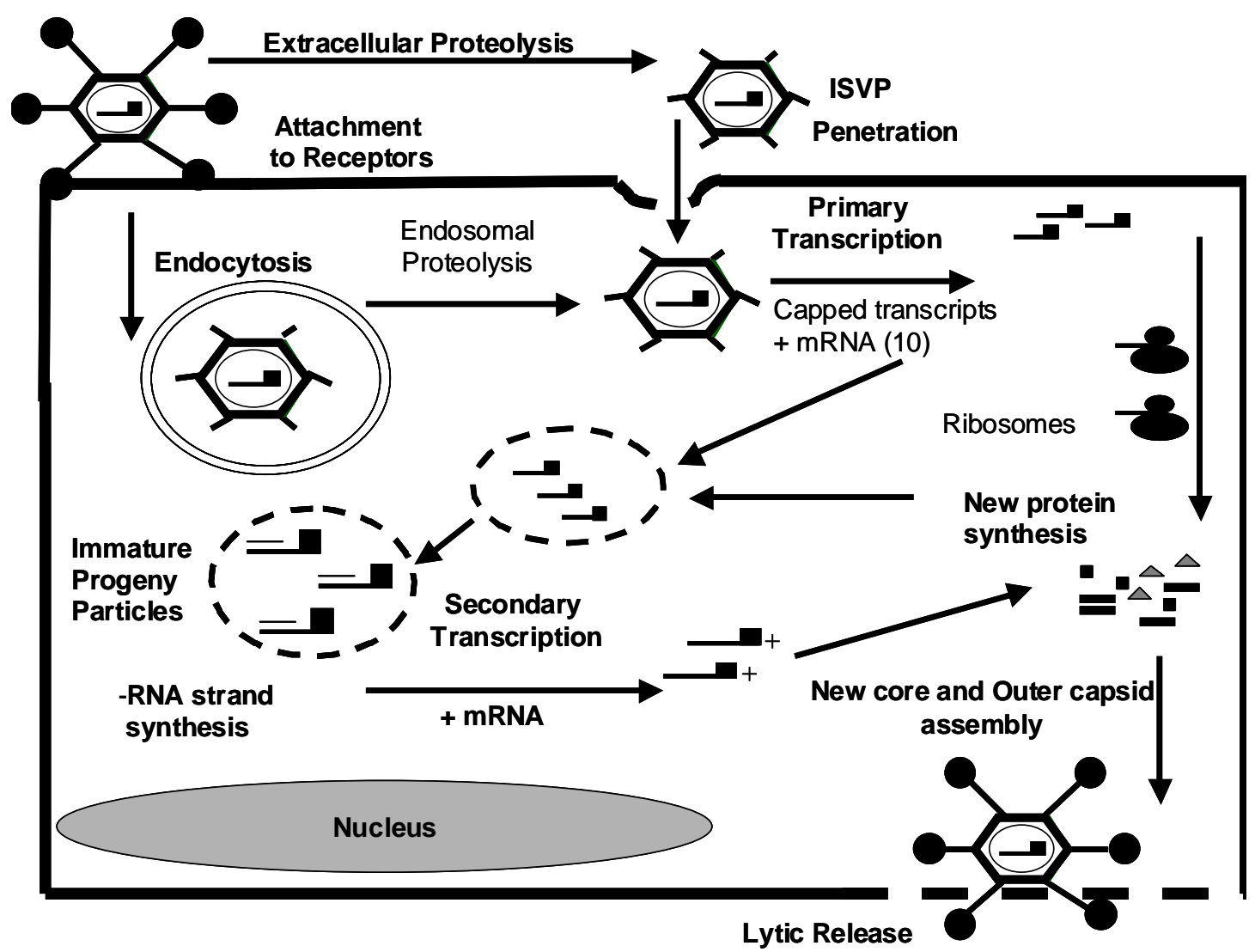

Figure 9. Illustration of Life Cycle of Reovirus. Reovirus binds to the host cell surface receptors and undergoes receptor-mediated endocytosis. Inside the host endosome, reovirus is partially uncoated by the action of endosomal proteases, which initiates viral replication. The replication of the reovirus genome is conservative and occurs in an asynchronous manner forming progeny virions with dsRNA. Newly synthesiszed viral proteins assemble to form core and outer capsids of progeny virus and finally virus is released from host cells by lysis. 
Immune responses to enteric reovirus infection.

Intestinal immune responses to reovirus include production and secretion of virusspecific IgA (226), development of virus-specific precursor CD8+ cytotoxic T-cells in the PP, lamina propria and epithelium $(77,225,226)$, and production of T-helper (Th) cell responses characterized by robust Th1 responses that produce IFN- $\gamma(97,235)$. Both innate and adaptive immune responses are induced following reovirus infection (113).

Innate immunity.

In SCID mice, reovirus infection activates and increases the number of natural killer (NK) cells in liver, suggesting that the influx of NK cells into the liver helps to slow down the viral infection and subsequent death of the mice (370). In immunocompetent mice, reovirus infection induces interleukin-15 (IL-15), an innate cytokine that activates a number of immune cells including NK cells, DCs and macrophages, mediating innate responses such as cytotoxic killing by NK cells, production of IL-12 and IFN- $\gamma$ from DCs and macrophages and synthesis of nitric oxide (NO) from macrophages $(101,245,279)$. In addition, proinflammatory cytokines including TNF- $\alpha$ and IL-1 $\beta$ are also induced following reovirus infections. TNF- $\alpha$ and IL-1 $\beta$ are secreted by epithelial cells in a p38 MAPK-dependent manner and by peritoneal macrophages following exposure to reovirus $(99,256)$. Thus, the innate immune arm comprises epithelial cells, NK cells, macrophages, and DCs all of which orchestrate and participate to provide protection following reovirus infection. 


\section{Adaptive immunity.}

Reovirus infection results in the stimulation of both humoral and cellular immune responses. Reovirus infection induces humoral immune responses characterized by the production of antibodies of the $\operatorname{IgG}$ and $\operatorname{IgA}$ isotypes $\{521,732,733,496,734,735,498\}$ and the development of T-cell responses including cytokine producing T-helper (Th) 1 and Th2 cells $(97,234,241,373)$. Antibody responses following either oral or systemic infection are directed mainly against structural proteins (234). IgA is important for protection of mice against reovirus infection. Following oral infection reovirus clearance was delayed in the intestine in B cell-deficient mice (18). Studies with IgA-deficient mice have demonstrated a crucial role for IgA in protection against reovirus entry into murine Peyer's patches (349). Hutchings et al. demonstrated that mice bearing IgA hybridomas specific for the $\sigma 1$ outer capsid protein of reovirus, such that the monoclonal $\operatorname{IgA}$ is transported into intestinal secretions by pIgR-mediated transcytosis, were protected against infection (154). In adult mice, reovirus $\sigma 1$-specific IgA antibodies protect the PPs from being re-infected upon secondary oral reovirus infections suggesting that $\operatorname{Ig} \mathrm{A}$ neutralizes reovirus in the lumen of the intestines and prevents it from binding to the M-cells of the PPs $(154,349)$. In addition, mouse pups suckled on reovirus-immune dams acquire IgA-mediated passive immunity and thus protected against lethal reovirus infection (78). In neonatal mice (10 days old), enteric reovirus infection leads to significant changes in the mucosal immune system, characterized by the induction of PP germinal centers and production and secretion of IgA. Most of this IgA is not specific for reovirus, but appears to be directed against environmental antigens (197). 
In addition, following exposure to reovirus by oral route, reovirus -specific IgG antibodies of the $\operatorname{IgG} 2 \mathrm{a}$ and $\operatorname{IgG} 2 \mathrm{~b}$ subclasses, appear in the serum and mesenteric lymph nodes (MLNs) (234). In response to systemic reovirus exposure, the majority of the antigen-specific spleen and lymph node B cells secrete IgG antibodies $(226,234)$. Like gut, reovirus infection of respiratory tract induces production of $\operatorname{IgA}$ and $\operatorname{IgG}$ antibodies $(374,412)$. Following oral reovirus infection, placental transfer of $\operatorname{IgG}$ can prevent neonatal pups from dying, with no evidence of meningoencephalitis (78). However, the reovirus $\sigma 1$-specific IgG did not prevent reovirus infection of the PPs as confirmed by detection of reovirus within the PPs and intestines (154,391). In addition, in SCID mice transfer of reovirus-specific IgG (18) did not clear reovirus infection of PPs. Taken together, it appears that IgA antibodies neutralize reovirus in the lumen of the intestines and prevent reovirus from infecting the mucosa, while $\operatorname{IgG}$ antibodies prevent the systemic spread of reovirus following oral infections.

Th cells respond as a result of uptake and presentation of viral antigens by APCs (103). Although the contribution of various cells types as APCs in infection has not yet been defined, it is likely that dendritic cells are the most important antigen-presenting cell for priming reovirus-specific naïve T-cells in the intestine and periphery.

In addition to humoral immune responses, reovirus induces potent effector CD8+ T-cells that mediate cytokine production and cellular cytotoxicity $(108,225,226,413)$. Virusspecific cytotoxic T-lymphocytes (CTLs) are induced within the PP following intestinal infection (226). CTLs migrate via efferent lymphatic vessels to the mesenteric lymph nodes, then through the thoracic duct lymph and the systemic circulation to the spleen (226) or to intestinal mucosal sites such as the intestinal epithelium where virus-specific 
cells can be found among the intraepithelial lymphocytes (IELs) $(64,77,224)$. Parenteral infection with reovirus induces virus-specific CTLs in the draining peripheral lymph nodes and spleen $(215,390)$.

Effects on Cell Signaling by Reovirus.

Interaction of virus with host cells in vitro initiates a number of signaling cascades including increased activation of calpains $(83,84)$, activation of c-Jun N-terminal kinase (JNK), and extracellular signal-related kinase (ERK) (70). These signaling cascades result in up-regulation of $\mathrm{NF \kappa B}$ activation $(68,69,73)$ and phosphorylation of c-Jun $(70)$, which increases transcription of regulated genes (275). While these signaling pathways are involved in inducing apoptosis in infected cells, particularly during infection with T3 (383), their roles in other reovirus-induced cellular changes have not been extensively characterized, although one report (131) has linked increased NFאB activation with production of chemokines and cytokines during virus exposure. Significantly, most or all of these changes in cell signaling in vitro occur independently of viral replication. Rather, other steps during infection such as binding to specific receptors, endocytosis and uncoating, and cellular exposure to viral RNA appear to be sufficient to affect the host cell biology $(19,131)$.

Reovirus as potential anticancer therapeutic.

Reovirus possesses the distinctive ablility to replicate in transformed cells and so reovirus infection in vivo is limited to cells with an activated Ras signaling pathway. In adults, reovirus infection is usually subclinical because most adults have reovirus specific 
antibodies and normal untransformed cells are unable to support reovirus replication. In normal cells, double stranded RNA structures in reovirus transcripts activate PKR, which subsequently phosphorylates eIF- $2 \alpha$ ultimately inhibiting translational initiation of viral genes. Studies with chemical analog of dsRNA, poly I:C have shown that PKR mediates

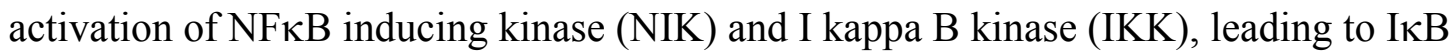
degradation and subsequent NFkB activation (415). However, in transformed cells with an activated Ras signaling pathway either Ras itself or another unidentified component downstream in the signaling pathway blocks PKR phosphorylation, which allows viral translation to proceed. Ras pathways are activated in approximately $30 \%$ of all human cancers including adenocarcinomas of the pancreas, colon, and lung; in addition to thyroid tumors and in myeloid leukemia and mutations in other elements in the Ras pathway also contributes to cancer development (40). So implications for the use of reovirus as an anticancer therapeutic agent are obvious as has been reported for reovirusmediated killing of oncogenic cell lines including breast, colon and ovarian cancers and in vivo murine cancer models $(3,71,148,274)$. Recently, Dr. Matthew C. Coffey has been instrumental in developing reovirus as a human cancer therapeutic named as REOLYSIN ${ }^{\circledR}$, which is a proprietary formulation of the human reovirus of Oncolytics technologies and has been demonstrated to replicate specifically in tumour cells bearing an activated Ras pathway. REOLYSIN $®$ is a potential therapeutic for upto two thirds of all human cancers, including, but not limited to, malignant glioma, pancreatic, colon and some lung cancers and is undergoing Phase I and Phase II clinical trials in Canada and United States. REOLYSIN $®$ appears to be promising tool to combat cancer as it utilizes naturally occurring reovirus without genetic modification to cancer cells, while other 
current anti-viral therapies have potentially harmful side effects, and must be genetically modified to remove those detrimental. Therefore, reovirus appears to be a great tool to probe the mucosal immune system and holds promise as an anti-cancer therapeutic.

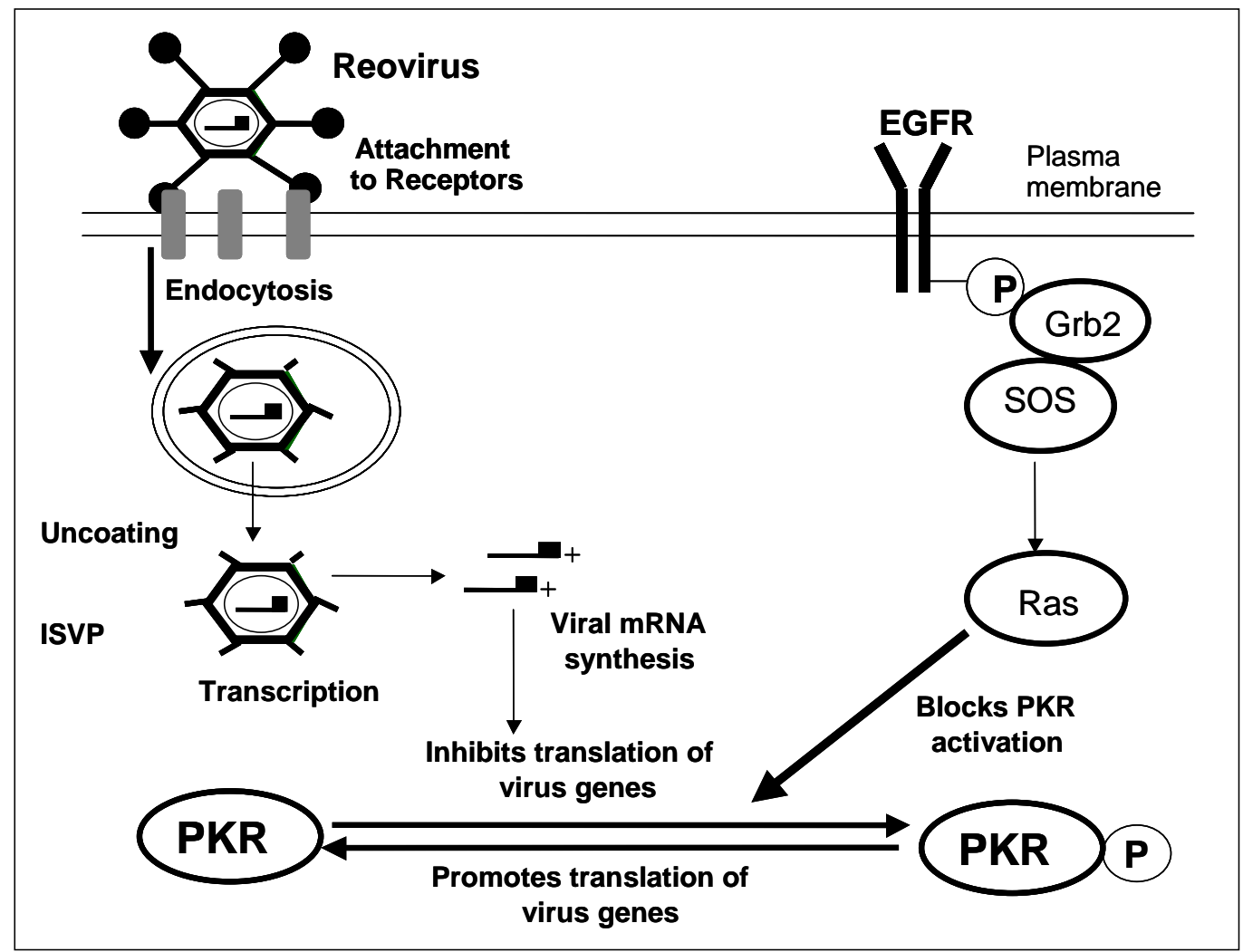

Figure 10. Usurpation of the Ras signaling pathway by reovirus. In untransformed, reovirus-resistant cells such as mature iecs double-stranded RNA structures in reovirus transcripts activate PKR, which subsequently phosphorylates eIF- $2 \alpha$, inhibiting translation initiation of viral genes. However, in cells with an activated Ras signaling pathway such as rapidly developing crypt cells of intestine, PKR phosphorylation in response to viral transcripts is inhibited either by Ras or an unidentified upstream element in the ras signaling pathway and viral translation proceeds unimpeded. Diagram is adapted from Strong et al. (1998) (358). 


\section{OVERVIEW OF EXPERIMENTS}

The second chapter of the dissertation is dedicated to examining the regulation IgAreceptor namely $\mathrm{pIgR}$ in reovirus infection and demonstrates that a newly appreciated effect of reovirus on mucosal epithelial cells is upregulation of $\mathrm{pIgR}$ expression. Upregulation of pIgR expression directly contributes to host defense by enhancing transcytosis of IgA from mucosal lamina propria into intestinal secretions where secretory IgA and free SC neutralize pathogens and inhibit binding of invading mucosal pathogens including virus and bacteria and prevent them from breaching the mucosal barrier. In chapter 2, a series of experiements have been reported that aimed to characterize the virus-host cell interactions that result in pIgR upregulation and the cell signaling pathways that are affected.

The third chapter in this dissertation is dedicated to examining downstream signal transduction pathways triggered by reovirus that likely contributes to upregulation of pIgR expression in intestinal epithelial cells. The main pathways examined include $\mathrm{NF} \kappa \mathrm{B}$ and IRF-1 and it has been demonstrated that activation of both these transcription factors contribute to upregulation of pIgR following reovirus infection, suggesting a coordinate regulation of $\mathrm{pIgR}$ gene transcription in response to virus.

Chapter four comprises of preliminary experiments that aimed to understand contribution of virus components in upregulation of pIgR. Preliminary experiments have been conducted to understand the importance of virus dsRNA in virus-mediated 
upregulation of $\mathrm{pIgR}$. Though these studies have not fully answered the important of RNA genome of virus in upregulation pIgR expression, it also has not ruled out its contribution. Continuation of these studies with either engineered virus lacking a RNA genome will provide valuable insights in future.

Chapter five comprises of preliminary experiments that aimed to understand the biological relevance of virus-mediated pIgR upregulation in an in vivo model. Experiments have been conducted in conventional and germ free mice to determine levels of $\mathrm{pIgR}$ expression in mice following reovirus infection and to compare if levels of pIgR are modulated in response to virus. In addition, the preliminary in vivo studies indicated an increase in pIgR expression following virus treatment, suggesting that immunologically competent but naïve intestinal epithelium can respond to enteric infection with virus. 


\title{
CHAPTER 2: REGULATION OF POLYMERIC
}

\section{IMMUNOGLOBULIN RECEPTOR (PIGR) EXPRESSION BY \\ $\underline{\text { REOVIRUS }}$}

\author{
KASTURI PAL ${ }^{1}$, CHARLOTTE S. KAETZEL ${ }^{2}$, KATHLEEN BRUNDAGE ${ }^{1}$, \\ CYNTHIA A. CUNNINGHAM ${ }^{1}$ AND CHRISTOPHER F. CUFF ${ }^{1 *}$ \\ ${ }^{1}$ Department of Microbiology, Immunology and Cell Biology \\ Robert C. Byrd Health Sciences Center, West Virginia University \\ Morgantown, West Virginia, USA 26506-9177 \\ ${ }^{2}$ Department of Microbiology, Immunology and Molecular Genetics, \\ University of Kentucky, Lexington, Kentucky, 40536.
}

Published in: Journal of General Virology. 2005. Volume 86(Pt 8): 2347-57. Used with permission from the authors and the Society for General Microbiology publisher, 08-15-05 


\section{SUMMARY}

Polymeric immunoglobulin receptor (pIgR) transcytoses dimeric IgA and IgA-coated immune complexes from the lamina propria across epithelia and into secretions. The effect of reovirus infection on regulation of pIgR expression in the human intestinal epithelial cell line HT-29 is characterized in this report. Both replication-competent and UV-inactivated reovirus at multiplicities of infection equivalent of 1-100 up-regulated pIgR mRNA by 24 hour post infection, and intracellular pIgR protein was increased at 48 hour following exposure to UV-inactivated virus. Binding of virus to HT-29 cells was required because pre-incubating virus with specific antiserum, but not non-immune serum, inhibited reovirus - mediated pIgR up-regulation. Endosomal acidification leading to uncoating of virus is a required step for pIgR up-regulation because ammonium chloride or bafilomycin-A1 pre-treatment inhibited virus-induced $\mathrm{pIgR}$ upregulation. Inhibition experiments using the calpain inhibitor N-acetyl-leucyl-leucylnorleucinal suggest that calpains are involved in reovirus -mediated pIgR up-regulation. Up-regulation of pIgR following virus infection appears to be an innate immune response against invading pathogens that could help the host effectively clear infection. Signaling induced by microbes and their products may serve to augment pIgR-mediated transcytosis of $\operatorname{IgA}$, linking the innate and acquired immune responses to viruses. 


\section{INTRODUCTION}

A hallmark feature of adaptive mucosal immune responses is the production and secretion of secretory immunoglobulin A (sIgA) (Lamm, 1997; Brandtzaeg et al., 1997; Kato et al., 2001). In the intestine, polymeric IgA produced by plasma cells in the lamina propria is transported across the adjacent mucosal epithelium into the lumen by the polymeric immunoglobulin receptor ( $\mathrm{pIgR}$ ) expressed on the basolateral surface of intestinal epithelial cells (Brandtzaeg, 1978; Brandtzaeg, 1985; Brandtzaeg et al., 1997). At the apical surface, pIgR is cleaved by an endopeptidase, releasing sIgA into luminal secretions (Musil \& Baenziger, 1987). The rate of IgA transcytosis depends on the level of $\mathrm{pIgR}$ expression because one molecule of pIgR must be synthesized for each molecule of transported IgA (Mostov \& Deitcher, 1986; Tamer et al., 1995; Song et al., 1995; Norderhaug et al., 1999). Thus, pIgR plays a role in mucosal host defense, and factors that influence expression of pIgR could affect mucosal immunity. A number of cytokines including gamma interferon (IFN- $\gamma$ ) (Denning, 1996; Ackermann et al., 1999; Schjerven et al., 2000), tumor necrosis factor alpha, interleukin 1b (Blanch et al., 1999), and interleukin 4 (Denning, 1996; Ackermann et al., 1999; Schjerven et al., 2000) increase pIgR expression in epithelial cells. However, little is known about regulation of pIgR during enteric virus infection.

Mammalian orthoreovirus (reovirus) are classified into 3 serotypes designated T1, T2, and $\mathrm{T} 3$ based on expression of the viral haemagglutinin, which serves as the viral ligand for cellular receptors (Weiner \& Fields, 1977). Reovirus infects the gastrointestinal tract in a wide range of mammalian species including mice and humans (Organ \& Rubin, 1998). Although both T1 and T3 infect hosts via the intestine, significant differences 
exist in the capacity of the serotypes to bind to intestinal epithelial cells and replicate in the intestine. Wolf et al. (Wolf et al., 1981; Wolf et al., 1983; Wolf et al., 1987) demonstrated that both T1 and T3 bind to microfold (M)-cells that overlie Peyer's patches (PP) in the small intestine. This specific binding and uptake by PP exposes the virus to innate and adaptive immune cells in the intestine (Weltzin et al., 1989).

Reovirus T3, but not T1, also binds to the apical surfaces of absorptive intestinal epithelial cells (IECs) and are endocytosed (Kauffman et al., 1983). It is unclear whether this is a 'dead-end' path for T3 virus. Endocytosed viruses appear to become trapped in lysosomes in IEC and basolateral transport has not been uniformly observed (Kauffman et al., 1983). On the other hand, at least in young animals, T3 infection induces villus shortening and mild mononuclear infiltration in the lamina propria (Branski et al., 1980). Alterations in IEC from T3-infected neonates include reduction in lactase and enterokinase activities, and increased maltase and leucine aminopeptidase activities (Branski et al., 1980). Together these results indicate that reovirus T3 can bind to and be taken up by IECs and affect IEC function, even though replication and viral shedding is limited.

Reoviruses induce robust mucosal and systemic mucosal immune responses (London et al., 1987; Cuff et al., 1993; Fan et al., 1998; Major et al., 1998). The intestinal cellular immune response is dominated by T-helper (Th) type 1 responses resulting in local production of IFN- $\gamma$ (Fan et al., 1998; Mathers \& Cuff, 2004) and development of virusspecific CTL responses in the intestine and periphery (London et al., 1987; London et al., 1989; London et al., 1990; Fulton et al., 2004). 
Rubin et al. (Rubin et al., 1985) reported that reovirus grows best in the rapidly developing cells of the crypts. In this model, virus is released from cells deep in the intestinal crypts and interacts with adjacent epithelial cells or is shed in the feces. Productive infection is limited to immature crypt enterocytes, perhaps due to a requirement for an activated Ras signaling pathway (Coffey et al., 1998; Strong et al., 1998).

Virus infection induces a number of changes in host cell biology that could influence cell function. Interaction of reovirus cell attachment protein $\sigma 1$ with its respective cell surface receptors including sialic acid and Junctional Adhesion Molecule (JAM) triggers a number of signaling cascades including increased activation of calpains (Debiasi et al., 1999; Debiasi et al., 2001), activation of c-Jun N-terminal kinase (JNK), and extracellular signal-related kinase (ERK) (Clarke et al., 2001). These signaling cascades result in upregulation of NF-кB activation (Tyler et al., 1995; Connolly et al., 2000; Hamamdzic et al., 2001) and phosphorylation of c-Jun (Clarke et al., 2001). While these signaling pathways are involved in inducing apoptosis in infected cells, particularly during infection with T3 (Tyler et al., 1995), their roles in other reovirus-induced cellular changes have not been characterized extensively, although one report (Hamamdzic et al., 2001) has linked increased NF-אB activation with production of chemokines and cytokines during reovirus exposure. Significantly, most or all of these changes in cell signaling in vitro occur independently of viral replication in as much as UV-inactivated virus mediates the observed effects (Tyler et al., 1995; Debiasi et al., 1999; Hamamdzic et al., 2001). These studies indicate that at least in vitro, replication incompetent virus can have many effects on cellular processes. 
Virus-host cell interactions and some of the possible cell signaling pathways involved in reovirus-mediated pIgR up-regulation are characterized in this report. Reovirus upregulated pIgR expression in the transformed human intestinal epithelial cell line, HT-29, and this up-regulation is independent of virus replication. Binding of the virus to its cellular receptors is required for reovirus-mediated pIgR up-regulation because treatment of virus with reovirus specific serum abolished the increase in $\mathrm{pIgR}$ expression. Endosomal acidification leading to uncoating of virus is necessary for virus-mediated pIgR up-regulation because ammonium chloride blocked the process. Furthermore, treatment of HT-29 cells with a specific inhibitor of calpain abrogated reovirus -mediated pIgR up-regulation. These observations support the hypothesis that IECs upregulate pIgR expression following exposure to enteric virus, possibly by altering cell-signaling pathways that control pIgR expression.

\section{METHODS}

Cells. HT-29 (ATCC HTB38) cells were cultured in McCoy's 5A Modified Medium (ATCC, Manassas, VA) supplemented with 10\% fetal bovine serum (FBS) and $1 \%$ penicillin-streptomycin. Calu-3 (ATCC 55-HTB) cells were cultured in Eagle's Minimum Essential Medium (ATCC) supplemented with $10 \%$ FBS and $1 \%$ penicillinstreptomycin. Cells were plated in T-25 flasks or 12 -well plates and incubated at $37^{\circ} \mathrm{C}$ for 24 hours to allow the formation adherent monolayers and then exposed to virus, UVinactivated virus, and/or inhibitors. 
Virus and antibodies. Third passage stocks of reovirus serotype 3, strain Dearing (T3/D, originally obtained from ATCC) were prepared in L929 cells and purified by 1,1,2-trichloro-1, 2,2-trifluoroethane (freon) extraction and $\mathrm{CsCl}$ gradient centrifugation (Smith et al., 1969). The concentration of virions in purified preparations was

determined by spectrophotometry where 1 absorbance unit at $260 \mathrm{~nm}=2.1 \times 10^{12}$ particles ml-1 (Smith et al., 1969) and by plaque assays (Cuff et al., 1990). T3/D was exposed to UV light at $100 \mu \mathrm{J} \mathrm{cm}^{2-1}$ for 2 minutes at a distance of $15 \mathrm{~cm}$ at room temperature. UV-inactivation reduced infectivity by approximately 1000 -fold as determined by a single cycle infection assay. Polyclonal anti-T3/D antiserum was obtained from mice infected with $3 \times 10^{7}$ p.f.u. of purified T3/D virions 1 month previously. One $\mathrm{ml}$ of serum completely neutralized a minimum of $1 \times 10^{10}$ p.f.u. of virus as assessed by in vitro neutralization (Cuff et al., 1990). In some experiments, UV-irradiated, virus-free L929 cell lysates or wheat germ agglutinin (Biomeda Corporation, Foster City, CA) were used to treat HT-29 cells.

RNA extraction and quantitative RT-PCR for PIgR mRNA. Total cellular RNA was extracted from HT-29 cells using RNeasy ${ }^{\circledR}$ mini kits (Qiagen, Valencia, CA) and RNA was reverse transcribed into cDNA using Superscript TM RNase H- Reverse Transcriptase (Invitrogen Life Technologies, Carlsbad, CA) according to manufacturers' protocols. Real-time PCR was performed using a Lightcycler (Roche Molecular Biochemicals, Indianapolis, IN). Taqman ${ }^{\circledR}$ primers and probes for human pIgR (from Applied Biosystems, Foster City, CA) were produced using published sequences (Blanch et al., 1999) and human b-actin was obtained from Biosource International Inc. 
(Camarillo, CA). Reactions were carried out in a total volume of $20 \mathrm{ml}$, and $2.5 \mathrm{mg}$ of bovine serum albumin (BSA) was added to each sample. PCR conditions were optimized for human $\mathrm{pIgR}$ and human $\beta$-actin primer pair as follows: denaturation for 1 cycle at 95 ${ }^{\circ} \mathrm{C}$ for 15 seconds; enzyme activation for 1 cycle at $50{ }^{\circ} \mathrm{C}$ for 2 minutes followed by 95 ${ }^{\circ} \mathrm{C}$ for 10 minutes; amplification for 55 cycles at $94{ }^{\circ} \mathrm{C}$ for $30 \mathrm{~s}$ followed by $60{ }^{\circ} \mathrm{C}$ for 1 minute; cool down for 1 cycle at $40{ }^{\circ} \mathrm{C}$ for 1 minute. Data were analyzed by determining 'crossing points' or the cycle number at which newly synthesized PCR product is first detected. Samples were analyzed in duplicate. PIgR expression was normalized with respect to $b$-actin expression by subtracting the $\beta$-actin crossing point from the $\mathrm{pIgR}$ crossing point for each sample. Preliminary experiments demonstrated that mRNA could be quantitatively reverse transcribed to cDNA and amplified by PCR over at least a 64fold range of concentrations (See Supplementary Figure in JGV Online). The fold induction of $\mathrm{pIgR}$ in virus-treated cells compared to the control was determined using the equation: Fold change $=K_{\text {gene }}{ }^{\Delta C p}$, where $K_{\text {gene }}$ is the amplification coefficient for the $\mathrm{pIgR}$ gene and $\Delta \mathrm{Cp}$ is the difference in crossing point between the normalized nontreated and virus-treated HT-29 cells (Schjerven et al., 2000). The theoretical value of $\mathrm{K}_{\text {gene }}$ is 2, and preliminary experiments indicated that the $\mathrm{K}_{\mathrm{gene}}$ value for this system ranged from 1.9 to 2.0 (See Supplementary Figure in JGV Online). Therefore, the $\mathrm{K}_{\text {gene }}$ value of 2 was used for data analysis.

ELISA for cell -associated pIgR. Concentrations of pIgR protein in cell lysates were determined by ELISA as described (Chintalacharuvu et al., 1991). Briefly, 96-well EIA/RIA (Costar, Acton, MA) flat-bottom plates were coated with guinea pig anti-human 
secretory component (SC). Human SC purified from colostrum (Kobayashi, 1971) was used to generate standard curves. Purified SC was diluted in cell lysis buffer (1X PBS, 1 $\%$ Nonidet P-40, $0.5 \%$ sodium deoxycholate, $0.1 \%$ SDS and protease inhibitors $1 \mathrm{mM}$ phenylmethylsulfonyl fluoride (PMSF) and $5 \mathrm{mg} \mathrm{ml-1}$ aprotinin). Bound SC was detected with rabbit anti-human SC, followed by horseradish peroxidase-conjugated donkey anti-rabbit IgG (Jackson ImmunoResearch Laboratories Inc., West Grove, PA) and $100 \mathrm{ml}$ of substrate, 2,2' -azinobis-3-ethylbenzthiazoline-6-sulfonic acid substrate (ABTS) (Sigma, St. Louis, MO) (0.3 mg ml-1 in 0.1 M citric acid, $\mathrm{pH} 4.35$ ) supplemented with $10 \mathrm{ml}$ of $30 \% \mathrm{H}_{2} \mathrm{O}_{2}$ per $10 \mathrm{ml}$ of ABTS. Color development was assessed at $405 \mathrm{~nm}$. Total protein concentration in cell lysates was determined using the bicinchoninic acid protein assay reagent kit (Pierce Biotechnology, Rockford, IL) according to the manufacturer's protocol. Data were expressed as ng $\mathrm{pIgR} \mathrm{mg}^{-1}$ total protein.

Inhibition of endosomal acidification. Ammonium chloride (Sigma) is an inhibitor of endosomal acidification that reduces intracellular digestion of reovirus outer capsid proteins and blocks reovirus induced apoptosis (Canning \& Fields, 1983; Sturzenbecker et al., 1987; Connolly \& Dermody, 2002). Bafilomycin-A1 (Sigma) is a specific inhibitor of vacuolar proton ATPase (Bowman et al., 1988; Yoshimori et al., 1991; Hacker et al., 1998) and blocks reovirus replication (Martinez et al., 1996). Adherent monolayers of HT-29 cells grown at $37^{\circ} \mathrm{C}$ in 12 well plates were pre-treated for 1.5 hours with various doses of ammonium chloride, or 1 hour with bafilomycin-A1 or DMSO (vehicle control). Inhibitor-containing medium was then removed and the cells 
were cultured in the presence or absence of UV-inactivated reovirus at a multiplicity of infection (MOI) equivalent of $50 \mathrm{pfu} / \mathrm{cell}$ for 1 hour. The MOI equivalent was calculated based on the concentration of replication competent virus prior to UV-inactivation. Virus-exposed cells were then incubated in medium that contained inhibitor. mRNA was isolated 24 hours post exposure to virus. Inhibitors used at the doses indicated were not visibly toxic to the cells.

Inhibition of calpains. Calpain inhibitor I (N-acetyl-leucyl-leucyl-norleucinal [aLLN]; Calbiochem, La Jolla, CA.) is a modified peptide that competes for the active site of calpain (Wang \& Yuen, 1994) and it was prepared as a $25 \mathrm{mM}$ stock in DMSO. Adherent monolayers of HT-29 cells were pre-treated with the indicated doses of aLLN or DMSO for 1 hour. Inhibitor-containing medium was then removed and cells were exposed to UV-inactivated reovirus at an MOI-equivalent of 50. After 1 hour incubation, inhibitors were added back to each culture (Debiasi et al., 1999) and mRNA was isolated at 24 hours after exposure to virus. Intracellular pIgR protein was isolated at 48 hours post exposure to virus. The inhibitor aLLN used at the doses indicated was not visibly toxic to the cells.

Immunofluorescence Analysis. HT-29 cells were grown on coverslips or T-25 flasks overnight and treated with $50 \mathrm{mM} \mathrm{NH}_{4} \mathrm{Cl}$ or $10 \mu \mathrm{M}$ aLLN for 1 hour at $37^{\circ} \mathrm{C}$. Cells were pulsed with virus at a particle to cell ratio of approximately $10^{5}$, or rendered non-adherent with trypsin-EDTA solution and then exposed to virus. For virus binding assays, viruspulsed cells were incubated on ice for 30 minutes and kept cold during subsequent 
staining. Additionally, all stains and washes were performed in solutions containing 0.04\% (w/v) sodium azide to inhibit endocytosis. Cells were analyzed using a BectonDickinson FACScalibur and Cell Quest Pro software (BD Biosciences, San Jose, CA) For intracellular staining experiments, virus-infected cells were incubated for 1-2 hours at $37^{\circ} \mathrm{C}$. Cells on coverslips were fixed for 15 minutes in PBS supplemented with $4 \%$ paraformaldehyde and 1\% Triton X-100 and then stained for 30 minutes with a 1:500 dilution of rabbit anti-reovirus antiserum diluted in PBS/1\% Triton X-100. The rabbit antiserum was previously raised in this laboratory. Coverslips were then washed in PBS/1\% Triton X-100 and stained for 15 minutes with a 1:100 dilution of Alexa 488-anti rabbit IgG (Molecular Probes, Eugene, OR) diluted in PBS /1\% Triton X-100. Coverslips were dried, mounted and analyzed with a laser scanning confocal microscope (Zeiss LSM 510).

Statistical analysis. Data from multiple experiments were expressed as the mean \pm SEM. The statistical significance of differences between mean values was assessed by either two-way-analysis of variance (ANOVA) followed by Tukey's test or one-way ANOVA followed by Orthogonal Contrast to test for both a trend in dose response and the threshold at which the effect appears. A P value of $<0.05$ was considered significant. 


\section{RESULTS}

Reovirus upregulates pIgR mRNA and protein in HT-29 cells. To determine whether reovirus is capable of modulating pIgR expression in epithelial cells, infectious reovirus T3/D or UV-inactivated virus was adsorbed to confluent monolayers of HT-29 cells at an MOI or equivalent of 1,10 , and 100 and pIgR mRNA was measured 24 hours post virus exposure by RT-PCR. No cytopathic effect was observed in cultures of cells exposed to replication competent or UV-inactivated virus for up to 48 hours of culture. Cytopathic effect was observed at 72 hours post-infection with replicating virus; no CPE was observed with UV-irradiated virus. Infectious virus increased pIgR mRNA 2-8 fold over several experiments. However, UV-inactivated virus was substantially more effective in up-regulating pIgR mRNA expression at equivalent amounts of virus (Fig. 1). No significant increase in pIgR mRNA was detected in cells treated with UV-irradiated Lcell lysates $\left(4 \times 10^{4}\right.$ cells $\left./ \mathrm{ml}\right)$, or wheat germ agglutinin $(50 \mathrm{mg} / \mathrm{ml})($ Fig. 2$)$; a ligand for sialic acid that serves as one of the cellular receptors for reovirus.

To determine whether the increased mRNA levels resulted in increased pIgR protein production, HT-29 cells were cultured in the presence or absence of infectious virus or UV-inactivated virus at an MOI equivalent of 50, and intracellular pIgR protein was measured from cell lysates by ELISA (Fig. 3). Increased levels of intracellular pIgR were detected by 48 hours of reovirus exposure. Thus, the elevation in protein levels followed the increased mRNA levels by 24 hours. As with the mRNA, UV-inactivated virus had a more pronounced effect than replicating virus. Immunoblot analysis additionally demonstrated upregulation of $\mathrm{pIgR}$ protein by UV-treated reovirus or IFN$\gamma$ (See Supplementary Fig. S2 in JGV Online ). 
Virus-specific antiserum blocks the effect of reovirus on pIgR up-regulation. To ascertain whether increased pIgR mRNA requires virus binding to the host cells, UVinactivated T3/D was pre-incubated with T3/D-immune or non-immune mouse serum prior to use on HT-29 cells. T3/D-immune but not non-immune serum blocked the virus-induced up-regulation of pIgR, indicating that virus binding to HT-29 cells is required to upregulate pIgR (Fig. 4).

\section{Inhibition of endosomal acidification blocks reovirus mediated pIgR up-regulation.}

Reovirus is endocytosed following binding to its cellular ligands, sialic acid and JAM (Borsa et al., 1979; Borsa et al., 1981; Sturzenbecker et al., 1987; Rubin et al., 1992; Barton et al., 2001b; Prota et al., 2003; Forrest et al., 2003). Acidification leads to partial uncoating of the virus inside endosomes, resulting in production of intermediate subviral particles that translocate to the cytoplasm and initiate transcription of viral genes (Borsa et al., 1979; Borsa et al., 1981; Sturzenbecker et al., 1987). To examine whether endosomal acidification is required for reovirus -mediated pIgR up-regulation, HT-29 cells were pre-treated for 90 minutes with various doses of ammonium chloride.

Inhibitor-containing medium (or control) was then removed, and the cells were cultured in the presence or absence of UV-inactivated reovirus at an MOI equivalent of 50 for 1 hour. Ammonium chloride was then added back to each well and pIgR mRNA was measured 24 hours post exposure to virus. Ammonium chloride blocked virus mediated pIgR mRNA up-regulation in a dose dependent manner (Fig. 5), suggesting that endosomal acidification leading to uncoating of virus plays a role in pIgR up-regulation. 
Bafilomycin-A1, another inhibitor of endosomal acidification that acts through inhibition of vacuolar proton ATPase (Bowman et al., 1988; Yoshimori et al., 1991; Martinez et al., 1996; Hacker et al., 1998), also blocked reovirus-induced pIgR upregulation (Fig. 6).

Calpain inhibition abrogates reovirus -mediated pIgR up-regulation. Calpains, calcium-dependent cysteine proteases, induce nuclear factor kappa B (NFkB) activation through the degradation of its cytosolic repressor inhibitory kappa B alpha (IкBa). Debiasi et al. demonstrated that calpain inhibitors reduced reovirus-mediated calpain acitivation in vitro (Debiasi et al., 1999) and in vivo (Debiasi et al., 2001). To determine whether calpains play a role in reovirus-mediated up-regulation of pIgR, HT-29 cells were pre-treated for 1 hour with the calpain I inhibitor aLLN at doses of 0.001 to $10 \mu \mathrm{M}$, or vehicle control DMSO. Medium containing inhibitor (or control) was then removed, and the cells were cultured in the presence or absence of UV-inactivated reovirus at an MOI equivalent of 50. After 1hour incubation, inhibitors were added back to each well and pIgR mRNA was measured 24 hours after exposure to virus. Virus-mediated upregulation of pIgR mRNA was inhibited by aLLN in a dose-dependent manner, suggesting that calpains play a role in virus-induced pIgR up-regulation (Fig. 7A). Under similar culture conditions, UV-inactivated T3/D failed to upregulate intracellular pIgR protein in cells treated for 48 hours with 1-10 $\mu \mathrm{M}$ aLLN (Fig. 7B and supplemental data in JGV Online), suggesting a role for calpain activation in pIgR up-regulation. Neither $\mathrm{NH}_{4} \mathrm{Cl}$ nor aLLN affected binding of virus to cellular receptors as determined by flow cytometric analysis of cells pulsed with virus at $4^{\circ} \mathrm{C}$ in the presence of sodium azide. Additionally, when inhibitor-treated, virus-infected cells were incubated at $37^{\circ} \mathrm{C}$ 
to allow endocytosis, bright intracellular perinuclear staining of reovirus was observed (Fig. 8).

\section{DISCUSSION}

pIgR contributes to host defense of mucosal surfaces by mediating efficient transport and secretion of IgA. How mucosal pathogens affect $\mathrm{pIgR}$ expression to the advantage of either the host or the pathogen is not clear. These studies are the first to show that reovirus increases pIgR mRNA and protein in mucosal epithelial cells. The results indicate that virus binding to cellular ligands and uncoating in acidified endosomes are required steps for virus-mediated pIgR up-regulation through a calpain-mediated pathway. UV-inactivated T3/D reovirus induced higher levels of $\mathrm{pIgR}$ expression than infectious virus, possibly because replicating virus usurps or inhibits normal host cell mRNA and protein synthesis to produce infectious virions (Kudo \& Graham, 1966; Ensminger \& Tamm, 1969; Zweerink \& Joklik, 1970; Sharpe \& Fields, 1981; Sharpe \& Fields, 1982).

Preliminary studies indicated that both replication competent and UV-inactivated T1 (strain Lang) was less efficient than T3/D in inducing pIgR up-regulation (data not shown). It has long been thought that during T1 infection, viral entry into IECs occurs through the basolateral surface (Rubin et al., 1985), most likely as a result of T1 binding to cellular JAM (Barton et al., 2001b; Prota et al., 2003; Forrest et al., 2003) and not through sialic acid (Wolf et al., 1981; Wolf et al., 1983; Wolf et al., 1987). Together these observations imply that perhaps sialic acid -mediated binding and entry is critical 
for pIgR upregulation. However, it has been recently reported that $\mathrm{T} 1$ can also bind to glycoconjugates containing alpha 2-3-linked sialic acid on M-cell apical surfaces (Helander et al., 2003). Therefore the role of sialic acid binding in mediating pIgR upregulation remains to be determined. Approaches to assessing the role of sialic acid include using reoviruses deficient in the ability to bind sialic acid, and pre-treating HT-29 cells with sialidase. Replication of virus in host cells is not required for reovirusmediated pIgR up-regulation, implying that this innate immune response can occur in the absence of significant virus replication.

Reovirus infection of the respiratory tract induces various types of pathology including acute pneumonia in juvenile mice (Morin et al., 1994; Morin et al., 1996). Reovirus also up-regulated pIgR mRNA expression by 15 -fold in the transformed human airway epithelium cell line Calu-3, while UV-inactivated virus up-regulated pIgR mRNA expression by as much as 25 -fold under similar conditions (See Supplementary Figure in JGV Online) suggesting that pIgR up-regulation in epithelial cells from both the respiratory tract and the intestine could clear infection more effectively by increasing transport of pIgA in the mucosal secretions.

Virus infection of host cells involves multiple steps including binding, uptake, and replication. The requirements of receptor engagement and uptake for virus-mediated pIgR up-regulation were also investigated. T3/D-immune but not non-immune serum blocked the up-regulation of pIgR, indicating that specific virus binding to HT-29 cells is required to induce pIgR up-regulation. Whether virus binding through JAM (Barton et al., 2001b; Prota et al., 2003; Forrest et al., 2003), sialic acid (Chappell et al., 1997; Chappell et al., 2000; Connolly et al., 2001; Barton et al., 2001a; Connolly \& Dermody, 
2002; Helander et al., 2003), or both, is required for pIgR up-regulation is under investigation. After binding, the virus undergoes receptor-mediated endocytosis (Borsa et al., 1979; Borsa et al., 1981; Sturzenbecker et al., 1987; Rubin et al., 1992) and subsequent endosomal acidification leads to partial uncoating of virus inside the endosomes (Borsa et al., 1981; Sturzenbecker et al., 1987). Ammonium chloride blocked virus-mediated pIgR up-regulation, indicating that endosomal acidification leading to viral disassembly is necessary for pIgR up-regulation. Ammonium chloride-mediated inhibition of viral disassembly has been previously shown to block reovirus-induced apoptosis (Connolly \& Dermody, 2002) without affecting binding or uptake of virus (Sturzenbecker et al., 1987), which was confirmed in this study. Bafilomycin-A, an inhibitor of vacuolar proton ATPases, was previously shown to block reovirus replication in cells infected with whole virions but not in cells infected with intermediate subviral particles (Martinez et al., 1996). Like $\mathrm{NH}_{4} \mathrm{Cl}$, bafilomycin-A1 inhibited reovirusinduced pIgR upregulation, further supporting the idea that viral uncoating is required for pIgR upregulation. It is possible that following degradation in the endosomes, liberated viral dsRNA interacts with intracellular Toll like receptor -3 (TLR-3) to induce intracellular signals that lead to pIgR up-regulation. TLR-3 is constitutively expressed in human intestinal epithelial cells (Cario \& Podolsky, 2000), although the precise intracellular location of TLR-3 has not yet been identified. In human dendritic cells TLR-3 is expressed intracellularly in vesicles and possibly at a low level in late endosomes (Matsumoto et al., 2003; Funami et al., 2004). Thus, TLR-3 signaling in response to reovirus dsRNA might be initiated following fusion of endosomes containing reovirus dsRNA from degraded virions with cellular vesicles containing TLR-3. 
However during virus replication it is possible that dsRNA synthesized inside newly formed capsids is shielded from intracellular TLR-3. Therefore an alternative activation pathway such as through TLR-7 in mice or TLR-8 in human, which recognize viral ssRNA (Diebold et al., 2004; Heil et al., 2004) might be responsible for the observed effects.

Alternatively, reovirus dsRNA may trigger cellular responses via a TLR -independent mechanism. Double stranded RNA may bind to the cellular RNA helicase, retinoic acidinducible gene-1 (RIG-1) (Li et al., 2005; Sumpter, Jr. et al., 2005), or melanoma differentiation-associated gene 5 (mda-5) (Kang et al., 2002; Andrejeva et al., 2004) and subsequently activate latent transcription factors including IFN regulatory factor 3 and

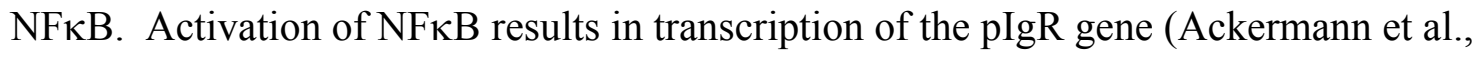
1999; Schjerven et al., 2001; Ackermann \& Denning, 2004) Because RIG-1 and mda-5 activate $\mathrm{NF \kappa B}$, and reovirus upregulates $\mathrm{NF \kappa B}$ activation, it is possible that one or both of these intracellular pathogen receptor/signaling molecules mediate the effect of reovirus on pIgR levels. These hypotheses are currently being investigated. UV inactivation of reovirus damages the dsRNA genome by bonding the pyrimidine molecules, which impairs replication and blocks transcription of early and late genes (Strong et al., 1998). However, it is not known whether there is residual transcription of viral mRNA in the UV-inactivated virus used in the experiments reported here.

The calpain inhibitor aLLN abolished virus-mediated pIgR up-regulation, suggesting an essential role for calpain activation in this process. Calpains are calcium dependent cysteine proteases widely distributed throughout the cytosol of many cell types (Murachi, 1989). Calpains exists in the cytosol as an inactive proenzyme bound to its endogenous 
inhibitor calpastatin (Croall \& DeMartino, 1991). Upon activation, calpains degrade a variety of substrates including proto-oncogenes, steroid hormone receptors, protein kinases, and cytoskeletal elements (Croall \& DeMartino, 1991). Calpains also regulate a number of cellular transcription factors, including activation of NFkB, by mediating degradation of its inhibitor IкB (Liu et al., 1996; Chen et al., 1997). It seems reasonable to speculate that reovirus-induced pIgR up-regulation is mediated through $\mathrm{NF \kappa B}$ activation via a calpain-mediated pathway, and this hypothesis is also under investigation. It has been speculated that aLLN can transiently affect endocytosis (Kamal et al., 1998), but no evidence was found to support that mechanism of action in the experiments reported here.

Enteroinvasive bacteria including Salmonella dublin, enteroinvasive Escherichia coli and Yersinia enterocolitica can increase NFkB activity in human intestinal epithelial cell lines, HT-29, Caco-2 and T84. NFkB activation leads to enhanced transcription of an array of downstream inflammatory genes including interleukin 8 , tumor necrosis factor alpha, and monocyte chemoattractant protein-1 (Elewaut et al., 1999). Thus, NFkB serves as a central regulator of the intestinal epithelial cell innate immune responses to infection with enteroinvasive bacteria, and perhaps enteric viruses as well.

Although not yet demonstrated, it is reasonable to speculate that reovirus infection leads to $\mathrm{pIgR}$ up-regulation in vivo. Reovirus replicates in the rapidly dividing cells of the intestinal crypts (Rubin et al., 1985), and viral replication appears to be restricted to host cells with an activated ras pathway (Strong et al., 1998). If only replicating virus induced pIgR upregulation, then the effect in vivo would be limited to crypt cells. However, reovirus replication is not necessary for up-regulating $\mathrm{pIgR}$ expression, so reovirus could 
potentially modulate pIgR levels in differentiated IECs lacking an activated ras pathway. At least in vitro, reovirus infection results in the production of replication competent and replication incompetent virus (Smith et al., 1969). This phenomenon likely occurs in vivo as well, and could result in production of particles that would efficiently induce pIgR expression in IECs independent of viral replication. Although it could be questioned whether UV-inactivated virus is equivalent to normally occurring, replication incompetent virus, $\mathrm{UV}$-inactivated virus has been used as a surrogate for replication incompetent virus in in vitro (Farone et al., 1993; Tyler et al., 1995; Debiasi et al., 1999; Hamamdzic et al., 2001; Labrada et al., 2002) and in vivo (Rubin et al., 1981) studies. Up-regulation of intestinal pIgR mRNA expression has been reported in formerly germfree mice colonized with Bacteroides thetaiotaomicron (Hooper et al., 2001). In addition, pIgR mRNA and protein expression is upregulated in mammary epithelial cells in sheep in response to exogenous hormones and glucocorticoid treatment (RinchevalArnold et al., 2002b), and this effect could be mediated through an IFN- $\gamma$-linked mechanism (Rincheval-Arnold et al., 2002a). Lamina propria mononuclear cell-derived IFN-g has been shown to upregulate pIgR expression in HT-29 cells (Youngman et al., 1994). Thus, along with the direct effects of the virus, reovirus infection induced IFN-g expression in the intestine (Fan et al., 1998; Mathers \& Cuff, 2004), so cytokinemediated up-regulation of pIgR might be operative in vivo. Virus-induced up-regulation of pIgR that augments IgA transcytosis could be an innate host defense mechanism against mucosal pathogens. 


\section{ACKNOWLEDGEMENTS}

This research was supported by grants AI034544, RR16440 and CA051998 from the National Institutes of Health, and by the National Cell Culture Center (Minneapolis, Minn.). The authors thank Dr. Gerald Hobbes (WVU) for advice on statistical analyses. 


\section{REFERENCES}

Ackermann, L. W. \& Denning, G. M. (2004). Nuclear factor-kappaB contributes to interleukin-4- and interferon-dependent polymeric immunoglobulin receptor expression in human intestinal epithelial cells. Immunology 111, 75-85.

Ackermann, L. W., Wollenweber, L. A. \& Denning, G. M. (1999). IL-4 and IFNgamma increase steady state levels of polymeric Ig receptor mRNA in human airway and intestinal epithelial cells. J Immunol 162, 5112-5118.

Andrejeva, J., Childs, K. S., Young, D. F., Carlos, T. S., Stock, N., Goodbourn, S. \& Randall, R. E. (2004). The V proteins of paramyxoviruses bind the IFN-inducible RNA helicase, mda-5, and inhibit its activation of the IFN-beta promoter. Proc Natl Acad Sci U $S$ A 101, 17264-17269.

Barton, E. S., Connolly, J. L., Forrest, J. C., Chappell, J. D. \& Dermody, T. S. (2001a). Utilization of sialic acid as a coreceptor enhances reovirus attachment by multistep adhesion strengthening. J Biol Chem 276, 2200-2211.

Barton, E. S., Forrest, J. C., Connolly, J. L., Chappell, J. D., Liu, Y., Schnell, F. J., Nusrat, A., Parkos, C. A. \& Dermody, T. S. (2001b). Junction adhesion molecule is a receptor for reovirus. Cell 104, 441-451. 
Blanch, V. J., Piskurich, J. F. \& Kaetzel, C. S. (1999). Cutting edge: coordinate regulation of IFN regulatory factor-1 and the polymeric Ig receptor by proinflammatory cytokines. J Immunol 162, 1232-1235.

Borsa, J., Morash, B. D., Sargent, M. D., Copps, T. P., Lievaart, P. A. \& Szekely, J. G. (1979). Two modes of entry of reovirus particles into L cells. J Gen Virol 45, 161170.

Borsa, J., Sargent, M. D., Lievaart, P. A. \& Copps, T. P. (1981). Reovirus: evidence for a second step in the intracellular uncoating and transcriptase activation process. Virology 111, 191-200.

Bowman, E. J., Siebers, A. \& Altendorf, K. (1988). Bafilomycins: a class of inhibitors of membrane ATPases from microorganisms, animal cells, and plant cells. Proc Natl Acad Sci U S A 85, 7972-7976.

Brandtzaeg, P. (1978). Polymeric IgA is complexed with secretory component (SC) on the surface of human intestinal epithelial cells. Scand J Immunol 8, 39-52.

Brandtzaeg, P. (1985). Role of J chain and secretory component in receptor-mediated glandular and hepatic transport of immunoglobulins in man. Scand J Immunol 22, 111146.

Brandtzaeg, P., Berstad, A. E., Farstad, I. N., Haraldsen, G., Helgeland, L., Jahnsen, F. L., Johansen, F. E., Natvig, I. B., Nilsen, E. M. \& Rugtveit, J. (1997). Mucosal immunity--a major adaptive defence mechanism. Behring Inst Mitt , 1-23. 
Branski, D., Lebenthal, E., Faden, H., Hatch, T. F. \& Krasner, J. (1980). Small intestinal epithelial brush border enzymatic changes in suckling mice infected with reovirus type 3. Pediatr Res 14, 803-805.

Canning, W. M. \& Fields, B. N. (1983). Ammonium chloride prevents lytic growth of reovirus and helps to establish persistent infection in mouse L cells. Science 219, 987988.

Cario, E. \& Podolsky, D. K. (2000). Differential alteration in intestinal epithelial cell expression of toll-like receptor 3 (TLR3) and TLR4 in inflammatory bowel disease. Infect Immun 68, 7010-7017.

Chappell, J. D., Duong, J. L., Wright, B. W. \& Dermody, T. S. (2000). Identification of carbohydrate-binding domains in the attachment proteins of type 1 and type 3 reoviruses. J Virol 74, 8472-8479.

Chappell, J. D., Gunn, V. L., Wetzel, J. D., Baer, G. S. \& Dermody, T. S. (1997). Mutations in type 3 reovirus that determine binding to sialic acid are contained in the fibrous tail domain of viral attachment protein sigma1. J Virol 71, 1834-1841.

Chen, F., Lu, Y., Kuhn, D. C., Maki, M., Shi, X., Sun, S. C. \& Demers, L. M. (1997). Calpain contributes to silica-induced I kappa B-alpha degradation and nuclear factorkappa B activation. Arch Biochem Biophys 342, 383-388.

Chintalacharuvu, K. R., Piskurich, J. F., Lamm, M. E. \& Kaetzel, C. S. (1991). Cell polarity regulates the release of secretory component, the epithelial receptor for 
polymeric immunoglobulins, from the surface of HT-29 colon carcinoma cells. J Cell Physiol 148, 35-47.

Clarke, P., Meintzer, S. M., Widmann, C., Johnson, G. L. \& Tyler, K. L. (2001). Reovirus infection activates JNK and the JNK-dependent transcription factor c-Jun. $J$ Virol 75, 11275-11283.

Coffey, M. C., Strong, J. E., Forsyth, P. A. \& Lee, P. W. (1998). Reovirus therapy of tumors with activated Ras pathway. Science 282, 1332-1334.

Connolly, J. L., Barton, E. S. \& Dermody, T. S. (2001). Reovirus binding to cell surface sialic acid potentiates virus-induced apoptosis. J Virol 75, 4029-4039.

Connolly, J. L. \& Dermody, T. S. (2002). Virion disassembly is required for apoptosis induced by reovirus. $J$ Virol 76, 1632-1641.

Connolly, J. L., Rodgers, S. E., Clarke, P., Ballard, D. W., Kerr, L. D., Tyler, K. L. \& Dermody, T. S. (2000). Reovirus-induced apoptosis requires activation of transcription factor NF-kappaB. J Virol 74, 2981-2989.

Croall, D. E. \& DeMartino, G. N. (1991). Calcium-activated neutral protease (calpain) system: structure, function, and regulation. Physiol Rev 71, 813-847.

Cuff, C. F., Cebra, C. K., Rubin, D. H. \& Cebra, J. J. (1993). Developmental relationship between cytotoxic alpha/beta $\mathrm{T}$ cell receptor-positive intraepithelial lymphocytes and Peyer's patch lymphocytes. Eur J Immunol 23, 1333-1339. 
Cuff, C. F., Lavi, E., Cebra, C. K., Cebra, J. J. \& Rubin, D. H. (1990). Passive immunity to fatal reovirus serotype 3-induced meningoencephalitis mediated by both secretory and transplacental factors in neonatal mice. J Virol 64, 1256-1263.

Debiasi, R. L., Edelstein, C. L., Sherry, B. \& Tyler, K. L. (2001). Calpain inhibition protects against virus-induced apoptotic myocardial injury. $J$ Virol 75, 351-361.

Debiasi, R. L., Squier, M. K., Pike, B., Wynes, M., Dermody, T. S., Cohen, J. J. \& Tyler, K. L. (1999). Reovirus-induced apoptosis is preceded by increased cellular calpain activity and is blocked by calpain inhibitors. J Virol 73, 695-701.

Denning, G. M. (1996). IL-4 and IFN-gamma synergistically increase total polymeric IgA receptor levels in human intestinal epithelial cells. Role of protein tyrosine kinases. $J$ Immunol 156, 4807-4814.

Diebold, S. S., Kaisho, T., Hemmi, H., Akira, S. \& Reis e Sousa. (2004). Innate antiviral responses by means of TLR7-mediated recognition of single-stranded RNA. Science 303, 1529-1531.

Elewaut, D., DiDonato, J. A., Kim, J. M., Truong, F., Eckmann, L. \& Kagnoff, M. F. (1999). NF-kappa B is a central regulator of the intestinal epithelial cell innate immune response induced by infection with enteroinvasive bacteria. J Immunol 163, 1457-1466.

Ensminger, W. D. \& Tamm, I. (1969). Cellular DNA and protein synthesis in reovirusinfected L cells. Virology 39, 357-360. 
Fan, J. Y., Boyce, C. S. \& Cuff, C. F. (1998). T-helper 1 and T-helper 2 cytokine responses in gut-associated lymphoid tissue following enteric reovirus infection. Cell Immunol 188, 55-63.

Farone, A. L., O'Brien, P. C. \& Cox, D. C. (1993). Tumor necrosis factor-alpha induction by reovirus serotype 3. J Leukoc Biol 53, 133-137.

Forrest, J. C., Campbell, J. A., Schelling, P., Stehle, T. \& Dermody, T. S. (2003). Structure-function analysis of reovirus binding to junctional adhesion molecule 1 . Implications for the mechanism of reovirus attachment. J Biol Chem 278, 48434-48444.

Fulton, J. R., Smith, J., Cunningham, C. \& Cuff, C. F. (2004). Influence of the route of infection on development of $\mathrm{T}$-cell receptor beta-chain repertoires of reovirus-specific cytotoxic T lymphocytes. J Virol 78, 1582-1590.

Funami, K., Matsumoto, M., Oshiumi, H., Akazawa, T., Yamamoto, A. \& Seya, T. (2004). The cytoplasmic 'linker region' in Toll-like receptor 3 controls receptor localization and signaling. Int Immunol 16, 1143-1154.

Hacker, H., Mischak, H., Miethke, T., Liptay, S., Schmid, R., Sparwasser, T., Heeg, K., Lipford, G. B. \& Wagner, H. (1998). CpG-DNA-specific activation of antigenpresenting cells requires stress kinase activity and is preceded by non-specific endocytosis and endosomal maturation. EMBO J 17, 6230-6240.

Hamamdzic, D., Phillips-Dorsett, T., Altman-Hamamdzic, S., London, S. D. \& London, L. (2001). Reovirus triggers cell type-specific proinflammatory responses 
dependent on the autocrine action of IFN-beta. Am J Physiol Lung Cell Mol Physiol 280, L18-L29.

Heil, F., Hemmi, H., Hochrein, H., Ampenberger, F., Kirschning, C., Akira, S., Lipford, G., Wagner, H. \& Bauer, S. (2004). Species-specific recognition of singlestranded RNA via toll-like receptor 7 and 8. Science 303, 1526-1529.

Helander, A., Silvey, K. J., Mantis, N. J., Hutchings, A. B., Chandran, K., Lucas, W. T., Nibert, M. L. \& Neutra, M. R. (2003). The viral sigma1 protein and glycoconjugates containing alpha2-3-linked sialic acid are involved in type 1 reovirus adherence to M-cell apical surfaces. J Virol 77, 7964-7977.

Hooper, L. V., Wong, M. H., Thelin, A., Hansson, L., Falk, P. G. \& Gordon, J. I. (2001). Molecular analysis of commensal host-microbial relationships in the intestine. Science 291, 881-884.

Kamal, A., Ying, Y. \& Anderson, R. G. (1998). Annexin VI-mediated loss of spectrin during coated pit budding is coupled to delivery of LDL to lysosomes. J Cell Biol 142, 937-947.

Kang, D. C., Gopalkrishnan, R. V., Wu, Q., Jankowsky, E., Pyle, A. M. \& Fisher, P. B. (2002). mda-5: An interferon-inducible putative RNA helicase with double-stranded RNA-dependent ATPase activity and melanoma growth-suppressive properties. Proc Natl Acad Sci U S A 99, 637-642.

Kato, H., Kato, R., Fujihashi, K. \& McGhee, J. R. (2001). Role of mucosal antibodies in viral infections. Curr Top Microbiol Immunol 260, 201-228. 
Kauffman, R. S., Wolf, J. L., Finberg, R., Trier, J. S. \& Fields, B. N. (1983). The sigma 1 protein determines the extent of spread of reovirus from the gastrointestinal tract of mice. Virology 124, 403-410.

Kobayashi, K. (1971). Studies on human secretory IgA: Comparative studies of the IgAbound secretory piece and the free secretory piece protein. Immunochemistry $\mathbf{8}, \mathbf{7 8 5 - 8 0 0 .}$

Kudo, H. \& Graham, A. F. (1966). Selective inhibition of reovirus induced RNA in L cells. Biochem Biophys Res Commun 24, 150-155.

Labrada, L., Bodelon, G., Vinuela, J. \& Benavente, J. (2002). Avian reoviruses cause apoptosis in cultured cells: viral uncoating, but not viral gene expression, is required for apoptosis induction. $J$ Virol 76, 7932-7941.

Lamm, M. E. (1997). Interaction of antigens and antibodies at mucosal surfaces. Annu Rev Microbiol 51, 311-340.

Li, K., Chen, Z., Kato, N., Gale, M., Jr. \& Lemon, S. M. (2005). Distinct poly-I: C and virus-activated signaling pathways leading to interferon-beta production in hepatocytes. $J$ Biol Chem .

Liu, Z. Q., Kunimatsu, M., Yang, J. P., Ozaki, Y., Sasaki, M. \& Okamoto, T. (1996). Proteolytic processing of nuclear factor kappa B by calpain in vitro. FEBS Lett 385, 109113. 
London, S. D., Cebra, J. J. \& Rubin, D. H. (1989). The reovirus-specific cytotoxic T cell response is not restricted to serotypically unique epitopes associated with the virus hemagglutinin

4. Microb Pathog 6, 43-50.

London, S. D., Cebra-Thomas, J. A., Rubin, D. H. \& Cebra, J. J. (1990). CD8 lymphocyte subpopulations in Peyer's patches induced by reovirus serotype 1 infection. $J$ Immunol 144, 3187-3194.

London, S. D., Rubin, D. H. \& Cebra, J. J. (1987). Gut mucosal immunization with reovirus serotype 1/L stimulates virus-specific cytotoxic $\mathrm{T}$ cell precursors as well as $\operatorname{IgA}$ memory cells in Peyer's patches. $J$ Exp Med 165, 830-847.

Major, A. S., Rubin, D. H. \& Cuff, C. F. (1998). Mucosal immunity to reovirus infection. Curr Top Microbiol Immunol 233 Reovir.ii, 163-177.

Martinez, C. G., Guinea, R., Benavente, J. \& Carrasco, L. (1996). The entry of reovirus into L cells is dependent on vacuolar proton-ATPase activity. $J$ Virol 70, 576579.

Mathers, A. R. \& Cuff, C. F. (2004). Role of interleukin-4 (IL-4) and IL-10 in serum immunoglobulin $\mathrm{G}$ antibody responses following mucosal or systemic reovirus infection. J Virol 78, 3352-3360.

Matsumoto, M., Funami, K., Tanabe, M., Oshiumi, H., Shingai, M., Seto, Y., Yamamoto, A. \& Seya, T. (2003). Subcellular localization of Toll-like receptor 3 in human dendritic cells. J Immunol 171, 3154-3162. 
Morin, M. J., Warner, A. \& Fields, B. N. (1994). A pathway for entry of retroviruses into the host through M cells of the respiratory tract. J Exp Med 180, 1523-1527.

Morin, M. J., Warner, A. \& Fields, B. N. (1996). Reovirus infection in rat lungs as a model to study the pathogenesis of viral pneumonia. $J$ Virol 70, 541-548.

Mostov, K. E. \& Deitcher, D. L. (1986). Polymeric immunoglobulin receptor expressed in MDCK cells transcytoses IgA. Cell 46, 613-621.

Murachi, T. (1989). Intracellular regulatory system involving calpain and calpastatin. Biochem Int 18, 263-294.

Musil, L. S. \& Baenziger, J. U. (1987). Cleavage of membrane secretory component to soluble secretory component occurs on the cell surface of rat hepatocyte monolayers. $J$ Cell Biol 104, 1725-1733.

Norderhaug, I. N., Johansen, F. E., Schjerven, H. \& Brandtzaeg, P. (1999).

Regulation of the formation and external transport of secretory immunoglobulins. Crit Rev Immunol 19, 481-508.

Organ, E. L. \& Rubin, D. H. (1998). Pathogenesis of reovirus gastrointestinal and hepatobiliary disease. Curr Top Microbiol Immunol 233 Reovir.ii, 67-83.

Prota, A. E., Campbell, J. A., Schelling, P., Forrest, J. C., Watson, M. J., Peters, T. R., Aurrand-Lions, M., Imhof, B. A., Dermody, T. S. \& Stehle, T. (2003). Crystal structure of human junctional adhesion molecule 1: implications for reovirus binding. Proc Natl Acad Sci U S A 100, 5366-5371. 
Rincheval-Arnold, A., Belair, L., Cencic, A. \& Djiane, J. (2002a). Up-regulation of polymeric immunoglobulin receptor mRNA in mammary epithelial cells by IFN-gamma. Mol Cell Endocrinol 194, 95-105.

Rincheval-Arnold, A., Belair, L. \& Djiane, J. (2002b). Developmental expression of pIgR gene in sheep mammary gland and hormonal regulation. J Dairy Res 69, 13-26.

Rubin, D., Weiner, H. L., Fields, B. N. \& Greene, M. I. (1981). Immunologic tolerance after oral administration of reovirus: requirement for two viral gene products for tolerance induction. J Immunol 127, 1697-1701.

Rubin, D. H., Kornstein, M. J. \& Anderson, A. O. (1985). Reovirus serotype 1 intestinal infection: a novel replicative cycle with ileal disease. $J$ Virol 53, 391-398.

Rubin, D. H., Weiner, D. B., Dworkin, C., Greene, M. I., Maul, G. G. \& Williams, W. V. (1992). Receptor utilization by reovirus type 3: distinct binding sites on thymoma and fibroblast cell lines result in differential compartmentalization of virions. Microb Pathog 12, 351-365.

Schjerven, H., Brandtzaeg, P. \& Johansen, F. E. (2000). Mechanism of IL-4-mediated up-regulation of the polymeric Ig receptor: role of STAT6 in cell type-specific delayed transcriptional response. J Immunol 165, 3898-3906.

Schjerven, H., Brandtzaeg, P. \& Johansen, F. E. (2001). A novel NF-kappa B/Rel site in intron 1 cooperates with proximal promoter elements to mediate TNF-alpha-induced transcription of the human polymeric Ig receptor. J Immunol 167, 6412-6420. 
Sharpe, A. H. \& Fields, B. N. (1981). Reovirus inhibition of cellular DNA synthesis: role of the S1 gene. J Virol 38, 389-392.

Sharpe, A. H. \& Fields, B. N. (1982). Reovirus inhibition of cellular RNA and protein synthesis: role of the S4 gene. Virology 122, 381-391.

Smith, R. E., Zweerink, H. J. \& Joklik, W. K. (1969). Polypeptide components of virions, top component and cores of reovirus type 3. Virology 39, 791-810.

Song, W., Vaerman, J. P. \& Mostov, K. E. (1995). Dimeric and tetrameric IgA are transcytosed equally by the polymeric Ig receptor. J Immunol 155, 715-721.

Strong, J. E., Coffey, M. C., Tang, D., Sabinin, P. \& Lee, P. W. (1998). The molecular basis of viral oncolysis: usurpation of the Ras signaling pathway by reovirus. EMBO J $17,3351-3362$.

Sturzenbecker, L. J., Nibert, M., Furlong, D. \& Fields, B. N. (1987). Intracellular digestion of reovirus particles requires a low $\mathrm{pH}$ and is an essential step in the viral infectious cycle. J Virol 61, 2351-2361.

Sumpter, R., Jr., Loo, Y. M., Foy, E., Li, K., Yoneyama, M., Fujita, T., Lemon, S. M. \& Gale, M., Jr. (2005). Regulating intracellular antiviral defense and permissiveness to hepatitis C virus RNA replication through a cellular RNA helicase, RIG-I. $J$ Virol 79, 2689-2699.

Tamer, C. M., Lamm, M. E., Robinson, J. K., Piskurich, J. F. \& Kaetzel, C. S. (1995). Comparative studies of transcytosis and assembly of secretory IgA in Madin- 
Darby canine kidney cells expressing human polymeric Ig receptor. J Immunol 155, 707714.

Tyler, K. L., Squier, M. K., Rodgers, S. E., Schneider, B. E., Oberhaus, S. M., Grdina, T. A., Cohen, J. J. \& Dermody, T. S. (1995). Differences in the capacity of reovirus strains to induce apoptosis are determined by the viral attachment protein sigma 1. J Virol 69, 6972-6979.

Wang, K. K. \& Yuen, P. W. (1994). Calpain inhibition: an overview of its therapeutic potential. Trends Pharmacol Sci 15, 412-419.

Weiner, H. L. \& Fields, B. N. (1977). Neutralization of reovirus: the gene responsible for the neutralization antigen. $J$ Exp Med 146, 1305-1310.

Weltzin, R., Lucia-Jandris, P., Michetti, P., Fields, B. N., Kraehenbuhl, J. P. \& Neutra, M. R. (1989). Binding and transepithelial transport of immunoglobulins by intestinal M cells: demonstration using monoclonal $\operatorname{IgA}$ antibodies against enteric viral proteins. J Cell Biol 108, 1673-1685.

Wolf, J. L., Dambrauskas, R., Sharpe, A. H. \& Trier, J. S. (1987). Adherence to and penetration of the intestinal epithelium by reovirus type 1 in neonatal mice. Gastroenterology 92, 82-91.

Wolf, J. L., Kauffman, R. S., Finberg, R., Dambrauskas, R., Fields, B. N. \& Trier, J. S. (1983). Determinants of reovirus interaction with the intestinal $M$ cells and absorptive cells of murine intestine. Gastroenterology 85, 291-300. 
Wolf, J. L., Rubin, D. H., Finberg, R., Kauffman, R. S., Sharpe, A. H., Trier, J. S. \&

Fields, B. N. (1981). Intestinal M cells: a pathway for entry of reovirus into the host.

Science 212, 471-472.

Yoshimori, T., Yamamoto, A., Moriyama, Y., Futai, M. \& Tashiro, Y. (1991).

Bafilomycin A1, a specific inhibitor of vacuolar-type H(+)-ATPase, inhibits acidification and protein degradation in lysosomes of cultured cells. J Biol Chem 266, 17707-17712.

Youngman, K. R., Fiocchi, C. \& Kaetzel, C. S. (1994). Inhibition of IFN-gamma activity in supernatants from stimulated human intestinal mononuclear cells prevents upregulation of the polymeric Ig receptor in an intestinal epithelial cell line. J Immunol 153, $675-681$.

Zweerink, H. J. \& Joklik, W. K. (1970). Studies on the intracellular synthesis of reovirus-specified proteins. Virology 41, 501-518. 


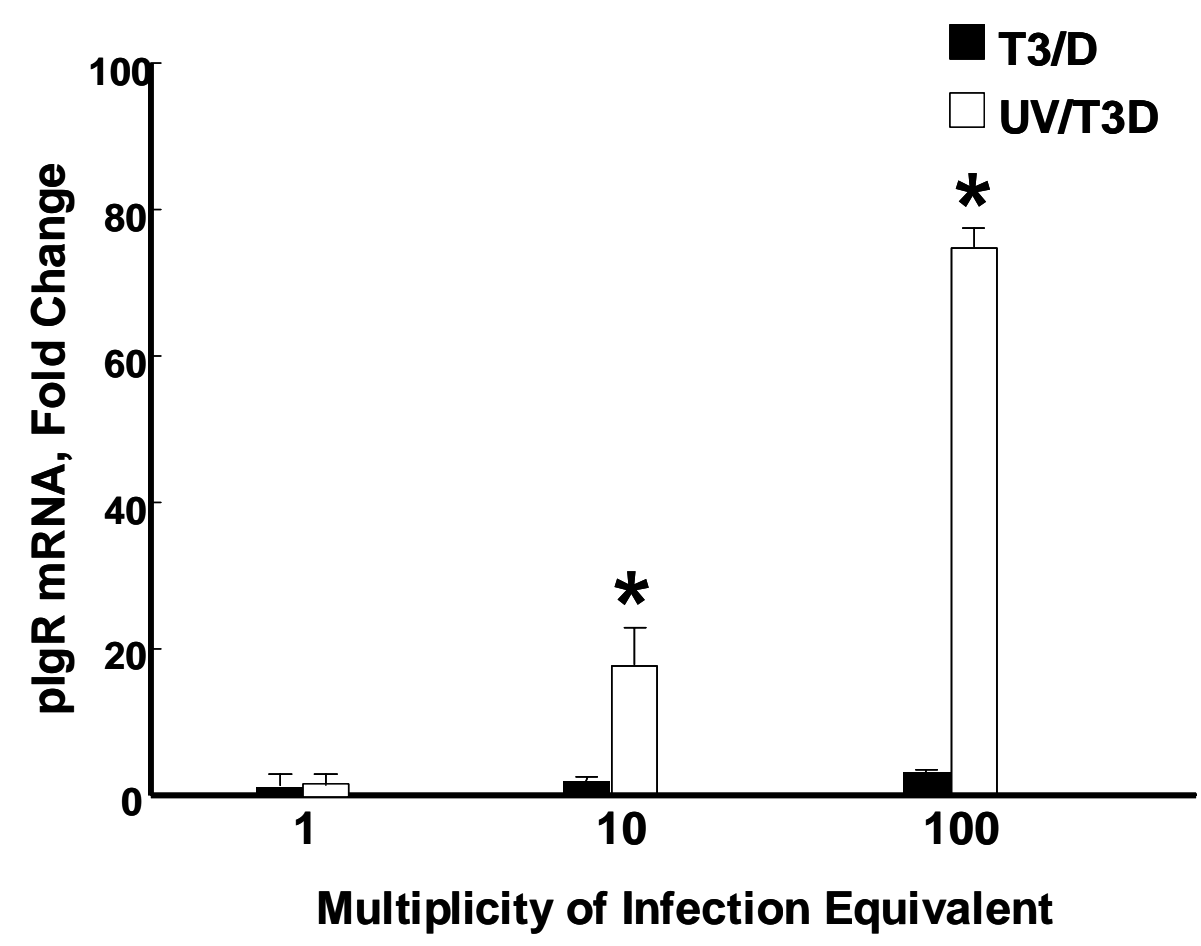

Fig. 1. Reovirus upregulates pIgR mRNA expression in HT-29 cells. Confluent monolayers of HT-29 cells were cultured at $37^{\circ} \mathrm{C}$ for 24 hours in the presence or absence of reovirus serotype 3 , strain Dearing (T3/D), (closed bars) or UV inactivated T3/D, (open bars) at multiplicities of infection (MOI) equivalents of 1, 10 and 100. Following incubation pIgR mRNA levels were quantified by real-time RT-PCR and normalized to $\beta$-actin mRNA. Samples were analyzed in duplicate. Data are expressed as fold-increases in pIgR mRNA in response to reovirus (mean \pm SEM). Data are compiled from three independent experiments. Asterisks indicate that the mean is significantly different from that of control cells (no virus) as determined by two-way ANOVA followed by Tukey's test ( $\mathrm{p}<0.050)$. 


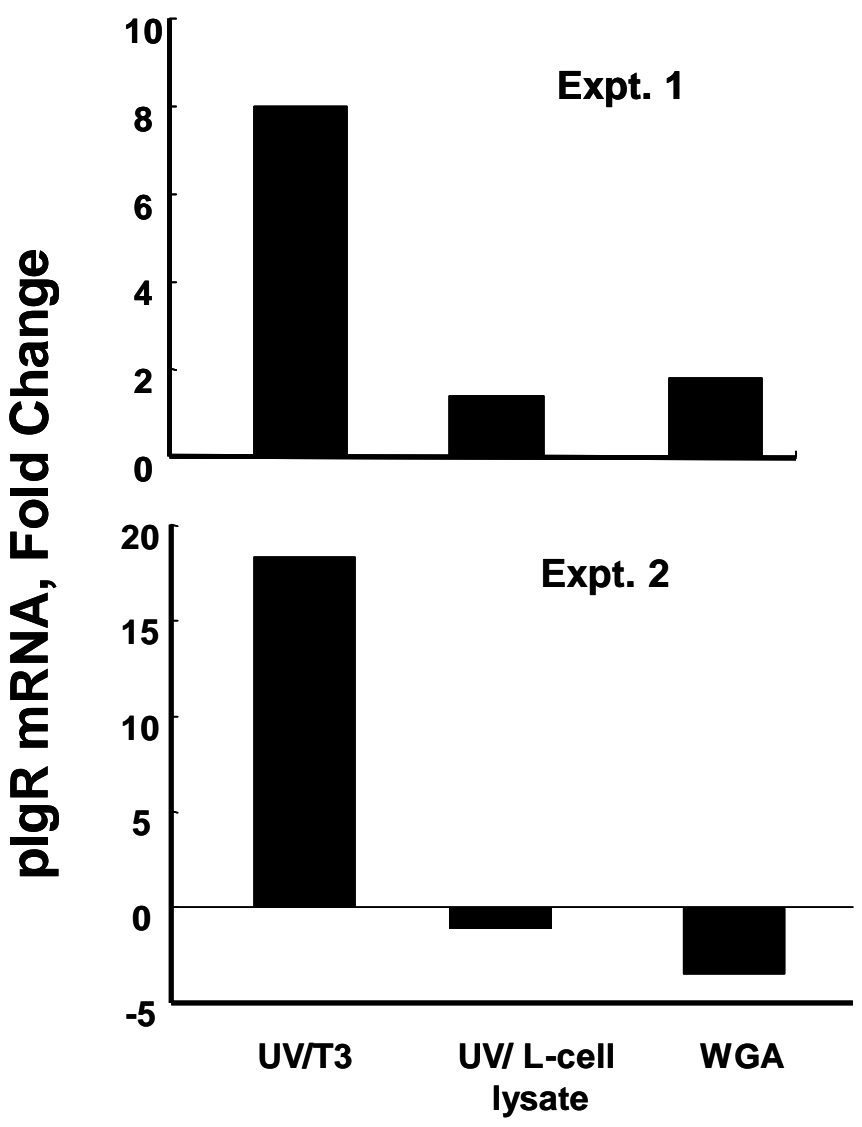

Fig. 2. UV-irradiated L-cell lysates $\left(4 \times 10^{4}\right.$ cells/ml) or wheat germ agglutinin (WGA) $(50 \mu \mathrm{g} / \mathrm{ml})$ does not upregulate pIgR mRNA expression in HT-29 cells. Confluent monolayers of HT-29 cells were cultured at $37^{\circ} \mathrm{C}$ for $24 \mathrm{~h}$ in the presence or absence of UV inactivated T3/D at MOI equivalents of 50 or UV-irradiated L-cell lysate or WGA. Following incubation pIgR mRNA levels were quantified by realtime RT-PCR and normalized to $\beta$-actin mRNA. Samples were analyzed in duplicate. Data are expressed as fold-increases in pIgR mRNA in response to reovirus or lysate or WGA. Data are from two separate independent experiments. 


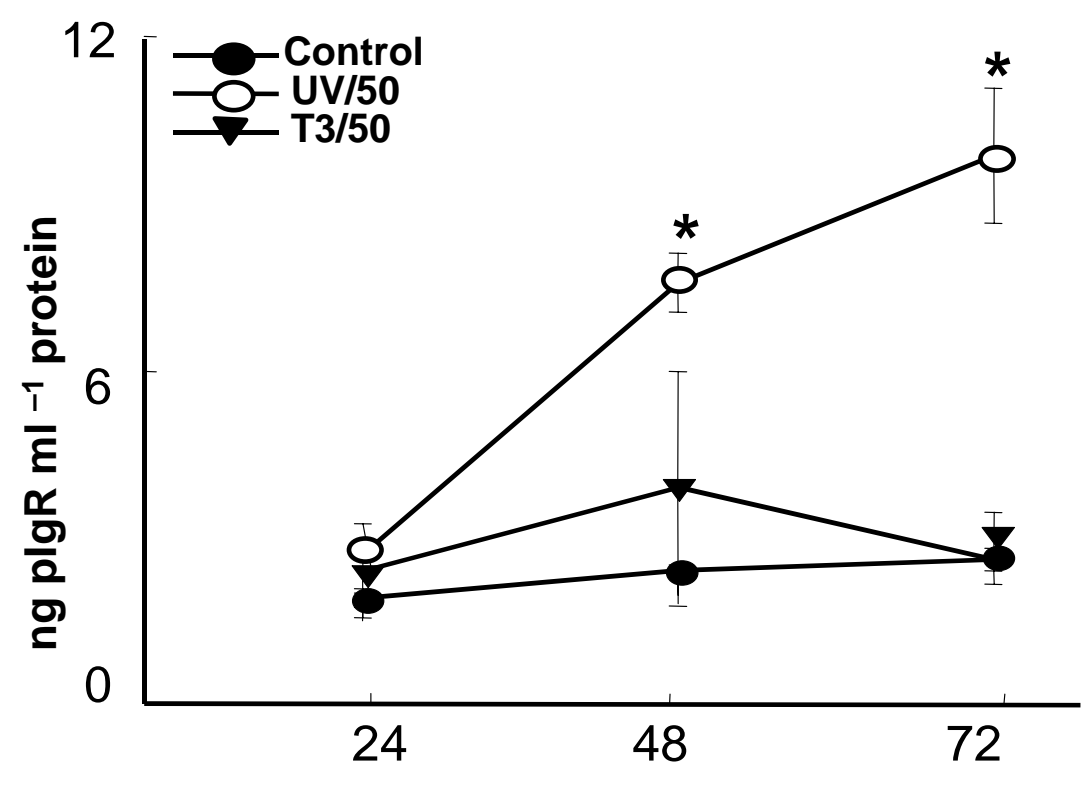

Hours post infection

Fig. 3. UV-inactivated reovirus increases pIgR protein levels in HT-29 cells. Confluent monolayers of HT-29 cells were cultured at $37^{\circ} \mathrm{C}$ for 48 hours in the presence or absence of reovirus T3/D or UVinactivated T3/D at an MOI equivalent of 50. Cells were collected at 24, 48 and 72 hours post -infection and lysed. Intracellular pIgR protein in cell lysates was measured by ELISA. Total protein concentration

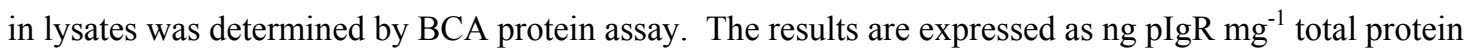
(mean $\pm \mathrm{SEM}$ ). Data are representative of three independent experiments. Asterisks indicate that the mean is significantly different from that of control cells (no virus) as determined by two-way ANOVA followed by Tukey's test $(\mathrm{p}<0.050)$. 


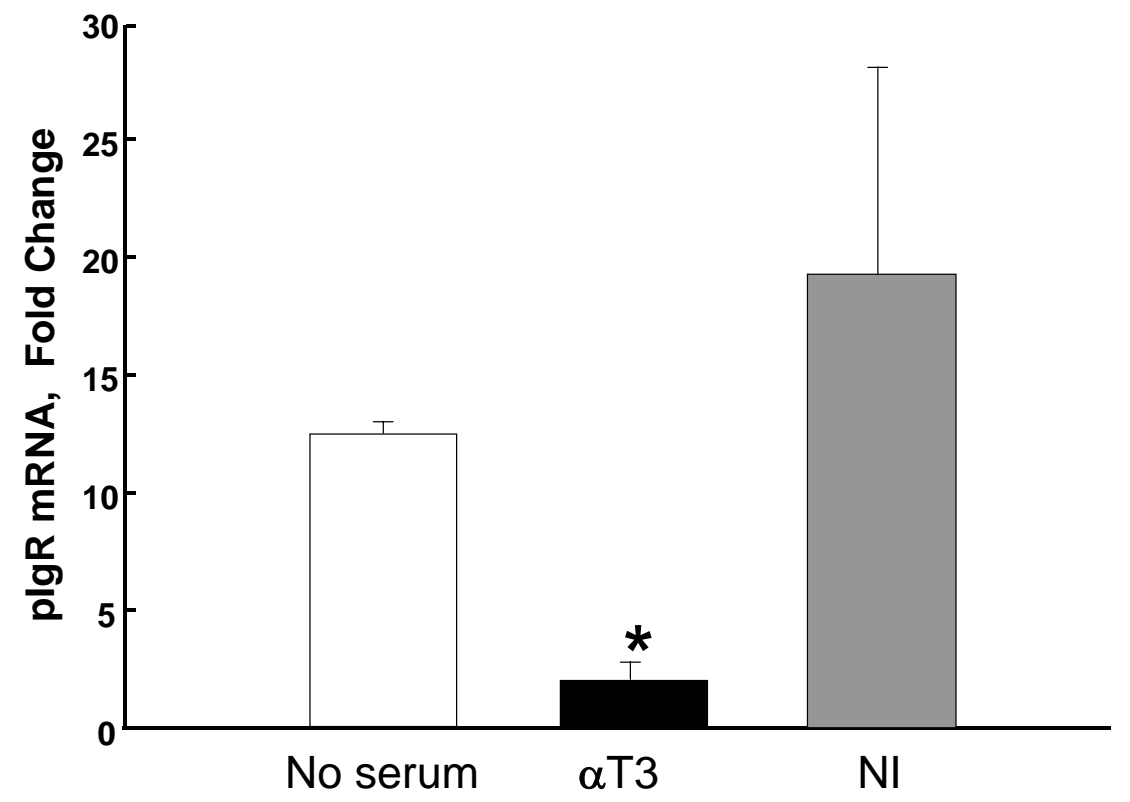

Fig. 4. Reovirus specific antibody abolishes up-regulation of pIgR mRNA in HT-29 cells. HT-29 cells were cultured in the presence or absence of UV- irradiated T3/D (MOI equivalent of 10) that had been pre-incubated for 30 minutes on ice with saline (no serum), mouse T3-immune serum ( $\alpha \mathrm{T} 3$ ) or mouse nonimmune serum (NI). pIgR mRNA levels were quantified 24 hour post exposure. Data are expressed as fold-increases in pIgR mRNA in response to reovirus (mean \pm SEM). Data are representative of three independent experiments. Asterisks indicate that the mean is significantly different from that of only virus (no serum) treated cells as determined by two-way ANOVA followed by Tukey's test $(\mathrm{p}<0.050)$. 


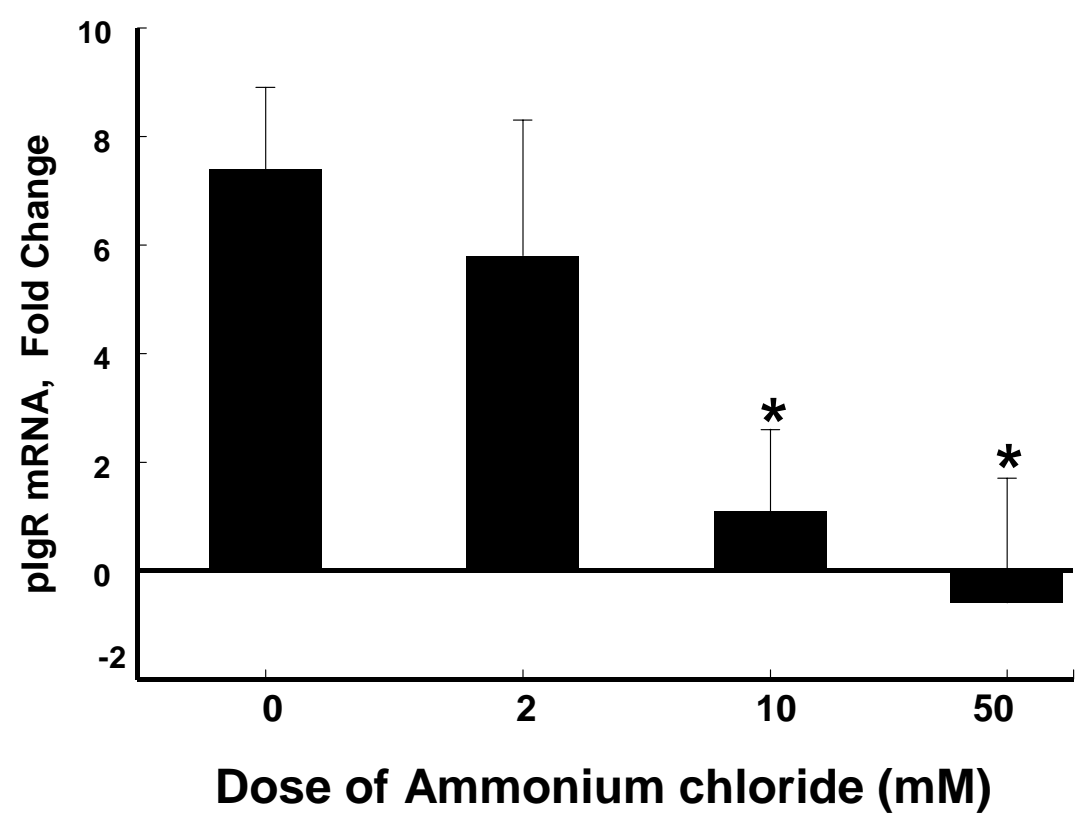

Fig. 5. Ammonium chloride blocks reovirus-mediated pIgR up-regulation in HT-29 cells. HT-29 cells were pre-treated for 90 minutes with indicated doses of ammonium chloride. Medium was then removed and cells were cultured in the presence or absence of UV-inactivated reovirus at an MOI equivalent of 50. Inhibitors were added back to each well after 1-hour incubation. pIgR mRNA levels were quantified 24 hour post exposure. Data are expressed as fold-increases in pIgR mRNA in response to virus compared to cells receiving no virus at each dose of ammonium chloride (mean $\pm \mathrm{SEM}$ ). Data are compiled from three independent experiments. Asterisks indicate that the mean is significantly different from that of control cells (no pre-treatment with ammonium chloride) as determined by one-way ANOVA followed by Orthogonal Contrast $(\mathrm{p}<0.050)$. 


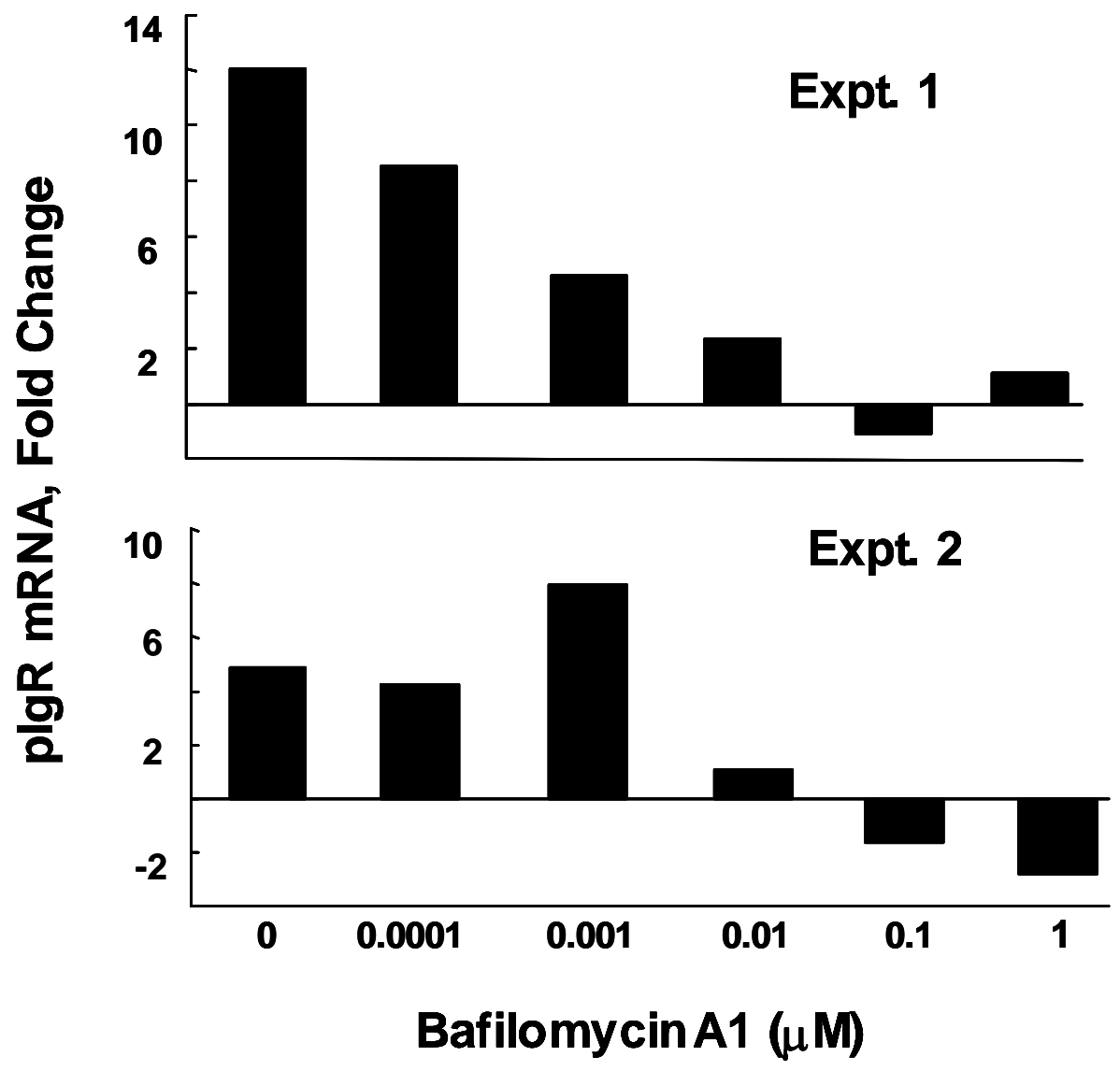

Fig. 6. Bafilomycin -A1 blocks reovirus-mediated pIgR up-regulation in HT-29 cells. HT-29 cells were pre-treated for 60 minutes with indicated doses of bafilomycin-A1. Medium containing inhibitor or (control DMSO) was then removed and cells were cultured in the presence or absence of UV-inactivated reovirus at an MOI equivalent of 50. Inhibitors were added back to each well after 1-hour incubation. Following incubation pIgR mRNA levels were quantified by real-time RT-PCR and normalized to $\beta$-actin mRNA. Samples were analyzed in duplicate. Data are expressed as fold- increases in pIgR mRNA in response to virus compared to cells receiving no virus at each dose of bafilomycin-A1. Data are from two separate independent experiments. 


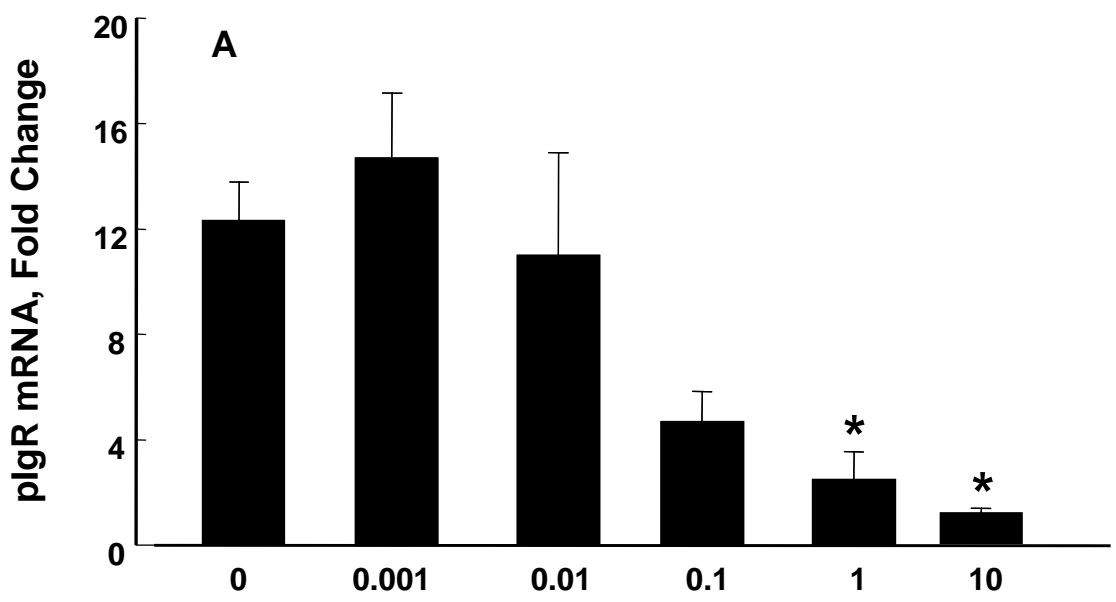

$\operatorname{aLLN}(\mu \mathrm{M})$

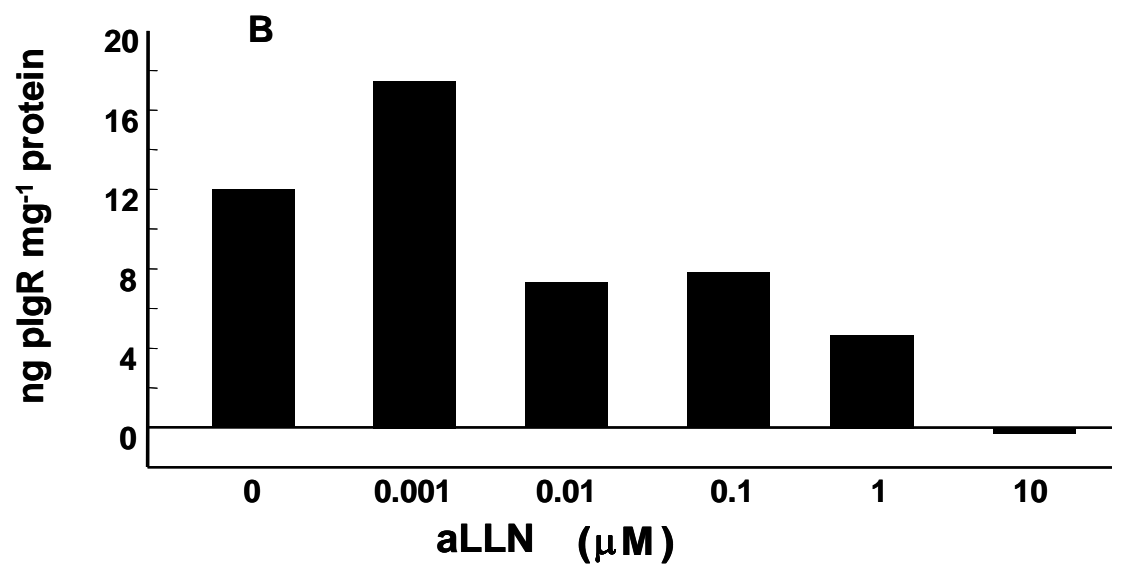

Fig. 7. Calpain inhibition abrogates reovirus-mediated pIgR up-regulation in HT-29 cells. (A) HT-

29 cells were pre-treated for 60 minutes with indicated doses of calpain inhibitor aLLN. Medium containing inhibitor (or control DMSO) was then removed, and the cells were cultured in the presence or absence of UV-inactivated reovirus at an MOI equivalent of 50. After 1 hour incubation, inhibitors were added back to each well and pIgR mRNA was quantified at $24 \mathrm{~h}$ post exposure. Data are expressed as foldincreases in pIgR mRNA in response to virus compared to cells receiving no virus at each dose of aLLN (mean \pm SEM). Data from Panel A are compiled from 3 independent experiments. Asterisks indicate that the mean is significantly different from that of control cells (no pre-treatment with aLLN) as determined by one-way ANOVA followed by Orthogonal Contrast $(\mathrm{p}<0.050)$. (B) Under identical culture conditions, cells were lysed at 48 hours post exposure to virus and pIgR protein levels were determined by ELISA. Data are from a single experiment. Data from an additional similar experiment can be found as a Supplementary Figure in JGV Online). 


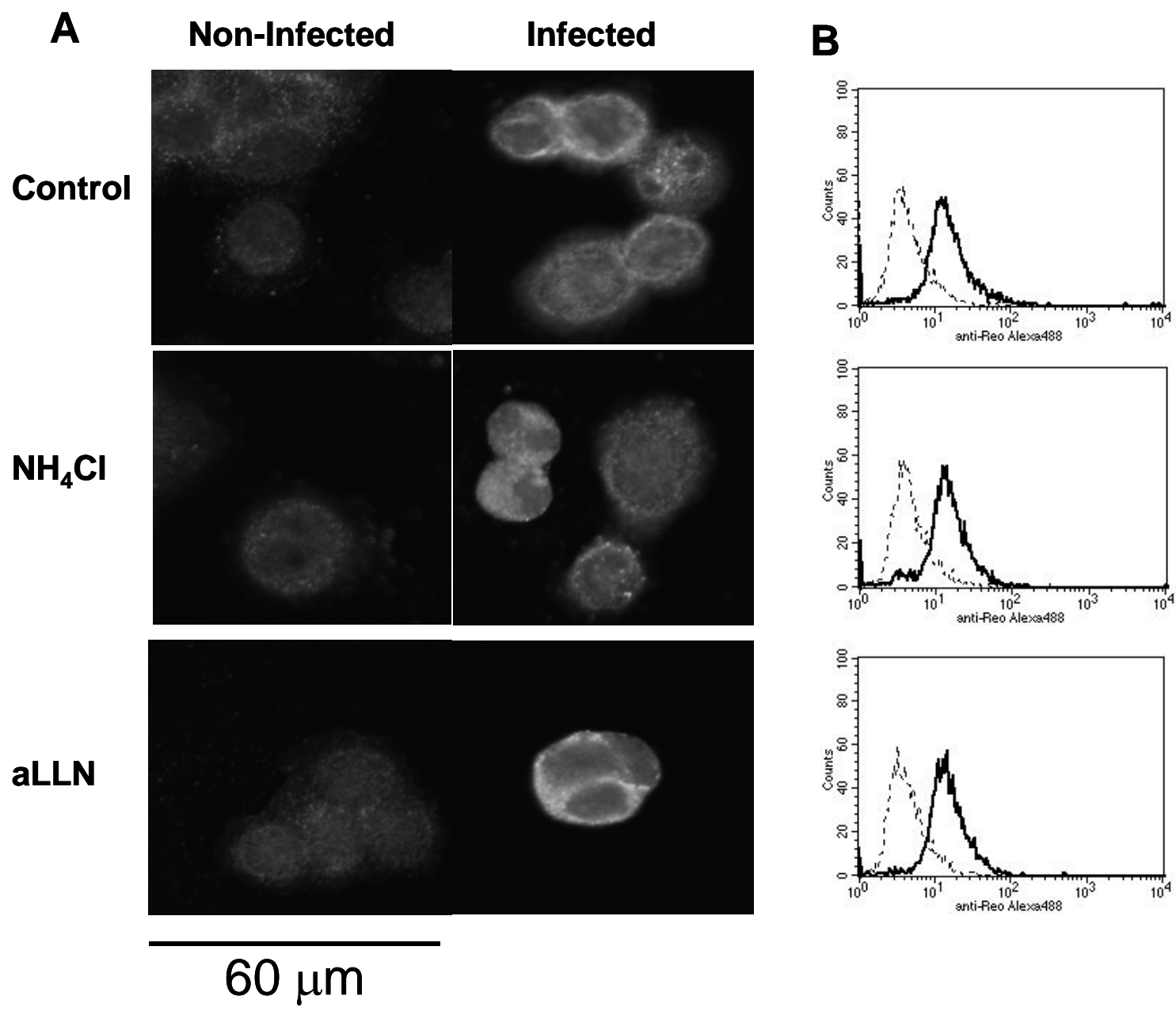

Fig. 8. Neither $\mathrm{NH}_{4} \mathrm{Cl}$ nor aLLN affect endocytosis of reovirus by HT-29 cells. (A) HT-29 cells grown on cover slips were pre-incubated for 1 hour in the presence or absence of $50 \mathrm{mM} \mathrm{NH}_{4} \mathrm{Cl}$ or $10 \mu \mathrm{M}$ ALLN at $37^{\circ} \mathrm{C}$ followed by exposure to reovirus for 30 minutes at a dose of $10^{5}$ particles /cell. Unbound virus was washed free and cells were incubated for an additional 90 minutes at $37^{\circ} \mathrm{C}$. Following incubation cells were fixed with $4 \%$ paraformaldehyde and stained with rabbit anti-reovirus followed by Alexa ${ }_{488}$-anti rabbit IgG. Intracellular staining was visualized using laser scanning confocal microscopy through multiple z planes. Images shown are taken through central planes on the cells and demonstrate perinuclear staining of virus. Each panel is approximately $60 \mu \mathrm{m}$ wide. (B) In a separate similar experiment, HT-29 cells were pre-treated with inhibitors in T-25 flasks, stripped from the flask with trypsin-EDTA, pulsed with reovirus and incubated at $37^{\circ} \mathrm{C}$ for 1 hour. Cells were then fixed, permeabilized, stained for reovirus antigen and analyzed by flow cytometry. Dashed lines indicate non-infected cells, solid line indicate reovirus-infected cells. 


\section{$\underline{\text { SUPPLEMENTAL DATA }}$}

Published in: Journal of General Virology. 2005. Volume 86(Pt 8): 2347-57. 

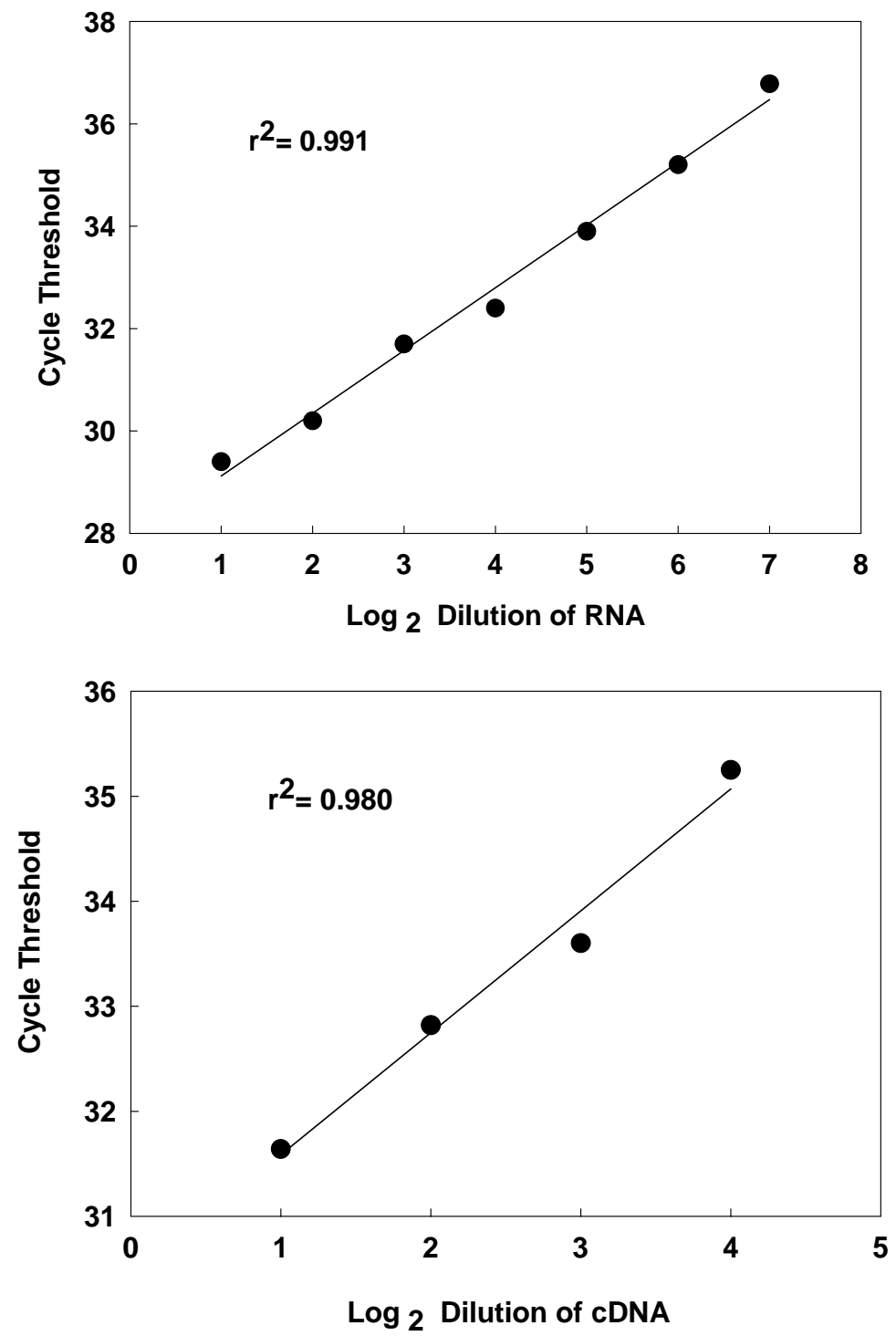

FIG S1. Linearity of RT-PCR reaction for PIgR using total mRNA and efficiency calculation of PCR reactions. (A) Total mRNA from a reovirus-stimulated HT-29 cells that contained high levels of pIgR mRNA were serially diluted in mRNA from human Jurkat cells (pIgR mRNA negative). Samples were reverse transcribed and resulting pIgR cDNA was amplified and quantitated using pIgR-specific primers. PCR products were detected with a pIgR-specific fluorescent probe as described in Methods. The cycle number that product is detected is graphed against the dilution of mRNA. Linearity of the response over a 64-fold concentration demonstrates that the reaction is quantitative and linear over a broad range of pIgR mRNA concentrations. (B) pIgR cDNA was serially diluted and amplified by PCR as described in Schjerven et al., 2000. Cycle thresholds for each sample were used to determined PCR efficiency as described in Schjerven et al.,2000. 


\section{IFN- $\gamma \quad$ UVIT3D control}

98kD plgR

Relative mRNA at

30

8

1

24 hours by RT-

Fig S2. Immunoblot analysis of pIgR protein in stimulated cells. Cells were cultured in 6-well plates and treated under the indicated conditions. Cells were treated with trypsin-EDTA, transferred to a microfuge tube, and pelleted by centrifuging at $1200 \mathrm{rpm}$ for $5 \mathrm{~min}$ at $4^{\circ} \mathrm{C}$. The cells were incubated in cell lysis buffer (1X PBS, $1 \%$ Nonidet P-40, $0.5 \%$ sodium deoxycholate, $0.1 \%$ SDS and protease inhibitors $1 \mathrm{mM}$ phenylmethylsulfonyl fluoride (PMSF) and $5 \mu \mathrm{g} \mathrm{ml}^{-1}$ aprotinin) for $20 \mathrm{~min}$ on ice, centrifuged at $12000 \mathrm{~g}$ for $15 \mathrm{~min}$ at $4^{\circ} \mathrm{C}$, and the supernatant fraction was transferred to a new microfuge tube. Total protein concentration in cell lysates was determined using the bicinchoninic acid protein assay reagent kit (Pierce Biotechnology, IL) according to the manufacturer's protocol. Equal amounts of protein $(140 \mu \mathrm{g})$ were separated on $7 \cdot 5 \%$ SDS polyacrylamide gels, transferred to nitrocellulose, and subjected to Western blot analysis using the indicated antibody. Briefly, non-specific binding was blocked by incubating the blots for $1 \mathrm{hr}$ at room temperature with non-fat dry milk (NFDM), 5\% NFDM in PBS with 0.05\% Tween 20. After each step the blots were washed four to five times for $10 \mathrm{~min}$ each with $1 \mathrm{X}$ PBS/ $0 \cdot 05 \%$ Tween

20. The blots were incubated overnight at $4^{\circ} \mathrm{C}$ with monoclonal anti-human secretory component (1: 2500, Sigma). Blots were then incubated for $1 \mathrm{hr}$ at room temperature with horseradish peroxidase (HRP)conjugated sheep anti-mouse (1:5000, Amersham Biosciences). Antibody binding was visualized using the ECL western blotting detection reagents (Amersham Biosciences, Piscataway, NJ) and film was developed in All-Pro 100 Plus X-ray Film Developer (All Pro Imaging). RT-PCR analysis from RNA samples collected 24 hours earlier indicated a 30-fold and 8-fold increase in pIgR message in IFN- $\gamma$ and reovirus treated cells over control levels. 


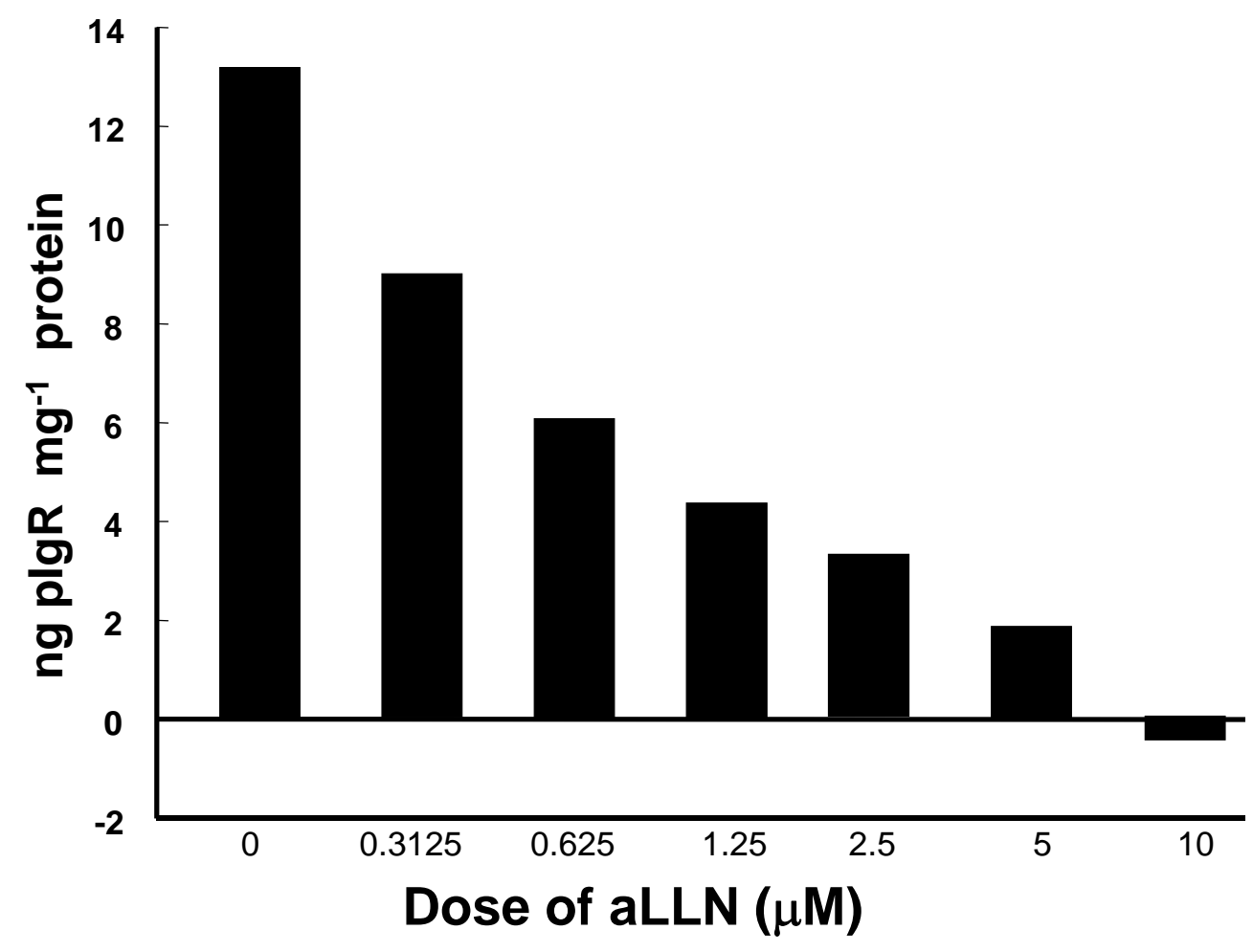

FIG. S3. Calpain inhibition ameliorates reovirus-mediated pIgR protein up-regulation in HT-29 cells. HT-29 cells were pre-treated for 60 minutes with indicated doses of calpain inhibitor aLLN. Medium containing inhibitor (or control) was then removed and the cells were cultured in the presence or absence of UV-inactivated reovirus at an MOI equivalent of 50. After 1 hour incubation, inhibitors were added back to each flask. Cells were lysed at 48 hours post exposure to virus and pIgR protein levels were determined by ELISA. 


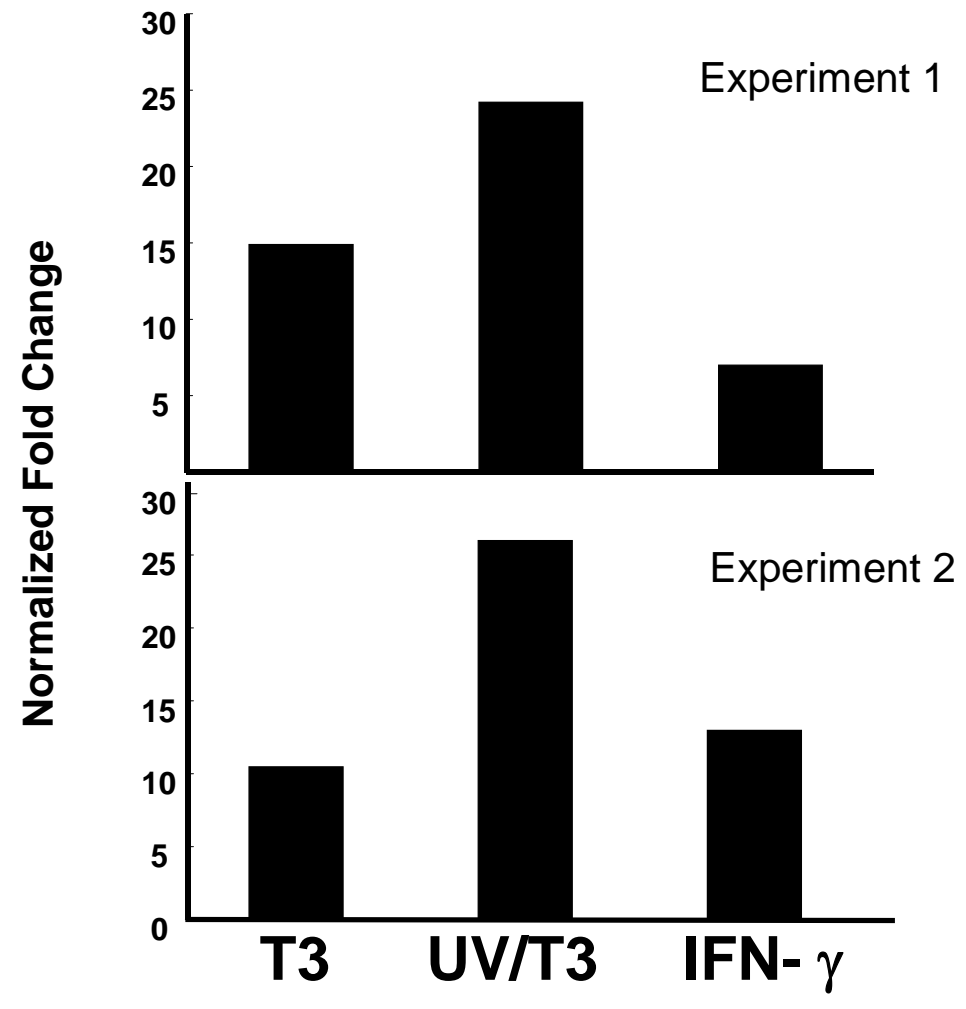

FIG. S4. Reovirus upregulates pIgR mRNA expression in Calu-3 cells. Confluent monolayers of Calu-3 cells were cultured at $37^{\circ} \mathrm{C}$ for 24 hours in the presence or absence of reovirus serotype 3 , strain Dearing (T3), UV inactivated T3, or IFN- $\gamma$ for $24 \mathrm{~h}$. Following incubation pIgR mRNA levels were quantified by real-time RT-PCR and normalized to $\beta$-actin mRNA. 


\title{
CHAPTER 3: ROLE OF NUCLEAR FACTOR KAPPA B (NFKB) IN REOVIRUS-MEDIATED UPREGULATION OF POLYMERIC IMMUNOGLOBULIN RECEPTOR EXPRESSION
}

\author{
KASTURI PAL ${ }^{1}$, MARIA E.C. BRUNO ${ }^{2}$, CHARLOTTE S. KAETZEL ${ }^{2}$ AND \\ CHRISTOPHER F. CUFF ${ }^{1} *$ \\ ${ }^{1}$ Department of Microbiology, Immunology and Cell Biology \\ Robert C. Byrd Health Sciences Center, West Virginia University \\ Morgantown, West Virginia, USA 26506-9177 \\ ${ }^{2}$ Department of Microbiology, Immunology and Molecular Genetics, \\ University of Kentucky, Lexington, Kentucky, 40536.
}

Used with permission from the authors 


\section{SUMMARY}

The role of nuclear factor kappa $\mathrm{B}(\mathrm{NF} \kappa \mathrm{B})$ in reovirus -induced polymeric immunoglobulin receptor (pIgR) upregulation in HT-29 intestinal epithelial cells was examined. Helenalin, a chemical inhibitor of NFKB activation, inhibited reovirusmediated pIgR mRNA and protein upregulation. Expression of dominant negative $\mathrm{I} \kappa \mathrm{B} \alpha$ blocked the ability of reovirus to upregulate pIgR mRNA. Reovirus increased transcriptional activity by reporter plasmids that contained a functional NFKB and interferon regulatory factor-1 (IRF-1) binding site from intron 1 and exon 1 of the PIGR gene respectively, but not by plasmids containing either one or both mutations. Together, these findings suggest that reovirus activates PIGR gene transcription by binding activated NFkB and IRF-1 to their respective cognate sites of the pIgR promoter. 
Secretory immunoglobulin A (sIgA) is the first line of specific immunological defense at mucosal surfaces (Lamm, 1997; Brandtzaeg et al., 1997; Kato et al., 2001). Dimeric IgA and larger polymers of IgA and IgM bind to polymeric immunoglobulin (pIg) receptor (pIgR) basolaterally on mucosal epithelial cells, and are transcytosed through the epithelium (Brandtzaeg, 1978; Brandtzaeg, 1985; Apodaca et al., 1994; Brandtzaeg et al., 1997; Kaetzel, 2005). At the apical surface, the pIgR -pIg complex or the empty receptor is proteolytically cleaved close to its transmembrane domain, releasing secretory IgA or the free secretory component into luminal secretions (Musil \& Baenziger, 1987). Because one molecule of pIgR is required for every molecule of transported polymeric immunoglobulin, synthesis of pIgR by epithelial cells is a rate-limiting step for generation of secretory $\mathrm{pIg}$. In addition to transporting IgA, free secretory component protects sIgA from proteolytic degradation and can inhibit binding of pathogens including Escherichia coli, Streptococcus pneumoniae, and bacterial toxins to the epithelium (Giugliano et al., 1995; Hammerschmidt et al., 1997; Dallas \& Rolfe, 1998; Hammerschmidt et al., 2000; de Araujo \& Giugliano, 2001; Kaetzel, 2005). Using pIgR knockout mice, Uren et al. reinforced the importance of $\mathrm{pIgR} / \mathrm{sIgA}$ for the protection of gastrointestinal surfaces against secreted bacterial toxins including cholera toxin. However, pIgR / sIgA was found to be dispensable for protection against infection with Salmonella typhimurium or Citrobacter rodentium (Uren et al., 2005). Sun et al. demonstrated the critical role of $\mathrm{p} \operatorname{IgR} / \operatorname{sIg} \mathrm{A}$ in protection against nasal colonization by $S$. pneumoniae in pIgR knockout mice (Sun et al., 2004). 
Expression of pIgR can be modulated by a variety of environmental stimuli including proinflammatory cytokines, hormones and commensal bacteria. Cytokines including gamma interferon (IFN- $\gamma$ ), tumour necrosis factor-alpha (TNF- $\alpha$ ), interleukin (IL)- 4, and IL-1 upregulate pIgR expression in epithelial cells (Schjerven et al., 2001; Ackermann \& Denning, 2004; Schjerven et al., 2004). Several hormones including estrogen, progesterone, androgens, glucocorticoids and prolactin also regulate pIgR expression (Bjercke \& Brandtzaeg, 1993; Kaushic et al., 1995; Chapman et al., 2000; Claessens et al., 2001; Yu-Lee, 2001; Rincheval-Arnold et al., 2002a; Rincheval-Arnold et al., 2002b). PIgR expression was increased in germfree mice following colonization with commensal Bacteroides thetaiotaomicron (Hooper et al., 2001) and following weaning, a time in which normal bacterial flora is established in mice (Jenkins et al., 2003). Microbial products such as bacterial lipopolysaccharide (LPS) and poly I:C, a chemical analog of viral double stranded RNA, also induced pIgR upregulation in HT-29 cells (Schneeman et al., 2005). In addition, chronic mucosal disorders including celiac disease, Helicobacter pylori gastritis, and Sjogren's syndrome increase pIgR synthesis (Brandtzaeg et al., 1992). Taken together, these studies suggest that pIgR contributes to maintaining the integrity of the mucosal barrier and regulation of receptor expression is a developmental response by epithelial cells that contributes to host defense.

Mammalian orthoreovirus (reovirus) infects the mucosa in a wide variety of mammalian species including mice and humans. Reovirus infection initiates a number of signaling cascades in host cells including increased activation of calpains (Debiasi et al., 1999; Debiasi et al., 2001), activation of c-Jun N-terminal kinase (JNK), and extracellular 
signal-related kinase (ERK) (Clarke et al., 2001). These signaling cascades result in upregulation of NFkB activation (Tyler et al., 1995; Connolly et al., 2000; Hamamdzic et al., 2001) and phosphorylation of c-Jun (Clarke et al., 2001). Significantly, most or all of these changes in cell signaling in vitro occur independently of viral replication in as much as UV-inactivated virus mediates the observed effects (Rubin et al., 1981; Tyler et al., 1995; Debiasi et al., 1999; Hamamdzic et al., 2001; Pal et al., 2005). Other steps during infection such as binding to specific receptors, endocytosis and uncoating, and cellular exposure to viral RNA also appear to affect host cell biology (Barton et al., 2001; Hamamdzic et al., 2001; Pal et al., 2005).

Reovirus upregulates pIgR mRNA and protein in transformed human intestinal epithelial HT-29 cells (Pal et al., 2005). This report examines the role of NFkB in reovirus induced pIgR upregulation. To determine whether NFкB activation is necessary for reovirus-mediated upregulation of pIgR, HT-29 cells were pre-treated for 1 hour with the NFאB inhibitor helenalin (Sigma, St. Louis, MO) at doses of 0.001 to $10 \mu \mathrm{M}$, or vehicle control DMSO. Helenalin specifically alkylates the p65 subunit of NFאB, rendering it incapable of binding to DNA. Inhibitor containing media was then removed and cells were cultured for 1 hour in the presence or absence of UV-inactivated reovirus serotype 3, strain Dearing (T3/D). Following incubation, inhibitors were added back to each well and pIgR mRNA was measured by real time reverse transcriptase (RT) PCR 24 hours after exposure to virus. Virus-mediated upregulation of pIgR mRNA was inhibited by helenalin in a dose-dependent manner (Fig. 1A). Under similar culture conditions, 1-10 $\mu \mathrm{M}$ helenalin blocked virus-mediated increase in intracellular pIgR protein as determined 
by ELISA (Fig. 1B). To further test the hypothesis that NFkB is involved in virusmediated pIgR upregulation, HT-29 cells were infected with recombinant adenovirus that over-expresses a dominant negative form of $\mathrm{I} \kappa \mathrm{B} \alpha(\mathrm{I} \mathrm{KBdn})$ that lacks two serine residues and cannot be phosphorylated. As a control for transfection efficiency cells were infected with an adenovirus vector expressing $\beta$-galactosidase (AdLacZ) (University of Iowa Gene Therapy Vector Core Facility, Iowa). 24 h later, confluent monolayers of HT-29 cells were cultured at $37^{\circ} \mathrm{C}$ for $24 \mathrm{~h}$ in the presence or absence of $\mathrm{UV}$-inactivated T3/D. The dominant negative construct has been previously shown to block cytokine-induced upregulation of pIgR (Ackermann \& Denning, 2004). The dominant negative mutant blocked the ability of UV-inactivated reovirus to upregulate pIgR mRNA when compared to cells transfected with a control adenovirus vector (AdLacZ), which also accounts for transfection efficiency (Fig. 2). To further examine whether reovirus can upregulate PIGR gene expression through NFKB or interferon regulatory factor -1 (IRF-1) mediated transcriptional activation, HT-29 cells were transfected for 2 hours with $1 \mu \mathrm{g}$ of wild type (WT), mutant plasmids or promoter-less (control) as indicated. 24 hours posttransfection, cells were cultured at $37^{\circ} \mathrm{C}$ in the presence or absence of UV-inactivated T3/D for another 24 hours. In these plasmids, transcription of the firefly luciferase reporter gene is driven by an $8.6 \mathrm{~kb}$ fragment of the human PIGR gene, including 2684 bp of 5' -flanking sequence, exon 1 (132 bp), intron 1 (5751 bp), and the first $56 \mathrm{bp}$ of exon 2, up to and including the translation start site (Schneeman et al., 2005). The 'NFkB mutant' plasmid contains a mutation that abolishes an $\mathrm{NF \kappa B}$-binding site in intron 1; the 'IRF-1 mutant' plasmid contains a mutation that abolishes an IRF-1 binding site in exon 1 , and the 'double mutant' plasmid contains both mutation. These mutations have been 
previously shown to inhibit TNF- $\alpha$ (Schjerven et al., 2001) and poly I: C (Schneeman et al., 2005)-induced activation of PIGR gene transcription. As a control for transfection efficiency, cells were co-transfected with 5 ng of pRL-CMV (Promega, Madison, WI, USA), in which the CMV promoter drives transcription of the Renilla luciferase gene. Cell lysates were analyzed for firefly and Renilla activities using the 'Dual- Luciferase Reporter Assay System' according to the manufacturer's protocol (Promega, Madison, WI, USA). Reovirus increased transcriptional activity from WT plasmid, but not from the mutant NFאB, mutant IRF-1 and double mutant plasmids (Fig. 3). Taken together, studies with the chemical inhibitor helenalin, the dominant negative mutant for IкB $\alpha$, and reporter gene promoter analysis suggest that reovirus activates PIGR gene transcription by binding of activated NFKB to its cognate site in intron 1 of pIgR promoter. Also, results using IRF-1 mutant and double negative mutant plasmids suggest that upregulation of PIGR gene transcription by reovirus involves co-operativity between IRF-1 and NFKB.

Activation of NFKB in the cytoplasm involves the inducible phosphorylation of its repressor IאB in response to stimuli, which then undergoes ubiquitin-mediated proteolysis, releasing $\mathrm{NF \kappa B}$ dimers to translocate to nucleus and bind target genes (DiDonato et al., 1995; Barnes \& Karin, 1997; May \& Ghosh, 1998). Studies with enteroinvasive bacteria have shown that signal transduction through $\mathrm{NF \kappa B}$ is a central regulator of innate immune responses triggered by the epithelium (Seydel et al., 1998; Elewaut et al., 1999). Reovirus could activate NFkB either directly or by a calpainmediated pathway (Debiasi et al., 1999; Connolly et al., 2000; Hamamdzic et al., 2001), 
and calpains have been shown to be critical for reovirus -mediated pIgR upregulation (Pal et al., 2005). However, it is possible that NFKB can be activated by other signals during reovirus infection of host cells including virus dsRNA and/or interferon- $\beta$ (IFN$\beta$ ). Future studies may reveal the role of IRF-3, dsRNA-Toll like receptor-3 (TLR3)dependent, or TLR3-independent pathways including RNA helicases retinoic acidinducible gene-1 (RIG-1) (Li et al., 2005; Sumpter, Jr. et al., 2005) or melanoma differentiation-associated gene 5 (mda-5)(Kang et al., 2002; Andrejeva et al., 2004) in virus-mediated $\mathrm{pIgR}$ upregulation. The present study suggests a phenomenon of IRF$\mathrm{NF \kappa B}$ synergy in reovirus-induced transcriptional activation. It is reasonable to speculate that the two sites act cooperatively such that an NFkB family member interacts with an IRF family member, perhaps IRF-3, to activate transcription of the pIgR gene as has been reported for the activation of the beta interferon (IFN- $\beta$ ) gene (Maniatis et al., 1998). Hempen et al. have suggested a complex model for the basal transcriptional regulation of human PIGR gene that involves cooperative binding among multiple transcription factors, including upstream stimulatory factor (USF) and AP2 (Hempen et al., 2002). Interestingly, during immune or inflammatory responses, basal regulatory factors may interact with various other inducible factors including NFkB, IRF-1 and STAT-6 to upregulate PIGR gene transcription. This study corroborates the importance of a central NFkB pathway in modulating immune responses by demonstrating its role in the upregulation of pIgR from epithelial cells against reovirus using three experimental approaches. Other pathways may also be involved. 
We are grateful to Finn-Eirik Johansen (Laboratory for Immunohistochemistry and Immunopathology (LIIPAT), Institute and Department of Pathology, University of Oslo, Rikshospitalet University Hospital, Oslo, Norway) for providing the PIGR gene reporter plasmids. This research was supported by grants AI034544, RR16440 (C.F.C.) and CA051998 (C.S.K.) from the National Institutes of Health, and by the National Cell Culture Center (Minneapolis, Minn.). The authors thank Dr. Gerald Hobbes (WVU) for advice on statistical analyses. 


\section{REFERENCES}

1. Ackermann, L. W. \& Denning, G. M. (2004). Nuclear factor-kappaB contributes to interleukin-4- and interferon-dependent polymeric immunoglobulin receptor expression in human intestinal epithelial cells. Immunology 111, 75-85.

2. Andrejeva, J., Childs, K. S., Young, D. F., Carlos, T. S., Stock, N., Goodbourn, S. \& Randall, R. E. (2004). The V proteins of paramyxoviruses bind the IFNinducible RNA helicase, mda-5, and inhibit its activation of the IFN-beta promoter. Proc Natl Acad Sci U S A 101, 17264-17269.

3. Apodaca, G., Katz, L. A. \& Mostov, K. E. (1994). Receptor-mediated transcytosis of IgA in MDCK cells is via apical recycling endosomes. $J$ Cell Biol 125, 67-86.

4. Barnes, P. J. \& Karin, M. (1997). Nuclear factor-kappaB: a pivotal transcription factor in chronic inflammatory diseases. $N$ Engl J Med 336, 1066-1071.

5. Barton, E. S., Chappell, J. D., Connolly, J. L., Forrest, J. C. \& Dermody, T. S. (2001). Reovirus receptors and apoptosis. Virology 290, 173-180.

6. Bjercke, S. \& Brandtzaeg, P. (1993). Glandular distribution of immunoglobulins, J chain, secretory component, and HLA-DR in the human endometrium throughout the menstrual cycle. Hum Reprod 8, 1420-1425.

7. Brandtzaeg, P. (1978). Polymeric IgA is complexed with secretory component (SC) on the surface of human intestinal epithelial cells. Scand J Immunol 8, 39-52. 
8. Brandtzaeg, P. (1985). Role of J chain and secretory component in receptormediated glandular and hepatic transport of immunoglobulins in man. Scand $J$ Immunol 22, 111-146.

9. Brandtzaeg, P., Berstad, A. E., Farstad, I. N., Haraldsen, G., Helgeland, L., Jahnsen, F. L., Johansen, F. E., Natvig, I. B., Nilsen, E. M. \& Rugtveit, J. (1997). Mucosal immunity--a major adaptive defence mechanism. Behring Inst Mitt $1-23$.

10. Brandtzaeg, P., Halstensen, T. S., Huitfeldt, H. S., Krajci, P., Kvale, D., Scott, H. \& Thrane, P. S. (1992). Epithelial expression of HLA, secretory component (poly-Ig receptor), and adhesion molecules in the human alimentary tract. Ann NY Acad Sci 664, 157-179.

11. Chapman, R. S., Duff, E. K., Lourenco, P. C., Tonner, E., Flint, D. J., Clarke, A. R. \& Watson, C. J. (2000). A novel role for IRF-1 as a suppressor of apoptosis. Oncogene 19, 6386-6391.

12. Claessens, F., Verrijdt, G., Schoenmakers, E., Haelens, A., Peeters, B., Verhoeven, G. \& Rombauts, W. (2001). Selective DNA binding by the androgen receptor as a mechanism for hormone-specific gene regulation. J Steroid Biochem Mol Biol 76, 23-30.

13. Clarke, P., Meintzer, S. M., Widmann, C., Johnson, G. L. \& Tyler, K. L. (2001). Reovirus infection activates JNK and the JNK-dependent transcription factor c-Jun. $J$ Virol 75, 11275-11283. 
14. Connolly, J. L., Rodgers, S. E., Clarke, P., Ballard, D. W., Kerr, L. D., Tyler, K. L. \& Dermody, T. S. (2000). Reovirus-induced apoptosis requires activation of transcription factor NF-kappaB. J Virol 74, 2981-2989.

15. Dallas, S. D. \& Rolfe, R. D. (1998). Binding of Clostridium difficile toxin A to human milk secretory component. J Med Microbiol 47, 879-888.

16. de Araujo, A. N. \& Giugliano, L. G. (2001). Lactoferrin and free secretory component of human milk inhibit the adhesion of enteropathogenic Escherichia coli to HeLa cells. BMC Microbiol 1, 25.

17. Debiasi, R. L., Edelstein, C. L., Sherry, B. \& Tyler, K. L. (2001). Calpain inhibition protects against virus-induced apoptotic myocardial injury. J Virol 75, $351-361$.

18. Debiasi, R. L., Squier, M. K., Pike, B., Wynes, M., Dermody, T. S., Cohen, J. J. \& Tyler, K. L. (1999). Reovirus-induced apoptosis is preceded by increased cellular calpain activity and is blocked by calpain inhibitors. $J$ Virol 73, 695-701.

19. DiDonato, J. A., Mercurio, F. \& Karin, M. (1995). Phosphorylation of I kappa B alpha precedes but is not sufficient for its dissociation from NF-kappa B. Mol Cell Biol 15, 1302-1311.

20. Elewaut, D., DiDonato, J. A., Kim, J. M., Truong, F., Eckmann, L. \& Kagnoff, M. F. (1999). NF-kappa B is a central regulator of the intestinal epithelial cell innate immune response induced by infection with enteroinvasive bacteria. $J$ Immunol 163, 1457-1466. 
21. Giugliano, L. G., Ribeiro, S. T., Vainstein, M. H. \& Ulhoa, C. J. (1995). Free secretory component and lactoferrin of human milk inhibit the adhesion of enterotoxigenic Escherichia coli. J Med Microbiol 42, 3-9.

22. Hamamdzic, D., Phillips-Dorsett, T., Altman-Hamamdzic, S., London, S. D. \& London, L. (2001). Reovirus triggers cell type-specific proinflammatory responses dependent on the autocrine action of IFN-beta. Am J Physiol Lung Cell Mol Physiol 280, L18-L29.

23. Hammerschmidt, S., Talay, S. R., Brandtzaeg, P. \& Chhatwal, G. S. (1997). SpsA, a novel pneumococcal surface protein with specific binding to secretory immunoglobulin A and secretory component. Mol Microbiol 25, 1113-1124.

24. Hammerschmidt, S., Tillig, M. P., Wolff, S., Vaerman, J. P. \& Chhatwal, G. S. (2000). Species-specific binding of human secretory component to SpsA protein of Streptococcus pneumoniae via a hexapeptide motif. Mol Microbiol 36, 726-736.

25. Hempen, P. M., Phillips, K. M., Conway, P. S., Sandoval, K. H., Schneeman, T. A., Wu, H. J. \& Kaetzel, C. S. (2002). Transcriptional regulation of the human polymeric Ig receptor gene: analysis of basal promoter elements. J Immunol 169, 1912-1921.

26. Hooper, L. V., Wong, M. H., Thelin, A., Hansson, L., Falk, P. G. \& Gordon, J. I. (2001). Molecular analysis of commensal host-microbial relationships in the intestine. Science 291, 881-884. 
27. Jenkins, S. L., Wang, J., Vazir, M., Vela, J., Sahagun, O., Gabbay, P., Hoang, L., Diaz, R. L., Aranda, R. \& Martin, M. G. (2003). Role of passive and adaptive immunity in influencing enterocyte-specific gene expression. Am J Physiol Gastrointest Liver Physiol 285, G714-G725.

28. Kaetzel, C. S. (2005). The polymeric immunoglobulin receptor: bridging innate and adaptive immune responses at mucosal surfaces. Immunol Rev 206, 83-99.

29. Kang, D. C., Gopalkrishnan, R. V., Wu, Q., Jankowsky, E., Pyle, A. M. \& Fisher, P. B. (2002). mda-5: An interferon-inducible putative RNA helicase with double-stranded RNA-dependent ATPase activity and melanoma growthsuppressive properties. Proc Natl Acad Sci U S A 99, 637-642.

30. Kato, H., Kato, R., Fujihashi, K. \& McGhee, J. R. (2001). Role of mucosal antibodies in viral infections. Curr Top Microbiol Immunol 260, 201-228.

31. Kaushic, C., Richardson, J. M. \& Wira, C. R. (1995). Regulation of polymeric immunoglobulin A receptor messenger ribonucleic acid expression in rodent uteri: effect of sex hormones. Endocrinology 136, 2836-2844.

32. Lamm, M. E. (1997). Interaction of antigens and antibodies at mucosal surfaces. Annu Rev Microbiol 51, 311-340.

33. Li, K., Chen, Z., Kato, N., Gale, M., Jr. \& Lemon, S. M. (2005). Distinct poly-I: $\mathrm{C}$ and virus-activated signaling pathways leading to interferon-beta production in hepatocytes. J Biol Chem . 
34. Maniatis, T., Falvo, J. V., Kim, T. H., Kim, T. K., Lin, C. H., Parekh, B. S. \& Wathelet, M. G. (1998). Structure and function of the interferon-beta enhanceosome. Cold Spring Harb Symp Quant Biol 63, 609-620.

35. May, M. J. \& Ghosh, S. (1998). Signal transduction through NF-kappa B. Immunol Today 19, 80-88.

36. Musil, L. S. \& Baenziger, J. U. (1987). Cleavage of membrane secretory component to soluble secretory component occurs on the cell surface of rat hepatocyte monolayers. J Cell Biol 104, 1725-1733.

37. Pal, K., Kaetzel, C. S., Brundage, K., Cunningham, C. A. \& Cuff, C. F. (2005). Regulation of polymeric immunoglobulin receptor expression by reovirus. J Gen Virol 86, 2347-2357.

38. Rincheval-Arnold, A., Belair, L., Cencic, A. \& Djiane, J. (2002a). Up-regulation of polymeric immunoglobulin receptor mRNA in mammary epithelial cells by IFNgamma. Mol Cell Endocrinol 194, 95-105.

39. Rincheval-Arnold, A., Belair, L. \& Djiane, J. (2002b). Developmental expression of pIgR gene in sheep mammary gland and hormonal regulation. J Dairy Res 69, 13-26.

40. Rubin, D., Weiner, H. L., Fields, B. N. \& Greene, M. I. (1981). Immunologic tolerance after oral administration of reovirus: requirement for two viral gene products for tolerance induction. J Immunol 127, 1697-1701. 
41. Schjerven, H., Brandtzaeg, P. \& Johansen, F. E. (2001). A novel NF-kappa $\mathrm{B} / \mathrm{Rel}$ site in intron 1 cooperates with proximal promoter elements to mediate TNFalpha-induced transcription of the human polymeric Ig receptor. J Immunol 167, 6412-6420.

42. Schjerven, H., Tran, T. N., Brandtzaeg, P. \& Johansen, F. E. (2004). De novo synthesized RelB mediates TNF-induced up-regulation of the human polymeric Ig receptor. J Immunol 173, 1849-1857.

43. Schneeman, T. A., Bruno, M. E., Schjerven, H., Johansen, F. E., Chady, L. \& Kaetzel, C. S. (2005). Regulation of the polymeric Ig receptor by signaling through TLRs 3 and 4: linking innate and adaptive immune response. J Immunol 175, 376384.

44. Seydel, K. B., Li, E., Zhang, Z. \& Stanley, S. L., Jr. (1998). Epithelial cellinitiated inflammation plays a crucial role in early tissue damage in amebic infection of human intestine. Gastroenterology 115, 1446-1453.

45. Sumpter, R., Jr., Loo, Y. M., Foy, E., Li, K., Yoneyama, M., Fujita, T., Lemon, S. M. \& Gale, M., Jr. (2005). Regulating intracellular antiviral defense and permissiveness to hepatitis $\mathrm{C}$ virus RNA replication through a cellular RNA helicase, RIG-I. J Virol 79, 2689-2699.

46. Sun, K., Johansen, F. E., Eckmann, L. \& Metzger, D. W. (2004). An important role for polymeric Ig receptor-mediated transport of IgA in protection against Streptococcus pneumoniae nasopharyngeal carriage. J Immunol 173, 4576-4581. 
47. Tyler, K. L., Squier, M. K., Rodgers, S. E., Schneider, B. E., Oberhaus, S. M., Grdina, T. A., Cohen, J. J. \& Dermody, T. S. (1995). Differences in the capacity of reovirus strains to induce apoptosis are determined by the viral attachment protein sigma 1. J Virol 69, 6972-6979.

48. Uren, T. K., Wijburg, O. L., Simmons, C., Johansen, F. E., Brandtzaeg, P. \& Strugnell, R. A. (2005). Vaccine-induced protection against gastrointestinal bacterial infections in the absence of secretory antibodies. Eur J Immunol 35, 180188.

49. Yu-Lee, L. (2001). Stimulation of interferon regulatory factor-1 by prolactin. Lupus 10, 691-699. 


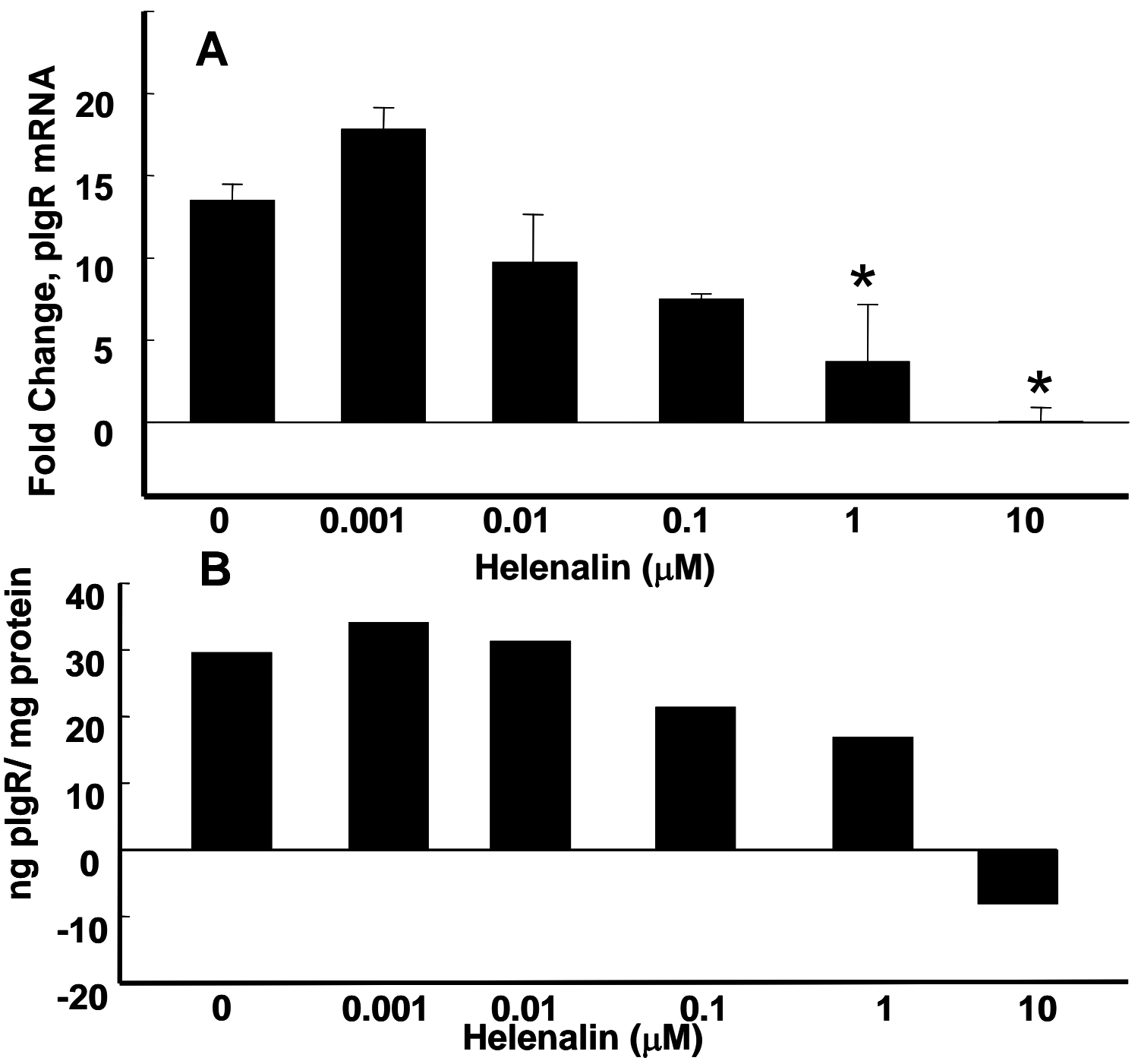

Fig. 1. Helenalin inhibits reovirus-mediated pIgR up-regulation in HT-29 cells. (A) HT-29 cells were pre-treated with indicated doses of $\mathrm{NF \kappa B}$ inhibitor helenalin and then cultured in the presence or absence of UV-inactivated reovirus at a multiplicity of infection (MOI) equivalent of 50. $24 \mathrm{~h}$ post exposure, pIgR mRNA levels were quantified by real-time RT-PCR and normalized to $\beta$-actin mRNA. Samples were analyzed in duplicate. Data are combined from 3 independent experiments and expressed as fold-increase in pIgR mRNA in response to reovirus compared to cells receiving no virus at each dose of helenalin (mean \pm SEM). Asterisks indicate that the mean is significantly different from that of control cells (no pretreatment with helenalin) as determined by one-way ANOVA followed by Tukey's test $(\mathrm{p}<0.050)$. Under similar culture conditions, cells were lysed at 48 hours post exposure to virus and pIgR protein levels were determined by ELISA. Data in panel B are from a single experiment. 


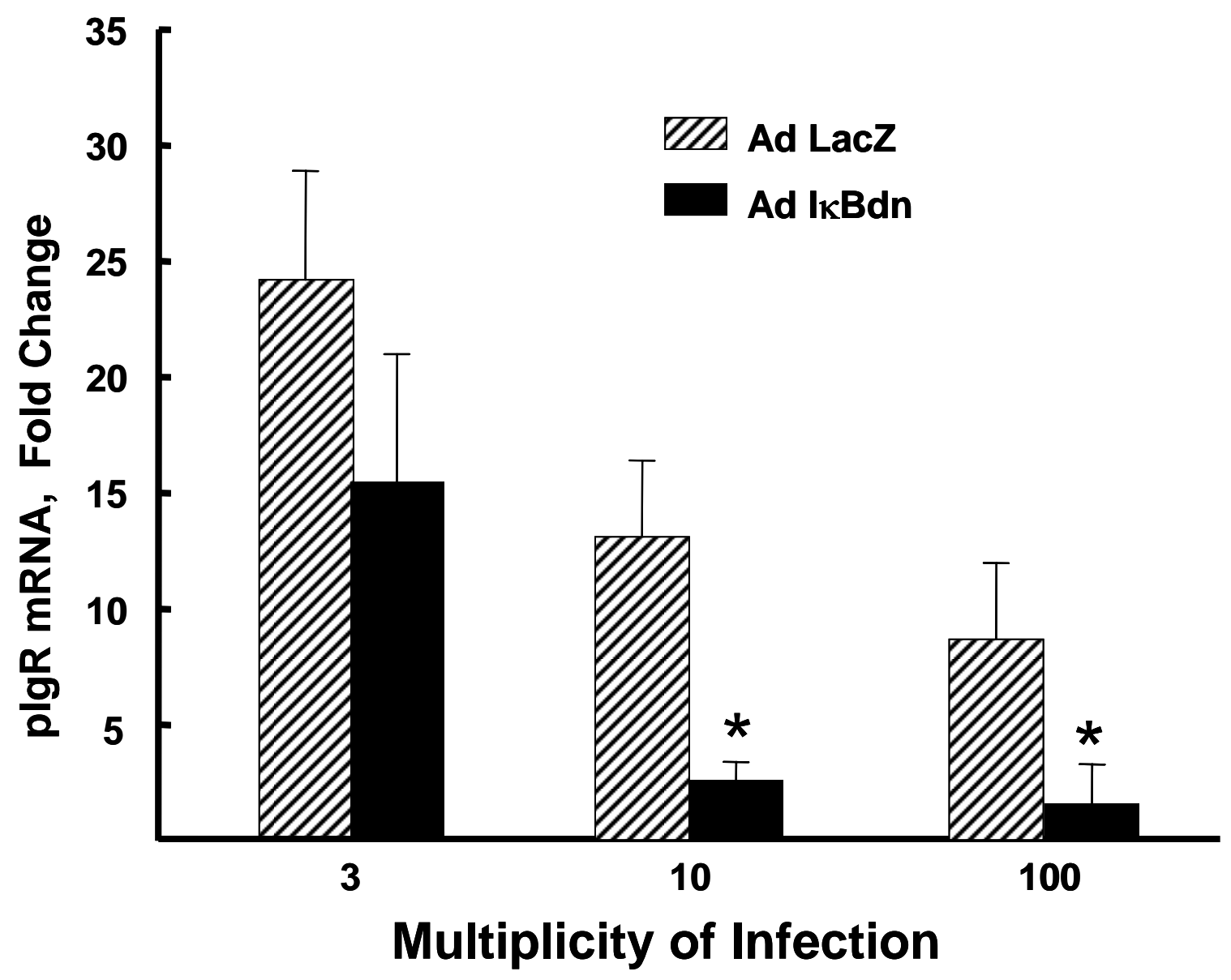

Fig. 2. Dominant negative mutant of IKB $\alpha$ blocks reovirus-mediated pIgR mRNA upregulation in HT-29 cells. HT-29 cells were transfected with adenovirus vector expressing $\beta$-galactosidase (AdLacZ) or

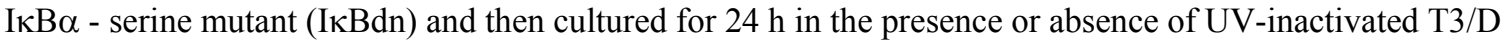
at an MOI equivalent of 50. Data are compiled from three independent experiments and expressed as fold increase in pIgR mRNA in response to reovirus (mean \pm SEM) compared to cells receiving no virus at each of indicated treatments. Upregulation of pIgR mRNA in the non-transfected cells was approximately 18 fold. Asterisks indicate that the mean is significantly different from that of control cells (Ad-LacZ) as determined by one-way ANOVA followed by Tukey's test $(\mathrm{p}<0.050)$. 


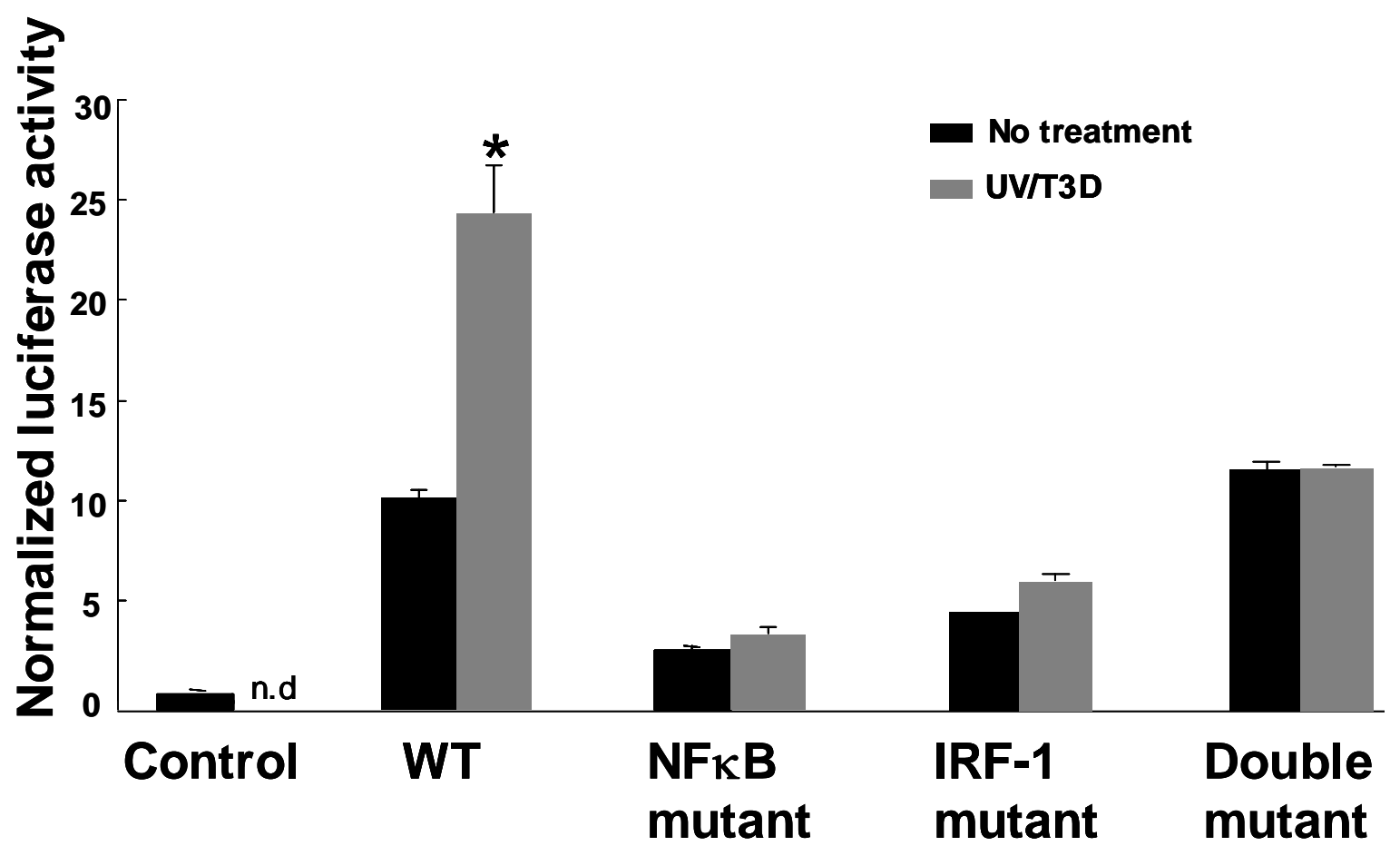

Fig. 3. Reovirus enhances transcription of wild-type PIGR gene reporter plasmids. HT-29 cells were co-transfected with promoterless control or indicated PIGR reporter plasmids and a Renilla luciferase plasmid and then cultured in the presence or absence of UV-inactivated T3/D at an MOI equivalent of 200. Data are compiled from two independent experiments, and are expressed as luciferase activity (normalized for co-transfected Renilla luciferase) of the same plasmid in response to reovirus treatment or mock treatment (mean $\pm \mathrm{SEM}, \mathrm{n}=6$ ). Asterisks indicate significant difference between experimental and controls (no virus) by one-way ANOVA followed by Tukey’s test $(\mathrm{p}<0.050)$. 


\section{CHAPTER 4: ASSESSING THE ROLE OF VIRAL DOUBLE}

\section{STRANDED RNA IN REOVIRUS MEDIATED UPREGULATION OF \\ POLYMERIC IMMUNOGLOBULIN RECEPTOR}

\section{KASTURI PAL AND CHRISTOPHER F. CUFF}

Department of Microbiology, Immunology, and Cell Biology,

Robert C. Byrd Health Sciences Center, West Virginia University,

Morgantown, West Virginia 26506-9177.

Unpublished data 


\section{INTRODUCTION}

Studies reported in Chapter 2 of this dissertation demonstrated that UV-inactivated reovirus up-regulates $\mathrm{pIgR} \mathrm{mRNA}$ and protein. This observation suggests that specific virus-host interactions, and not viral replication, initiate signaling pathways that regulate pIgR expression. Reovirus is a 10-segmented dsRNA-containing virus that infects a wide variety of mammalian species including mice and humans $(12,14)$. Reovirus enters host cells by receptor-mediated endocytosis, and inside the acidified endosomes it undergoes partial disassembly resulting in intermediate subviral particles (ISVPs) and / or liberation of viral dsRNA genome from degraded virions $(3,4,15)$. Viral dsRNA is a wellcharacterized PAMP that is recognized by TLR3 $(1,8,9,13)$. TLR-3 is constitutively expressed in human intestinal epithelial cells (5), although the precise intracellular location of TLR-3 has not yet been identified. However, in human dendritic cells TLR-3 is expressed intracellularly in vesicles and possibly at a low level in late endosomes $(7,9,10)$. An intracellular localization on TLR3 is consistent with its role of responding to viral nucleic acids likely available for interaction during partial viral disassembly and / or during replication inside host cells (2). Recently, Schneeman et al. reported that cell surface expression of TLR3 by transformed human intestinal epithelial cell line HT-29 is enhanced following prolonged stimulation with chemical analog of viral dsRNA, poly I:C (13). Taken, together it appears that IECs including HT-29 cell line express TLR3 and a TLR-mediated recognition of viral dsRNA exists in them.

The working hypothesis of this project is that viral dsRNA released during endosomal processing is sufficient to trigger signaling cascades resulting in $\mathrm{pIgR}$ up-regulation. 
This is important globally because it demonstrates that viruses (and not only chemical analogs of dsRNA) can trigger innate immune responses in cells that do not support virus replication. To examine if TLR3-mediated recognition of dsRNA leads to upregulation of pIgR in IECs, first the role of poly I: C in modulating pIgR expression in HT-29 cells was assessed. Second, the ability of purified reovirus dsRNA to modulate pIgR expression in HT-29 cells was also examined.

\section{METHODS}

Cells. HT-29 (ATCC HTB38) cells were cultured in McCoy's 5A Modified Medium (ATCC, Manassas, VA) supplemented with 10\% fetal bovine serum (FBS) and $1 \%$ penicillin-streptomycin. Cells were plated in 12 -well plates and incubated at $37^{\circ} \mathrm{C}$ for 24 hours to allow the formation adherent monolayers and then exposed to UV-inactivated reovirus, poly I:C (Sigma, St. Louis, MO) and/or purified reovirus dsRNA.

RNA extraction and quantitative RT-PCR for PIgR mRNA. Total cellular RNA was extracted from HT-29 cells using RNeasy ${ }^{\circledR}$ mini kits (Qiagen, Valencia, CA) and RNA was reverse transcribed into cDNA using Superscript TM RNase H- Reverse Transcriptase (Invitrogen Life Technologies, Carlsbad, CA) according to manufacturers' protocols. Real-time PCR was performed using a Lightcycler (Roche Molecular Biochemicals, Indianapolis, IN) as described previously in Chapter 2. 
Double Stranded reovirus RNA extraction. L929 cells were grown in T-75 flask and then infected with reovirus T3/D at an MOI of 10. Infected L-cell cultures were incubated at $37^{\circ} \mathrm{C}$ for about 36 hours until $\mathrm{CPE}$ was well advanced (>70\%). 36 hours post infection, cells were trypsinized and centrifuged at $1200 \mathrm{rpm}$ for $5 \mathrm{mins}$ at $4^{\circ} \mathrm{C}$. Supernatant was discarded and cells were resuspended in TRI reagent (Molecular Research Center) at a concentration of $5 \times 10^{6}-1 \times 10^{7}$ cells / ml, and dsRNA was extracted by the acid-phenol/guanidinium thiocyanate procedure, according to the manufacturer's instructions. The cell lysate was passed several times through pipette and then transferred to a new eppendorf tube and incubated for $5 \mathrm{mins}$ at room temperature to allow complete dissociation of nucleoprotein complexes. $100 \mu \mathrm{l}$ of BCP per $1 \mathrm{ml}$ of TRIreagent was added to lysates, and shaken vigorously for 15 secs. The resulting mixture was incubated at room temperature for 10 mins and then centrifuged at $12000 \mathrm{~g}$ for 15 mins at $4^{\circ} \mathrm{C}$. Following centrifugation, the mixture separates into a lower red phenol-chloroform phase, interphase and the colorless upper aqueous phase. RNA remains exclusively in the aqueous phase whereas DNA and proteins are in the interphase and organic phase. The volume of the aqueous phase is about $60 \%$ of the volume of TRIreagent used for homogenization. The aqueous phase was transferred to a new tube. $500 \mu \mathrm{l}$ of isopropanol ( $500 \mu \mathrm{l}$ per $1 \mathrm{ml}$ of TRI reagent) was added to the aqueous phase. RNA was precipitated from the aqueous phase by mixing with an equal volume of isopropanol. Lysate was stored at room temperature for $10 \mathrm{mins}$ and centrifuged at $12000 \mathrm{~g}$ for 8 mins at $4^{\circ} \mathrm{C}$. RNA, which was often invisible before centrifugation, was precipitated at this step and appeared as a gel-like or white pellet on the side and bottom of the tube. The supernatant was removed very carefully and the RNA pellet was washed 
(by vortexing) with $1 \mathrm{ml}$ of $75 \%$ ethanol and then centrifuged at $7500 \mathrm{~g}$ for $5 \mathrm{mins}$ at $4{ }^{\circ} \mathrm{C}$. The ethanol wash was removed and RNA pellet was briefly air -dried for 3-5min. It is important not to completely dry the RNA pellet as this greatly decreases its solubility in water. The RNA pellet was dissolved in $120 \mu \mathrm{l}$ of RNAse free water. This was followed by precipitation with $2 \mathrm{M} \mathrm{LiCl}$ to remove single-stranded RNA as follows:

(1) Add $8 \mathrm{M} \mathrm{LiCl}$ (Sigma) to a final concentration of $2 \mathrm{M} \mathrm{LiCl}$, that is add $40 \mathrm{ul}$ of $\mathrm{LiCl}$ to $120 \mu \mathrm{l}$ total RNA. Leave in an ice-water slurry for 2 hours. Centrifuge at $14000-16000 \mathrm{~g}$ for 30 mins. The dsRNA is purified from the supernatant using a column from a Gel Extraction Kit (Qiagen).

(2) Transfer the supernatant to a new tube (note the precipate formed after addition of $\mathrm{LiCl}$ is ss $\mathrm{RNA}$ ). To the supernatant (which is $120+40=160 \mu \mathrm{l}$ ), add $480 \mu \mathrm{l}(3$

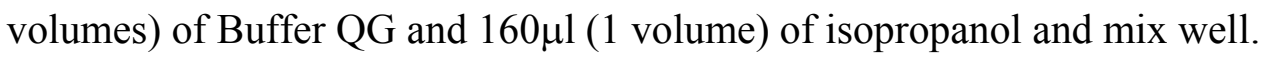

(3) Place a QIAquick spin column in a provided $2 \mathrm{ml}$ collection tube. Add the sample mixture to the QIAquick column and centrifuge for 1min. (Maximum volume of column is $800 \mu 1)$.

(4) Discard flow-through and place the QIAquick column back in the same collection tube.

(5) To wash add 750 $\mu$ l of Buffer PE to QIAquick column and centrifuge for 1min.

(6) Discard flow-through and centrifuge the QIAquick column for an additional 1min at $>10000 \mathrm{~g}(\sim 13000 \mathrm{rpm})$.

(7) Place QIAquick column into a clean $1.5 \mathrm{ml}$ microcentrifuge tube. To elute DNA, add $50 \mu \mathrm{l}$ of Buffer EB or Nuclease free water to the center of the QIAquick 
membrane and centrifuge the column for $1 \mathrm{~min}$ at maximum speed. Store the DNA at $-80^{\circ} \mathrm{C}$.

\section{RESULTS}

\section{TLR3 mediated signaling upregulates pIgR mRNA expression in HT-29 cells.}

To determine whether TLR3 signaling regulated pIgR expression in human IEC, HT29 colon carcinoma cells were treated with indicated doses of chemical analog of viral dsRNA (poly I: C) or exposed to UV-inactivated reovirus at an MOI of 50 for 24 hours. The concentration of the virus was $148 \mathrm{ng} / \mu 1$. Preliminary experiments demonstrated that poly I: C upregulates pIgR mRNA expression in HT-29 cells in a dose-dependent manner, suggesting that TLR3 mediated signaling in IECs play a role in pIgR upregulation. A dose of $100-\mu \mathrm{g} / \mathrm{ml}$ poly I: C was optimal and $\mathrm{pIgR}$ was induced by as much as 20 fold (Fig. 1).

\section{Extracellular reovirus dsRNA does not upregulate pIgR expression in HT-29 cells.} Although poly I: $\mathrm{C}$ is an almost universally accepted analog for viral dsRNA, there are few studies that test the role of TLR3-mediated activation in response to actual viral dsRNA. Confluent monolayers of HT-29 cells were incubated at $37^{\circ} \mathrm{C}$ in presence or absence of intact UV-inactivated reovirus at an MOI of 50 (764 ng of RNA) or equivalent amounts of purified dsRNA from reovirus or UV-irradiated purified reovirus dsRNA under cell culture conditions that ensured that the RNA was not degraded (Fig. 2). 24 hours post exposure to intact virus or naked dsRNA, pIgR mRNA was measured by real time quantitative RT-PCR as described previously. Although intact virus increased pIgR 
mRNA expression by 20 fold, the purified reovirus dsRNA did not induce pIgR mRNA, suggesting that extracellular dsRNA does not trigger TLR3 signaling in IECs (Fig. 3).

\section{DISCUSSION}

The first line of specific defense against invading mucosal pathogens is provided by sIgA. The pIgR-mediated transport of IgA by IECs is very impressive resulting in the daily delivery of $3 \mathrm{~g}$ of $\operatorname{sg} \mathrm{A}$ into the intestinal secretions of the average adult (11). A number of factors including proinflammatory cytokines and microbial interaction including reovirus modulates $\mathrm{pIgR}$ expression and thereby impact mucosal immunity. This report describes efforts to understand the importance of dsRNA signature of reovirus to enhance pIgR expression in HT-29 cells.

Several mechanisms could facilitate association of reovirus dsRNA with intracellular PRRs including TLR3. Delivery of reovirus into acidified endosomes leads to viral uncoating and formation of intermediate sub-viral particles (ISVP), which are subsequently delivered to the cytoplasm. Although the dsRNA genome should be protected within ISVP, it is possible that some dsRNA might be released within the endosomal/lysosomal pathway. If TLR3 is present in endosomal vesicles, dsRNA binding and signal transduction could be initiated following endosome-lysosome fusion and acid activation (6). The intracellular distribution of TLR3 has not been examined in detail, but immunofluorescence images of normal human IEC and dendritic cells suggest that TLR3 is present intracellularly in endosomes $(5,6,9)$ as well as possibly on the cell surface $(5,13)$. Alternatively, "naked" dsRNA from partially disassembled virions might 
be released from dying cells, providing an early warning system to adjacent uninfected cells. The dsRNA can signal through TLR3 to activate IRF-3 and NFKB ultimately leading to pIgR upregulation.

These studies were inconclusive for a role of viral dsRNA as an activator of pIgR expression during virus infection and might suggest alternative mechanisms of activation. Two apparently contradictory observations have been reported in this study. Poly I:C induced pIgR mRNA expression in HT-29 cells suggesting a role for TLR3 mediated viral dsRNA recognition in pIgR upregulation. However, purified reovirus dsRNA added extracellularly to HT-29 cells failed to induce pIgR mRNA expression. Our data demonstrated that reovirus dsRNA when incubated with HT-29 cells was not degraded. Why extracellular reovirus dsRNA did not induce pIgR expression could be explained in the following ways. First, extracellular reovirus dsRNA may not get access to cell surface TLR3. Second, even if reovirus dsRNA binds to TLR3 on surface, we do not know if extracellular TLR is functional and capable of signaling. Third, there are no cell surface-expressed TLR3 on HT-29 cells with which reovirus dsRNA can interact and tranduce signals. Although prolonged stimulation with poly I:C leads to cell surface expression of TLR3 (13), it is possible that under our experimental conditions in the absence of pre-stimulation with poly I:C, HT-29 cells did not express extracellular TLR3 . Fourth, extracellular 'naked' reovirus dsRNA is not endocytosed by HT-29 cells in which case it may interact with intracellular TLR3. It is likely that both poly I:C and purified dsRNA exerts its effect in inducing pIgR expression via interaction with intracellular TLR3. Although poly I:C is added extracellularly, it might diffuse non- 
specifically through cell membrane and thus excites intracellular TLR3 but extracellular 'naked' dsRNA fails to enter cell. Thus, the results with poly I:C support an important role for dsRNA-TLR3 signaling in virus-mediated pIgR upregulation and negative findings with extracellular reovirus dsRNA does not rule out the importance of viral genome in the process. Future experiments will be required to test the hypothesis that reovirus mediated up-regulation of pIgR expression occurs through TLR3 signaling. It is possible to transfect the dsRNA or modify it for endocytic uptake and assess pIgR upregulation in HT-29 cells. In addition cells can be transfected with TIR-deleted TLR3 or dominant negative TRIF or si RNA to TLR3 to examine the involvement of TLR3 and its downstream adaptor molecules in pIgR upregulation. 


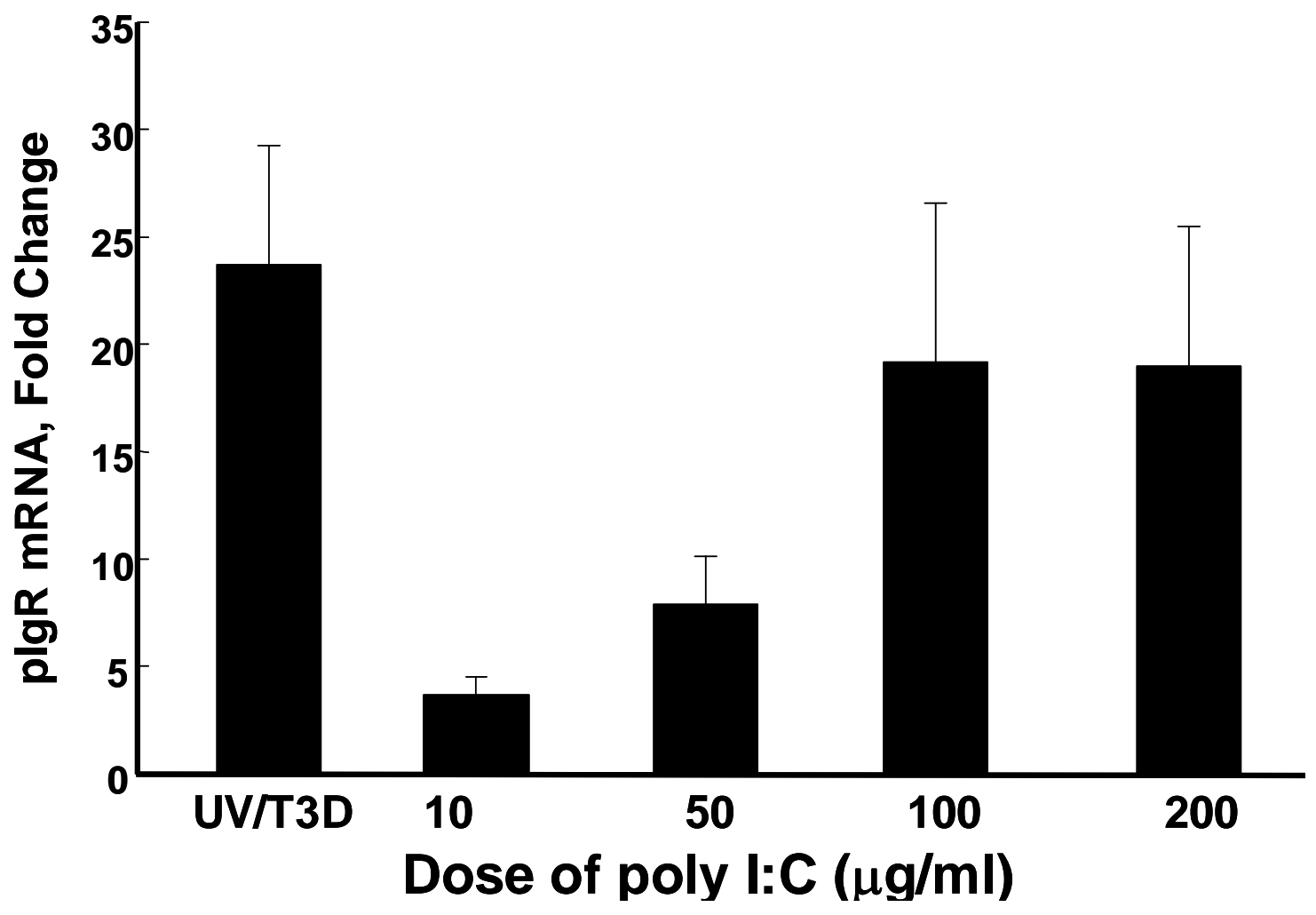

Fig. 1. Poly I:C upregulates pIgR mRNA expression in HT-29 cells. Confluent monolayers of HT-29 cells were cultured at $37^{\circ} \mathrm{C}$ for $24 \mathrm{~h}$ in the presence or absence of UV inactivated T3/D or poly I:C. $24 \mathrm{~h}$ post treatment pIgR mRNA levels were quantified by real-time RT-PCR and normalized to $\beta$-actin mRNA. Samples were analyzed in duplicate to minimize error. Data are combined from 3 independent experiments and expressed as fold-increase in pIgR mRNA in response to reovirus or poly I:C compared to cells receiving no treatment (mean $\pm \mathrm{SEM}$ ). Asterisks indicate that the mean is significantly different from that of control cells (no treatment with virus or poly I:C) as determined by one-way ANOVA followed by Tukey's test $(\mathrm{p}<0.050)$. 


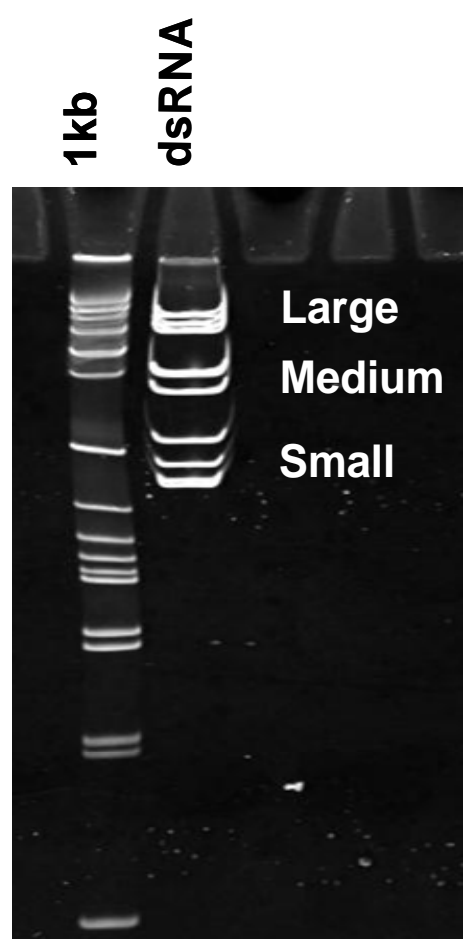

Reovirus ds RNA

Fig. 2. The intact, segmented dsRNA genome from reovirus was purified using the methods of Potgieter et al. 


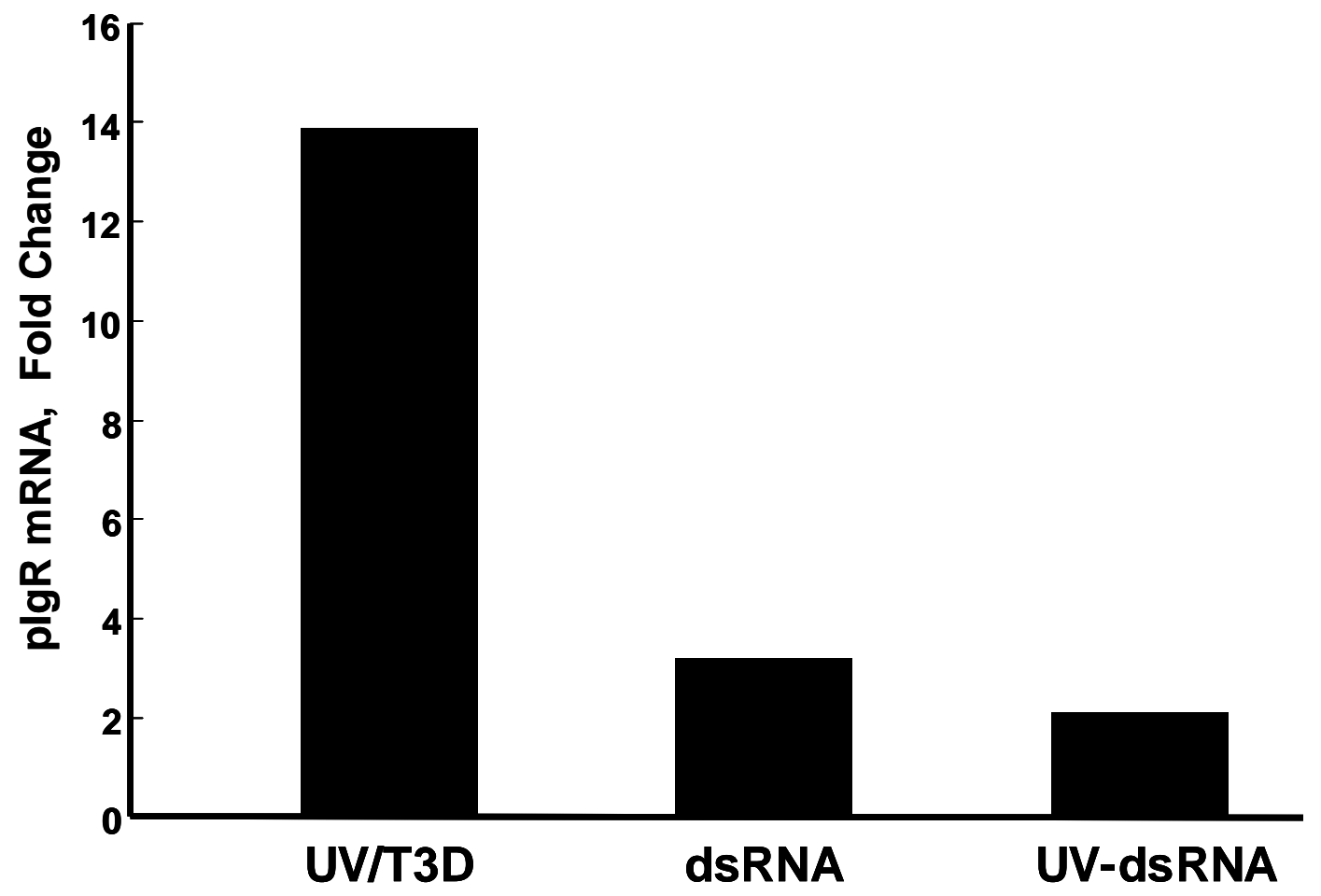

Fig. 3. Extracellular reovirus dsRNA does not upregulate pIgR mRNA expression in HT-29 cells. Confluent monolayers of HT-29 cells were cultured at $37^{\circ} \mathrm{C}$ for $24 \mathrm{~h}$ in the presence or absence of UV inactivated T3/D or reovirus dsRNA $(148 \mu \mathrm{g} / \mathrm{ml})$ or UV-inactivated dsRNA $(148 \mu \mathrm{g} / \mathrm{ml})$. Culture conditions were optimized so that dsRNA was not degraded after 1 hour of initial addition to media. Following incubation pIgR mRNA levels were quantified by real-time RT-PCR and normalized to $\beta$-actin mRNA. Samples were analyzed in duplicate to minimize error. Data are expressed as fold increases in pIgR mRNA in response to reovirus. Data are representative of two independent experiments. 


\section{REFERENCES}

1. Alexopoulou, L., A. C. Holt, R. Medzhitov, and R. A. Flavell. 2001. Recognition of double-stranded RNA and activation of NF-kappaB by Toll-like receptor 3 . Nature 413:732-738.

2. Bell, J. K., I. Botos, P. R. Hall, J. Askins, J. Shiloach, D. M. Segal, and D. R. Davies. 2005. The molecular structure of the Toll-like receptor 3 ligand-binding domain. Proc. Natl. Acad. Sci. U. S. A 102:10976-10980.

3. Borsa, J., B. D. Morash, M. D. Sargent, T. P. Copps, P. A. Lievaart, and J. G. Szekely. 1979. Two modes of entry of reovirus particles into L cells. J Gen. Virol. 45:161-170.

4. Borsa, J., M. D. Sargent, P. A. Lievaart, and T. P. Copps. 1981. Reovirus: evidence for a second step in the intracellular uncoating and transcriptase activation process. Virology 111:191-200.

5. Cario, E. and D. K. Podolsky. 2000. Differential alteration in intestinal epithelial cell expression of toll-like receptor 3 (TLR3) and TLR4 in inflammatory bowel disease. Infect. Immun. 68:7010-7017.

6. de Bouteiller, O., E. Merck, U. A. Hasan, S. Hubac, B. Benguigui, G. Trinchieri, E. E. Bates, and C. Caux. 2005. Recognition of double-stranded RNA by human toll-like receptor 3 and downstream receptor signaling requires multimerization and an acidic pH. J Biol. Chem. 280:38133-38145.

7. Funami, K., M. Matsumoto, H. Oshiumi, T. Akazawa, A. Yamamoto, and T. Seya. 2004. The cytoplasmic 'linker region' in Toll-like receptor 3 controls receptor localization and signaling. Int. Immunol 16:1143-1154.

8. Matsumoto, M., K. Funami, H. Oshiumi, and T. Seya. 2004. Toll-like receptor 3: a link between toll-like receptor, interferon and viruses. Microbiol Immunol 48:147-154. 
9. Matsumoto, M., K. Funami, M. Tanabe, H. Oshiumi, M. Shingai, Y. Seto, A. Yamamoto, and T. Seya. 2003. Subcellular localization of Toll-like receptor 3 in human dendritic cells. J Immunol 171:3154-3162.

10. Matsumoto, M., K. Funami, M. Tanabe, H. Oshiumi, M. Shingai, Y. Seto, A. Yamamoto, and T. Seya. 2003. Subcellular Localization of Toll-Like Receptor 3 in Human Dendritic Cells. J Immunol 171:3154-3162.

11. Mestecky, J., M. W. Russell, S. Jackson, and T. A. Brown. 1986. The human IgA system: a reassessment. Clin Immunol Immunopathol. 40:105-114.

12. Organ, E. L. and D. H. Rubin. 1998. Pathogenesis of reovirus gastrointestinal and hepatobiliary disease. Curr. Top. Microbiol Immunol 233 Reovir.ii:67-83.

13. Schneeman, T. A., M. E. Bruno, H. Schjerven, F. E. Johansen, L. Chady, and C. S. Kaetzel. 2005. Regulation of the polymeric Ig receptor by signaling through TLRs 3 and 4: linking innate and adaptive immune response. J Immunol 175:376384.

14. Shatkin, A. J., J. D. Sipe, and P. Loh. 1968. Separation of ten reovirus genome segments by polyacrylamide gel electrophoresis. J Virol. 2:986-991.

15. Sturzenbecker, L. J., M. Nibert, D. Furlong, and B. N. Fields. 1987. Intracellular digestion of reovirus particles requires a low $\mathrm{pH}$ and is an essential step in the viral infectious cycle. J Virol. 61:2351-2361. 
CHAPTER 5: ASSESS POLYMERIC IMMUNOGLOBULIN

RECEPTOR (PIGR) EXPRESSION IN INTESTINAL EPITHELIAL

\author{
CELLS DURING IN VIVO VIRUS INFECTION
}

\author{
KASTURI PAL AND CHRISTOPHER F. CUFF \\ Department of Microbiology, Immunology, and Cell Biology, \\ Robert C. Byrd Health Sciences Center, West Virginia University, \\ Morgantown, West Virginia 26506-9177.
}

Unpublished data 


\section{INTRODUCTION}

In the previous studies we demonstrated that reovirus upregulates pIgR expression in transformed lung and intestinal epithelial cell lines and characterized a number of underlying signal transduction mechanisms involved in reovirus-mediated pIgR upregulation. But the important biological question is whether reovirus upregulates pIgR in vivo because it leads to an understanding of how non-lymphoid cells mount innate immune responses that amplify or synergize with the adaptive response. Hooper et al. (4) demonstrated that pIgR expression was increased in germfree mice following colonization with commensal bacteria. Other studies demonstrated that pIgR expression is upregulated following weaning, and is under partial control of adaptive immunity (5). A number of cytokines including IFN- $\gamma(1,2)$, TNF- $\alpha_{2} \operatorname{IL}-1 \beta(3)$ and IL-4 $(1,2,7)$ have been shown to increase $\mathrm{pIgR}$ expression in epithelial cells but the contribution in vivo of specific cytokines versus the pathogen itself to pIgR expression is not known. So it is reasonable to hypothesize that reovirus infection and the subsequent production of Th1 cytokines such as IFN- $\gamma$ and TNF- $\alpha$ upregulates pIgR in vivo, which can increase IgA production in secretions and contribute to host defense. The first step to further these studies includes comparison of pIgR expression levels in intestine of naïve and reovirus infected mice as reported in Chapter 5. 


\section{METHODS}

Animals and infections. Male Balb/c mice were purchased from Charles River Laboratories, Inc. (Wilmington, MA). Mice were housed under specific-pathogen-free conditions in micro-isolater cages and used between the ages of 3 and 4 weeks. Mice were treated in accordance with West Virginia University laboratory animal guidelines. Germ free mice were raised in special germ free facility in University of Pennsylvania, PA and infection of mice and subsequent collection of intestinal tissues were conducted in Late Dr. John Cebra's laboratory at U. Penn. Reovirus serotype 3, strain Dearing (T3/D) was purified according to previous protocols (6). Mice were infected orally with reovirus T3/D at doses of $10^{7}-10^{8}$ plaque forming units (pfu) diluted in $50 \mu$ l boratebuffered gelatin, using 20-gauge feeding needles.

Collection of mouse intestine. Small intestines were removed from mice and intestine was cut longitudinally and then approximately $2 \mathrm{~cm}$ segments were cut from duodenum, jejunum and ileum. Intestinal contents were removed by thoroughly washing in HBSS supplemented with $10 \mathrm{mM}$ HEPES and $0.35 \mathrm{~g} / \mathrm{L} \mathrm{NaHCO}_{3}$. Each intestinal segment was transferred to tubes containing $0.5 \mathrm{ml}$ of RNALater ${ }^{\mathrm{TM}}$ (Ambion, Inc Austin, TX) to stabilize RNA in tissues and held on ice till RNA isolation or stored at $-80{ }^{\circ} \mathrm{C}$.

RNA extraction and quantitative RT-PCR for mouse pIgR mRNA. Approximately $35 \mu \mathrm{g}$ pieces of intestinal tissues in RNALater ${ }^{\mathrm{TM}}$ were homogenized sequentially by 
mechanical disruption in Buffer RLT (Qiagen, Valencia, CA) followed by homogenization using Qiashredders ${ }^{\mathrm{TM}}$ (Qiagen). Total RNA isolation was performed using RNeasy ${ }^{\circledR}$ mini /RNase-free DNase set (Qiagen) following manufactures protocols. RNA was quantified by spectrophotometry at $260 / 280 \mathrm{~nm}$. RNA was reverse transcribed into cDNA using Superscript TM RNase H- Reverse Transcriptase (Invitrogen Life Technologies, Carlsbad, CA) in a Genius thermocycler (Techne, Inc, Princeton, NJ) according to manufacturer's protocols. Real-time PCR was performed using a Lightcycler (Roche Molecular Biochemicals, Indianapolis, IN). Taqman ${ }^{\circledR}$ primers and probes for mice pIgR (from Applied Biosystems, Foster City, CA) were produced using published sequences (Blanch et al., 1999) and mouse GAPDH was obtained from Biosource International Inc. (Camarillo, CA). Reactions were carried out in a total volume of $20 \mu \mathrm{l}$. PCR conditions were optimized for mouse pIgR primer pair as follows: enzyme activation for 1 cycle at $50{ }^{\circ} \mathrm{C}$ for 2 minutes followed by $95{ }^{\circ} \mathrm{C}$ for 10 minutes; amplification for 45 cycles at $94{ }^{\circ} \mathrm{C}$ for $45 \mathrm{~s}$ followed by $61{ }^{\circ} \mathrm{C}$ for $45 \mathrm{~s}$ and then $72^{\circ} \mathrm{C}$ for $110 \mathrm{~s}$; cool down for 1 cycle at $40{ }^{\circ} \mathrm{C}$ for 1 minute. PCR conditions were optimized for mouse GAPDH primer pair as follows: enzyme activation for 1 cycle at $50{ }^{\circ} \mathrm{C}$ for 2 minutes followed by $95{ }^{\circ} \mathrm{C}$ for 10 minutes; amplification for 45 cycles at $94{ }^{\circ} \mathrm{C}$ for $30 \mathrm{~s}$ followed by $60{ }^{\circ} \mathrm{C}$ for 1 minute; cool down for 1 cycle at $40{ }^{\circ} \mathrm{C}$ for 1 minute. Data were analyzed by determining 'crossing points' or the cycle number at which newly synthesized PCR product is first detected. Samples were analyzed in duplicate. pIgR expression was normalized with respect to $\beta$-actin expression by subtracting the $\beta$-actin crossing point from the $\mathrm{pIgR}$ crossing point for each sample. The fold induction of $\mathrm{pIgR}$ in virus-treated mice compared to the control was determined using the equation: Fold 
change $=\mathrm{K}_{\mathrm{gene}}{ }^{\Delta \mathrm{Cp}}$, where Kgene is the amplification coefficient for the pIgR gene and $\Delta \mathrm{Cp}$ is the difference in crossing point between the normalized non-treated and virustreated mice (Schjerven et al., 2000). The theoretical value of $\mathrm{K}_{\mathrm{gene}}=2$ was used for data analysis.

\section{RESULTS AND DISCUSSION}

To determine if reovirus modulates expression of pIgR in intestine following oral infection, mRNA levels for $\mathrm{pIgR}$ in different segments of intestine was assessed by quantitative RT-PCR. In adult mice, no apparent difference in pIgR mRNA expression was detected 48 hours post infection (Table 1). In germ free mice, no difference in pIgR levels was observed in any region of intestine including duodenum, jejunum and ileum 3day post infection. Interestingly, pIgR mRNA was upregulated approximately 3 -fold by 7 days after infection in the ilea from infected mice compared to non-infected age matched mice while a 2 fold decrease was observed in the ilea 4 days post infection (Fig. 1). These preliminary data suggest that immunologically competent but naïve intestinal epithelium can respond to enteric infection with reovirus.

The gut of conventional mice harbors a plethora of commensal microbes that are well tolerated by mucosal immune system. It is reasonable to speculate that in response to the presence of microbes and their metabolic products, the IECs in conventional mice express high level of pIgR and so it becomes a challenge to measure any further increase in pIgR expression when another pathogen such as reovirus is introduced in these mice. However, if pIgR expression in IECs is modulated by microbial interactions, then it is 
possible to measure such change in $\mathrm{pIgR}$ expression in germ free mice that have a naïve quiescent gut environment. Hooper et al. reported a 2-4-fold increase in the pIgR mRNA expression when the gut of germ free mice is colonized with commensal bacterial Bacteroides thetaiotaomicron (4), which is consistent with the observation made in this study.

Table 1: Expression of pIgR and GAPDH mRNA in mouse intestine 48 hours post infection with reovirus.

\begin{tabular}{cccc}
\hline SAMPLES & MOUSE PIGR C.P. & GAPDH C.P. & FOLD CHANGE \\
\hline Control / D & $24.8^{*}$ & 21.8 & \\
Control / J & 27.1 & 21.8 & \\
Control / I & 24.5 & 22.1 & $-1.4 * *$ \\
Reovirus / D & 24.6 & 21.1 & 1.2 \\
Reovirus / J & 25.8 & 20.8 & -2.3 \\
Reovirus / I & 24.2 & 20.6 & \\
\hline
\end{tabular}

*Data are represented as average of crossing points (C.P.) from 2 control mice and 3 infected mice.

$\mathrm{D}=$ Duodenum, $\mathrm{J}=$ Jejunum, $\mathrm{I}=$ Ileum.

** The fold induction of pIgR in virus-treated mice compared to the control was determined using the equation: Fold change $=\mathrm{K}_{\text {gene }}{ }^{\Delta \mathrm{Cp}}$, where $\mathrm{K}_{\text {gene }}$ is the amplification coefficient for the pIgR gene and $\Delta \mathrm{C}_{\mathrm{p}}$ is the difference in crossing point between the normalized non-treated and virus-treated mice (Schjerven et al., 2000). 


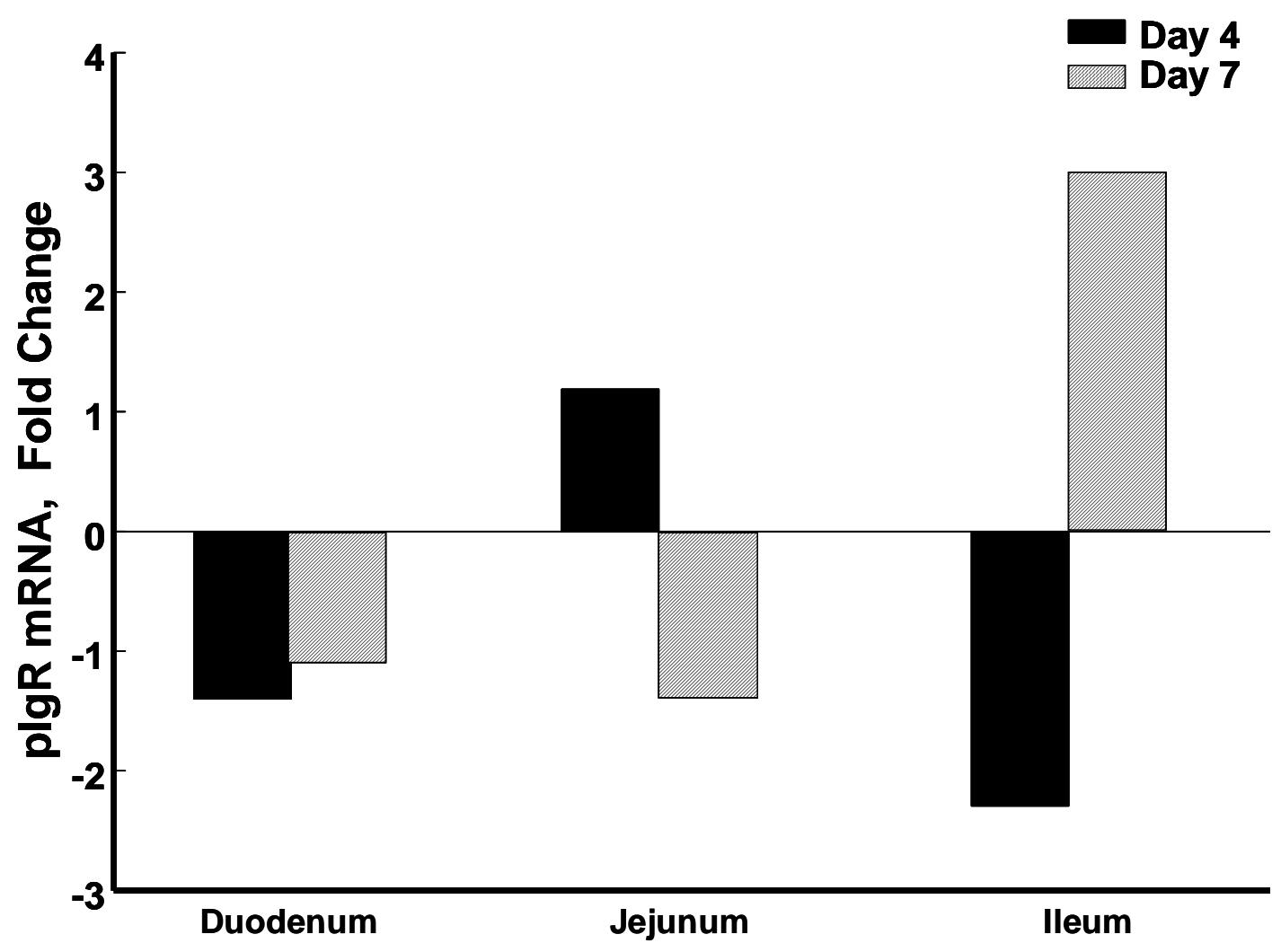

Fig. 1. Expression of pIgR mRNA in germfree mice. Germfree mice were mock infected or infected with reovirus T3/D and duodenum, jejunum, and ileum was analyzed for pIgR mRNA expression by real time quantitative RT-PCR. Samples were analyzed in duplicate to minimize error. Data are expressed as fold change in pIgR mRNA in response to reovirus. Data is from a single experiment. 


\section{REFERENCES}

1. Ackermann, L. W. and G. M. Denning. 2004. Nuclear factor-kappaB contributes to interleukin-4- and interferon-dependent polymeric immunoglobulin receptor expression in human intestinal epithelial cells. Immunology 111:75-85.

2. Ackermann, L. W., L. A. Wollenweber, and G. M. Denning. 1999. IL-4 and IFN-gamma increase steady state levels of polymeric Ig receptor mRNA in human airway and intestinal epithelial cells. J Immunol 162:5112-5118.

3. Blanch, V. J., J. F. Piskurich, and C. S. Kaetzel. 1999. Cutting edge: coordinate regulation of IFN regulatory factor- 1 and the polymeric Ig receptor by proinflammatory cytokines. J. Immunol. 162:1232-1235.

4. Hooper, L. V., M. H. Wong, A. Thelin, L. Hansson, P. G. Falk, and J. I. Gordon. 2001. Molecular analysis of commensal host-microbial relationships in the intestine. Science 291:881-884.

5. Jenkins, S. L., J. Wang, M. Vazir, J. Vela, O. Sahagun, P. Gabbay, L. Hoang, R. L. Diaz, R. Aranda, and M. G. Martin. 2003. Role of passive and adaptive immunity in influencing enterocyte-specific gene expression. Am. J Physiol Gastrointest. Liver Physiol 285:G714-G725.

6. Major, A. S. and C. F. Cuff. 1997. Enhanced mucosal and systemic immune responses to intestinal reovirus infection in beta2-microglobulin-deficient mice. J. Virol. 71:5782-5789.

7. Schjerven, H., P. Brandtzaeg, and F. E. Johansen. 2000. Mechanism of IL-4mediated up-regulation of the polymeric Ig receptor: role of STAT6 in cell typespecific delayed transcriptional response. J Immunol 165:3898-3906. 


\section{CHAPTER 6: GENERAL DISCUSSION}

Enteric viruses including rotavirus, calicivirus (including noroviruses and sapporovirus), astrovirus, and adenovirus are the major cause of gastrointestinal diseases in humans $(260,282)$. Gastrointestinal disease is the second most common cause of morbidity throughout the world after acute upper respiratory tract (URT) infections. Diarrhea is not as dramatic an illness as Acquired Immunodeficiency Syndrome (AIDS) but it continues to be a major cause of morbidity and mortality worldwide resulting in an estimated 1000 deaths among children each day $(125,126)$. An estimate of the number of diarrheal episodes in children below 5 years of age in Africa, Latin America and Asia for a 1 year period indicated more than 450 million cases of diarrhea occurred and that $1-4 \%$ were fatal, ranking diarrhea first among infectious diseases in the categories of both frequency and mortality in children $(98,206,219)$.

Human enteric viruses represent a diverse group. However, most of them are nonenveloped RNA viruses. Rotavirus and Norovirus are the two common agents that cause acute gastroenteritis (389). Rotaviruses are the most common cause of severe diarrhea worldwide (282). In addition, Centers for Disease Control (CDC) estimates that 23 million cases of acute gastroenteritis are due to norovirus infection, and at least $50 \%$ of all food borne outbreaks of gastroenteritis can be attributed to highly contagious noroviruses. Symptoms range from gastroenteritis to more life threatening diseases such as myocarditis and aseptic meningitis (228). The burden of diarrheal disease caused by these enteric viruses are of great economic importance, causing millions of lost working 
days each year to mini-epidemics in families, hospital wards and rural villages in developing countries. Enteric viruses contribute to massive mortality caused by infantile diarrhea in developing countries where infections may be exacerbated by malnutrition, unsanitary conditions and / or be favored by co-infection with other enteropathogens $(124,127,218)$. Transmission of these enteric viruses occurs primarily through the oralfecal route. However, other routes including foodborne and waterborne transmission potentially via contaminated water exist. The proportion that is directly food borne or waterborne is unclear, but it is likely to be substantial. One well-documented source of food-borne infection is consumption of shellfish polluted by sewage (13).

Relatively little is known about different aspects of enteric virus infection, in part because many enteric viruses are difficult to grow in cell culture and few animal models of infection exist for elucidating mechanisms of anti-viral host defense in the intestine. However it is transparent that these enteric human pathogens dramatically affect public health and significantly impact economy worldwide. Thus, eliminating enteric infection in children is a desirable goal. On the other hand, there have been dramatic increases in allergic diseases in children living in developed countries where there are reduced episodes of severe gastrointestinal infections by pathogens including viruses. This association has contributed to the 'Hygiene Hypothesis', which suggests that the decreased incidences of mucosal infection early in life reduce the ability of the immune system to mature properly and increases the susceptibility to allergic responses $(313,314)$. Therefore, there is a need for intensive research to understand virus-host interactions and the ensuing immune responses following infection with enteric viruses, particularly in 
immunologically immature individuals. Such work will contribute to better management of chronic diarrhea, which is a persistent threat in developing countries and of great economic significance in developed countries. In addition, research in this area hold the promise of development of novel therapies including designing of efficacious vaccines for infantile diarrhea and utilizing reovirus to 'mature' the mucosal immune system to improve the efficacy of enteric virus targeted vaccines that are given early in life.

Reovirus infection in mice is an excellent model to study host-pathogen interactions, in part because experimental reovirus infection induces a spectrum of pathologies resembling diseases caused by enteric viruses and thus serves as a probe to understand mucosal immunity. Rotavirus belongs to the virus family Reoviridae, which also include Orthoreovirus (commonly called reovirus) that infect the human gastrointestinal and respiratory tracts.

The intestinal immune system has evolved under the contradictory pressures of protecting the host epithelium from potential pathogenic threats and tolerating the co-existence of myriad commensal organisms in lumen. The IECs are an integral component of the intestinal immune system and the power to recognize and discriminate between nefarious pathogens and friendly commensals hold the key to maintaining a state of controlled inflammation in the gut $(139,333)$. IECs act at the interface between the innate and acquired immune responses to microorganisms in the gastrointestinal tract. IECs mount innate responses upon direct contact with microbes or their metabolic products resulting in production of antimicrobial substances that fight infection directly, and secretion of 
chemokines and cytokines that enhance acquired, antigen-specific immune responses. A hallmark feature of adaptive mucosal immune responses is production and secretion of sIgA. During the response, pIgA antibodies or the empty receptor is transcytosed across secretory epithelia by the pIgR expressed on the basolateral surface of IECs producing sIgA and FSC in intestinal secretions. The rate of IgA transcytosis depends on the level of pIgR expression because one molecule of pIgR must be synthesized for each molecule of transported IgA. Thus, pIgR plays a role in mucosal host defense, and factors that influence expression of pIgR affect mucosal immunity. Expression of the PIGR gene is a significant developmental response by epithelial cells that appears to be under the control of multiple environmental factors including infection. Signaling induced by microbes and their products may serve to augment pIgR-mediated transcytosis of IgA, linking the innate and acquired immune responses to viruses and bacteria. Both FSC and SIgA contribute to clearance of infection and thus maintain integrity of the mucosal barrier. Therefore it was very logical to conduct research to further the understanding of regulation of pIgR expression by IECs during enteric virus infection and evaluate how IECs respond to assault by reovirus. The experiments reported in this dissertation confirm that a newly appreciated role of the IECs in sensing the mucosal pathogen reovirus is upregulation of pIgR expression by IECs, which serves as an innate host defense mechanism that subsequently affect the development of antigen-specific adaptive immune responses.

The work reported in this dissertation demonstrated that reovirus upregulates pIgR mRNA and protein expression in IECs in a replication independent fashion and that 
binding of virus to cellular receptors and partial disassembly of virus inside acidified endosomes are required steps for this innate immune response by IECs. How the host cells respond to reovirus at a molecular level and upregulate expression of pIgR was a very intriguing question. So, we sought to delineate the possible signaling events that are triggered following interaction of reovirus with IECs that ultimately lead to upregulation of pIgR expression by the host cells.

Reovirus infection triggers a number of signaling cascades including increased activation of calpains, JNKand ERK $(70,73,83)$. These signaling cascades result in activation of NFkB and phosphorylation of c-Jun $(69,70,73,131,383)$. In addition, extensive studies have demonstrated that NFKB is a central regulator of the IEC response to infection with enteric microbial pathogens and to proinflammatory cytokines including TNF- $\alpha$ and IL1. Although enteric microbial pathogens utilize a number of different strategies to interact with or invade the IECs, they trigger signaling events in IECs that activate NFKB and upregulate the expression of an array of NFkB responsive genes and their products including proinflammatory cytokines, antimicrobial peptides and chemotactic cytokines $(29,93,160,276)$. We conducted a series of studies to investigate whether epithelial cell $\mathrm{NF \kappa B}$ signaling mediate upregulation of pIgR expression during reovirus infection. The major pathway leading to $\mathrm{NF \kappa B}$ activation comprises inducible degradation of its

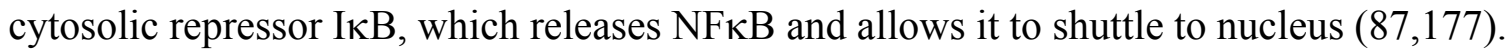
The findings reported in this dissertation suggest that reovirus activates NFKB either directly or via a calpain-mediated pathway that ultimately degrades IкB. In addition, promoter analysis studies suggested that reovirus enhances PIGR gene transcription by 
binding activated NFKB and IRF-1 to their respective cognate sites of the pIgR promoter resulting in increased expression of pIgR by IECs.

$\mathrm{NF \kappa B}$ is known to regulate the transcription of genes that are proinflammatory and required for host innate immunity and defense and those that are anti-apoptotic $(93,177,178,217)$. The anti-apoptotic role of NFKB is evident from the ability of this transcription factor to prevent TNF- $\alpha$ induced apoptosis in several experimental models and IECs $(26,222,250,309,387)$. Cellular transcription factors are often targeted by viral pathogens to modulate host cell signaling events and influence cell fate. Multiple family of viruses including human immunodeficiency virus type 1 (HIV-1) (324), human T-cell lymphotropic virus (361), hepatitis B virus, hepatitis C virus $(363,364,408)$, rotavirus (59), and influenza virus $(291,292)$ activate NFKB to promote viral replication and prevent virus-induced apoptosis. However, NFאB activation also induces immune responses to infecting virus. NFKB can also be activated by the chemical analog of viral dsRNA, poly I:C, suggesting that dsRNA viruses or viruses that generate dsRNA intermediates can exploit various aspects of NFKB biology. Recently, it has been shown that dsRNA-activated serine threonine protein kinase, PKR is involved in dsRNA-

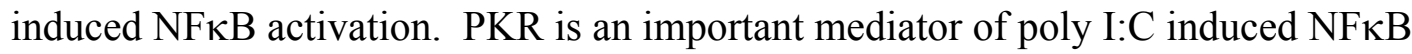
signaling that involved sequential activation of NIK and IKK leading to degradation of

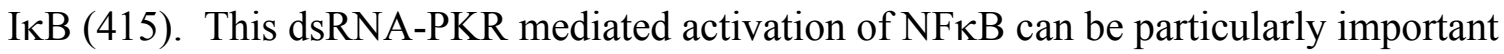
in reovirus-induced pIgR upregulation in IECs because PKR is activated in response to dsRNA signature in reovirus infected cells. It makes perfect sense that reovirus replication in vivo is restricted to the immature Ras positive cells of intestinal crypts as 
Ras or a downstream component of Ras signaling pathway blocks activation of PKR and thus permits viral replication and translation. Now, we know that viruses by blocking PKR activation inhibit NFאB activation that could trigger inflammatory and immune responses including upregulation of pIgR expression by host against invading pathogens.

Clarke et al. reported that reovirus infection induces two distinct phases of NFKB regulation, which are required to efficiently activate virus-induced apoptosis in host cells. In the first phase, 2-4 hours post infection; NFאB is activated followed by inhibition of

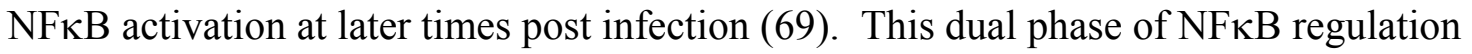
has serious consequences for the reovirus and host epithelial cells. NFкB activation has an anti-apoptotic effect on host cells that provides reovirus enough time to establish infection. In addition, the ability of reovirus to block NFKB activation at later times post infection promotes virus-induced apoptosis in host cells that might serve to increase virus spread. Some viruses including Sindbis virus and Dengue virus are known to activate

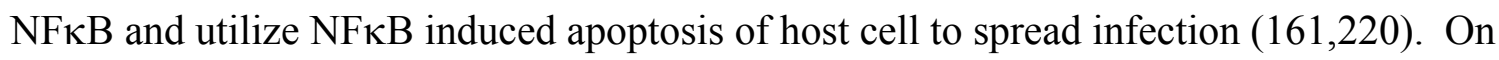
the other hand, our studies have demonstrated that reovirus upregulates pIgR expression via an NFאB mediated pathway, suggesting that activation of this transcription factor promotes host immune responses to reovirus. So the paradoxical question is whether $\mathrm{NF} \kappa \mathrm{B}$ activation is beneficial to the host or does it favor the virus? It can be reasoned that the anti-apoptotic effects of $\mathrm{NF \kappa B}$ activation is important for both the virus and the host because a delay in the onset of apoptosis by host cells allows the virus to adapt to cellular environment and establish infection while providing sufficient time for the 
epithelial cells to generate signals leading to induction of immune responses including upregulation of pIgR, against the invading pathogen.

Although, reovirus mediated upregulation of pIgR occurs primarily via NFkB activation, it is possible that other signaling pathways including TLRs and RNA helicases might be involved. Since reovirus is a dsRNA-containing virus, analysis of additional signal transduction pathways in IECs that recognize dsRNA as pathogen-associated signatures might be relevant. The finding that endocytosis of reovirus and subsequent acidification of endosomes in intestinal epithelial cell line HT-29 was a required step in pIgR upregulation suggests a role for viral disassembly in the process. It is possible that following degradation in the endosomes, liberated viral dsRNA interacts with intracellular TLR-3 to induce intracellular signals that lead to pIgR up-regulation. TLR-3 is constitutively expressed in human IECs, although the precise intracellular location of TLR-3 has not yet been identified $(54,55,56,338)$. Thus, TLR-3 signaling in response to reovirus dsRNA might be initiated following fusion of endosomes containing reovirus dsRNA from degraded virions with cellular vesicles containing TLR-3.

Experiments reported in Chapter 4 of this dissertation demonstrated upregulation of $\mathrm{pIgR}$ expression by poly I:C, chemical analog of viral dsRNA and not by extracellular dsRNA purified from reovirus. These contradictory results could be explained by the fact that poly I:C diffuses non-specifically inside cells and exert its effect in upregulating pIgR expression by stimulating intracellular TLR3. However, extracellular dsRNA incubated with cells under conditions where the RNA was intact still failed to elicit similar response 
because of the inability of cells to endocytose 'naked' dsRNA or lack of interaction with surface expressed TLR3. Overall these studies indicate responsiveness of IECs to poly I:C and imply that the viral dsRNA - TLR3 pathway might be involved in pIgR upregulation. In addition, during virus replication it is possible that dsRNA synthesized inside newly formed capsids is shielded from intracellular TLR-3. Therefore an alternative activation pathway such as through TLR-8, which recognizes viral ssRNA might be responsible for the observed effects $(91,140)$. Alternatively, reovirus dsRNA may trigger cellular responses via a TLR -independent mechanism. Double stranded RNA may bind to the cellular RNA helicase, retinoic acid-inducible gene-1 (RIG-1) or melanoma differentiation-associated gene 5 (mda-5) and subsequently activate latent transcription factors including IRF 3 and NFkB $(6,174,216,359)$. However, further experimentation will be required to test these hypotheses and gain a full understanding of spectrum of pathways involved in modulation of pIgR expression by IECs in response to pathogenic interactions.

Knowing that reovirus upregulates pIgR expression in transformed lung and intestinal epithelial cell lines, we addressed the important biological question and this is whether reovirus upregulates pIgR expression in vivo. This is an important question because it leads to an understanding of how non-lymphoid cells initiate immune responses that amplify or synergize with the antigen-specific adaptive response. Studies by Hooper et al. suggest that commensal bacteria can induce pIgR expression in vivo (150). Other studies demonstrated that $\mathrm{pIgR}$ expression is upregulated during weaning, and is under partial control of adaptive immunity (163). Although a number of cytokines have been 
well documented to increase pIgR expression in vitro, the contribution of specific cytokines versus reovirus itself in pIgR upregulation in vivo is not known. In addition, enteric reovirus infection in germfree and neonatal mice stimulate the development of germinal centers and induces virus -specific and 'bystander' IgA responses, suggesting that the pathogen stimulate immunologically competent but naïve mucosal tissues, which respond by initiating innate immune responses in IECs that shape the nature of subsequent adaptive immunity $(197,398)$. The preliminary in vivo experiments reported in Chapter 5 of this dissertation indicates that pIgR mRNA expression is upregulated in germfree but not conventionally reared adult mice following oral reovirus infection. Why a change in pIgR expression could be measured in germ free mice but not in conventional mice has been discussed in details in Chapter 5. Overall, it seems that commensal and pathogenic microorganisms can upregulate pIgR expression by signaling through IECs, which serves to bridge the innate and adaptive immune responses at mucosal surfaces. Future work on pIgR expression during virus infection in vivo will advance our understanding of the way that innate responses are regulated by adaptive responses in the intestine, and will provide much needed in vivo correlates to observations initially made in vitro using transformed intestinal epithelial cell lines. Future in vivo studies in germfree and neonatal mice should aim to understand the contribution of the virus itself or cytokines induced in mucosal virus infection to upregulate intestinal pIgR expression.

Studies with the pIgR knockout mice model have demonstrated the specific requirement of sIgA in mucosal homeostasis and protection at mucosal surfaces $(167,348)$. Although 
pIgR knockout mice lack mucosal Igs, they accumulate pIgA in circulation at levels of 100-fold higher than wild type mice (385). However, pIgR knockout mice demonstrated the importance of $\mathrm{pIgR}$ / sIgA for the protection of gastrointestinal surfaces against secreted bacterial toxins including cholera toxin (386). Sun et al. demonstrated the critical role of $\mathrm{pIgR} / \mathrm{sIgA}$ in protection against nasal colonization by S. pneumoniae in pIgR knockout mice (360). In addition, chronic inflammatory mucosal disorders including celiac disease, Helicobacter pylori gastritis, and Sjogren's syndrome increase pIgR synthesis likely under the influence of inflammatory mediators including TNF$\alpha$ and IFN- $\gamma$ (49). Murthy et al. demonstrated an important role for $\mathrm{pIgR} / \mathrm{sIgA}$ in controlling colonic inflammation during dextran sulphate sodium (DSS) induced colitis in pIgR knockout mice. PIgR knockout mice displayed greater mucosal ulceration, inflammation, edema and necrosis compared to wild type suggesting an immunoregulatory role for $\mathrm{pIgR}$ and / or FSC at mucosal surfaces in controlling inflammation and maintaining integrity of epithelial barrier (Murthy et al., Journal of Gastroenterology and Hepatology, 2006, In Press).

Interestingly, pIgR can play a dual role in host defense as well as pathogen entry. In vitro studies by Zhang et al. have confirmed that pIgR can translocate Streptococcus pneumoniae across human nasopharyngeal epithelial cells. Human pIgR can bind to a major pneumococcal adhesin, choline binding protein $\mathrm{A}(\mathrm{CbpA})$ and the whole complex can then be endocytosed and transcytosed in a retrograde fashion, suggesting that mucosal pathogens like pneumococci may co-opt the pIgR transcytosis machinery to breach the epithelial barrier (410). It has been demonstrated that human pIgR via 
domains 3 and 4 bind to hexapeptide motif in the choline-binding protein SpsA of $S$. pneumoniae $(95,227)$. The SpsA-pIgR interaction mediates adherence and internalization of the human pathogen into epithelial cells $(95,133,134,227)$. Whether a similar mechanism of retrograde transcytosis of pIgR is utilized by reovirus to enter IECs from apical surface is an important question that can be addressed in future studies. It will be very intriguing to determine if pIgR is the 'defender of the fort' or it may present itself as a 'Trojan horse' for reovirus to hitch a ride from intestinal lumen in the mucosal epithelium. The fact that pIgR can also facilitate pathogen entry, raises the question of whether pIgR is a host virulence factor, rather than an innate defense molecule. The apical-to-basolateral transcytosis of pIgR is rather inefficient and presence of FSC and sIgA in secretions should limit binding and retrograde transport of pathogens in IECs. However, an imbalance in any of these factors, or an overwhelming infection might favor pIgR-mediated retrograde transcytosis and invasion of IECs. So, in reality, whether pIgR is exclusively a component of innate immunity or might function as a host virulence factor in reovirus infection of IECs is an open question. Considering, the unconventional role of $\mathrm{pIgR}$ as a virulence factor, the findings of reovirus-mediated $\mathrm{pIgR}$ upregulation in IECs might rather promote viral pathogenesis than reinforcing host defense.

Expression of PIGR gene is a significant developmental response by epithelial cells that appears to be under the control of multiple environmental factors including infection. We have demonstrated that infection with an enteric pathogen, reovirus enhances PIGR gene transcription leading to upregulation of pIgR expression by IECs. It can be speculated that manipulation of $\mathrm{pIgR}$ expression early in life could provide means to improve innate 
resistance to mucosal infection, improve the efficacy of mucosal vaccines administered early in life, or improve the ability of the developing mucosal immune system to regulate itself properly. In the long term, one could propose innovative therapies using reovirus, either active or inactive, which 'mature' the mucosal immune system, particularly in infants. The outcomes of such therapy could result in improvement of the efficacy of mucosal vaccines or stimulate mucosal immune responses in infants. A 'mature' immune system in infants helps to combat the development of immunologic abnormalities such as dysregulated responses that could lead to allergies and / or autoimmune diseases that result from a lack of antigenic exposure early in life. Overall, this research will influence approaches to designing novel vaccines and therapeutics targeted against enteric virusmediated diseases including diarrhea that will greatly impact and improve public health, will deepen the understanding of IEC biology, host-virus interactions and ensuing innate and adaptive immune responses particularly in the intestinal tract. 


\section{GENERAL REFERENCES}

1. Ackermann, L. W., L. A. Wollenweber, and G. M. Denning. 1999. IL-4 and IFN-gamma increase steady state levels of polymeric Ig receptor mRNA in human airway and intestinal epithelial cells. J Immunol 162:5112-5118.

2. Acs, G., H. Klett, M. Schonberg, J. Christman, D. H. Levin, and S. C. Silverstein. 1971. Mechanism of reovirus double-stranded ribonucleic acid synthesis in vivo and in vitro. J Virol. 8:684-689.

3. Alain, T., K. Hirasawa, K. J. Pon, S. G. Nishikawa, S. J. Urbanski, Y. Auer, J. Luider, A. Martin, R. N. Johnston, A. Janowska-Wieczorek, P. W. Lee, and A. E. Kossakowska. 2002. Reovirus therapy of lymphoid malignancies. Blood 100:4146-4153.

4. Alexopoulou, L., A. C. Holt, R. Medzhitov, and R. A. Flavell. 2001. Recognition of double-stranded RNA and activation of NF-kappaB by Toll-like receptor 3. Nature 413:732-738.

5. Amerongen, H. M., G. A. Wilson, B. N. Fields, and M. R. Neutra. 1994. Proteolytic processing of reovirus is required for adherence to intestinal $\mathrm{M}$ cells. $\mathrm{J}$ Virol. 68:8428-8432.

6. Andrejeva, J., K. S. Childs, D. F. Young, T. S. Carlos, N. Stock, S. Goodbourn, and R. E. Randall. 2004. The V proteins of paramyxoviruses bind the IFN-inducible RNA helicase, mda-5, and inhibit its activation of the IFN-beta promoter. Proc. Natl. Acad. Sci. U. S. A 101:17264-17269.

7. Apodaca, G., L. A. Katz, and K. E. Mostov. 1994. Receptor-mediated transcytosis of IgA in MDCK cells is via apical recycling endosomes. J. Cell Biol. 125:67-86.

8. Armitage, R. J., W. C. Fanslow, L. Strockbine, T. A. Sato, K. N. Clifford, B. M. Macduff, D. M. Anderson, S. D. Gimpel, T. Davis-Smith, C. R. 
Maliszewski, and . 1992. Molecular and biological characterization of a murine ligand for CD40. Nature 357:80-82.

9. Armitage, R. J., C. R. Maliszewski, M. R. Alderson, K. H. Grabstein, M. K. Spriggs, and W. C. Fanslow. 1993. CD40L: a multi-functional ligand. Semin. Immunol 5:401-412.

10. Aroeti, B. and K. E. Mostov. 1994. Polarized sorting of the polymeric immunoglobulin receptor in the exocytotic and endocytotic pathways is controlled by the same amino acids. EMBO J. 13:2297-2304.

11. Asahi, Y., T. Yoshikawa, I. Watanabe, T. Iwasaki, H. Hasegawa, Y. Sato, S. Shimada, M. Nanno, Y. Matsuoka, M. Ohwaki, Y. Iwakura, Y. Suzuki, C. Aizawa, T. Sata, T. Kurata, and S. Tamura. 2002. Protection against influenza virus infection in polymeric Ig receptor knockout mice immunized intranasally with adjuvant-combined vaccines. J Immunol 168:2930-2938.

12. Asahi-Ozaki, Y., T. Yoshikawa, Y. Iwakura, Y. Suzuki, S. Tamura, T. Kurata, and T. Sata. 2004. Secretory IgA antibodies provide cross-protection against infection with different strains of influenza B virus. J Med. Virol. 74:328335.

13. Ashbolt, N. J. 2004. Microbial contamination of drinking water and disease outcomes in developing regions. Toxicology 198:229-238.

14. Bach, S. P., A. G. Renehan, and C. S. Potten. 2000. Stem cells: the intestinal stem cell as a paradigm. Carcinogenesis 21:469-476.

15. Bakos, M. A., A. Kurosky, and R. M. Goldblum. 1991. Characterization of a critical binding site for human polymeric Ig on secretory component. J Immunol 147:3419-3426.

16. Bakos, M. A., S. G. Widen, and R. M. Goldblum. 1994. Expression and purification of biologically active domain I of the human polymeric immunoglobulin receptor. Mol. Immunol 31:165-168.

17. Bals, R., X. Wang, Z. Wu, T. Freeman, V. Bafna, M. Zasloff, and J. M. Wilson. 1998. Human beta-defensin 2 is a salt-sensitive peptide antibiotic expressed in human lung. J Clin Invest 102:874-880. 
18. Barkon, M. L., B. L. Haller, and H. W. Virgin. 1996. Circulating immunoglobulin $\mathrm{G}$ can play a critical role in clearance of intestinal reovirus infection. J Virol. 70:1109-1116.

19. Barton, E. S., J. D. Chappell, J. L. Connolly, J. C. Forrest, and T. S. Dermody. 2001. Reovirus receptors and apoptosis. Virology 290:173-180.

20. Barton, E. S., J. L. Connolly, J. C. Forrest, J. D. Chappell, and T. S. Dermody. 2001. Utilization of sialic acid as a coreceptor enhances reovirus attachment by multistep adhesion strengthening. J Biol. Chem. 276:2200-2211.

21. Barton, E. S., J. C. Forrest, J. L. Connolly, J. D. Chappell, Y. Liu, F. J. Schnell, A. Nusrat, C. A. Parkos, and T. S. Dermody. 2001. Junction adhesion molecule is a receptor for reovirus. Cell 104:441-451.

22. Barton, E. S., B. E. Youree, D. H. Ebert, J. C. Forrest, J. L. Connolly, T. Valyi-Nagy, K. Washington, J. D. Wetzel, and T. S. Dermody. 2003. Utilization of sialic acid as a coreceptor is required for reovirus-induced biliary disease. J Clin. Invest 111:1823-1833.

23. Barton, G. M. and R. Medzhitov. 2003. Toll-like receptor signaling pathways. Science 300:1524-1525.

24. Bass, D. M., D. Bodkin, R. Dambrauskas, J. S. Trier, B. N. Fields, and J. L. Wolf. 1990. Intraluminal proteolytic activation plays an important role in replication of type 1 reovirus in the intestines of neonatal mice. J Virol. 64:18301833.

25. Beaulieu, J. F., P. H. Vachon, and S. Chartrand. 1991. Immunolocalization of extracellular matrix components during organogenesis in the human small intestine. Anat. Embryol. (Berl) 183:363-369.

26. Beg, A. A. and D. Baltimore. 1996. An essential role for NF-kappaB in preventing TNF-alpha-induced cell death. Science 274:782-784.

27. Bell, J. K., I. Botos, P. R. Hall, J. Askins, J. Shiloach, D. M. Segal, and D. R. Davies. 2005. The molecular structure of the Toll-like receptor 3 ligand-binding domain. Proc. Natl. Acad. Sci. U. S. A 102:10976-10980. 
28. Bell, J. K., G. E. Mullen, C. A. Leifer, A. Mazzoni, D. R. Davies, and D. M. Segal. 2003. Leucine-rich repeats and pathogen recognition in Toll-like receptors. Trends Immunol 24:528-533.

29. Berin, M. C., M. B. Dwinell, L. Eckmann, and M. F. Kagnoff. 2001. Production of MDC/CCL22 by human intestinal epithelial cells. Am. J Physiol Gastrointest. Liver Physiol 280:G1217-G1226.

30. Berneman, A., L. Belec, V. A. Fischetti, and J. P. Bouvet. 1998. The specificity patterns of human immunoglobulin $\mathrm{G}$ antibodies in serum differ from those in autologous secretions. Infect. Immun. 66:4163-4168.

31. Bjercke, S. and P. Brandtzaeg. 1993. Glandular distribution of immunoglobulins, J chain, secretory component, and HLA-DR in the human endometrium throughout the menstrual cycle. Hum. Reprod. 8:1420-1425.

32. Bjerknes, M. and H. Cheng. 1981. The stem-cell zone of the small intestinal epithelium. I. Evidence from Paneth cells in the adult mouse. Am. J Anat. 160:5163.

33. Bjerknes, M. and H. Cheng. 1981. The stem-cell zone of the small intestinal epithelium. II. Evidence from paneth cells in the newborn mouse. Am. J Anat. 160:65-75.

34. Blanch, V. J., J. F. Piskurich, and C. S. Kaetzel. 1999. Cutting edge: coordinate regulation of IFN regulatory factor-1 and the polymeric Ig receptor by proinflammatory cytokines. J. Immunol. 162:1232-1235.

35. Bodkin, D. K., M. L. Nibert, and B. N. Fields. 1989. Proteolytic digestion of reovirus in the intestinal lumens of neonatal mice. J Virol. 63:4676-4681.

36. Bomsel, M., M. Heyman, H. Hocini, S. Lagaye, L. Belec, C. Dupont, and C. Desgranges. 1998. Intracellular neutralization of HIV transcytosis across tight epithelial barriers by anti-HIV envelope protein dIgA or IgM. Immunity. 9:277287.

37. Bomsel, M. and K. E. Mostov. 1994. Both the Gs alpha and beta gamma subunits of the heterotrimeric G protein, Gs, control the sorting of the polymeric immunoglobulin receptor into transcytotic vesicles. Biochem. Soc. Trans. 22:463468. 
38. Bonizzi, G. and M. Karin. 2004. The two NF-kappaB activation pathways and their role in innate and adaptive immunity. Trends Immunol 25:280-288.

39. Borsutzky, S., B. B. Cazac, J. Roes, and C. A. Guzman. 2004. TGF-beta receptor signaling is critical for mucosal IgA responses. J Immunol 173:33053309.

40. Bos, J. L. 1989. ras oncogenes in human cancer: a review. Cancer Res. 49:46824689.

41. Bouvet, J. P. and V. A. Fischetti. 1999. Diversity of antibody-mediated immunity at the mucosal barrier. Infect. Immun. 67:2687-2691.

42. Brandtzaeg, P. 1971. Human secretory immunoglobulins. II. Salivary secretions from individuals with selectively excessive or defective synthesis of serum immunoglobulins. Clin Exp. Immunol 8:69-85.

43. Brandtzaeg, P. 1973. Structure, synthesis and external transfer of mucosal immunoglobulins. Ann. Immunol (Paris) 124:417-438.

44. Brandtzaeg, P. 1978. Polymeric IgA is complexed with secretory component (SC) on the surface of human intestinal epithelial cells. Scand. J Immunol 8:3952.

45. Brandtzaeg, P. 1985. Role of J chain and secretory component in receptormediated glandular and hepatic transport of immunoglobulins in man. Scand. J Immunol 22:111-146.

46. Brandtzaeg, P., A. E. Berstad, I. N. Farstad, G. Haraldsen, L. Helgeland, F. L. Jahnsen, F. E. Johansen, I. B. Natvig, E. M. Nilsen, and J. Rugtveit. 1997. Mucosal immunity--a major adaptive defence mechanism. Behring Inst. Mitt.123.

47. Brandtzaeg, P., I. N. Farstad, F. E. Johansen, H. C. Morton, I. N. Norderhaug, and T. Yamanaka. 1999. The B-cell system of human mucosae and exocrine glands. Immunol Rev. 171:45-87. 
48. Brandtzaeg, P., I. Fjellanger, and S. T. Gjeruldsen. 1970. Human secretory immunoglobulins. I. Salivary secretions from individuals with normal or low levels of serum immunoglobulins. Scand. J Haematol. Suppl 12:3-83.

49. Brandtzaeg, P., T. S. Halstensen, H. S. Huitfeldt, P. Krajci, D. Kvale, H. Scott, and P. S. Thrane. 1992. Epithelial expression of HLA, secretory component (poly-Ig receptor), and adhesion molecules in the human alimentary tract. Ann. N. Y. Acad. Sci. 664:157-179.

50. Branski, D., E. Lebenthal, H. Faden, T. F. Hatch, and J. Krasner. 1980. Small intestinal epithelial brush border enzymatic changes in suckling mice infected with reovirus type 3. Pediatr. Res. 14:803-805.

51. Bruno, M. E. and C. S. Kaetzel. 2005. Long-term exposure of the HT-29 human intestinal epithelial cell line to TNF causes sustained up-regulation of the polymeric Ig receptor and proinflammatory genes through transcriptional and posttranscriptional mechanisms. J Immunol 174:7278-7284.

52. Bruno, M. E., R. B. West, T. A. Schneeman, E. H. Bresnick, and C. S. Kaetzel. 2004. Upstream stimulatory factor but not c-Myc enhances transcription of the human polymeric immunoglobulin receptor gene. Mol. Immunol 40:695708.

53. Cario, E., D. Brown, M. McKee, K. Lynch-Devaney, G. Gerken, and D. K. Podolsky. 2002. Commensal-associated molecular patterns induce selective tolllike receptor-trafficking from apical membrane to cytoplasmic compartments in polarized intestinal epithelium. Am. J Pathol. 160:165-173.

54. Cario, E., G. Gerken, and D. K. Podolsky. 2002. "For whom the bell tolls!" -innate defense mechanisms and survival strategies of the intestinal epithelium against lumenal pathogens. Z. Gastroenterol. 40:983-990.

55. Cario, E. and D. K. Podolsky. 2000. Differential alteration in intestinal epithelial cell expression of toll-like receptor 3 (TLR3) and TLR4 in inflammatory bowel disease. Infect. Immun. 68:7010-7017.

56. Cario, E., I. M. Rosenberg, S. L. Brandwein, P. L. Beck, H. C. Reinecker, and D. K. Podolsky. 2000. Lipopolysaccharide activates distinct signaling pathways in intestinal epithelial cell lines expressing Toll-like receptors. J Immunol 164:966-972. 
57. Casanova, J. E., G. Apodaca, and K. E. Mostov. 1991. An autonomous signal for basolateral sorting in the cytoplasmic domain of the polymeric immunoglobulin receptor. Cell 66:65-75.

58. Casanova, J. E., P. P. Breitfeld, S. A. Ross, and K. E. Mostov. 1990. Phosphorylation of the polymeric immunoglobulin receptor required for its efficient transcytosis. Science 248:742-745.

59. Casola, A., R. P. Garofalo, S. E. Crawford, M. K. Estes, F. Mercurio, S. E. Crowe, and A. R. Brasier. 2002. Interleukin-8 gene regulation in intestinal epithelial cells infected with rotavirus: role of viral-induced IkappaB kinase activation. Virology 298:8-19.

60. Cazac, B. B. and J. Roes. 2000. TGF-beta receptor controls B cell responsiveness and induction of IgA in vivo. Immunity. 13:443-451.

61. Chadee, K., W. A. Petri, Jr., D. J. Innes, and J. I. Ravdin. 1987. Rat and human colonic mucins bind to and inhibit adherence lectin of Entamoeba histolytica. J Clin Invest 80:1245-1254.

62. Chapman, R. S., E. K. Duff, P. C. Lourenco, E. Tonner, D. J. Flint, A. R. Clarke, and C. J. Watson. 2000. A novel role for IRF-1 as a suppressor of apoptosis. Oncogene 19:6386-6391.

63. Chapuis, R. M. and M. E. Koshland. 1975. Linkage and assembly of polymeric IgA immunoglobulins. Biochemistry 14:1320-1326.

64. Chen, D., F. Lee, J. J. Cebra, and D. H. Rubin. 1997. Predominant T-cell receptor Vbeta usage of intraepithelial lymphocytes during the immune response to enteric reovirus infection. J Virol. 71:3431-3436.

65. Chinery, R., J. Williamson, and R. Poulsom. 1996. The gene encoding human intestinal trefoil factor (TFF3) is located on chromosome 21q22.3 clustered with other members of the trefoil peptide family. Genomics 32:281-284.

66. Chintalacharuvu, K. R. and S. L. Morrison. 1997. Production of secretory immunoglobulin A by a single mammalian cell. Proc. Natl. Acad. Sci. U. S. A 94:6364-6368. 
67. Claessens, F., G. Verrijdt, E. Schoenmakers, A. Haelens, B. Peeters, G. Verhoeven, and W. Rombauts. 2001. Selective DNA binding by the androgen receptor as a mechanism for hormone-specific gene regulation. J Steroid Biochem. Mol. Biol. 76:23-30.

68. Clarke, P., R. L. Debiasi, S. M. Meintzer, B. A. Robinson, and K. L. Tyler. 2005. Inhibition of NF-kappa B activity and cFLIP expression contribute to viralinduced apoptosis. Apoptosis. 10:513-524.

69. Clarke, P., S. M. Meintzer, L. A. Moffitt, and K. L. Tyler. 2003. Two distinct phases of virus-induced nuclear factor kappa $B$ regulation enhance tumor necrosis factor-related apoptosis-inducing ligand-mediated apoptosis in virus-infected cells. J Biol. Chem. 278:18092-18100.

70. Clarke, P., S. M. Meintzer, C. Widmann, G. L. Johnson, and K. L. Tyler. 2001. Reovirus infection activates JNK and the JNK-dependent transcription factor c-Jun. J Virol. 75:11275-11283.

71. Coffey, M. C., J. E. Strong, P. A. Forsyth, and P. W. Lee. 1998. Reovirus therapy of tumors with activated Ras pathway. Science 282:1332-1334.

72. Cohen, P. S. and D. C. Laux. 1995. Bacterial adhesion to and penetration of intestinal mucus in vitro. Methods Enzymol. 253:309-314.

73. Connolly, J. L., S. E. Rodgers, P. Clarke, D. W. Ballard, L. D. Kerr, K. L. Tyler, and T. S. Dermody. 2000. Reovirus-induced apoptosis requires activation of transcription factor NF-kappaB. J. Virol. 74:2981-2989.

74. Coyne, R. S., M. Siebrecht, M. C. Peitsch, and J. E. Casanova. 1994. Mutational analysis of polymeric immunoglobulin receptor/ligand interactions. Evidence for the involvement of multiple complementarity determining region (CDR)-like loops in receptor domain I. J Biol. Chem. 269:31620-31625.

75. Craig, S. W. and J. J. Cebra. 1971. Peyer's patches: an enriched source of precursors for IgA-producing immunocytes in the rabbit. J Exp. Med. 134:188200.

76. Crottet, P. and B. Corthesy. 1998. Secretory component delays the conversion of secretory IgA into antigen-binding competent $F\left(a^{\prime}\right) 2$ : a possible implication for mucosal defense. J Immunol 161:5445-5453. 
77. Cuff, C. F., C. K. Cebra, D. H. Rubin, and J. J. Cebra. 1993. Developmental relationship between cytotoxic alpha/beta $\mathrm{T}$ cell receptor-positive intraepithelial lymphocytes and Peyer's patch lymphocytes. Eur. J Immunol 23:1333-1339.

78. Cuff, C. F., E. Lavi, C. K. Cebra, J. J. Cebra, and D. H. Rubin. 1990. Passive immunity to fatal reovirus serotype 3 -induced meningoencephalitis mediated by both secretory and transplacental factors in neonatal mice. J Virol. 64:1256-1263.

79. Dallas, S. D. and R. D. Rolfe. 1998. Binding of Clostridium difficile toxin A to human milk secretory component. J Med. Microbiol 47:879-888.

80. Darmoul, D., D. Brown, M. E. Selsted, and A. J. Ouellette. 1997. Cryptdin gene expression in developing mouse small intestine. Am. J Physiol 272:G197G206.

81. de Araujo, A. N. and L. G. Giugliano. 2001. Lactoferrin and free secretory component of human milk inhibit the adhesion of enteropathogenic Escherichia coli to HeLa cells. BMC. Microbiol 1:25.

82. de Oliveira, I. R., A. N. de Araujo, S. N. Bao, and L. G. Giugliano. 2001. Binding of lactoferrin and free secretory component to enterotoxigenic Escherichia coli. FEMS Microbiol Lett. 203:29-33.

83. Debiasi, R. L., C. L. Edelstein, B. Sherry, and K. L. Tyler. 2001. Calpain inhibition protects against virus-induced apoptotic myocardial injury. J. Virol. 75:351-361.

84. Debiasi, R. L., M. K. Squier, B. Pike, M. Wynes, T. S. Dermody, J. J. Cohen, and K. L. Tyler. 1999. Reovirus-induced apoptosis is preceded by increased cellular calpain activity and is blocked by calpain inhibitors. J. Virol. 73:695-701.

85. Deitcher, D. L. and K. E. Mostov. 1986. Alternate splicing of rabbit polymeric immunoglobulin receptor. Mol. Cell Biol. 6:2712-2715.

86. Delacroix, D. L., C. Dive, J. C. Rambaud, and J. P. Vaerman. 1982. IgA subclasses in various secretions and in serum. Immunology 47:383-385. 
87. Delhase, M. and M. Karin. 1999. The I kappa B kinase: a master regulator of NF-kappa B, innate immunity, and epidermal differentiation. Cold Spring Harb. Symp. Quant. Biol. 64:491-503.

88. Diamond, G., D. E. Jones, and C. L. Bevins. 1993. Airway epithelial cells are the site of expression of a mammalian antimicrobial peptide gene. Proc. Natl. Acad. Sci. U. S. A 90:4596-4600.

89. Diamond, G., J. P. Russell, and C. L. Bevins. 1996. Inducible expression of an antibiotic peptide gene in lipopolysaccharide-challenged tracheal epithelial cells. Proc. Natl. Acad. Sci. U. S. A 93:5156-5160.

90. Diamond, G., M. Zasloff, H. Eck, M. Brasseur, W. L. Maloy, and C. L. Bevins. 1991. Tracheal antimicrobial peptide, a cysteine-rich peptide from mammalian tracheal mucosa: peptide isolation and cloning of a cDNA. Proc. Natl. Acad. Sci. U. S. A 88:3952-3956.

91. Diebold, S. S., T. Kaisho, H. Hemmi, S. Akira, and Reis e Sousa. 2004. Innate antiviral responses by means of TLR7-mediated recognition of single-stranded RNA. Science 303:1529-1531.

92. Eisenhauer, P. B., S. S. Harwig, and R. I. Lehrer. 1992. Cryptdins: antimicrobial defensins of the murine small intestine. Infect. Immun. 60:35563565 .

93. Elewaut, D., J. A. DiDonato, J. M. Kim, F. Truong, L. Eckmann, and M. F. Kagnoff. 1999. NF-kappa B is a central regulator of the intestinal epithelial cell innate immune response induced by infection with enteroinvasive bacteria. J Immunol 163:1457-1466.

94. Elkins, K. L., R. M. Buller, P. W. Stashak, and P. J. Baker. 1991. CD4+ T cells regulate the magnitude of the antibody response to several helper $\mathrm{T}$ cell independent antigens. Immunobiology 183:69-78.

95. Elm, C., R. Braathen, S. Bergmann, R. Frank, J. P. Vaerman, C. S. Kaetzel, G. S. Chhatwal, F. E. Johansen, and S. Hammerschmidt. 2004. Ectodomains 3 and 4 of human polymericiImmunoglobulin receptor (hpIgR) mediate invasion of Streptococcus pneumoniae into the epithelium. J Biol. Chem. 279:6296-6304. 
96. Fallgreen-Gebauer, E., W. Gebauer, A. Bastian, H. D. Kratzin, H. Eiffert, B. Zimmermann, M. Karas, and N. Hilschmann. 1993. The covalent linkage of secretory component to IgA. Structure of sIgA. Biol. Chem. Hoppe Seyler 374:1023-1028.

97. Fan, J. Y., C. S. Boyce, and C. F. Cuff. 1998. T-helper 1 and T-helper 2 cytokine responses in gut-associated lymphoid tissue following enteric reovirus infection. Cell Immunol 188:55-63.

98. Fang, G. D., A. A. Lima, C. V. Martins, J. P. Nataro, and R. L. Guerrant. 1995. Etiology and epidemiology of persistent diarrhea in northeastern Brazil: a hospital-based, prospective, case-control study. J Pediatr. Gastroenterol. Nutr 21:137-144.

99. Farone, A. L., P. C. O'Brien, and D. C. Cox. 1993. Tumor necrosis factor-alpha induction by reovirus serotype 3. J Leukoc. Biol. 53:133-137.

100. Farrell, J. J., D. Taupin, T. J. Koh, D. Chen, C. M. Zhao, D. K. Podolsky, and T. C. Wang. 2002. TFF2/SP-deficient mice show decreased gastric proliferation, increased acid secretion, and increased susceptibility to NSAID injury. J Clin Invest 109:193-204.

101. Fawaz, L. M., E. Sharif-Askari, and J. Menezes. 1999. Up-regulation of NK cytotoxic activity via IL-15 induction by different viruses: a comparative study. J Immunol 163:4473-4480.

102. Fernandez, M. I., T. Pedron, R. Tournebize, J. C. Olivo-Marin, P. J. Sansonetti, and A. Phalipon. 2003. Anti-inflammatory role for intracellular dimeric immunoglobulin a by neutralization of lipopolysaccharide in epithelial cells. Immunity. 18:739-749.

103. Fleeton, M. N., N. Contractor, F. Leon, J. D. Wetzel, T. S. Dermody, and B. L. Kelsall. 2004. Peyer's patch dendritic cells process viral antigen from apoptotic epithelial cells in the intestine of reovirus-infected mice. J Exp. Med. 200:235245.

104. Forstner, J. F. 1978. Intestinal mucins in health and disease. Digestion 17:234263. 
105. Forstner, J. F., N. W. Roomi, R. E. Fahim, and G. G. Forstner. 1981. Cholera toxin stimulates secretion of immunoreactive intestinal mucin. Am. J Physiol 240:G10-G16.

106. Frey, A., K. T. Giannasca, R. Weltzin, P. J. Giannasca, H. Reggio, W. I. Lencer, and M. R. Neutra. 1996. Role of the glycocalyx in regulating access of microparticles to apical plasma membranes of intestinal epithelial cells: implications for microbial attachment and oral vaccine targeting. J Exp. Med. 184:1045-1059.

107. Fujita, Y., A. T. Cheung, and T. J. Kieffer. 2004. Harnessing the gut to treat diabetes. Pediatr. Diabetes 5 Suppl 2:57-69.

108. Fulton, J. R., J. Smith, C. Cunningham, and C. F. Cuff. 2004. Influence of the route of infection on development of T-cell receptor beta-chain repertoires of reovirus-specific cytotoxic T lymphocytes. J Virol. 78:1582-1590.

109. Funami, K., M. Matsumoto, H. Oshiumi, T. Akazawa, A. Yamamoto, and T. Seya. 2004. The cytoplasmic 'linker region' in Toll-like receptor 3 controls receptor localization and signaling. Int. Immunol 16:1143-1154.

110. Funda, D. P., L. Tuckova, M. A. Farre, T. Iwase, I. Moro, and H. TlaskalovaHogenova. 2001. CD14 is expressed and released as soluble CD14 by human intestinal epithelial cells in vitro: lipopolysaccharide activation of epithelial cells revisited. Infect. Immun. 69:3772-3781.

111. Ganz, T. and R. I. Lehrer. 1995. Defensins. Pharmacol. Ther. 66:191-205.

112. Gebhard, A. and A. Gebert. 1999. Brush cells of the mouse intestine possess a specialized glycocalyx as revealed by quantitative lectin histochemistry. Further evidence for a sensory function. J Histochem. Cytochem. 47:799-808.

113. George, A., S. I. Kost, C. L. Witzleben, J. J. Cebra, and D. H. Rubin. 1990. Reovirus-induced liver disease in severe combined immunodeficient (SCID) mice. A model for the study of viral infection, pathogenesis, and clearance. J Exp. Med. 171:929-934. 
114. Gewirtz, A. T., T. A. Navas, S. Lyons, P. J. Godowski, and J. L. Madara. 2001. Cutting edge: bacterial flagellin activates basolaterally expressed TLR5 to induce epithelial proinflammatory gene expression. J Immunol 167:1882-1885.

115. Giancotti, F. G. 2003. A structural view of integrin activation and signaling. Dev. Cell 4:149-151.

116. Giancotti, F. G. and E. Ruoslahti. 1999. Integrin signaling. Science 285:10281032.

117. Girardin, S. E., R. Tournebize, M. Mavris, A. L. Page, X. Li, G. R. Stark, J. Bertin, P. S. DiStefano, M. Yaniv, P. J. Sansonetti, and D. J. Philpott. 2001. CARD4/Nod1 mediates NF-kappaB and JNK activation by invasive Shigella flexneri. EMBO Rep. 2:736-742.

118. Giugliano, L. G., S. T. Ribeiro, M. H. Vainstein, and C. J. Ulhoa. 1995. Free secretory component and lactoferrin of human milk inhibit the adhesion of enterotoxigenic Escherichia coli. J Med. Microbiol 42:3-9.

119. Gordon, J. I. 1989. Intestinal epithelial differentiation: new insights from chimeric and transgenic mice. J Cell Biol. 108:1187-1194.

120. Gordon, J. I. and M. L. Hermiston. 1994. Differentiation and self-renewal in the mouse gastrointestinal epithelium. Curr. Opin. Cell Biol. 6:795-803.

121. Grand, R. J., J. B. Watkins, and F. M. Torti. 1976. Development of the human gastrointestinal tract. A review. Gastroenterology 70:790-810.

122. Grey, H. M., C. A. Abel, W. J. Yount, and H. G. Kunkel. 1968. A subclass of human gamma-A-globulins (gamma-A2) which lacks the disulfied bonds linking heavy and light chains. J Exp. Med. 128:1223-1236.

123. Griffiss, J. M. 1983. Biologic function of the serum IgA system: modulation of complement-mediated effector mechanisms and conservation of antigenic mass. Ann. N. Y. Acad. Sci. 409:697-707.

124. Guerrant, R. L. 1994. Lessons from diarrheal diseases: demography to molecular pharmacology. J Infect. Dis. 169:1206-1218. 
125. Guerrant, R. L., B. A. Carneiro-Filho, and R. A. Dillingham. 2003. Cholera, diarrhea, and oral rehydration therapy: triumph and indictment. Clin Infect. Dis. 37:398-405.

126. Guerrant, R. L., J. M. Hughes, N. L. Lima, and J. Crane. 1990. Diarrhea in developed and developing countries: magnitude, special settings, and etiologies. Rev. Infect. Dis. 12 Suppl 1:S41-S50.

127. Guerrant, R. L., A. A. Lima, M. Barboza, S. Young, T. Silva, L. Barrett, Y. Bao, J. Fox, and S. Moore. 1999. Mechanisms and impact of enteric infections. Adv. Exp. Med. Biol. 473:103-112.

128. Haelens, A., G. Verrijdt, E. Schoenmakers, P. Alen, B. Peeters, W. Rombauts, and F. Claessens. 1999. The first exon of the human sc gene contains an androgen responsive unit and an interferon regulatory factor element. Mol. Cell Endocrinol. 153:91-102.

129. Haller, B. L., M. L. Barkon, G. P. Vogler, and H. W. Virgin. 1995. Genetic mapping of reovirus virulence and organ tropism in severe combined immunodeficient mice: organ-specific virulence genes. J Virol. 69:357-364.

130. Halpern, M. S. and M. E. Koshland. 1973. The stoichiometry of J chain in human secretory IgA. J Immunol 111:1653-1660.

131. Hamamdzic, D., T. Phillips-Dorsett, S. Altman-Hamamdzic, S. D. London, and L. London. 2001. Reovirus triggers cell type-specific proinflammatory responses dependent on the autocrine action of IFN-beta. Am. J Physiol Lung Cell Mol. Physiol 280:L18-L29.

132. Hamburger, A. E., A. P. West, Jr., and P. J. Bjorkman. 2004. Crystal structure of a polymeric immunoglobulin binding fragment of the human polymeric immunoglobulin receptor. Structure. 12:1925-1935.

133. Hammerschmidt, S., S. R. Talay, P. Brandtzaeg, and G. S. Chhatwal. 1997. SpsA, a novel pneumococcal surface protein with specific binding to secretory immunoglobulin A and secretory component. Mol. Microbiol 25:1113-1124.

134. Hammerschmidt, S., M. P. Tillig, S. Wolff, J. P. Vaerman, and G. S. Chhatwal. 2000. Species-specific binding of human secretory component to 
SpsA protein of Streptococcus pneumoniae via a hexapeptide motif. Mol. Microbiol 36:726-736.

135. Hayashi, F., K. D. Smith, A. Ozinsky, T. R. Hawn, E. C. Yi, D. R. Goodlett, J. K. Eng, S. Akira, D. M. Underhill, and A. Aderem. 2001. The innate immune response to bacterial flagellin is mediated by Toll-like receptor 5. Nature 410:1099-1103.

136. Hayashi, T., M. Morimoto, H. Iwata, and T. Onodera. 1998. Interferon-gamma plays a role in pancreatic islet-cell destruction of reovirus type 2-induced diabetes-like syndrome in DBA/1 suckling mice. Int. J Exp. Pathol. 79:313-320.

137. Hayashi, T., M. Morimoto, H. Iwata, and T. Onodera. 2001. Possible involvement of IL-12 in reovirus type-2-induced diabetes in newborn DBA/1 mice. Scand. J Immunol 53:572-578.

138. Hayashi, T., Y. Yasutomi, K. Hasegawa, Y. Sasaki, and T. Onodera. 2003. Interleukin-4-expressing plasmid DNA inhibits reovirus type-2-triggered autoimmune insulitis in DBA/1 J suckling mice. Int. J Exp. Pathol. 84:101-106.

139. Hecht, G. 1999. Innate mechanisms of epithelial host defense: spotlight on intestine. Am. J Physiol 277:C351-C358.

140. Heil, F., H. Hemmi, H. Hochrein, F. Ampenberger, C. Kirschning, S. Akira, G. Lipford, H. Wagner, and S. Bauer. 2004. Species-specific recognition of single-stranded RNA via toll-like receptor 7 and 8. Science 303:1526-1529.

141. Helander, A., K. J. Silvey, N. J. Mantis, A. B. Hutchings, K. Chandran, W. T. Lucas, M. L. Nibert, and M. R. Neutra. 2003. The viral sigma1 protein and glycoconjugates containing alpha2-3-linked sialic acid are involved in type 1 reovirus adherence to M cell apical surfaces. J Virol. 77:7964-7977.

142. Hempen, P. M., K. M. Phillips, P. S. Conway, K. H. Sandoval, T. A. Schneeman, H. J. Wu, and C. S. Kaetzel. 2002. Transcriptional regulation of the human polymeric Ig receptor gene: analysis of basal promoter elements. J. Immunol. 169:1912-1921.

143. Hendrickson, B. A., D. A. Conner, D. J. Ladd, D. Kendall, J. E. Casanova, B. Corthesy, E. E. Max, M. R. Neutra, C. E. Seidman, and J. G. Seidman. 1995. 
Altered hepatic transport of immunoglobulin A in mice lacking the J chain. J Exp. Med. 182:1905-1911.

144. Hendrickson, B. A., L. Rindisbacher, B. Corthesy, D. Kendall, D. A. Waltz, M. R. Neutra, and J. G. Seidman. 1996. Lack of association of secretory component with IgA in J chain-deficient mice. J Immunol 157:750-754.

145. Hermos, J. A., M. Mathan, and J. S. Trier. 1971. DNA synthesis and proliferation by villous epithelial cells in fetal rats. J Cell Biol. 50:255-258.

146. Hexham, J. M., K. D. White, L. N. Carayannopoulos, W. Mandecki, R. Brisette, Y. S. Yang, and J. D. Capra. 1999. A human immunoglobulin (Ig)A calpha3 domain motif directs polymeric Ig receptor-mediated secretion. J Exp. Med. 189:747-752.

147. Hiemstra, P. S., A. Gorter, M. E. Stuurman, L. A. van Es, and M. R. Daha. 1987. Activation of the alternative pathway of complement by human serum IgA. Eur. J Immunol 17:321-326.

148. Hirasawa, K., S. G. Nishikawa, K. L. Norman, T. Alain, A. Kossakowska, and P. W. Lee. 2002. Oncolytic reovirus against ovarian and colon cancer. Cancer Res. 62:1696-1701.

149. Hirt, R. P., G. J. Hughes, S. Frutiger, P. Michetti, C. Perregaux, O. PoulainGodefroy, N. Jeanguenat, M. R. Neutra, and J. P. Kraehenbuhl. 1993. Transcytosis of the polymeric Ig receptor requires phosphorylation of serine 664 in the absence but not the presence of dimeric IgA. Cell 74:245-255.

150. Hooper, L. V., M. H. Wong, A. Thelin, L. Hansson, P. G. Falk, and J. I. Gordon. 2001. Molecular analysis of commensal host-microbial relationships in the intestine. Science 291:881-884.

151. Horiuchi, K., I. Naito, K. Nakano, S. Nakatani, K. Nishida, T. Taguchi, and A. Ohtsuka. 2005. Three-dimensional ultrastructure of the brush border glycocalyx in the mouse small intestine: a high resolution scanning electron microscopic study. Arch. Histol. Cytol. 68:51-56.

152. Hornef, M. W., T. Frisan, A. Vandewalle, S. Normark, and A. RichterDahlfors. 2002. Toll-like receptor 4 resides in the Golgi apparatus and 
colocalizes with internalized lipopolysaccharide in intestinal epithelial cells. $\mathrm{J}$ Exp. Med. 195:559-570.

153. Hornef, M. W., B. H. Normark, A. Vandewalle, and S. Normark. 2003. Intracellular recognition of lipopolysaccharide by toll-like receptor 4 in intestinal epithelial cells. J Exp. Med. 198:1225-1235.

154. Hutchings, A. B., A. Helander, K. J. Silvey, K. Chandran, W. T. Lucas, M. L. Nibert, and M. R. Neutra. 2004. Secretory immunoglobulin A antibodies against the sigma1 outer capsid protein of reovirus type 1 Lang prevent infection of mouse Peyer's patches. J Virol. 78:947-957.

155. Inman, F. P. and J. Mestecky. 1974. The J chain of polymeric immunoglobulins. Contemp. Top. Mol. Immunol 3:111-141.

156. Inohara, N. and G. Nunez. 2001. The NOD: a signaling module that regulates apoptosis and host defense against pathogens. Oncogene 20:6473-6481.

157. Inohara, N. and G. Nunez. 2003. NODs: intracellular proteins involved in inflammation and apoptosis. Nat. Rev. Immunol 3:371-382.

158. Inohara, N., Y. Ogura, and G. Nunez. 2002. Nods: a family of cytosolic proteins that regulate the host response to pathogens. Curr. Opin. Microbiol 5:7680 .

159. Iwaki, D., H. Mitsuzawa, S. Murakami, H. Sano, M. Konishi, T. Akino, and Y. Kuroki. 2002. The extracellular toll-like receptor 2 domain directly binds peptidoglycan derived from Staphylococcus aureus. J Biol. Chem. 277:2431524320 .

160. Izadpanah, A., M. B. Dwinell, L. Eckmann, N. M. Varki, and M. F. Kagnoff. 2001. Regulated MIP-3alpha/CCL20 production by human intestinal epithelium: mechanism for modulating mucosal immunity. Am. J Physiol Gastrointest. Liver Physiol 280:G710-G719.

161. Jan, J. T., B. H. Chen, S. H. Ma, C. I. Liu, H. P. Tsai, H. C. Wu, S. Y. Jiang, K. D. Yang, and M. F. Shaio. 2000. Potential dengue virus-triggered apoptotic pathway in human neuroblastoma cells: arachidonic acid, superoxide anion, and NF-kappaB are sequentially involved. J Virol. 74:8680-8691. 
162. Janoff, E. N., C. Fasching, J. M. Orenstein, J. B. Rubins, N. L. Opstad, and A. P. Dalmasso. 1999. Killing of Streptococcus pneumoniae by capsular polysaccharide-specific polymeric IgA, complement, and phagocytes. J Clin Invest 104:1139-1147.

163. Jenkins, S. L., J. Wang, M. Vazir, J. Vela, O. Sahagun, P. Gabbay, L. Hoang, R. L. Diaz, R. Aranda, and M. G. Martin. 2003. Role of passive and adaptive immunity in influencing enterocyte-specific gene expression. Am. J Physiol Gastrointest. Liver Physiol 285:G714-G725.

164. Johansen, F. E., B. A. Bosloven, P. Krajci, and P. Brandtzaeg. 1998. A composite DNA element in the promoter of the polymeric immunoglobulin receptor regulates its constitutive expression. Eur. J. Immunol. 28:1161-1171.

165. Johansen, F. E., R. Braathen, and P. Brandtzaeg. 2000. Role of J chain in secretory immunoglobulin formation. Scand. J Immunol 52:240-248.

166. Johansen, F. E., R. Braathen, and P. Brandtzaeg. 2001. The J chain is essential for polymeric Ig receptor-mediated epithelial transport of IgA. J Immunol 167:5185-5192.

167. Johansen, F. E., M. Pekna, I. N. Norderhaug, B. Haneberg, M. A. Hietala, P. Krajci, C. Betsholtz, and P. Brandtzaeg. 1999. Absence of epithelial immunoglobulin A transport, with increased mucosal leakiness, in polymeric immunoglobulin receptor/secretory component-deficient mice. J. Exp. Med. 190:915-922.

168. Joklik, W. K. and M. R. Roner. 1996. Molecular recognition in the assembly of the segmented reovirus genome. Prog. Nucleic Acid Res. Mol. Biol. 53:249-281.

169. Kaetzel, C. S. 2005. The polymeric immunoglobulin receptor: bridging innate and adaptive immune responses at mucosal surfaces. Immunol Rev. 206:83-99.

170. Kaetzel, C. S., V. J. Blanch, P. M. Hempen, K. M. Phillips, J. F. Piskurich, and K. R. Youngman. 1997. The polymeric immunoglobulin receptor: structure and synthesis. Biochem. Soc. Trans. 25:475-480.

171. Kaetzel, C. S., J. K. Robinson, K. R. Chintalacharuvu, J. P. Vaerman, and M. E. Lamm. 1991. The polymeric immunoglobulin receptor (secretory 
component) mediates transport of immune complexes across epithelial cells: a local defense function for IgA. Proc. Natl. Acad. Sci. U. S. A 88:8796-8800.

172. Kagan, B. L., T. Ganz, and R. I. Lehrer. 1994. Defensins: a family of antimicrobial and cytotoxic peptides. Toxicology 87:131-149.

173. Kahn, E. 2004. Biliary atresia revisited. Pediatr. Dev. Pathol. 7:109-124.

174. Kang, D. C., R. V. Gopalkrishnan, Q. Wu, E. Jankowsky, A. M. Pyle, and P. B. Fisher. 2002. mda-5: An interferon-inducible putative RNA helicase with double-stranded RNA-dependent ATPase activity and melanoma growthsuppressive properties. Proc. Natl. Acad. Sci. U. S. A 99:637-642.

175. Kantele, A. 1992. Mucosa--the first specific immune defense system in the body. Duodecim 108:2088-2096.

176. Karam, S. M. 1995. New insights into the stem cells and the precursors of the gastric epithelium. Nutrition 11:607-613.

177. Karin, M. and M. Delhase. 2000. The I kappa B kinase (IKK) and NF-kappa B: key elements of proinflammatory signalling. Semin. Immunol 12:85-98.

178. Karin, M. and A. Lin. 2002. NF-kappaB at the crossroads of life and death. Nat. Immunol 3:221-227.

179. Kato, H., R. Kato, K. Fujihashi, and J. R. McGhee. 2001. Role of mucosal antibodies in viral infections. Curr. Top. Microbiol Immunol 260:201-228.

180. Kauffman, R. S., J. L. Wolf, R. Finberg, J. S. Trier, and B. N. Fields. 1983. The sigma 1 protein determines the extent of spread of reovirus from the gastrointestinal tract of mice. Virology 124:403-410.

181. Kaushic, C., J. M. Richardson, and C. R. Wira. 1995. Regulation of polymeric immunoglobulin A receptor messenger ribonucleic acid expression in rodent uteri: effect of sex hormones. Endocrinology 136:2836-2844.

182. Kawanishi, H., L. Saltzman, and W. Strober. 1983. Mechanisms regulating IgA class-specific immunoglobulin production in murine gut-associated lymphoid 
tissues. II. Terminal differentiation of postswitch sIgA-bearing Peyer's patch B cells. J Exp. Med. 158:649-669.

183. Kawanishi, H., L. E. Saltzman, and W. Strober. 1983. Mechanisms regulating IgA class-specific immunoglobulin production in murine gut-associated lymphoid tissues. I. T cells derived from Peyer's patches that switch sIgM B cells to sIgA B cells in vitro. J Exp. Med. 157:433-450.

184. Kelly, D., S. Conway, and R. Aminov. 2005. Commensal gut bacteria: mechanisms of immune modulation. Trends Immunol 26:326-333.

185. Kiermaier, A., J. M. Gawn, L. Desbarats, R. Saffrich, W. Ansorge, P. J. Farrell, M. Eilers, and G. Packham. 1999. DNA binding of USF is required for specific E-box dependent gene activation in vivo. Oncogene 18:7200-7211.

186. Kilian, M. and K. Holmgren. 1981. Ecology and nature of immunoglobulin A1 protease-producing streptococci in the human oral cavity and pharynx. Infect. Immun. 31:868-873.

187. Kilian, M., J. Mestecky, R. Kulhavy, M. Tomana, and W. T. Butler. 1980. IgA1 proteases from Haemophilus influenzae, Streptococcus pneumoniae, Neisseria meningitidis, and Streptococcus sanguis: comparative immunochemical studies. J Immunol 124:2596-2600.

188. Kilian, M., J. Mestecky, and M. W. Russell. 1988. Defense mechanisms involving $\mathrm{Fc}$-dependent functions of immunoglobulin A and their subversion by bacterial immunoglobulin A proteases. Microbiol Rev. 52:296-303.

189. Kilian, M., J. Mestecky, and R. E. Schrohenloher. 1979. Pathogenic species of the genus Haemophilus and Streptococcus pneumoniae produce immunoglobulin A1 protease. Infect. Immun. 26:143-149.

190. Kilian, M., J. Reinholdt, H. Lomholt, K. Poulsen, and E. V. Frandsen. 1996. Biological significance of IgA1 proteases in bacterial colonization and pathogenesis: critical evaluation of experimental evidence. APMIS 104:321-338.

191. Kilian, M., B. Thomsen, T. E. Petersen, and H. S. Bleeg. 1983. Occurrence and nature of bacterial IgA proteases. Ann. N. Y. Acad. Sci. 409:612-624. 
192. Kindon, H., C. Pothoulakis, L. Thim, K. Lynch-Devaney, and D. K.

Podolsky. 1995. Trefoil peptide protection of intestinal epithelial barrier function: cooperative interaction with mucin glycoprotein. Gastroenterology 109:516-523.

193. Kopp, E. B. and R. Medzhitov. 1999. The Toll-receptor family and control of innate immunity. Curr. Opin. Immunol 11:13-18.

194. Koshland, M. E. 1975. Structure and function of the J chain. Adv. Immunol 20:41-69.

195. Koshland, M. E. 1985. The coming of age of the immunoglobulin J chain. Annu. Rev. Immunol 3:425-453.

196. Krajci, P., D. Kvale, K. Tasken, and P. Brandtzaeg. 1992. Molecular cloning and exon-intron mapping of the gene encoding human transmembrane secretory component (the poly-Ig receptor). Eur. J Immunol 22:2309-2315.

197. Kramer, D. R. and J. J. Cebra. 1995. Role of maternal antibody in the induction of virus specific and bystander IgA responses in Peyer's patches of suckling mice. Int. Immunol 7:911-918.

198. Kvale, D. and P. Brandtzaeg. 1995. Butyrate differentially affects constitutive and cytokine-induced expression of HLA molecules, secretory component (SC), and ICAM-1 in a colonic epithelial cell line (HT-29, clone m3). Adv. Exp. Med. Biol. 371A:183-188.

199. Kvale, D. and P. Brandtzaeg. 1995. Constitutive and cytokine induced expression of HLA molecules, secretory component, and intercellular adhesion molecule-1 is modulated by butyrate in the colonic epithelial cell line HT-29. Gut 36:737-742.

200. Lamm, M. E. 1997. Interaction of antigens and antibodies at mucosal surfaces. Annu. Rev. Microbiol 51:311-340.

201. Lamm, M. E., M. B. Mazaneca, J. G. Nedrud, and C. S. Kaetzel. 1995. New functions for mucosal IgA. Adv. Exp. Med. Biol. 371A:647-650.

202. Lamm, M. E., J. G. Nedrud, C. S. Kaetzel, and M. B. Mazanec. 1995. IgA and mucosal defense. APMIS 103:241-246. 
203. Lamm, M. E. and J. M. Phillips-Quagliata. 2002. Origin and homing of intestinal IgA antibody-secreting cells. J Exp. Med. 195:F5-F8.

204. Lamm, M. E., J. K. Robinson, and C. S. Kaetzel. 1992. Transport of IgA immune complexes across epithelial membranes: new concepts in mucosal immunity. Adv. Exp. Med. Biol. 327:91-94.

205. Lamping, N., R. Dettmer, N. W. Schroder, D. Pfeil, W. Hallatschek, R. Burger, and R. R. Schumann. 1998. LPS-binding protein protects mice from septic shock caused by LPS or gram-negative bacteria. J Clin Invest 101:20652071.

206. Lang, D. R. and R. L. Guerrant. 1995. Summary of the 29th United StatesJapan joint Conference on Cholera and Related Diarrheal Diseases. J Infect. Dis. 171:8-12.

207. Le Roy, D., F. Di Padova, Y. Adachi, M. P. Glauser, T. Calandra, and D. Heumann. 2001. Critical role of lipopolysaccharide-binding protein and CD14 in immune responses against gram-negative bacteria. J Immunol 167:2759-2765.

208. Le Roy, D., F. Di Padova, R. Tees, S. Lengacher, R. Landmann, M. P. Glauser, T. Calandra, and D. Heumann. 1999. Monoclonal antibodies to murine lipopolysaccharide (LPS)-binding protein (LBP) protect mice from lethal endotoxemia by blocking either the binding of LPS to LBP or the presentation of LPS/LBP complexes to CD14. J Immunol 162:7454-7460.

209. Lee, P. W., E. C. Hayes, and W. K. Joklik. 1981. Protein sigma 1 is the reovirus cell attachment protein. Virology 108:156-163.

210. Lehrer, R. I., A. Barton, K. A. Daher, S. S. Harwig, T. Ganz, and M. E. Selsted. 1989. Interaction of human defensins with Escherichia coli. Mechanism of bactericidal activity. J Clin Invest 84:553-561.

211. Lehrer, R. I. and T. Ganz. 2002. Defensins of vertebrate animals. Curr. Opin. Immunol 14:96-102.

212. Lehrer, R. I., A. K. Lichtenstein, and T. Ganz. 1993. Defensins: antimicrobial and cytotoxic peptides of mammalian cells. Annu. Rev. Immunol 11:105-128. 
213. Lemay, G. 1988. Transcriptional and translational events during reovirus infection. Biochem. Cell Biol. 66:803-812.

214. Lerner, A. M., J. D. Cherry, J. O. Klein, And M. Finland. 1962. Infections With Reoviruses. N. Engl. J Med. 267:947-952.

215. Letvin, N. L., R. S. Kauffman, and R. Finberg. 1981. T lymphocyte immunity to reovirus: cellular requirements for generation and role in clearance of primary infections. J Immunol 127:2334-2339.

216. Li, K., Z. Chen, N. Kato, M. Gale, Jr., and S. M. Lemon. 2005. Distinct poly-I: $\mathrm{C}$ and virus-activated signaling pathways leading to interferon-beta production in hepatocytes. J Biol. Chem.

217. Li, Z. W., W. Chu, Y. Hu, M. Delhase, T. Deerinck, M. Ellisman, R. Johnson, and M. Karin. 1999. The IKKbeta subunit of IkappaB kinase (IKK) is essential for nuclear factor kappaB activation and prevention of apoptosis. J Exp. Med. 189:1839-1845.

218. Lima, A. A., G. Fang, J. B. Schorling, L. De Albuquerque, J. F. McAuliffe, S. Mota, R. Leite, and R. L. Guerrant. 1992. Persistent diarrhea in Northeast Brazil: etiologies and interactions with malnutrition. Acta Paediatr. 81 Suppl 381:39-44.

219. Lima, A. A., S. R. Moore, M. S. Barboza, Jr., A. M. Soares, M. A. Schleupner, R. D. Newman, C. L. Sears, J. P. Nataro, D. P. Fedorko, T. Wuhib, J. B. Schorling, and R. L. Guerrant. 2000. Persistent diarrhea signals a critical period of increased diarrhea burdens and nutritional shortfalls: a prospective cohort study among children in northeastern Brazil. J Infect. Dis. 181:1643-1651.

220. Lin, K. I., S. H. Lee, R. Narayanan, J. M. Baraban, J. M. Hardwick, and R. R. Ratan. 1995. Thiol agents and Bcl-2 identify an alphavirus-induced apoptotic pathway that requires activation of the transcription factor NF-kappa B. J Cell Biol. 131:1149-1161.

221. Lindh, E. 1975. Increased risistance of immunoglobulin A dimers to proteolytic degradation after binding of secretory component. J Immunol 114:284-286. 
222. Liu, Z. G., H. Hsu, D. V. Goeddel, and M. Karin. 1996. Dissection of TNF receptor 1 effector functions: JNK activation is not linked to apoptosis while NFkappaB activation prevents cell death. Cell 87:565-576.

223. Loeffler, M., A. Birke, D. Winton, and C. Potten. 1993. Somatic mutation, monoclonality and stochastic models of stem cell organization in the intestinal crypt. J Theor. Biol. 160:471-491.

224. London, S. D., J. J. Cebra, and D. H. Rubin. 1989. Intraepithelial lymphocytes contain virus-specific, MHC-restricted cytotoxic cell precursors after gut mucosal immunization with reovirus serotype 1/Lang. Reg Immunol 2:98-102.

225. London, S. D., J. A. Cebra-Thomas, D. H. Rubin, and J. J. Cebra. 1990. CD8 lymphocyte subpopulations in Peyer's patches induced by reovirus serotype 1 infection. J Immunol 144:3187-3194.

226. London, S. D., D. H. Rubin, and J. J. Cebra. 1987. Gut mucosal immunization with reovirus serotype $1 / \mathrm{L}$ stimulates virus-specific cytotoxic $\mathrm{T}$ cell precursors as well as IgA memory cells in Peyer's patches. J Exp. Med. 165:830-847.

227. Lu, L., M. E. Lamm, H. Li, B. Corthesy, and J. R. Zhang. 2003. The human polymeric immunoglobulin receptor binds to Streptococcus pneumoniae via domains 3 and 4. J Biol. Chem. 278:48178-48187.

228. Lundgren, O. and L. Svensson. 2001. Pathogenesis of rotavirus diarrhea. Microbes. Infect. 3:1145-1156.

229. Luscher, B. and L. G. Larsson. 1999. The basic region/helix-loop-helix/leucine zipper domain of Myc proto-oncoproteins: function and regulation. Oncogene 18:2955-2966.

230. Lycke, N., L. Erlandsson, L. Ekman, K. Schon, and T. Leanderson. 1999. Lack of J chain inhibits the transport of gut IgA and abrogates the development of intestinal antitoxic protection. J Immunol 163:913-919.

231. Maaser, C., M. P. Housley, M. Iimura, J. R. Smith, B. A. Vallance, B. B. Finlay, J. R. Schreiber, N. M. Varki, M. F. Kagnoff, and L. Eckmann. 2004. Clearance of Citrobacter rodentium requires B cells but not secretory immunoglobulin A (IgA) or IgM antibodies. Infect. Immun. 72:3315-3324. 
232. Mack, D. R. and P. M. Sherman. 1991. Mucin isolated from rabbit colon inhibits in vitro binding of Escherichia coli RDEC-1. Infect. Immun. 59:10151023.

233. Macpherson, A. J., A. Lamarre, K. McCoy, G. R. Harriman, B. Odermatt, G. Dougan, H. Hengartner, and R. M. Zinkernagel. 2001. IgA production without $\mathrm{mu}$ or delta chain expression in developing B cells. Nat. Immunol 2:625-631.

234. Major, A. S. and C. F. Cuff. 1996. Effects of the route of infection on immunoglobulin $\mathrm{G}$ subclasses and specificity of the reovirus-specific humoral immune response. J Virol. 70:5968-5974.

235. Major, A. S., D. H. Rubin, and C. F. Cuff. 1998. Mucosal immunity to reovirus infection. Curr. Top. Microbiol Immunol 233 Reovir.ii:163-177.

236. Mantle, M., L. Basaraba, S. C. Peacock, and D. G. Gall. 1989. Binding of Yersinia enterocolitica to rabbit intestinal brush border membranes, mucus, and mucin. Infect. Immun. 57:3292-3299.

237. Mantle, M., G. G. Forstner, and J. F. Forstner. 1984. Antigenic and structural features of goblet-cell mucin of human small intestine. Biochem. J 217:159-167.

238. Martin, K., T. B. Kirkwood, and C. S. Potten. 1998. Age changes in stem cells of murine small intestinal crypts. Exp. Cell Res. 241:316-323.

239. Martin, M. G., J. Wang, T. W. Li, J. T. Lam, E. M. Gutierrez, R. S. Solorzano-Vargas, and A. H. Tsai. 1998. Characterization of the 5'-flanking region of the murine polymeric IgA receptor gene. Am. J Physiol 275:G778G788.

240. Mashimo, H., D. C. Wu, D. K. Podolsky, and M. C. Fishman. 1996. Impaired defense of intestinal mucosa in mice lacking intestinal trefoil factor. Science 274:262-265.

241. Mathers, A. R. and C. F. Cuff. 2004. Role of interleukin-4 (IL-4) and IL-10 in serum immunoglobulin $\mathrm{G}$ antibody responses following mucosal or systemic reovirus infection. J Virol. 78:3352-3360. 
242. Matsumoto, M., K. Funami, H. Oshiumi, and T. Seya. 2004. Toll-like receptor 3: a link between toll-like receptor, interferon and viruses. Microbiol Immunol 48:147-154.

243. Matsumoto, M., K. Funami, M. Tanabe, H. Oshiumi, M. Shingai, Y. Seto, A. Yamamoto, and T. Seya. 2003. Subcellular localization of Toll-like receptor 3 in human dendritic cells. J Immunol 171:3154-3162.

244. Matsumoto, M., K. Funami, M. Tanabe, H. Oshiumi, M. Shingai, Y. Seto, A. Yamamoto, and T. Seya. 2003. Subcellular Localization of Toll-Like Receptor 3 in Human Dendritic Cells. J Immunol 171:3154-3162.

245. Mattei, F., G. Schiavoni, F. Belardelli, and D. F. Tough. 2001. IL-15 is expressed by dendritic cells in response to type I IFN, double-stranded RNA, or lipopolysaccharide and promotes dendritic cell activation. J Immunol 167:11791187.

246. Mazanec, M. B., C. S. Kaetzel, M. E. Lamm, D. Fletcher, and J. G. Nedrud. 1992. Intracellular neutralization of virus by immunoglobulin A antibodies. Proc. Natl. Acad. Sci. U. S. A 89:6901-6905.

247. Mazanec, M. B., C. S. Kaetzel, M. E. Lamm, D. Fletcher, J. Peterra, and J. G. Nedrud. 1995. Intracellular neutralization of Sendai and influenza viruses by IgA monoclonal antibodies. Adv. Exp. Med. Biol. 371A:651-654.

248. Mazanec, M. B., J. G. Nedrud, C. S. Kaetzel, and M. E. Lamm. 1993. A threetiered view of the role of IgA in mucosal defense. Immunol. Today 14:430-435.

249. Mbawuike, I. N., S. Pacheco, C. L. Acuna, K. C. Switzer, Y. Zhang, and G. R. Harriman. 1999. Mucosal immunity to influenza without IgA: an IgA knockout mouse model. J Immunol 162:2530-2537.

250. McCole, D. F., L. Eckmann, F. Laurent, and M. F. Kagnoff. 2000. Intestinal epithelial cell apoptosis following Cryptosporidium parvum infection. Infect. Immun. 68:1710-1713.

251. McGhee, J. R., K. Fujihashi, J. Xu-Amano, R. J. Jackson, C. O. Elson, K. W. Beagley, and H. Kiyono. 1993. New perspectives in mucosal immunity with emphasis on vaccine development. Semin. Hematol. 30:3-12. 
252. Medzhitov, R. 2001. Toll-like receptors and innate immunity. Nat. Rev. Immunol 1:135-145.

253. Medzhitov, R. and C. Janeway, Jr. 2000. Innate immunity. N. Engl. J Med. 343:338-344.

254. Mestecky, J. and J. R. McGhee. 1987. Immunoglobulin A (IgA): molecular and cellular interactions involved in IgA biosynthesis and immune response. Adv. Immunol 40:153-245.

255. Mestecky, J., M. W. Russell, S. Jackson, and T. A. Brown. 1986. The human IgA system: a reassessment. Clin Immunol Immunopathol. 40:105-114.

256. Meusel, T. R. and F. Imani. 2003. Viral induction of inflammatory cytokines in human epithelial cells follows a 338 mitogen-activated protein kinase-dependent but NF-kappa B-independent pathway. J Immunol 171:3768-3774.

257. Mizel, S. B., A. P. West, and R. R. Hantgan. 2003. Identification of a sequence in human toll-like receptor 5 required for the binding of Gram-negative flagellin. J Biol. Chem. 278:23624-23629.

258. Monteiro, R. C. and J. G. van De Winkel. 2003. IgA Fc receptors. Annu. Rev. Immunol 21:177-204.

259. Montgomery, R. K., A. E. Mulberg, and R. J. Grand. 1999. Development of the human gastrointestinal tract: twenty years of progress. Gastroenterology 116:702-731.

260. Moreno-Espinosa, S., T. Farkas, and X. Jiang. 2004. Human caliciviruses and pediatric gastroenteritis. Semin. Pediatr. Infect. Dis. 15:237-245.

261. Morrison, S. L. and M. E. Koshland. 1972. Characterization of the J chain from polymeric immunoglobulins (IgA-IgM-immunological specificity-primary structure). Proc. Natl. Acad. Sci. U. S. A 69:124-128.

262. Morton, H. C. and P. Brandtzaeg. 2001. CD89: the human myeloid IgA Fc receptor. Arch. Immunol Ther. Exp. (Warsz. ) 49:217-229. 
263. Morton, H. C., M. van Egmond, and J. G. van De Winkel. 1996. Structure and function of human IgA Fc receptors (Fc alpha R). Crit Rev. Immunol 16:423-440.

264. Mostov, K. E. 1994. Transepithelial transport of immunoglobulins. Annu. Rev. Immunol. 12:63-84.

265. Mostov, K. E., Y. Altschuler, S. J. Chapin, C. Enrich, S. H. Low, F. Luton, J. Richman-Eisenstat, K. L. Singer, K. Tang, and T. Weimbs. 1995. Regulation of protein traffic in polarized epithelial cells: the polymeric immunoglobulin receptor model. Cold Spring Harb. Symp. Quant. Biol. 60:775-781.

266. Mostov, K. E., K. A. de Bruyn, and D. L. Deitcher. 1986. Deletion of the cytoplasmic domain of the polymeric immunoglobulin receptor prevents basolateral localization and endocytosis. Cell 47:359-364.

267. Mostov, K. E. and D. L. Deitcher. 1986. Polymeric immunoglobulin receptor expressed in MDCK cells transcytoses IgA. Cell 46:613-621.

268. Musil, L. S. and J. U. Baenziger. 1987. Cleavage of membrane secretory component to soluble secretory component occurs on the cell surface of rat hepatocyte monolayers. J Cell Biol. 104:1725-1733.

269. Negrao-Correa, D. 2001. Importance of immunoglobulin E (IgE) in the protective mechanism against gastrointestinal nematode infection: looking at the intestinal mucosae. Rev. Inst. Med. Trop. Sao Paulo 43:291-299.

270. Negrao-Correa, D. and M. M. Teixeira. 2006. The mutual influence of nematode infection and allergy. Chem. Immunol Allergy 90:14-28.

271. Neutra, M. R., N. J. Mantis, A. Frey, and P. J. Giannasca. 1999. The composition and function of $\mathrm{M}$ cell apical membranes: implications for microbial pathogenesis. Semin. Immunol 11:171-181.

272. Noelle, R. J., M. Roy, D. M. Shepherd, I. Stamenkovic, J. A. Ledbetter, and A. Aruffo. 1992. A 39-kDa protein on activated helper T cells binds CD40 and transduces the signal for cognate activation of B cells. Proc. Natl. Acad. Sci. U. S. A 89:6550-6554. 
273. Norderhaug, I. N., F. E. Johansen, H. Schjerven, and P. Brandtzaeg. 1999. Regulation of the formation and external transport of secretory immunoglobulins. Crit Rev. Immunol 19:481-508.

274. Norman, K. L., M. C. Coffey, K. Hirasawa, D. J. Demetrick, S. G. Nishikawa, L. M. DiFrancesco, J. E. Strong, and P. W. Lee. 2002. Reovirus oncolysis of human breast cancer. Hum. Gene Ther. 13:641-652.

275. O'Donnell, S. M., G. H. Holm, J. M. Pierce, B. Tian, M. J. Watson, R. S. Chari, D. W. Ballard, A. R. Brasier, and T. S. Dermody. 2006. Identification of an NF-\{kappa\}B-Dependent Gene Network in Cells Infected by Mammalian Reovirus. J. Virol. 80:1077-1086.

276. O'Neil, D. A., E. M. Porter, D. Elewaut, G. M. Anderson, L. Eckmann, T. Ganz, and M. F. Kagnoff. 1999. Expression and regulation of the human betadefensins hBD-1 and hBD-2 in intestinal epithelium. J Immunol 163:6718-6724.

277. O'Neill, L. A., K. A. Fitzgerald, and A. G. Bowie. 2003. The Toll-IL-1 receptor adaptor family grows to five members. Trends Immunol 24:286-290.

278. Offit, P. A. and D. H. Rubin. 1982. Viral diseases: infections of the gastrointestinal tract. Compr. Ther. 8:21-26.

279. Ohteki, T., K. Suzue, C. Maki, T. Ota, and S. Koyasu. 2001. Critical role of IL-15-IL-15R for antigen-presenting cell functions in the innate immune response. Nat. Immunol 2:1138-1143.

280. Okamoto, C. T., S. P. Shia, C. Bird, K. E. Mostov, and M. G. Roth. 1992. The cytoplasmic domain of the polymeric immunoglobulin receptor contains two internalization signals that are distinct from its basolateral sorting signal. J. Biol. Chem. 267:9925-9932.

281. Okamoto, C. T., W. Song, M. Bomsel, and K. E. Mostov. 1994. Rapid internalization of the polymeric immunoglobulin receptor requires phosphorylated serine 726. J. Biol. Chem. 269:15676-15682.

282. Oliveira, C. S. and A. C. Linhares. 1999. [Rotavirus: clinical features and prevention]. J Pediatr. (Rio J) 75 Suppl 1:S91-S102. 
283. Onodera, T., A. B. Jenson, J. W. Yoon, and A. L. Notkins. 1978. Virusinduced diabetes mellitus: reovirus infection of pancreatic beta cells in mice. Science 201:529-531.

284. Organ, E. L. and D. H. Rubin. 1998. Pathogenesis of reovirus gastrointestinal and hepatobiliary disease. Curr. Top. Microbiol Immunol 233 Reovir.ii:67-83.

285. Ortega-Cava, C. F., S. Ishihara, M. A. Rumi, K. Kawashima, N. Ishimura, H. Kazumori, J. Udagawa, Y. Kadowaki, and Y. Kinoshita. 2003. Strategic compartmentalization of Toll-like receptor 4 in the mouse gut. J Immunol 170:3977-3985.

286. Otte, J. M., E. Cario, and D. K. Podolsky. 2004. Mechanisms of cross hyporesponsiveness to Toll-like receptor bacterial ligands in intestinal epithelial cells. Gastroenterology 126:1054-1070.

287. Ouellette, A. J. 1997. Paneth cells and innate immunity in the crypt microenvironment. Gastroenterology 113:1779-1784.

288. Ouellette, A. J. 2005. Paneth cell alpha-defensins: peptide mediators of innate immunity in the small intestine. Springer Semin. Immunopathol. 27:133-146.

289. Ouellette, A. J., R. M. Greco, M. James, D. Frederick, J. Naftilan, and J. T. Fallon. 1989. Developmental regulation of cryptdin, a corticostatin/defensin precursor mRNA in mouse small intestinal crypt epithelium. J Cell Biol. 108:1687-1695.

290. Ouellette, A. J. and M. E. Selsted. 1996. Paneth cell defensins: endogenous peptide components of intestinal host defense. FASEB J 10:1280-1289.

291. Pahl, H. L. and P. A. Baeuerle. 1995. Expression of influenza virus hemagglutinin activates transcription factor NF-kappa B. J Virol. 69:1480-1484.

292. Pahl, H. L. and P. A. Baeuerle. 1997. The ER-overload response: activation of NF-kappa B. Trends Biochem. Sci. 22:63-67.

293. Palladino, G., K. Mozdzanowska, G. Washko, and W. Gerhard. 1995. Virusneutralizing antibodies of immunoglobulin $\mathrm{G}(\mathrm{IgG})$ but not of $\operatorname{IgM}$ or $\operatorname{Ig} \mathrm{A}$ 
isotypes can cure influenza virus pneumonia in SCID mice. J Virol. 69:20752081.

294. Paulsson, M. 1992. Basement membrane proteins: structure, assembly, and cellular interactions. Crit Rev. Biochem. Mol. Biol. 27:93-127.

295. Paulsson, M., S. Fujiwara, M. Dziadek, R. Timpl, G. Pejler, G. Backstrom, U. Lindahl, and J. Engel. 1986. Structure and function of basement membrane proteoglycans. Ciba Found. Symp. 124:189-203.

296. Phillips, T. E., T. H. Phillips, and M. R. Neutra. 1984. Regulation of intestinal goblet cell secretion. III. Isolated intestinal epithelium. Am. J Physiol 247:G674G681.

297. Phillips-Quagliata, J. M., M. E. Roux, M. Arny, P. Kelly-Hatfield, M. McWilliams, and M. E. Lamm. 1983. Migration and regulation of B-cells in the mucosal immune system. Ann. N. Y. Acad. Sci. 409:194-203.

298. Philpott, D. J. and S. E. Girardin. 2004. The role of Toll-like receptors and Nod proteins in bacterial infection. Mol. Immunol 41:1099-1108.

299. Philpott, D. J., S. E. Girardin, and P. J. Sansonetti. 2001. Innate immune responses of epithelial cells following infection with bacterial pathogens. Curr. Opin. Immunol 13:410-416.

300. Pine, R. 1997. Convergence of TNFalpha and IFNgamma signalling pathways through synergistic induction of IRF-1/ISGF-2 is mediated by a composite GAS/kappaB promoter element. Nucleic Acids Res. 25:4346-4354.

301. Piskurich, J. F., J. A. France, C. M. Tamer, C. A. Willmer, C. S. Kaetzel, and D. M. Kaetzel. 1993. Interferon-gamma induces polymeric immunoglobulin receptor mRNA in human intestinal epithelial cells by a protein synthesis dependent mechanism. Mol. Immunol. 30:413-421.

302. Piskurich, J. F., K. R. Youngman, K. M. Phillips, P. M. Hempen, M. H. Blanchard, J. A. France, and C. S. Kaetzel. 1997. Transcriptional regulation of the human polymeric immunoglobulin receptor gene by interferon-gamma. Mol. Immunol. 34:75-91. 
303. Plaut, A. G. 1997. Trefoil peptides in the defense of the gastrointestinal tract. N. Engl. J Med. 336:506-507.

304. Podolsky, D. K. 1999. Mucosal immunity and inflammation. V. Innate mechanisms of mucosal defense and repair: the best offense is a good defense. Am. J Physiol 277:G495-G499.

305. Podolsky, D. K. 2000. Mechanisms of regulatory peptide action in the gastrointestinal tract: trefoil peptides. J Gastroenterol. 35 Suppl 12:69-74.

306. Podolsky, D. K., K. Lynch-Devaney, J. L. Stow, P. Oates, B. Murgue, M. De Beaumont, B. E. Sands, and Y. R. Mahida. 1993. Identification of human intestinal trefoil factor. Goblet cell-specific expression of a peptide targeted for apical secretion. J Biol. Chem. 268:12230.

307. Porter, E. M., L. Liu, A. Oren, P. A. Anton, and T. Ganz. 1997. Localization of human intestinal defensin 5 in Paneth cell granules. Infect. Immun. 65:23892395.

308. Porter, E. M., E. van Dam, E. V. Valore, and T. Ganz. 1997. Broad-spectrum antimicrobial activity of human intestinal defensin 5. Infect. Immun. 65:23962401.

309. Potoka, D. A., E. P. Nadler, X. Zhou, X. R. Zhang, J. S. Upperman, and H. R. Ford. 2000. Inhibition of NF-kappaB by IkappaB prevents cytokine-induced NO production and promotes enterocyte apoptosis in vitro. Shock 14:366-373.

310. Potten, C. S. 1974. The epidermal proliferative unit: the possible role of the central basal cell. Cell Tissue Kinet. 7:77-88.

311. Potten, C. S. 1998. Stem cells in gastrointestinal epithelium: numbers, characteristics and death. Philos. Trans. R. Soc. Lond B Biol. Sci. 353:821-830.

312. Potten, C. S. and R. J. Morris. 1988. Epithelial stem cells in vivo. J Cell Sci. Suppl 10:45-62.

313. Prescott, S. L. 2003. Allergy: the price we pay for cleaner living? Ann. Allergy Asthma Immunol 90:64-70. 
314. Prioult, G. and C. Nagler-Anderson. 2005. Mucosal immunity and allergic responses: lack of regulation and/or lack of microbial stimulation? Immunol Rev. 206:204-218.

315. Quan, C. P., E. Ruffet, K. Arihiro, R. Pires, and J. P. Bouvet. 1996. High affinity serum-derived Fab fragments as another source of antibodies in the gut lumen of both neonates and adults. Scand. J Immunol 44:108-114.

316. Quan, C. P., S. Watanabe, F. Forestier, and J. P. Bouvet. 1998. Human amniotic IgA inhibits natural IgG autoantibodies of maternal or unrelated origin. Eur. J Immunol 28:4001-4009.

317. Quondamatteo, F. 2002. Assembly, stability and integrity of basement membranes in vivo. Histochem. J 34:369-381.

318. Renegar, K. B., G. D. Jackson, and J. Mestecky. 1998. In vitro comparison of the biologic activities of monoclonal monomeric IgA, polymeric IgA, and secretory IgA. J Immunol 160:1219-1223.

319. Rincheval-Arnold, A., L. Belair, A. Cencic, and J. Djiane. 2002. Up-regulation of polymeric immunoglobulin receptor mRNA in mammary epithelial cells by IFN-gamma. Mol. Cell Endocrinol. 194:95-105.

320. Rincheval-Arnold, A., L. Belair, and J. Djiane. 2002. Developmental expression of $\mathrm{pIgR}$ gene in sheep mammary gland and hormonal regulation. $\mathrm{J}$ Dairy Res. 69:13-26.

321. Roos, A., L. H. Bouwman, D. J. Gijlswijk-Janssen, M. C. Faber-Krol, G. L. Stahl, and M. R. Daha. 2001. Human IgA activates the complement system via the mannan-binding lectin pathway. J Immunol 167:2861-2868.

322. Rosen, L. 1960. Serologic grouping of reoviruses by hemagglutination-inhibition. Am. J Hyg. 71:242-249.

323. Rosen, L. 1962. Reoviruses in animals other than man. Ann. N. Y. Acad. Sci. 101:461-465.

324. Roulston, A., R. Lin, P. Beauparlant, M. A. Wainberg, and J. Hiscott. 1995. Regulation of human immunodeficiency virus type 1 and cytokine gene 
expression in myeloid cells by NF-kappa B/Rel transcription factors. Microbiol Rev. 59:481-505.

325. Rubin, D. H., M. A. Eaton, and A. O. Anderson. 1986. Reovirus infection in adult mice: the virus hemagglutinin determines the site of intestinal disease. Microb. Pathog. 1:79-87.

326. Rubin, D. H., M. J. Kornstein, and A. O. Anderson. 1985. Reovirus serotype 1 intestinal infection: a novel replicative cycle with ileal disease. J Virol. 53:391398.

327. Russell, M. W., J. Reinholdt, and M. Kilian. 1989. Anti-inflammatory activity of human IgA antibodies and their Fab alpha fragments: inhibition of IgGmediated complement activation. Eur. J Immunol 19:2243-2249.

328. Sajjan, S. U. and J. F. Forstner. 1990. Role of the putative "link" glycopeptide of intestinal mucin in binding of piliated Escherichia coli serotype O157:H7 strain CL-49. Infect. Immun. 58:868-873.

329. Sakuma, S. and Y. Watanabe. 1971. Unilateral synthesis of reovirus doublestranded ribonucleic acid by a cell-free replicase system. J Virol. 8:190-196.

330. Sakuma, S. and Y. Watanabe. 1972. Reovirus replicase-directed synthesis of double-stranded ribonucleic acid. J Virol. 10:628-638.

331. Sanderson, I. R. and W. A. Walker. 1993. Uptake and transport of macromolecules by the intestine: possible role in clinical disorders (an update). Gastroenterology 104:622-639.

332. Sands, B. E. and D. K. Podolsky. 1996. The trefoil peptide family. Annu. Rev. Physiol 58:253-273.

333. Sansonetti, P. J. 2004. War and peace at mucosal surfaces. Nat. Rev. Immunol 4:953-964.

334. Schjerven, H., P. Brandtzaeg, and F. E. Johansen. 2000. Mechanism of IL-4mediated up-regulation of the polymeric Ig receptor: role of STAT6 in cell typespecific delayed transcriptional response. J Immunol 165:3898-3906. 
335. Schjerven, H., P. Brandtzaeg, and F. E. Johansen. 2001. A novel NF-kappa $\mathrm{B} /$ Rel site in intron 1 cooperates with proximal promoter elements to mediate TNF-alpha-induced transcription of the human polymeric Ig receptor. J Immunol 167:6412-6420.

336. Schjerven, H., T. N. Tran, P. Brandtzaeg, and F. E. Johansen. 2004. De novo synthesized RelB mediates TNF-induced up-regulation of the human polymeric Ig receptor. J Immunol 173:1849-1857.

337. Schnare, M., G. M. Barton, A. C. Holt, K. Takeda, S. Akira, and R. Medzhitov. 2001. Toll-like receptors control activation of adaptive immune responses. Nat. Immunol 2:947-950.

338. Schneeman, T. A., M. E. Bruno, H. Schjerven, F. E. Johansen, L. Chady, and C. S. Kaetzel. 2005. Regulation of the polymeric Ig receptor by signaling through TLRs 3 and 4: linking innate and adaptive immune response. J Immunol 175:376384.

339. Schonberg, M., S. C. Silverstein, D. H. Levin, and G. Acs. 1971. Asynchronous synthesis of the complementary strands of the reovirus genome. Proc. Natl. Acad. Sci. U. S. A 68:505-508.

340. Schonwetter, B. S., E. D. Stolzenberg, and M. A. Zasloff. 1995. Epithelial antibiotics induced at sites of inflammation. Science 267:1645-1648.

341. Schumann, R. R. and J. Zweigner. 1999. A novel acute-phase marker: lipopolysaccharide binding protein (LBP). Clin Chem. Lab Med. 37:271-274.

342. Seidel, B. M., S. Schubert, B. Schulze, and M. Borte. 2001. Secretory IgA, free secretory component and IgD in saliva of newborn infants. Early Hum. Dev. 62:159-164.

343. Selb, B. and B. Weber. 1994. A study of human reovirus IgG and IgA antibodies by ELISA and western blot. J Virol. Methods 47:15-25.

344. Shatkin, A. J., J. D. Sipe, and P. Loh. 1968. Separation of ten reovirus genome segments by polyacrylamide gel electrophoresis. J Virol. 2:986-991. 
345. Sherman, P., N. Fleming, J. Forstner, N. Roomi, and G. Forstner. 1987.

Bacteria and the mucus blanket in experimental small bowel bacterial overgrowth. Am. J Pathol. 126:527-534.

346. Sherry, B. 1998. Pathogenesis of reovirus myocarditis. Curr. Top. Microbiol Immunol 233:51-66.

347. Sherry, B. 2002. The role of interferon regulatory factors in the cardiac response to viral infection. Viral Immunol 15:17-28.

348. Shimada, S., M. Kawaguchi-Miyashita, A. Kushiro, T. Sato, M. Nanno, T. Sako, Y. Matsuoka, K. Sudo, Y. Tagawa, Y. Iwakura, and M. Ohwaki. 1999. Generation of polymeric immunoglobulin receptor-deficient mouse with marked reduction of secretory IgA. J Immunol 163:5367-5373.

349. Silvey, K. J., A. B. Hutchings, M. Vajdy, M. M. Petzke, and M. R. Neutra. 2001. Role of immunoglobulin A in protection against reovirus entry into Murine Peyer's patches. J Virol. 75:10870-10879.

350. Singh, P. K., H. P. Jia, K. Wiles, J. Hesselberth, L. Liu, B. A. Conway, E. P. Greenberg, E. V. Valore, M. J. Welsh, T. Ganz, B. F. Tack, and P. B.

McCray, Jr. 1998. Production of beta-defensins by human airway epithelia. Proc. Natl. Acad. Sci. U. S. A 95:14961-14966.

351. Singh, P. K., B. F. Tack, P. B. McCray, Jr., and M. J. Welsh. 2000. Synergistic and additive killing by antimicrobial factors found in human airway surface liquid. Am. J Physiol Lung Cell Mol. Physiol 279:L799-L805.

352. Sirito, M., Q. Lin, J. M. Deng, R. R. Behringer, and M. Sawadogo. 1998. Overlapping roles and asymmetrical cross-regulation of the USF proteins in mice. Proc. Natl. Acad. Sci. U. S. A 95:3758-3763.

353. Solorzano-Vargas, R. S., J. Wang, L. Jiang, H. V. Tsai, L. O. Ontiveros, M. A. Vazir, R. J. Aguilera, and M. G. Martin. 2002. Multiple transcription factors in 5'-flanking region of human polymeric Ig receptor control its basal expression. Am. J Physiol Gastrointest. Liver Physiol 283:G415-G425.

354. Song, W., M. Bomsel, J. Casanova, J. P. Vaerman, and K. Mostov. 1994. Stimulation of transcytosis of the polymeric immunoglobulin receptor by dimeric IgA. Proc. Natl. Acad. Sci. U. S. A 91:163-166. 
355. Spiekermann, G. M., P. W. Finn, E. S. Ward, J. Dumont, B. L. Dickinson, R. S. Blumberg, and W. I. Lencer. 2002. Receptor-mediated immunoglobulin G transport across mucosal barriers in adult life: functional expression of FcRn in the mammalian lung. J Exp. Med. 196:303-310.

356. Stewart, M. J., M. A. Blum, and B. Sherry. 2003. PKR's protective role in viral myocarditis. Virology 314:92-100.

357. Stolzenberg, E. D., G. M. Anderson, M. R. Ackermann, R. H. Whitlock, and M. Zasloff. 1997. Epithelial antibiotic induced in states of disease. Proc. Natl. Acad. Sci. U. S. A 94:8686-8690.

358. Strong, J. E., M. C. Coffey, D. Tang, P. Sabinin, and P. W. Lee. 1998. The molecular basis of viral oncolysis: usurpation of the Ras signaling pathway by reovirus. EMBO J 17:3351-3362.

359. Sumpter, R., Jr., Y. M. Loo, E. Foy, K. Li, M. Yoneyama, T. Fujita, S. M. Lemon, and M. Gale, Jr. 2005. Regulating intracellular antiviral defense and permissiveness to hepatitis $\mathrm{C}$ virus RNA replication through a cellular RNA helicase, RIG-I. J Virol. 79:2689-2699.

360. Sun, K., F. E. Johansen, L. Eckmann, and D. W. Metzger. 2004. An important role for polymeric Ig receptor-mediated transport of IgA in protection against Streptococcus pneumoniae nasopharyngeal carriage. J Immunol 173:4576-4581.

361. Sun, S. C. and D. W. Ballard. 1999. Persistent activation of NF-kappaB by the tax transforming protein of HTLV-1: hijacking cellular IkappaB kinases. Oncogene 18:6948-6958.

362. Tabeta, K., P. Georgel, E. Janssen, X. Du, K. Hoebe, K. Crozat, S. Mudd, L. Shamel, S. Sovath, J. Goode, L. Alexopoulou, R. A. Flavell, and B. Beutler. 2004. Toll-like receptors 9 and 3 as essential components of innate immune defense against mouse cytomegalovirus infection. Proc. Natl. Acad. Sci. U. S. A 101:3516-3521.

363. Tai, D. I. and S. L. Tsai. 2001. Apoptosis in viral hepatitis B and C. Chang Gung. Med. J 24:285-293.

364. Tai, D. I., S. L. Tsai, Y. M. Chen, Y. L. Chuang, C. Y. Peng, I. S. Sheen, C. T. Yeh, K. S. Chang, S. N. Huang, G. C. Kuo, and Y. F. Liaw. 2000. Activation 
of nuclear factor kappaB in hepatitis $\mathrm{C}$ virus infection: implications for pathogenesis and hepatocarcinogenesis. Hepatology 31:656-664.

365. Takeda, K. and S. Akira. 2003. Toll receptors and pathogen resistance. Cellular Microbiology 5:143-153.

366. Takenouchi-Ohkubo, N., T. Takahashi, M. Tsuchiya, J. Mestecky, Z. Moldoveanu, and I. Moro. 2000. Role of nuclear factor-kappaB in the expression by tumor necrosis factor-alpha of the human polymeric immunoglobulin receptor (plgR) gene. Immunogenetics 51:289-295.

367. Tamer, C. M., M. E. Lamm, J. K. Robinson, J. F. Piskurich, and C. S. Kaetzel. 1995. Comparative studies of transcytosis and assembly of secretory IgA in Madin-Darby canine kidney cells expressing human polymeric Ig receptor. J. Immunol. 155:707-714.

368. Tangye, S. G., D. T. Avery, and P. D. Hodgkin. 2003. A division-linked mechanism for the rapid generation of Ig-secreting cells from human memory B cells. J Immunol 170:261-269.

369. Tarkowski, A., C. Lue, Z. Moldoveanu, H. Kiyono, J. R. McGhee, and J. Mestecky. 1990. Immunization of humans with polysaccharide vaccines induces systemic, predominantly polymeric IgA2-subclass antibody responses. J Immunol 144:3770-3778.

370. Taterka, J., J. J. Cebra, and D. H. Rubin. 1995. Characterization of cytotoxic cells from reovirus-infected SCID mice: activated cells express natural killer- and lymphokine-activated killer-like activity but fail to clear infection. J Virol. 69:3910-3914.

371. Taupin, D. and D. K. Podolsky. 2003. Trefoil factors: initiators of mucosal healing. Nat. Rev. Mol. Cell Biol. 4:721-732.

372. Teller, I. C. and J. F. Beaulieu. 2001. Interactions between laminin and epithelial cells in intestinal health and disease. Expert. Rev. Mol. Med. 2001:1-18.

373. Thompson, A. H., L. London, and S. D. London. 1999. Heterogeneous cytokine production by acutely stimulated bronchoalveolar $\mathrm{T}$ lymphocytes in reovirus 1/Lang-infected mice. Cell Immunol 198:120-130. 
374. Thompson, A. H., J. G. McRoberts, S. R. Crowe, L. London, and S. D. London. 1999. Optimal induction of upper respiratory tract immunity to reovirus 1/L by combined upper and lower respiratory tract inoculation. Vaccine 17:14041415.

375. Timpl, R. 1994. Proteoglycans of basement membranes. EXS 70:123-144.

376. Timpl, R. 1996. Macromolecular organization of basement membranes. Curr. Opin. Cell Biol. 8:618-624.

377. Timpl, R. and J. C. Brown. 1996. Supramolecular assembly of basement membranes. Bioessays 18:123-132.

378. Timpl, R., M. Paulsson, M. Dziadek, and S. Fujiwara. 1987. Basement membranes. Methods Enzymol. 145:363-391.

379. Tomasetto, C., N. Rockel, M. G. Mattei, R. Fujita, and M. C. Rio. 1992. The gene encoding the human spasmolytic protein (SML1/hSP) is in 21q 22.3, physically linked to the homologous breast cancer marker gene BCEI/pS2. Genomics 13:1328-1330.

380. Tomasi, T. B., Jr., E. M. Tan, A. Solomon, And R. A. Prendergast. 1965. Characteristics Of An Immune System Common To Certain External Secretions. J Exp. Med. 121:101-124.

381. Tyler, K. L., R. T. Bronson, K. B. Byers, and B. Fields. 1985. Molecular basis of viral neurotropism: experimental reovirus infection. Neurology 35:88-92.

382. Tyler, K. L., R. J. Sokol, S. M. Oberhaus, M. Le, F. M. Karrer, M. R. Narkewicz, R. W. Tyson, J. R. Murphy, R. Low, and W. R. Brown. 1998. Detection of reovirus RNA in hepatobiliary tissues from patients with extrahepatic biliary atresia and choledochal cysts. Hepatology 27:1475-1482.

383. Tyler, K. L., M. K. Squier, S. E. Rodgers, B. E. Schneider, S. M. Oberhaus, T. A. Grdina, J. J. Cohen, and T. S. Dermody. 1995. Differences in the capacity of reovirus strains to induce apoptosis are determined by the viral attachment protein sigma 1. J. Virol. 69:6972-6979. 
384. Tyler, K. L., H. W. Virgin, R. Bassel-Duby, and B. N. Fields. 1989. Antibody inhibits defined stages in the pathogenesis of reovirus serotype 3 infection of the central nervous system. J Exp. Med. 170:887-900.

385. Uren, T. K., F. E. Johansen, O. L. Wijburg, F. Koentgen, P. Brandtzaeg, and R. A. Strugnell. 2003. Role of the polymeric Ig receptor in mucosal B cell homeostasis. J Immunol 170:2531-2539.

386. Uren, T. K., O. L. Wijburg, C. Simmons, F. E. Johansen, P. Brandtzaeg, and R. A. Strugnell. 2005. Vaccine-induced protection against gastrointestinal bacterial infections in the absence of secretory antibodies. Eur. J Immunol 35:180-188.

387. Van Antwerp, D. J., S. J. Martin, T. Kafri, D. R. Green, and I. M. Verma. 1996. Suppression of TNF-alpha-induced apoptosis by NF-kappaB. Science 274:787-789.

388. van Loghem, E. and J. Biewenga. 1983. Allotypic and isotypic aspects of human immunoglobulin A. Mol. Immunol 20:1001-1007.

389. Veeravigrom, M., A. Theamboonlers, and Y. Poovorawan. 2004. Epidemiology and clinical manifestation of rotavirus and norwalk-like viruses in Thai children. J Med. Assoc. Thai. 87 Suppl 2:S50-S54.

390. Virgin, H. W., T. S. Dermody, and K. L. Tyler. 1998. Cellular and humoral immunity to reovirus infection. Curr. Top. Microbiol Immunol 233:147-161.

391. Virgin, H. W. and K. L. Tyler. 1991. Role of immune cells in protection against and control of reovirus infection in neonatal mice. J Virol. 65:5157-5164.

392. Walker, W. A. and I. R. Sanderson. 1992. Epithelial barrier function to antigens. An overview. Ann. N. Y. Acad. Sci. 664:10-17.

393. Wang, A. C. and H. H. Fudenberg. 1974. Genetics and evolution of human immunoglobulin A. Adv. Exp. Med. Biol. 45:161-165.

394. Watanabe, Y. and A. F. Graham. 1967. Structural units of reovirus ribonucleic acid and their possible functional significance. J Virol. 1:665-677. 
395. Watanabe, Y., L. Prevec, and A. F. Graham. 1967. Specificity in transcription of the reovirus genome. Proc. Natl. Acad. Sci. U. S. A 58:1040-1046.

396. Weiner, D. B., K. Girard, W. V. Williams, T. McPhillips, and D. H. Rubin. 1988. Reovirus type 1 and type 3 differ in their binding to isolated intestinal epithelial cells. Microb. Pathog. 5:29-40.

397. Weiner, H. L., D. Drayna, D. R. Averill, Jr., and B. N. Fields. 1977. Molecular basis of reovirus virulence: role of the S1 gene. Proc. Natl. Acad. Sci. U. S. A 74:5744-5748.

398. Weinstein, P. D. and J. J. Cebra. 1991. The preference for switching to IgA expression by Peyer's patch germinal center B cells is likely due to the intrinsic influence of their microenvironment. J Immunol 147:4126-4135.

399. Wolf, J. L., R. Dambrauskas, A. H. Sharpe, and J. S. Trier. 1987. Adherence to and penetration of the intestinal epithelium by reovirus type 1 in neonatal mice. Gastroenterology 92:82-91.

400. Wolf, J. L., R. S. Kauffman, R. Finberg, R. Dambrauskas, B. N. Fields, and J. S. Trier. 1983. Determinants of reovirus interaction with the intestinal M cells and absorptive cells of murine intestine. Gastroenterology 85:291-300.

401. Wolf, J. L., D. H. Rubin, R. Finberg, R. S. Kauffman, A. H. Sharpe, J. S. Trier, and B. N. Fields. 1981. Intestinal M cells: a pathway for entry of reovirus into the host. Science 212:471-472.

402. Wright, N. A. and M. Irwin. 1982. The kinetics of villus cell populations in the mouse small intestine. I. Normal villi: the steady state requirement. Cell Tissue Kinet. 15:595-609.

403. Wright, N. A., A. R. Morley, D. R. Appleton, J. M. Marks, A. P. Douglas, and A. J. Watson. 1973. Measurement of cell production rate in the human small bowel. Pathol. Microbiol (Basel) 39:251-253.

404. Yamamoto, M. and S. Akira. 2004. [TIR domain--containing adaptors regulate TLR-mediated signaling pathways]. Nippon Rinsho 62:2197-2203. 
405. Yamamoto, M., S. Sato, H. Hemmi, S. Uematsu, K. Hoshino, T. Kaisho, O. Takeuchi, K. Takeda, and S. Akira. 2003. TRAM is specifically involved in the Toll-like receptor 4-mediated MyD88-independent signaling pathway. Nat. Immunol 4:1144-1150.

406. Yamamoto, M., S. Sato, K. Mori, K. Hoshino, O. Takeuchi, K. Takeda, and S. Akira. 2002. Cutting edge: a novel Toll/IL-1 receptor domain-containing adapter that preferentially activates the IFN-beta promoter in the Toll-like receptor signaling. J Immunol 169:6668-6672.

407. Yamamoto, M., K. Takeda, and S. Akira. 2004. TIR domain-containing adaptors define the specificity of TLR signaling. Mol. Immunol 40:861-868.

408. You, L. R., C. M. Chen, and Y. H. Lee. 1999. Hepatitis C virus core protein enhances NF-kappaB signal pathway triggering by lymphotoxin-beta receptor ligand and tumor necrosis factor alpha. J Virol. 73:1672-1681.

409. Yu-Lee, L. 2001. Stimulation of interferon regulatory factor-1 by prolactin. Lupus 10:691-699.

410. Zhang, J. R., K. E. Mostov, M. E. Lamm, M. Nanno, S. Shimida, M. Ohwaki, and E. Tuomanen. 2000. The polymeric immunoglobulin receptor translocates pneumococci across human nasopharyngeal epithelial cells. Cell 102:827-837.

411. Zhao, C., I. Wang, and R. I. Lehrer. 1996. Widespread expression of betadefensin hBD-1 in human secretory glands and epithelial cells. FEBS Lett. 396:319-322.

412. Zuercher, A. W., S. E. Coffin, M. C. Thurnheer, P. Fundova, and J. J. Cebra. 2002. Nasal-associated lymphoid tissue is a mucosal inductive site for virusspecific humoral and cellular immune responses. J Immunol 168:1796-1803.

413. Zuercher, A. W., H. Q. Jiang, M. C. Thurnheer, C. F. Cuff, and J. J. Cebra. 2002. Distinct mechanisms for cross-protection of the upper versus lower respiratory tract through intestinal priming. J Immunol 169:3920-3925.

414. Zweigner, J., H. J. Gramm, O. C. Singer, K. Wegscheider, and R. R. Schumann. 2001. High concentrations of lipopolysaccharide-binding protein in serum of patients with severe sepsis or septic shock inhibit the lipopolysaccharide response in human monocytes. Blood 98:3800-3808. 


\section{Zamanian-Daryoush, M., T. H. Mogensen, J.A. DiDonato, and B.R.}

Williams.2000. NF-kappaB activation by double-stranded-RNA-activated protein kinase (PKR) is mediated through NF-kappaB-inducing kinase and IkappaB kinase. Mol Cell Biol 20:1278-1290. 